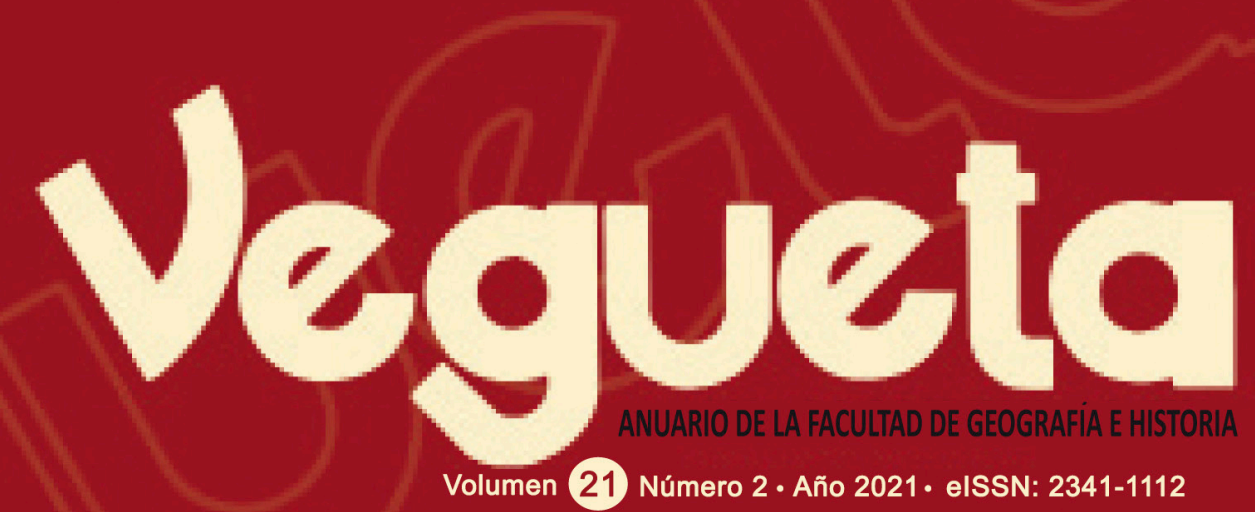





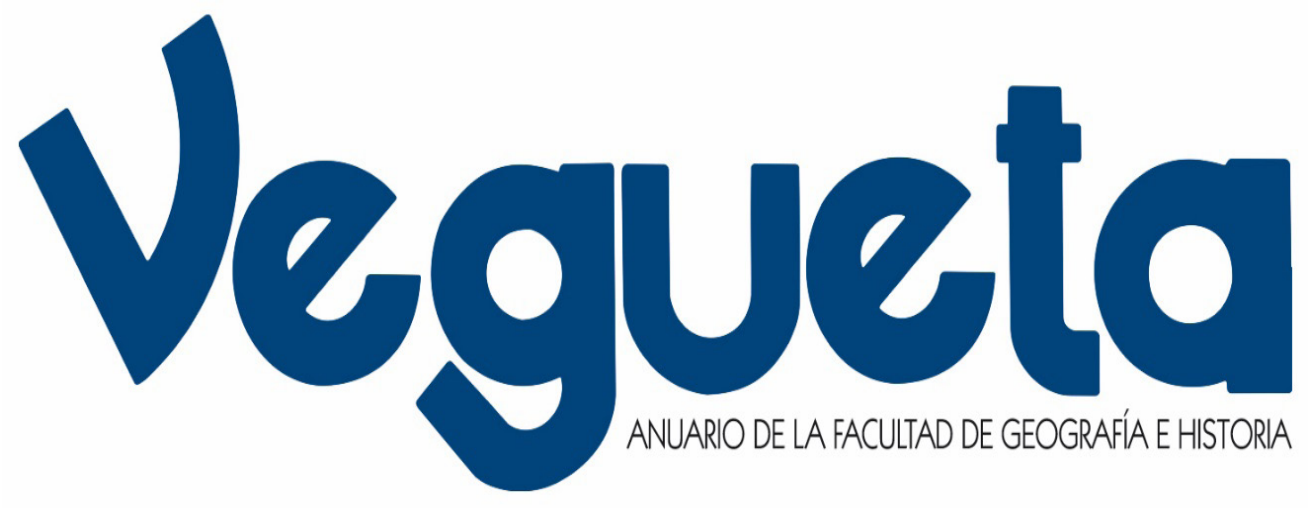

ISSN: 1133-598X

eISSN: 2341-1112

\section{Vol. 21, N² \\ (2021)}

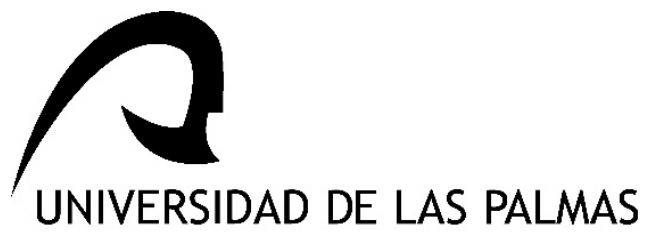

DE GRAN CANARIA 



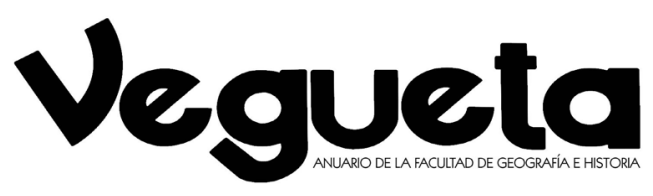

Vol. 21. Núm. 2 • 2021 • D.L.: GC1206-1214

ISSN: 1133-598X • eISSN: 2341-1112

https://doi.org/10.51349/veg

Periodicidad: Semestral

Vegueta: Anuario de la Facultad de Geografía e Historia (ISSN: 1133-598X; eISSN: 2341-112) es una revista científica, editada por la Facultad de Geografía e Historia de la Universidad de Las Palmas de Gran Canaria (España). Se publica anualmente desde 1992 y es una revista interdisciplinar que acepta trabajos de investigación originales e inéditos en cualquiera de las lenguas habituales en el ámbito académico, sobre Historia, Geografía e Historia del Arte, una vez superan un proceso de evaluación anónimo por expertos anónimos (sistema de doble ciego). La revista se divide en tres secciones: Dossier, Estudios y Reseñas. La sección Dossier está abierta a la publicación de temas monográficos, necesariamente interdisciplinares, coordinados y revisados por un especialista en la materia. La sección Estudios publica trabajos de investigación originales e inéditos enviados a la revista, una vez superan el proceso de evaluación anónimo por expertos externos. Finalmente, la sección Reseñas publica recensiones críticas de monografías significativas en el ámbito temático de la revista.

Vegueta está indexada en Web of Science (Emerging Sources Citation Index), SCOPUS, European Reference Index for Humanities \& Social Sciences (ERIH PLUS), REDIB, Google Scholar Metrics y Latindex, así como en directorios de revistas como Dialnet, DICE, RESH y MIAR. Vegueta posee una categoría B en la Clasificación Integrada de Revistas Científicas (CIRC) y ha obtenido el Sello de Calidad FECYT en la VI Convocatoria de evaluación de revistas científica españolas (2018), renovado en 2020.

Vegueta: Anuario de la Facultad de Geografía e Historia (ISSN: 1133-598X; eISSN: 2341-112) is a peer-reviewed journal edited by the Faculty of Geography and History of the University of Las Palmas de Gran Canaria. Vegueta has been published yearly since 1992. The main objective of this journal is to contribute to knowledge dissemination amongst researchers in the field of History, Geography and History of Art. Vegueta includes original and unpublished research papers within the area of Humanities. To be considered for publication, the contributions must be written in any of the main scientific languages, and go trough a "double-blind" peer-reviewed process. The journal is divided into three sections: Monograph Section, Miscellanea and Reviews. The Monograph Section is open to monographic topics complying with the prerequisite of being interdisciplinary. This section is coordinated and reviewed by a research specialist in the field. The Miscellanea Section publishes original and previously unreleased contributions, after going through a "double-blind" peer-reviewed process. Finally, the Reviews Section is open to works about relevant books dealing with the major topics of the journal.

Vegueta is indexed in Web of Science (Emerging Sources Citation Index), European Reference Index for Vegueta is indexed in Web of Science (Emerging Sources Citation Index), SCOPUS, European Reference Index for Humanities \& Social Sciences (ERIH PLUS), REDIB, Google Scholar Metrics and Latindex. Also in other journal directories such as Dialnet, DICE, RESH y MIAR. Vegueta has obtained the category B in the Integrated Classification of Scientific Journals (CIRC) and has obtained the FECYT Seal of Quality in the 6th Call for evaluation of spanish journals (2018), renovated in 2020.

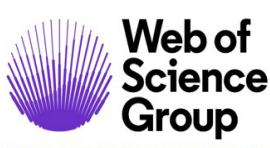

EMERGING SOURCES CITATION INDEX

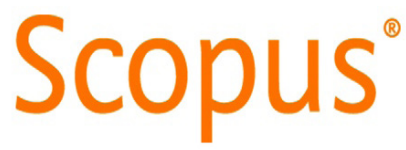

(B)

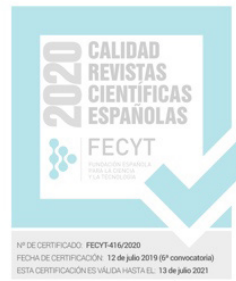

Correspondencia / Mailing Address: Vegueta. Anuario de la Facultad de Geografía e Historia, Universidad de Las Palmas de Gran Canaria, Facultad de Geografía e Historia, Pza. de la Constitución, s/n. E-35004 Las Palmas de Gran Canaria. España. Teléfono: (+34) 928451717 / 451 713. Fax: (+34) 928451 701. Correo: revistavegueta@ulpgc.es Web: http://revistavegueta. ulpgc.es/ojs. DOI: https://doi.org/10.51349/veg

(C) ULPGC. Los originales de los textos publicados en la revista Vegueta, edición impresa y electrónica, son propiedad de la Universidad de Las Palmas de Gran Canaria y se encuentra en acceso abierto, distribuidos bajo los términos de la licencia Creative Commons Atribución-NoComercial-SinDerivar (by-nc-sd) Spain 3.0, siendo necesario citar la procedencia en cualquier reproducción parcial o total del contenido. 


\section{Vegueta}

Vol. 21. Núm. 2 • 2021 • D.L.: GC1206-1214

ISSN: 1133-598X • eISSN: 2341-1112 https://doi.org/10.51349/veg Periodicidad: Semestral

\section{EQUIPO EDITORIAL / EDITORIAL BOARD}

\author{
Dirección / Editor in Chief \\ Manuel Ramírez-Sánchez (ULPGC, España) \\ Secretaría / Deputy Editor in Chief \\ María del Cristo González Marrero (ULPGC, \\ España)
}

\section{Consejo de Redacción / Editorial Board}

Antonio Castillo Gómez (U. de Alcalá, España) Gerardo Delgado Aguiar (ULPGC, España)

Pedro Javier Dorta Antequera (U. de La Laguna, España)

Laura Mariateressa Durante (U. degli Studi di Napoli Federico II, Italia)

Antonio Carlos Gaeta (U. Estadual Paulista, São Paulo, Brasil)

Juan Marchena Fernández (U. Pablo de Olavide, España)

María Victoria Marzol Jaén (U. de La Laguna, España)

Gonzalo Pasamar Alzuria (U. de Zaragoza, España)

Purificación Ruiz Flaño (U. de Valladolid, España)

Enrica Salvatori (U. di Pisa, Italia)

María Teresa Sánchez Salazar (U. Nacional Autónoma de México, México)

Juan Manuel Santana Pérez (ULPGC, España) Marie-Ange Teston (U. Jean Molin-Lyon 3, Francia)

Elisa Varela Rodríguez (U. de Girona, España)

\section{Consejo Asesor / Advisory Board}

José Arnáez Vadillo (U. de La Rioja, España)

Juan Manuel Barragán Muñoz (U. de Cádiz, España)

Youssef Bokbot (Institut National des Sciences de l'Archéologie et du Patrimoine, Maruecos) João Manuel de Lemos Baptista (U. de Aveiro, Portugal)

Francisco Comín Comín (U. de Alcalá, España) Heriberto Cruz Solís (U. de Guadalajara, México)

Jean Marc Delaunay (Université Sorbonne Nouvelle - Paris 3, Francia)
Carmen Fraga González (U. de La Laguna, España)

Mauro S. Hernández Pérez (U. de Alicante, España)

Paloma Ibarra Benlloch (U. de Zaragoza, España)

Carlos Martínez Shaw (U. Nacional de Educación a Distancia, España)

María Montserrat Gárate Ojanguren (U. del País Vasco, España

Francisco M. Gimeno Blay (U. de Valencia, España)

José Ojeda Zújar (U. de Sevilla, España) Ascensión Padilla Blanco (U. de Alicante, España)

Ramón Pérez González (U. de La Laguna, España)

Horst Pietschmann (Universität Hamburg, Alemania)

Xavier Pons Fernández (U. Autónoma de Barcelona, España)

Enrique Propín Frejomil (U. Nacional Autónoma de México, México)

Carlos Reyero Hermosilla (U. Autónoma de Madrid, España)

Reinaldo Rojas (U. Pedagógica Experimental Libertador, Venezuela)

José Manuel Rubio Recio (U. de Sevilla, España)

Pere Salvá Tomàs (U. de les Illes Balears, España)

Jean Stubbs, Institute of the Americas (U. College London, Reino Unido)

\section{Editor traducción inglés/English Translation} Editor

Romén Reyes-Peschl (U. of Kent, Reino Unido

\section{Edición / Edition}

Facultad de Geografía e Historia de la Universidad de Las Palmas de Gran Canaria

\section{Colaboración / Collaboration}

Departamento de Ciencias Históricas (ULPGC)

Departamento de Geografía (ULPGC) 


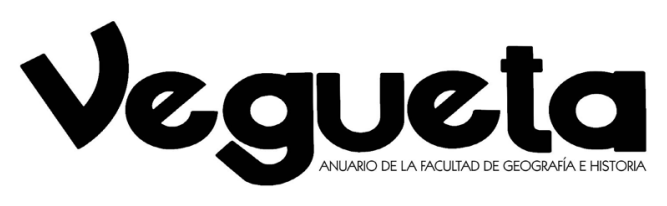

Vol. 21. Núm. 2 • 2021 • D.L.: GC1206-1214

ISSN: 1133-598X • eISSN: 2341-1112 https://doi.org/10.51349/veg Periodicidad: Semestral

\section{SUMARIO / SUMMARY}

\section{Estudios / Studies}

Manuel-Reyes García Hurtado, Bernard Renau d'Éliçagaray en España durante la Guerra de Sucesión / Bernard Renau d'Éliçagaray in Spain During the War of the Spanish Succession.

Francisco JaVIER Illana López, Un señorío en la alta Andalucía del siglo xVII: Antonio Álvarez de Bohorques, I marqués de Los Trujillos, o la ambición señorial / A Manor in the High Andalusia of the Seventeenth Century: Antonio Alvarez de Bohorques, 1st Marquis of Los Trujillos, or Manorial Ambition.

Víctor JimÉNEZ BARRADo, Cartografía digital disidente: el caso de Santiago de Chile durante el estallido social de 2019/Dissident Digital Cartography: The Case of Santiago de Chile during the Social Outburst of 2019.

IrMa MoRa Aguiar, La transcripción del alfabeto líbico-bereber canario: el ejemplodeElHierro / The Alphabetic Transcription ofCanarian Libyco-Berber Script: The Case of El Hierro..

Álvaro Francisco Morote Seguido, Joan Carles Membrado Tena, La toponimia como recurso didáctico para la enseñanza de la Geografía. Una propuesta a partir de tres salidas de campo en la Huerta de València (España) / Toponymy as a Didactic Resource for Teaching Geography: A Proposal Based on Three Field Trips to Huerta de Valencia (Spain).

Margarita Novo Malvárez, Joseph R. Hartman, La Catedral de la Inmaculada Concepción de Kansas City (Missouri). Un recurso patrimonial en un escenario de diversidad religiosa / The Cathedral of the Immaculate Conception in Kansas City, Missouri: A Heritage Asset in a Scenario of Religious Diversity.

Ismael Rodríguez Marrero, La imagen del Japón imperial a través de la prensa canaria: los inicios de la segunda guerra sino-japonesa / The Image of Imperial Japan in the Canarian Press: The Beginning of the Second Sino-Japanese War. 


\section{Reseñas / Reviews}

Manuel Casado Arboniés, «Óscar Recio Morales, Alejandro O’Reilly, inspector general. Poder militar, familia y territorio en el reinado de Carlos III, Sílex Ediciones, Colección Sílex Universidad, Madrid, 2020, 516 págs., ISBN: 978-84-7737-837-2»; Víctor GARCía GonZÁLEZ, «ManuelReyes García Hurtado (ed.), Las innovaciones de la Armada en la España del siglo de Jorge Juan, Biblioteca de Historia CSIC, Madrid, 2020, 618 págs., ISBN: 978-84-00-10646-1»; DANIEL GARCía Pulido, «Valeria Aguiar Bobet, El orientalismo a la vuelta de la esquina. Crónicas y relatos sobre Marruecos en la prensa tinerfeña entre los siglos XIX y XX, Ediciones Idea, Santa Cruz de Tenerife, 2020, 247 págs. (Cuadernos del Magreb, 14) ISBN 978-84-18138-47-8»; ITZEA GOIKOLEA-AMIANO, "Yolanda AixelàCabré (ed.), "Local versions and the global impacts of Euro-African memories: A revision through Spanish colonial imprints", Culture and History Digital Journal, 9 (2), December 2020, https:/ / doi.org/10.3989/ chdj.2020.v9.i2»; Francisco Manuel Pastor Garrigues, «Jennifer Guerra Hernández, Canarias ante la guerra de Marruecos (1909-1927). Miradas desde el Atlántico, Las Palmas de Gran Canaria, Cabildo de Gran Canaria, 2019, 307 págs., ISBN: 978-84-8103-928-3»; MAnuel De PAz SÁnchez, "Ángel Dámaso Luis León, El Rey de la Octava Isla. Canarias ante Chávez y la Revolución Bolivariana, Ediciones Idea, Santa Cruz de Tenerife, 2020, 226 págs., ISBN 978-84-18138-66-9»; IRINA YÁNYSHEV NÉSTEROVA, «Juan Manuel Matés-Barco and Leonardo Caruana de las Cagigas (eds.), Entrepreneurship in Spain: A History, Routledge, 52 Vanderbilt Avenue, New York, NY 10017 and 2 Park Square, Milton Park, Abingdon, Oxon, OX14 4RN, 2021, 200 pages, ISBN: 978-0-367- 64922- 7 (hbk), ISBN: 9781-003-12697-3 (ebk)» 
Estudios / Studies 

Vegueta. Anuario de la Facultad de Geografía e Historia

21 (2), 2021, 9-38

eISSN: 2341-1112

https://doi.org/10.51349/veg.2021.2.01

\title{
Bernard Renau d'Éliçagaray en España durante la Guerra de Sucesión
}

\author{
Bernard Renau d'Éliçagaray in Spain During the War \\ of the Spanish Succession
}

\author{
Manuel-Reyes García Hurtado \\ Universidade da Coruña \\ https:// orcid.org/0000-0002-4263-164X \\ reyes@udc.es
}

Recibido: 18/11/2020; Revisado: 03/04/2021; Aceptado: 10/05/2021

\section{Resumen}

Estudiamos las actividades de un marino e ingeniero francés, Bernard Renau d'Éliçagaray, como modelo de todos aquellos que en un plano intermedio de la Administración realizaron el trabajo de campo para posibilitar una implantación segura y rápida de los Borbones en el trono de España. Su misión consistió en garantizar que la instauración de la nueva dinastía se llevara a cabo de manera pacífica y, en caso contrario, con total conocimiento del estado de defensa de los principales puertos y fortificaciones para resistir el embate de quienes cuestionaran la legitimidad de Felipe v.

Palabras clave: Ingeniería naval, Fortificación, Cádiz, Renau d’Éliçagaray, correspondencia.

\begin{abstract}
This article examines the activities of Bernard Renau d'Éliçagaray a French naval officer and engineer, taking them as a model for all those who, whilst in an intermediate administrative role, carried out fieldwork to rapidly and securely enthrone the Bourbons in Spain. His mission was to ensure that the new dynasty was established peacefully, but failing that, his extensive knowledge of the main ports' and fortifications' defences would help to resist the onslaught by those who questioned Philip V's legitimacy.
\end{abstract}

Key words: Naval Engineering, Fortification, Cadiz, Renau d'Éliçagaray, Correspondence. 


\section{INTRODUCCIÓN ${ }^{1}$}

Felipe v llegó a España en febrero de 1701 acompañado por una cohorte de franceses de su máxima confianza que iban a ser los encargados de transformar la estructura de la Administración, ocupando los puestos más relevantes en la Corte, todos ellos de sobra conocidos y que han merecido numerosos estudios y monografías. Sin embargo, el trabajo de esta élite política tuvo que sortear un problema de primer orden como fue preparar el territorio para el paulatinamente más encendido ambiente prebélico y solo un año después, en 1702, la guerra abierta contra los aliados partidarios del archiduque Carlos. La profunda reestructuración que se planteó, los planes económicos, las reformas, debieron simultanearse, convivir o postergarse mientras la Guerra de Sucesión convertía a España en un campo de batalla. Era por tanto imprescindible, y Felipe v asî lo defendió desde su acceso al trono, no solo atender a las grandes cuestiones estructurales de la monarquía, sino conocer el estado real del territorio para garantizar su defensa. Y es aquí donde hicieron acto de presencia individuos que desde París se enviaron a España, seleccionados entre aquellos con una formación técnica más elevada, una capacidad de gestión contrastada y una voluntad de servicio al nuevo monarca, aunque sea solo, al menos en los primeros años, por su estrecha vinculación a su rey Luis XIV. Entre todos estos hombres que desarrollaron su labor en la Península Ibérica, vamos a centrarnos en las aportaciones de alguien que es hoy tan desconocido como fue enorme su prestigio en su época, Bernard Renau d'Eliçagaray (1652-1719).

En otro lugar ya hemos analizado su biografía y la tarea que llevó a cabo en Galicia en el primer lustro del siglo XVIII (GARCía Hurtado, 2022), de modo que ahora solo presentaremos algunos de los rasgos más destacados de la misma y que nos ayudarán a comprender qué supuso su actividad en el desarrollo de las numerosas disciplinas que cultivó. Renau, desde un origen humilde, tuvo oportunidad de entrar en contacto con la construcción naval y la Armada al ser adoptado por el intendente del naciente arsenal de Rochefort (Colbert de Marcin). Sus aptitudes para las ciencias y los contactos familiares le permitieron tener acceso directo a la Corte de Versalles y, con sucesivos apoyos de los secretarios de Marina, formar parte de los consejos en que se decidió cuál debía ser la tipología de las embarcaciones de la flota francesa (su modelo se impuso), los planes estratégicos de las campañas navales anuales (en algún caso llegó a cuestionar la decisión adoptada y se modificó a su favor), proporcionar a la Armada nuevas armas (morteros) y llevar a cabo personalmente expediciones (al Caribe) o diseñarlas (al Ártico; HamY, 1895: 182 y 1901; EmMAnuel, 1959: 92 y ss.; HenRat, 1984). Todo esto sin dejar de lado su labor como científico y autor innovador (miembro de la Académie des Sciences desde 1699), ni su relevante papel como discípulo aventajado del mariscal de Vauban. Estamos ante alguien que la historiografía francesa no ha olvidado (especialmente en el siglo XVIII en su papel de científico, y en el xx en su carácter de vasco por parte de publicaciones locales; Fontenelle, 1721; D’Erlo, 1905; Saint-Saud, 1930; Bagneux, 1932 y 1933; ETCHEGOIN, 1939; ElissagARAY DE JAURGAIN, 2004). Sin embargo, todos han obviado la etapa de su vida que transcurrió en España, quizá porque sus biógrafos iniciales

1 Trabajo realizado en el marco del Proyecto I+D de Generación de Conocimiento «Dinámicas y conflictividad en el litoral del Noroeste peninsular en la Edad Moderna» (ref. PGC2018-093841-B-C33), del Ministerio de Ciencia, Innovación y Universidades, con una cofinanciación del 80\% FEDER. 
solo ofrecieron sobre ella unas simples pinceladas o porque para recomponerla era preciso localizar y analizar su correspondencia con Versalles de este período. Prestaremos especial atención a su etapa en la ciudad de Cádiz, que era considerada tanto en España como en Francia como el antemural, como la plaza clave que debía ser mantenida a cualquier precio bajo el gobierno de Felipe v.

Desde el punto de vista práctico, Renau fue un constructor naval y un ingeniero militar, pero tanto lo primero como lo segundo para él no fueron más que consecuencias de su condición de científico, pues lo que él aportó como innovación fue la aplicación de un método basado en el estudio tanto a sus trabajos en el mar como en tierra. Si en determinados momentos Renau planteó abiertamente la necesidad no ya de reformar, porque casi era inexistente, la flota militar española, sino de configurarla con unas unidades que poseyeran unas magníficas condiciones marineras y artilleras, fue porque poseía los conocimientos para lograrlo y porque mostró su frontal rechazo, casi desprecio, por el hecho de que se confiara esta renovación a alguien como Antonio de Gaztañeta (ODRIOzOLA, 1979: 107-110, 193195 y 1998: 98-99; FernÁNDEZ GonZÁlez, 1992; APESTEGuI, 1992; QuiNTERO, 2020: 602; García Hurtado, 2022). La carta de presentación de Renau era inmejorable, pues era autor del primer texto que se conoce dedicado a la arquitectura naval, la Mémoire sur les constructions des vaisseaux, dans lequel il y a une méthode pour en conduire les façons (1679; BRIOIST y VÉRIN, 2008), manuscrito de 17 páginas con notas marginales y dibujos (FERREIRO, 2007: 70), e introdujo la aplicación de la física a la construcción naval (VÉRIN, 1993: 351-357). Pero la situación económica y de guerra abierta le llevaron a centrarse en la que fue su principal misión en España: visitar una serie de ciudades costeras, elaborar informes sobre sus defensas y mejorar sus fortificaciones. Esto no impidió que diera a conocer sus ideas, pues una de sus características era la obstinación. De hecho, en octubre de 1708 se constituyó una junta para el restablecimiento de la Armada, de la que formó parte Renau, si bien «no estaba al tanto de sus proyectos» (Hrodej, 2006: 35). En cualquier caso, esta junta se disolvió.

Para acercarnos a su figura y sus aportaciones, vamos a exponer su trabajo como hombre de ciencia, previamente a su llegada a España y posteriormente al regresar a su patria, una de sus dimensiones más ignoradas, que nos permitirá calibrar su relevancia en la época y la importancia de que fuera seleccionado para llevar a cabo una importante misión en la primera década del reinado de Felipe v en la Península Ibérica.

\section{LA PRODUCCIÓN CIENTÍFICA DE RENAU}

Renau, como hemos adelantado, era un «ingeniero anfibio» ${ }^{2}$ (FONTENELLE, 1721: 110), y además de su adaptación a ambos medios, también hizo gala de su capacidad para actuar en el campo de batalla y en la soledad del estudio. Así, en 1689 dio a la imprenta, por orden del rey, su De la theorie de la manouvre des vaisseaux (Figura 1). Expuso que la navegación constaba de dos partes, una era el pilotaje, sobre la que existían numerosos tratados, y la otra era la maniobra, de la que se vanagloriaba de que su texto era el primero («no conozco que se haya dado ninguna», RENAU, 1689: prefacio) a pesar de ser el elemento más esencial, pues en

2 Todas las referencias textuales han sido traducidas al castellano por el autor. 
función de ella se podían obtener ventajas sobre el enemigo, tanto para atacarle como para escapar, para doblar un cabo, evitar un obstáculo o seguir una ruta. Todo esto se aprendía a bordo, solo tenía como base la experiencia y, por tanto, era preciso mucho tiempo, además de destreza, para dominarla. Afirmó que la elaboración de una teoría reduciría el tiempo de aprendizaje y lo haría menos costoso y más sencillo, pues se efectuaría en tierra. Solo en un segundo momento se aplicaría sobre una nave lo ya estudiado y no se exigirían largas navegaciones y años de práctica. La maniobra era fundamental porque de ella dependían todas las evoluciones de una nave, ${ }^{3}$ y para controlarlas había que dominar y conocer el funcionamiento de elementos como los mástiles, las vergas, las velas, el timón, la quilla, etc. La posición, el ángulo, de cada uno de estos determinaba un efecto diferente, y lo que Renau señaló es que, en el contexto de la Revolución Científica, se podía reducir a ciencia y reglas ciertas, que todo se podía matematizar con la aplicación de la geometría a la mecánica, sin negar la dificultad de los cálculos (él partía de la base de que el lector poseía conocimientos de los principios de geometría). Antes de analizar el efecto de esta obra en el ámbito científico, donde veremos que su recepción no estuvo exenta de críticas, es obligado señalar algunas de las aportaciones de Renau. En primer lugar, va a establecer la importancia que tenía colocar la vela en la posición más ventajosa con respecto al viento y a la ruta que la nave debía seguir. En segundo lugar, subrayó la relevancia de adoptar en cada circunstancia el ángulo óptimo del timón y de la quilla. Las ideas eran correctas y novedosas. Era muy loable su intento de formular matemáticamente cómo solucionar los problemas y combinaciones que surgían sobre la superficie marina a una embarcación, pero Renau no poseía ni instrumentos como el cálculo diferencial, todavía en fase de desarrollo, ni el caudal de conocimientos de los más ilustres matemáticos de la época, que fue a quienes debió hacer frente. Ahora bien, es importante señalar que jamás se sintió inferior a ninguno de sus contrincantes, y que pese a que durante veinticinco años se mantuvo abierta la disputa, no cedió jamás ni se dio por vencido. De esto no hay que deducir que los argumentos de sus adversarios no fueran demoledores o correctos, sino que otra de las características de su personalidad es que una vez que adoptaba una idea, porque consideraba que era cierta, su obstinación le llevaba a defenderla hasta el final y jamás la modificaba (RICHER, 1815: 173).

3 Para el uso particular de cada maniobra, Renau recomendaba el Exercice en général de toutes les manoeuvres qui se font à la mer de Anne-Hilarion de CoTENTIN, conde de Tourville, publicado en 1693. 


\section{DE LA \\ THEORIE}

D E L A

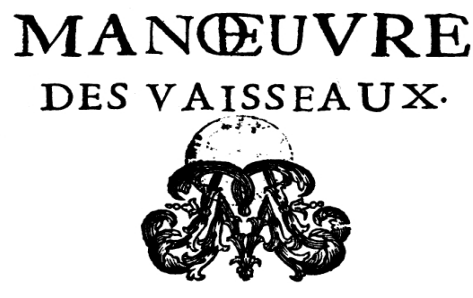

A P ARIS,

Chez ESTIEN N M C A A L E T' premier Imprimeur du Roy, ruë S. Jacques, à l'Image S. Paul

M. DC. L X X X I X.

De l'exprés commandement de $S a$ Majefté.

Figura 1. Portada De la theorie de la mancuvre des vaisseaux.

Pocos años después, Christiaan Huygens publicó una serie de textos en los que ponía de manifiesto errores que había detectado en la obra. El primero apareció en septiembre de 1693 en la Bibliothèque universelle et historique (195-203). Bernoulli afirmó que el libro del ingeniero general de la Marina Renau (195) «está escrito con mucho cuidado, limpieza y método, y demuestra conocimiento en la geometría y el análisis» (HuYGENS, 1693: 195-196). De hecho, admitía que todos los principios expuestos eran verdaderos y que el problema no radicaba en estos, sino en que la teoría no derivaba de una aplicación correcta de los mismos. Este hecho le obligaba a exponerlo públicamente, pues las consecuencias, al tratarse de un texto dirigido a los pilotos, serían muy graves. Renau, movido por el renombre de su crítico, revisó su obra, pero su respuesta fue una completa reafirmación de sus ideas, sin el menor espacio para la autocrítica, llegando a considerar que de seguir las indicaciones de Huygens se derivarían «absurdidades» (RENAU, 1712: 5). Pocos meses más tarde apareció la réplica de Huygens, en abril de 1694 en Histoire des Ouvrages des Savans (355-361). Huygens estaba sorprendido, porque consideraba que lo expuesto en 1693 sobre el error capital de Renau era tan evidente y, a juicio de matemáticos con los que lo había consultado, sin posibilidad de réplica que no se esperaba una respuesta del francés en defensa de su teoría, evidenciando que no le convencieron sus argumentos. Así pues, llevó a cabo un ataque frontal (HuYGENS, 1694: 355-356 y 361):

me encuentro obligado de mostrar todavía con más evidencia de la que lo he hecho, que su teoría solo puede ser sostenida trastocando los principios de la mecánica establecidos desde hace mucho tiempo y de los cuales él no querría ni osaría negar la verdad. Para no alargar inútilmente nuestra disputa, deteniéndome en diversas razones que el señor Renau me opone, mostraré solamente que, como había señalado, él está equivocado en la proposición sobre la cual gira toda su teoría, después de lo 
cual indicaré en pocas palabras lo que ha podido dar lugar a su error.

Señalo, por lo demás, que toda esta teoría, como él la había dado, sería cierta si las resistencias del agua fueran como las velocidades del navío, en lugar de que ellas son como los cuadrados de estas velocidades.

Ni que decir tiene que Renau hizo caso omiso a todas estas críticas y quedó absolutamente convencido de que sus contestaciones habían cerrado el debate (FERREIRO, 2007: 88-91 y 93). Fue muchos años después, una vez ya retornado a Francia tras su estancia en España, cuando él mismo afirmó que un amigo le había dado a conocer que Johann Bernoulli había publicado artículos donde cuestionaba su teoría. Sus textos habían aparecido en las Acta Eruditorum de 1695 (537-553) y 1696 (332-337), y en ellos se centraba en la velocidad. Es en respuesta a estas censuras de finales del siglo XVII por lo que Renau publica su Mémoire "para evitar errores considerables en la mecánica y en la navegación, donde tienen efectos funestos, poniendo la resolución a la luz del día para que nadie pueda en adelante equivocarse ni ponerla en duda» (RENAU, 1712: 7).

Sin embargo, Renau, con su publicación de 1712 reabrió un debate que había quedado olvidado para sus contemporáneos, y quien tomó el relevo de Jacob Huygens fue Johann Bernoulli (FERREIRO, 2007: 87, 88, 91, 92-94, 119). Este reconoció que correspondía a Renau el mérito y el honor de haber sido el primero y el único que se había propuesto profundizar en la materia de la maniobra. Señaló que durante la disputa de Renau y Huygens el matemático francés marqués de l'Hôpital (Guillaume François Antoine), deseando conocer su opinión, le había remitido un extracto de los argumentos, declarándose a favor de Renau. Esta cuestión la tenía olvidada, hasta que recibió una carta del matemático Pierre Rémond de Montmort, quien le informó de que Renau, persistiendo en sus ideas, preparaba un texto contra Huygens. Esto le llevó a leer el libro de Renau por primera vez, derivándose de esto que no solo se retractó de su inicial opinión favorable, sino que afirmó haber descubierto otro error muy importante relativo a la deriva del navío, que dio a conocer en 1714. Por azar, cuando Bernoulli estaba terminando su Essai, donde desmontaba la teoría de Renau, este le envío su Mémoire de 1712 junto a una carta fechada el 6 de junio de 1713, a la que respondió Bernoulli el 12 de julio de 1713. Se inició así un intercambio epistolar que recordaba al anterior con Huygens, donde, manteniendo siempre las formas, criticaba uno y justificaba el otro sus propuestas (BERNOULLI, 1742: 129-144, 145-152 y 153-167). En la respuesta de Bernoulli de 12 de julio de 1713 le notificó a Renau que, tras la lectura de su libro, no solo estaba de acuerdo con Huygens y su crítica a la velocidad de un navío en una ruta oblicua, sino que declaraba haber encontrado otro error sobre la fijación del ángulo de la deriva, es decir, de la verdadera ruta de un navío. La recepción de esta carta debió sorprender sobremanera a Renau, pues de quien esperaba obtener un dictamen positivo, en concordancia con el apoyo que le había expresado años antes, ahora recibía la censura más amarga y aumentada. Bernoulli atacó los cimientos de su teoría y le avanzó lo último que hubiera deseado leer: «En fin, señor, viendo que toda vuestra teoría solo está fundada sobre los dos principios, que usted supone, para la determinación de la deriva y de la velocidad, ella caería necesariamente por la destrucción de estos dos principios. Yo he trabajado en una nueva teoría, pero más difícil en verdad y desprovista de esta simplicidad que reina en la vuestra» (BERNOULLI, 1742: 131). En posdata añadía que, tras todo lo que le había explicado, no creía necesario 
entrar a responder sobre las tres pretendidas absurdidades que Renau afirmaba que provocaba el principio de Huygens (BERnOUlLI, 1742: 140).

Como era de esperar, Renau escribió a Bernoulli el 15 de septiembre. Lejos de entrar en la crítica completa de lo expuesto por Bernoulli, se centró en cuestiones de la Mémoire sobre las que le planteó cuestiones y se mostró agradecido por su colaboración para subsanar sus errores, «en caso de que me haya equivocado» (BERNOULLI, 1742: 145). Este intercambio finalizó el 7 de noviembre cuando Bernoulli se propuso demostrarle que lo que presentó se basaba en sólidas razones y fuertes pruebas, para que se hiciera evidente la verdad y se disipara el error. Entró en el plano personal y le reconoció que comprendía cuáles eran sus sentimientos al ver cuestionada una teoría que era tan sencilla y cómoda, pero que lamentablemente «no está fundada sobre la verdad, sino sobre lo verosímil» (BERNOULLI, 1742: 154). Añadió que su libro fue publicado por orden del rey, que tuvo una magnífica acogida por los sabios, aunque solo porque se dejaron llevar por la opinión y no lo leyeron con suficiente atención. El tono era directo, pero cortés, lo que no impidió que Bernoulli terminara señalando que esperaba «que a usted no le ofenderá la franqueza con la que le descubro mis pensamientos» (BERNOULLI, 1742: 167). Tras Huygens y Bernoulli la obra de Renau apenas se sostenía. Bernoulli pensó que el silencio de Renau significaba que había aceptado su derrota, pero no creemos que esto sucediera. Renau, al menos de manera escrita, no reconoció jamás que su teoría fuera errónea.

En Francia, por otro lado, Renau ocupó un lugar en el olimpo de la ciencia naval. Antes de él, el primer autor que pretendió ofrecer una teoría sobre la maniobra fue el padre Pardies con Mouvement local et forces mouvantes (1671), pero no fue más allá de paralogismos. Uno de los defectos de Renau fue haber fundamentado sus ideas en Pardies, pero lo que es indudable es que su texto marcó un antes y un después, pues contó con el apoyo de Luis XIV, afirmando abiertamente que ofrecía los principios de una nueva ciencia. ${ }^{4} \mathrm{Como}$ hemos visto, Bernoulli (1714) perseguía subsanar las dos carencias centrales de la teoría de Renau. Años más tarde, el francés Pitot (1731) señaló que la obra de Bernoulli contaba con el respaldo de los geómetras, pero no tanto con el de los marinos, de modo que él se aprestó a redactar un pequeño tratado donde ofrecía «soluciones más simples y más cortas», se aplicaban los principios a «navíos ordinarios» y presentaba, por primera vez, unas tablas que Bernoulli había señalado que serían de gran utilidad para la navegación, facilitando en gran medida operaciones matemáticas complejas: calcular la velocidad, determinar las posiciones más adecuadas de la quilla y de las velas, etc. Las soluciones de las tablas se deducían de los principios establecidos en la teoría, «sin emplear ningún cálculo algebraico a fin de ponerla más al alcance de los pilotos» (Рітот, 1731: prefacio). La teoría era inexcusable, pero a juicio de Pitot a los marinos no les era preciso su dominio ni el de las fórmulas que la gobiernan, sino solo el resultado de la misma que venía reflejado en las tablas. Este camino de simplificación para el empleo de los textos dedicados a la maniobra fue el que siguió Savérien en 1745. Sin ocultar sus errores (Histoire de l'Académie, 1751: 115; ${ }^{5}$ Montucla, 1758: 474-475), los autores franceses colocaron a Renau en un lugar preponderante:

4 Si seguimos la cronología habría que citar a Hoste, P. (1692): Recueil des traités de mathématique, qui peuvent être necessaires à un Gentil-homme, pour servir par mer, ou par terre. ... Tome Troisieme, Chez J. Anisson, Paris, «Traité x. De la maneuvre des vaisseaux»: 71-178.

5 (1751) Histoire de l'Académie Royale des Sciences. Année M. DCCXLVI, Imprimerie Royale, Paris. 
Fue el primero que emprendió la tarea de profundizar en esta materia y de dar principios para determinar la situación más ventajosa de las velas y de la proa de los navíos con relación al viento y a la ruta que se deseaba seguir, pero esta obra, excelente por otra parte, contenía cosas que fueron contestadas por Huygens y en 1714 por Jean Bernoulli... Renau fue el primero que dio principios sobre esta materia; Bouguer ha sido el primero que la ha profundizado y agotado en sus dos importantes

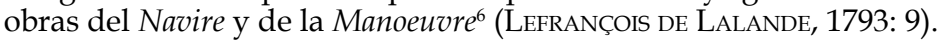

\section{PLANIFICAR LA DEFENSA DEL TERRITORIO: PROYECTOS, REFLEXIONES Y PENURIAS}

Renau llegó a España en marzo de 1701 con la convicción de que permanecería aquí no más allá de cinco meses. Sin embargo, este fue su hogar hasta 1709, cuando regresó de manera definitiva a Francia. Su correspondencia nos permite seguir sus peripecias por la Península Ibérica y conocer la cronología de sus viajes, los lugares que visita (Lisboa, Barcelona, Madrid, La Coruña, Vigo, Pontevedra, Tuy, Bayona, etc.) y aquel en que reside durante largos años, Cádiz. No se indica jamás el nombre de su corresponsal en París, pero sin ninguna duda es Pontchartrain (ministro de Marina de 1699 a 1715). Durante el transcurso de los ocho años asistimos a su evolución personal, desde el activo e infatigable memorialista e ingeniero que proyecta, dibuja y combate en Madrid para obtener recursos económicos, a un hombre hastiado, fatigado, frustrado en sus expectativas, arruinado por su compromiso expreso con la plaza de Cádiz y que anhela cruzar los Pirineos y no regresar jamás. Es importante tener en cuenta la dependencia de Renau, que era distinta en el plano administrativo y político que en el laboral, y además esto último fue cambiante. Así, el Renau que entró en España era capitán de navío, ${ }^{7}$ y en España hasta avanzado el tiempo no se le otorgó el grado de mariscal de campo y de teniente general. Esto implicó que no cobrara su salario durante años, como veremos. Otra consecuencia de su singularidad era que a quien informaba puntualmente, ante quien respondía, de quien recibía órdenes, a quien debía explicar qué tareas desarrollaba, era a Pontchartrain, a nadie en Madrid. La resolución con la que se expresaba, sus críticas a personalidades de la Corte (españolas y francesas), mostraba tanto esa independencia como la confianza en la discreción de su corresponsal. Bien distinto es que los proyectos que elaboraba, los mapas que levantaba, los presentara en Madrid, pero eran una copia, pues el original solía acompañar a sus cartas. De hecho, el único plano que se conserva de su estancia en España, de los muchos que sabemos que levantó por referencias y descripciones en su correspondencia, es el que hizo de la Puerta de Tierra de Cádiz (Figura 4) y se encuentra en los Archives Nationales de París, a continuación de la memoria en que lo disecciona. Recibido el visto bueno de París, el plano se presentaba en Madrid, porque su principal tarea en la Corte era la de convencer al cardenal Portocarrero (PeÑA, 2005) de las bondades de sus ideas y

6 Bouguer, P. (1746): Traité du navire, de sa construction, et de ses mouvemens, su gran obra, y (1757): De la Mancuvre des vaisseaux, ou Traité de méchanique et de dynamique dans lequel on réduit à des solutions très simples les problèmes de marine les plus difficiles, qui ont pour objet le mouvement du navire.

7 Este grado le fue concedido por Luis XIV, ya que aunque estaba vinculado a la secretaría de Marina no tenía graduación, lo que provocaba que cuando impartía su enseñanza a los oficiales estos rechazaban tener que recibir instrucción de él. 
obtener financiación para ejecutarlas. Esta dicotomía no debió resultar fácil para él, pues era un hombre de acción, de trabajo a pie de campo, y en sus visitas a Madrid daba cuenta de la reiteración de promesas incumplidas, de la sucesión de reuniones cuyas decisiones no se implementaban, de su incomprensión ante la grave dejación que, a su juicio, realizaba la Corona de su función como garante de la protección del territorio con su auxilio en tropas y dinero. Tuvo acceso a las primeras autoridades en la Corte, pero las consecuencias prácticas de sus contactos fueron mínimas en el plano real, y esto fue minando su creencia en que su misión en España tuviera algún sentido.

Desde el punto de vista estratégico Francia concedía una gran importancia a Cádiz y al flanco sur de España, con especial atención a Gibraltar, plaza para la que ya en 1702 se presentó un proyecto para cerrarla ante posibles incursiones de ingleses y holandeses, ${ }^{8}$ quienes planeaban una guerra conjunta contra Francia y España. De este modo, se impedía que pudieran penetrar en el Mediterráneo y colaborar con la flota imperial en Italia, que precisaba para su subsistencia de los recursos de esas dos potencias y operativamente de las unidades que estas proporcionaban. Esta acción se consideraba que sería el golpe más sensible que se podría dar a los enemigos. En estas fechas, ningún analista planteaba la variable de que una parte del territorio de la Corona en la Península se levantara en armas contra Felipe, por lo que fue en el litoral costero e isleño donde se centraron los proyectos de defensa ante un ataque o invasión. Dejando de lado Galicia (GARCía HuRTADO, 2022), en el Mediterráneo se localizaban una serie de radas donde las flotas enemigas podían echar el ancla, pero todos coincidían en que solo había un puerto en el que una flota podía protegerse de una tempestad, y era el puerto de Mahón. Por tanto, se recomendó que se analizara la seguridad de Menorca ${ }^{9}$ para evitar que cayera en manos enemigas, con escaso éxito. ${ }^{10}$ Se consideraba fundamental que las flotas adversarias no llegasen a controlar ningún puerto o territorio costero, para obligarlas a depender de manera absoluta para su subsistencia del auxilio de convoyes, que podrían ser interceptados y neutralizados en el estrecho de Gibraltar o en el Mediterráneo por la flota francesa. Vemos pues que la arquitectura defensiva en el sur y el Mediterráneo pivotaba sobre Cádiz, Gibraltar y Mahón. En este análisis coincidían plenamente los aliados, como los franco-españoles tuvieron oportunidad de comprobar.

Renau, en la primera carta que conservamos (enero de 1702), exponía que había elaborado un proyecto para Gibraltar, que había entregado al marqués de Leganés (Bernardo Ares, 2008). En él distinguía, dentro de las obras que eran absolutamente imprescindibles, aquellas más urgentes y de un coste más reducido, ${ }^{11}$ planteaba aprovechar las disposiciones ventajosas del terreno para hacer de ese punto un lugar infranqueable, así como construir un muelle que proporcionaría un puerto considerable y de un enorme valor estratégico. Menos

8 Proposition du sieur Stageno, Génois, de fermer le Détroit de Gibraltar, 1702. Archives Nationales de París (en adelante AN), MAR/B/4/22.

9 La artillería en las murallas de Ciudadela era la misma en 1701 que en 1712, de metal de mala calidad y solo disponía de 40 cañones útiles, al tiempo que en Mahón se había permitido construir casas adosadas a las murallas. RAMIS, 1832: 28, 45-47.

10 Menorca fue conquistada por una escuadra angloholandesa en 1708, pasando a la soberanía de Gran Bretaña en virtud del Tratado de Utrecht de 1713, y así permaneció hasta 1802, con un intervalo en posesión española entre 1782 y 1798.

11 Lisboa, 24 de enero de 1702. AN, MAR/B/4/22. 
de dos meses más tarde se encontraba en Madrid, donde debía mantener una importante conversación sobre esto con el cardenal Portocarrero. ${ }^{12}$ La conquista de Gibraltar en 1704 y el posterior fracasado asedio de la plaza por las tropas de Felipe v, acción en la que Renau tuvo un papel muy destacado, tanto en el plano operativo (asistió, como mariscal de campo, a la apertura de la trinchera el 21 de octubre $)^{13}$ como técnico, levantando un plano que fue la base en Francia de otros muchos a los largo del siglo XVIII (Figura 2), centraron su trabajo en 1705.

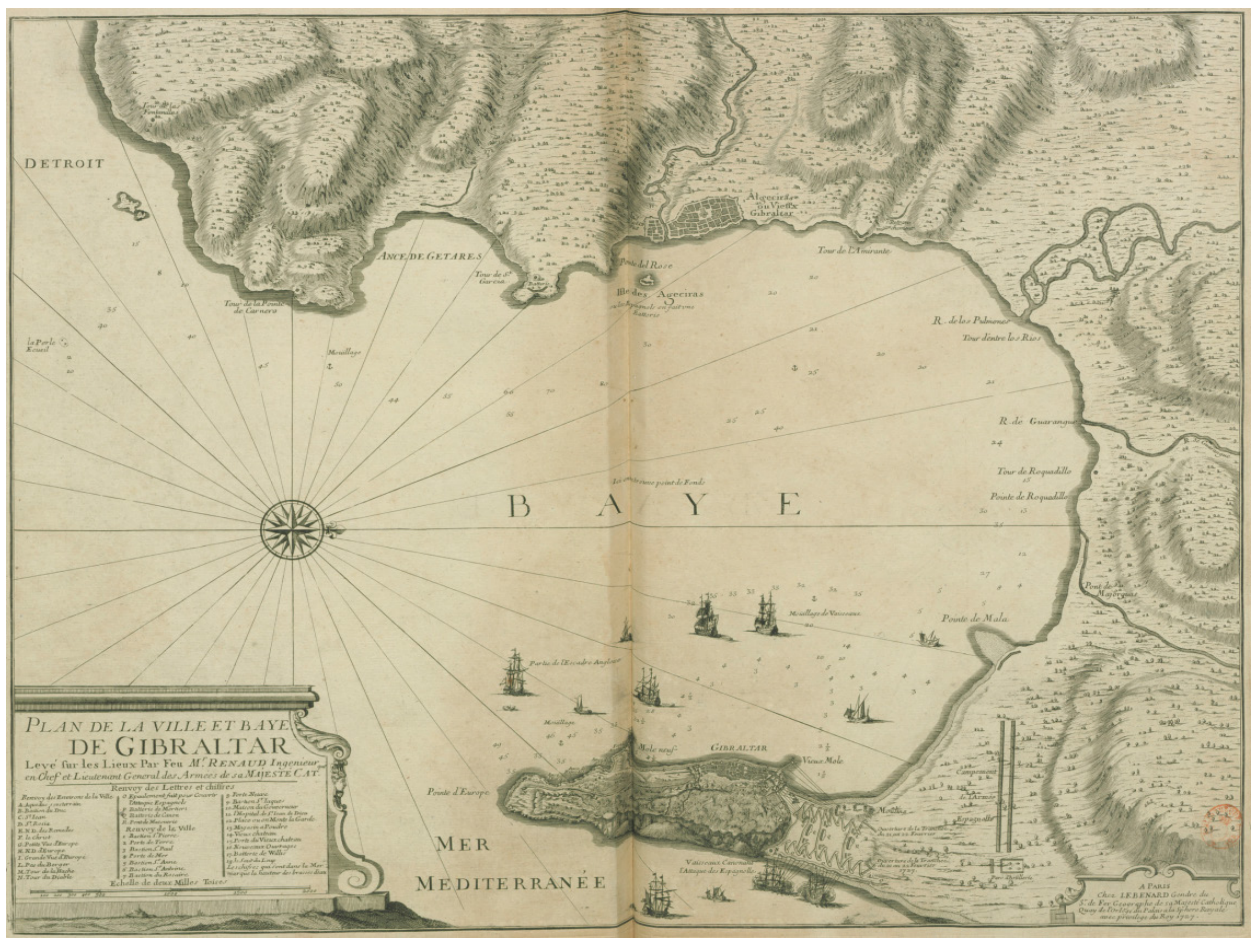

Figura 2. RenAu D'Éliçagaray, Bernard, Plan de la ville et baye de Gibraltar levé sur les lieux par feu $M^{r}$. Renaud Ingenieur en Chef et Lieutenant General des Armées de Sa Majesté Cat.que, 1727. Bibliothèque Nationale de France, GE BB-565 (12, 26).

Sobre Mahón, donde nunca estuvo, un ingeniero le informó del estado de la plaza y de sus deficiencias. Acto seguido se reunió en Barcelona con el conde de Palma (virrey de Cataluña), de quien dependía ese puerto, para establecer los elementos imprescindibles que había que mandar a Menorca. Su periplo culminó en Madrid, donde se entrevistó con el cardenal Portocarrero el 17 de abril de 1702, informándole de la necesidad de enviar inmediatamente 500 soldados de infantería para la guardia del castillo y 200 para la isla, ya que en esos momentos el primero contaba solo con 100 soldados y 100 campesinos, «todos los habitantes

12 Madrid, 4 de marzo de 1702. AN, MAR/B/4/22

13 Gaceta de Madrid, 51, martes 4 de noviembre de 1704: 201. 
de la isla abiertamente muy mal intencionados hacia nosotros». ${ }^{14}$ La petición del gobernador era de 3.000, cifra inasumible. Renau creía que con 200 soldados de caballería se podría controlar a los civiles e incluso hacerles combatir en caso de apremio o colaborar en la defensa del castillo. En cuanto a artillería, cureñas, pólvora, armas y bombas la carencia era absoluta, y lo que era peor es que no tenía la menor idea de dónde obtener los cañones y la pólvora. Como francés que era, no podía dejar de mirar por los intereses de su rey, y consideraba que Mahón presentaba una buena oportunidad de negocio para Francia si esta se proponía abastecerla de todo lo que precisaba.

El estado que presentaba Cádiz en 1702 era de extrema debilidad (Figura 3). ${ }^{15}$ La escasez de cañones era alarmante, pues no había ni siquiera suficientes para la defensa de la ciudad, que además eran pequeños, lo que solo los hacía útiles en una plaza para una refriega, pero lo que se precisaban eran piezas de gran longitud para hacer frente a una flota atacante. Solicitó artillería de gran calibre (de cuarenta a cincuenta cañones) para las baterías de Santa Catalina, Trocadero, Puntal y Matagorda, que servirían para proteger a la flota en caso de precisar refugiarse en Cádiz, a las que habría que mejorar con plataformas y parapetos de albañilería. Afirmó que la plaza se hallaba desguarnecida de tropas, y estaba a expensas de que Portocarrero cumpliera lo que le informó de que iba a dar órdenes al marqués de Villadarias (RESA, 2016) para que se trabajara allí, para que se estableciera en Cádiz el regimiento de Granada, así como «que se haría pasar de Cataluña levas». ${ }^{16}$

Cuando Renau tuvo noticia de los rumores del inicio de la guerra se encontraba en Madrid y se debatió entre dirigirse inmediatamente a Cádiz, pues lo consideraba el enclave más importante y que preferirían acometer los enemigos, o continuar con sus gestiones en la Corte, en concreto que se reclutaran y enviaran allí dos regimientos y que se le entregaran fondos al capitán general para poder llevar a cabo las obras de fortificación. A su juicio, todo lo anterior, «no seremos capaces de hacerles oír una vez nos hayamos ido de aquí». ${ }^{17} \mathrm{El}$ ingeniero francés debió enfrentarse a una nueva tarea, que fue la de negociar en la Corte el envío de hombres y dinero. En mayo continuaba en Madrid e informó de que estaba haciendo cuanto se hallaba en su mano para inclinar al cardenal a que enviara las tropas a Cádiz y realizara las obras más necesarias. ${ }^{18}$ Sin embargo, temía que sus esfuerzos fueran contraproducentes al final, porque se estaba empleando el dinero que estaba destinado a la subsistencia de las tropas a la recluta, por lo que la consecuencia podía ser que los soldados con experiencia abandonasen al no recibir sus salarios y solo se dispusiera de bisoños. Transcurrieron las semanas, pero no sus gestiones en paralelo. Le sorprendía la parsimonia del funcionamiento de la Administración española: «lo que apenas puedo creer por la lentitud con la cual se actúa aquí en todas las cosas». ${ }^{19}$ Aunque tampoco Francia se había adaptado a sus ritmos, porque Renau era un «ingeniero con prisa» (SAINT-SAUD, 1930: 267).

$\mathrm{Su}$ temor se acentuaba porque consideraba que una monarquía como la española, con territorios ultramarinos dispersos y distantes, dependía para

14 Madrid, 18 de abril de 1702. AN, MAR/B/4/22, f. 332v.

15 Madrid, 4 de marzo de 1702. AN, MAR/B/4/22.

16 Madrid, 18 de abril de 1702 . AN, MAR/B/4/22, f. 333r.-v.

17 Madrid, 29 de abril de 1702. AN, MAR/B/4/22, f. 334v.

18 Madrid, 4 de mayo de 1702 . AN, MAR/B/4/22.

19 Madrid, 13 de mayo de 1702. AN, MAR/B/4/22, f. 342r.

Vegueta, 21 (2), 2021, 9-38. eISSN: 2341-1112 
su sostenimiento de una marina fuerte, de la que carecía completamente. Le invadió el temor de que los aliados planeasen un ataque naval con 15 o 18.000 hombres, pues no habría posibilidad de hacerle frente al no disponer de tropas, mientras que los navíos estarían perfectamente abastecidos y podrían determinar de manera súbita en qué punto llevar a cabo su operación. Adelantándose de manera clarividente al desembarco de la flota del archiduque en Cádiz ese mismo verano, señaló todos los lugares en que los aliados podrían poner en tierra a sus hombres en el entorno gaditano, que eran numerosos: el río San Pedro, la desembocadura del Guadalquivir, Puerto Real, Chiclana. Afirmó que la ciudad de Cádiz caería fácilmente, al impedir que penetraran por tierra subsistencias. Renau, que antes que ingeniero fue marino, puso sobre la mesa un argumento a favor de la restauración de la flota española: todos los preparativos para evitar un desembarco enemigo superarían el presupuesto necesario para poner a punto una flota que pudiera oponerse al mismo. Esta idea era sencilla sobre el papel, pero no había tiempo y esto exigiría pensar no en el corto plazo, lo que un período de guerra no permitía, y una amplitud de miras que no era compatible con el cortoplacismo de las decisiones de la Corte. Por otro lado, le desanimaba que sus propuestas para disponer de 15.000 soldados, siguiendo las ideas que calificaba de magníficas del marqués de Leganés, habían resultado inútiles, ya que había oído que solo se iban a enviar a Cádiz soldados que se habían reclutado en Galicia para las Indias, lo que no sería nunca una solución. Por azares del destino de Madrid no se dirigió a Cádiz, sino a Galicia para revisar sus puertos y defensas, por lo que no se halló presente en el ataque de George Rooke a la ciudad del sur, pero sí en el que culminó con la captura de los galeones en la batalla de Rande (GARcía Hurtado, 2022). Antes de su marcha hacia el noroeste preparó todo el material que había elaborado (proyecto y memorias) para que se le entregase al ingeniero que le sustituirá. Su última recomendación fue que el cardenal enviara allí dos regimientos, porque lo más importante, dado que Cádiz era una plaza que estaba mal cerrada, era disponer de cuantiosos hombres para establecer una estrecha vigilancia en todo su perímetro a fin de evitar sorpresas. 


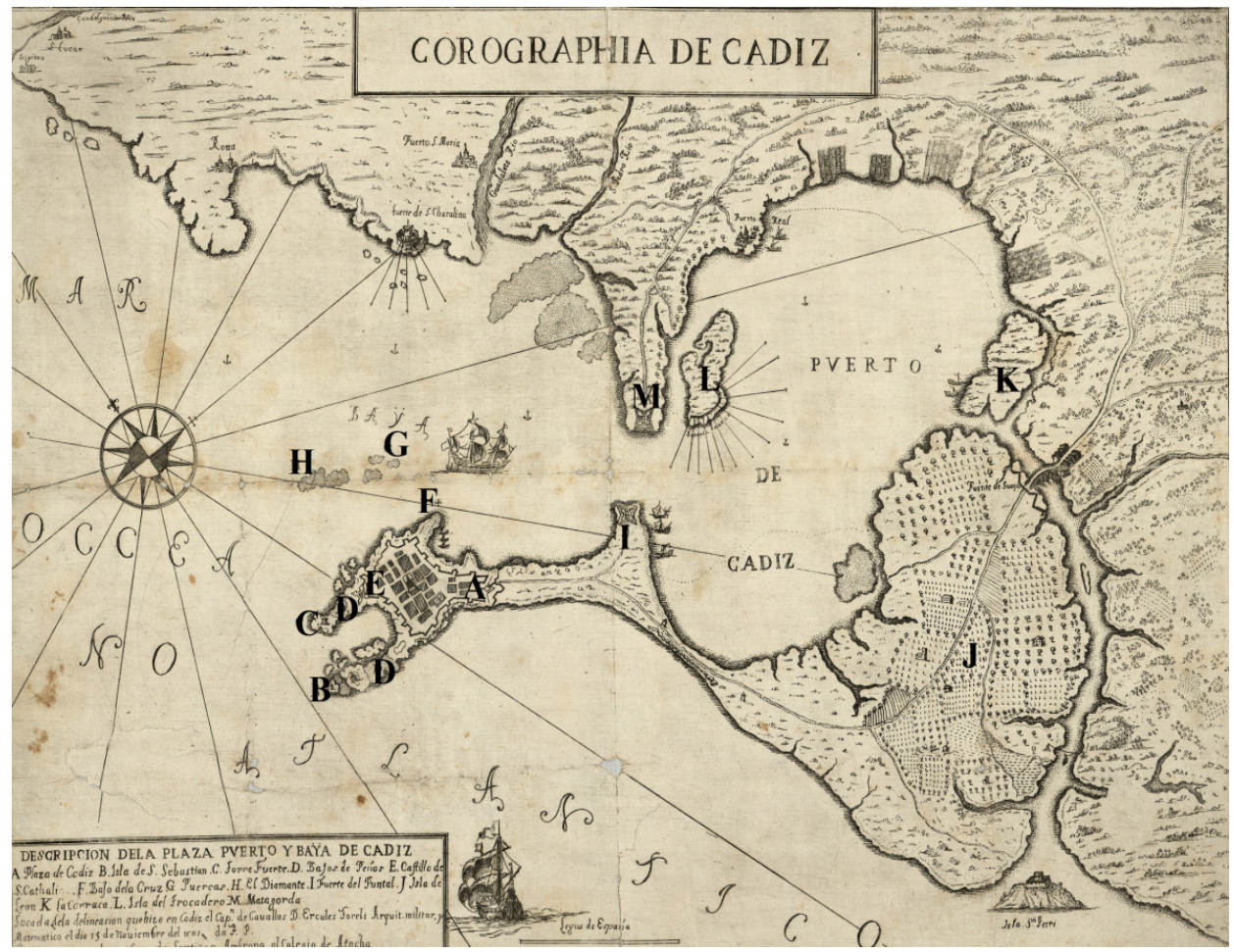

Figura 3. Torel, Hércules, Corographia de Cadiz, 1702. Archivo General de Simancas (en adelante AGS), Mapas, Planos y Dibujos (en adelante MPD), 06, 008. Cádiz representado el 15 de noviembre de 1701 . El autor era capitán de caballos, arquitecto militar y matemático. A: plaza de Cádiz; B: isla de San Sebastián; C: Torre Fuerte; D: bajos de Peñas; E: castillo de Santa Catalina; F: bajo de la Cruz; G: Puercas; H: el Diamante; I: fuerte del Puntal; J: isla de León; K: La Carraca; L: isla de Trocadero; M: Matagorda.

El fracaso angloholandés del verano de 1702 en Cádiz (GonZÁlez BeltráN, 2003; Segura García, 2005), el primer lugar de la península atacado por los aliados, lejos de disminuir el temor a un nuevo intento lo incrementó, de modo que se sucedieron las memorias sobre la defensa de Cádiz en $1703 .{ }^{20}$ Pierre Arnoul (DÉsos, 2016: 76 nota 35) es quien sustituyó a Renau durante su estancia en Galicia. La primera de las memorias tenemos constancia de que se presentó al cardenal d'Estrées (embajador de Francia en España) y después al cardenal Portocarrero. Se consideró que el enemigo habría aprendido de los errores cometidos ante «la plaza de armas de España», de modo que había que prepararse para un nuevo ataque, lo que exigía actuar en toda el área, desde el castillo de Santa Catalina hasta la barra de Sanlúcar. La desconfianza hacia los españoles abarcaba desde la capacidad de sus ingenieros, que se estimaba muy reducida, a la pericia de

20 Mémoire de M. Arnoul sur la défense de Cadix et de Gibraltar (en una traducción al español), Mémoire sur le port de Cadix, Mémoire du sieur de Ressons sur les batteries de Cadix, Mémoire sur l'arsenal de Cadix et l'état présent de la Marine d'Espagne y Mémoire sur la défense de Cadix et ses côtes. 
sus obreros para los trabajos más sencillos. Esto le sirvió a Arnoul para solicitar que se enviaran de Francia 100 albañiles y 80 canteros y mineros, aludiendo a la oportunidad de negocio en estas tierras para «algunos emprendedores inteligentes y expeditivos». ${ }^{21}$ Esta memoria fue extractada por Arnoul y d'Estrées para que el cardenal pudiera decidir sobre la misma más fácilmente. Se le entregó al marqués de Rivas y este se la presentó al rey, quien ordenó que se ejecutara. Pero no sería tan sencillo. El cardenal estimó necesario que se pronunciara el Consejo de Castilla, y la respuesta de este fue «hacer una consulta para oponerse en términos muy fuertes, y que señala sobre todo la pena de que una comisión semejante se le dé a un francés». ${ }^{22}$ Es sorprendente, y no puede sino ocultar otras razones, que les resultara inaceptable que un ingeniero francés llevara a cabo lo que desde hacía dos años él y otros efectuaban en todo el territorio de la Corona.

Consideramos que la verdadera razón de este airado rechazo obedeció a que Arnoul realizaba críticas muy duras sobre la administración y recaudación de rentas, apreciando corrupción y fraudes indisimulados y reiterados. Así, por ejemplo, en El Puerto de Santa María afirmaba que los derechos eran «saqueados en parte por los mismos que tienen su dirección». ${ }^{23}$ No se ocultaba el enfado del Consejo por estas afirmaciones injuriosas: «Se ha juzgado solamente a propósito de señalar al final cuán molesto es se pierda el tiempo en semejantes cosas, en lugar de pensar seriamente en ponerse en defensa contra los enemigos». ${ }^{24}$ Arnoul lo que estaba denunciando era la detracción de recursos económicos que eran la base para poder financiar cualquier defensa. No se trató de una reacción en contra de los franceses, pues en paralelo se aprobó que Felipe v escribiera a Luis XIV para que se fabricaran en Francia para Cádiz 4.000 bombas de 12 pulgadas y 2.000 de 9, y que se trajera de Provenza el material que Arnoul demandaba para las obras. El resto de memorias oscilan entre las que alababan los esfuerzos realizados en el diseño de las baterías, aunque afirmando que eran necesarios cañones de gran calibre, y las que criticaban duramente los navíos españoles, por ser «muy elevados sobre el agua, de una construcción grosera y siguiendo las apariencias malos veleros», y la formación de la oficialidad, «no parecen muy hábiles», ${ }^{25}$ además de ser escasa, mal pagada y crítica con el gobierno. Renau no se despreocupó de Cádiz, y aunque se encontrara en Galicia o en Madrid, siguió en contacto con Arnoul y le transmitía en cada momento en qué debía centrarse. ${ }^{26}$ Del mismo modo, Arnoul solicitó a Renau que le enviara el material con las propuestas que había realizado para Cádiz y que había aprobado el rey, así como le requirió su opinión sobre a qué debía prestar atención preferente, a cuyas peticiones Renau respondió de manera inmediata. ${ }^{27}$

Finalizada su estancia en Galicia a finales de 1703, Renau se incorporó al ejército con destino en Extremadura, lo que simultaneó con el estudio de las principales plazas fronterizas (GARCíA HuRTADO, 2022). No se conservan cartas

21 Mémoire de M. Arnoul sur la défense de Cadix et de Gibraltar, 1703. AN, MAR/B/4/24, f. sin numerar. $22 \mathrm{AN}, \mathrm{MAR} / \mathrm{B} / 4 / 24$, f. $58 \mathrm{r}$.

$23 \mathrm{AN}, \mathrm{MAR} / \mathrm{B} / 4 / 24, \mathrm{f} .58 \mathrm{v}$

$24 \mathrm{AN}, \mathrm{MAR} / \mathrm{B} / 4 / 24, \mathrm{f} .58 \mathrm{v}$

25 Mémoire sur l'arsenal de Cadix et l'état présent de la Marine d'Espagne, 1703. AN, MAR/B/4/24, f. sin numerar.

26 Le subraya la importancia de que aumente la batería de Trocadero todo lo que pueda y finalizarla lo antes posible. Vid. Madrid, 17 de marzo de 1703. AN, MAR/B/4/24, f. 211r.

27 Mémoire de M. Renau sur Cadix. Madrid, 12 de marzo de 1703. AN, MAR/B/4/24, ff. 234r.-239r. 
de Renau en los Archives Nationales de París fechadas en 1704 y 1705, que obviamente debieron centrarse en la pérdida de Gibraltar en agosto de $1704^{28}$ y el subsiguiente fracasado asedio, desde septiembre de ese año hasta mayo de 1705. En 1706 la correspondencia tuvo como asunto principal la plaza gaditana. Sus opiniones cada vez eran más críticas con quienes tomaban las decisiones en la guerra y con la Corte, donde sus reuniones tanto con el embajador de Francia como con Orry (quien aparece ya bajo unos colores muy sombríos, pues no en vano fue su principal enemigo) no tenían resultados efectivos: «ellos tienen una infinidad de asuntos»; «El señor Orry pretende haber arreglado esto y haber dado todas las órdenes necesarias para las reclutas. Yo no sé de qué manera». ${ }^{29}$ Hay quien identifica el origen de esta animadversión: «Además, su integridad molesta a muchas personas, entre otras a Orry cuyos procedimientos le irritan de tal modo que entra en una santa cólera y habla de enviarlo a la horca» (BAGNEUX, 1932: 287). Orry, queestuvo «en el corazón dela organización del ejército y de su equipamiento» (DuBET, 2008: 151-158; HANOTIN, 2009: 171), compartía el análisis de Renau del mal estado de los puertos españoles y de su incapacidad para defenderse ante un ataque (HANOTIN, 2009: 74), pero más allá de esto muchas cosas les separaban. Orry había defendido que la flota no se refugiara en Vigo en 1702, sino que se dirigiera a Francia, y el desastre pudo ser un motivo de enemistad, pues Renau tuvo que rebatir el informe de Château-Renault donde este se exculpaba (GARCíA HuRTADO, 2022). El carácter de ambos era muy distinto. Renau jamás fue un hombre político, más bien al contrario, precisó de la protección de figuras de primer nivel en París y Madrid que apreciaban su valía y su obstinación. Pudo ver en Orry al responsable del estado lamentable en que se encontraba el aprovisionamiento de material bélico en Cádiz (el propio Orry lo llegó a reconocer), además de ser quien le garantizaba en sus entrevistas en Madrid que dispondría de recursos económicos para llevar a cabos las obras de fortificación, pero esto o se dilataba en el tiempo o simplemente no se verificaba. Esto era muy distinto a lo que había vivido en la década precedente en Francia, cuando desde Versalles se apoyaban sus iniciativas, sus estrategias militares y sus inventos. Llegó a España con una tarea definida y se encontraba con la imposibilidad de desarrollarla, y si debía personificar en alguien al causante de esta frustración (sentimiento de fracaso que le atormentaba) ese será Orry. Sea como fuere, Orry era «el enemigo jurado de Renau» (ELISSAGARAY DE JAURGAIN, 2004: 185).

En Madrid informó a principios de enero sobre el estado de la plaza de Cádiz y de sus necesidades, para así poder preparar la campaña de ese año, pero ignoraba qué resolución se tomaría y si existían fondos. Para él era crucial que se enviaran tropas y que presupuestariamente se abordara su mantenimiento. Declaró sentir miedo porque los soldados no existían, no eran reales, solo un proyecto, mientras que las costas estaban indefensas, el ejército del rey lejos de Castilla, Extremadura y Andalucía y el peligro se cernía tanto desde Portugal como por la posibilidad de que los aliados enviaran combatientes a España. La inseguridad se incrementaba por la circunstancia de que las tropas no estaban contentas ni en estado de servir, pues no recibían una paga suficiente ni regular. Además de minar su capacidad de combate, podían no ser capaces de evitar levantamientos en las localidades. Llevaba en España casi cinco años, aún le quedaban otros tres, y ya manifestaba

28 Renau trabajó en la fortificación de la plaza, pero la escasa guarnición que la defendía, unos 100 hombres, poco pudo hacer frente a los 2.000 soldados y 61 embarcaciones de Rooke.

29 Madrid, 20 de enero de 1706. AN, MAR/B/4/30, ff. 97r. y 98v. 
abiertamente que deseaba retornar a su país, pues, tras haber realizado proyectos de casi todas las plazas que se le habían encomendado, no observaba avances en la dirección correcta, por lo que «si no hay nada que hacer espero que el rey no considere mal que yo regrese a Francia», ${ }^{30}$ para lo que añade que informaría al embajador francés y solicitaría la aprobación de Felipe v. El 4 de febrero se reunió nuevamente durante una mañana completa con Orry para tratar todo lo concerniente a Cádiz. Ese día obtuvo su compromiso de que le enviaría 32.000 escudos cada mes hasta mayo con destino a las fortificaciones, así como de que iba a hacer que se trabajara sin descanso siguiendo los planos de Renau, que este le entregó para que fueran enviados a los ingenieros en Cádiz. Esa jornada significó, en el plano político, alcanzar la cumbre para Renau. Obtuvo todo lo que llevaba años solicitando. Orry le aseguró que se pagaría puntualmente a las tropas, el envío de uniformes, armas, sillas de montar, botas, se acelerarían los trabajos en la batería de Trocadero, incrementándola hasta treinta piezas de cañón, se finalizaría la muralla iniciada cinco años antes, que había quedado demasiado baja y era fácilmente sorteable en caso de un desembarco, y otras mejoras. Por si fuera poco, días después, el 12 de febrero, Felipe v le informó que deseaba que entrara a servir en su ejército y que con este objeto iba a escribir a Luis XIV. Renau era escuchado en la Corte, se valoraba su trabajo y el rey deseaba contar con él en primera línea. ${ }^{31}$

Dos meses más tarde la realidad se impuso. Lejos de haber llegado soldados a Cádiz el marqués de Villadarias había detraído los escasos que allí había para realizar operaciones en otros lugares (en este caso, en Niebla). Ninguna de las palabras de Orry se habían transformado en hechos. No ocultó su profundo enfado e hizo amplio uso de la ironía, aunque evitando cargar contra Orry, pues no se podía permitir un enfrentamiento directo con él, y centró su crítica en el gobernador de Cádiz (Duverger) y sus ingenieros. Como si hubiera vivido en un sueño del que acababa de despertar, dio rienda suelta al hastío acumulado durante años ante las promesas vacías y su profundo sentimiento de soledad:

estoy muy furioso de deciros que aún no se ha hecho nada, y que temo que tampoco lo hagamos en el futuro, es decir, para esta campaña... no estamos en el tiempo de las hadas para hacer en una noche palacios magníficos sin dinero y sin obreros. No quiero tener un proceso con el señor Orry, quien quizá dirá y procurará con cartas y por todo lo que a él le plazca que ha enviado aquí todo el dinero que ha prometido y que debemos tener aún actualmente para hacer todo, porque eso nos llevaría demasiado lejos y el tiempo apremia. Estaré de acuerdo con todo lo que se quiera, pero en este caso diré que el señor Duverger, el gobernador de esta plaza, en lo que a él respecta, y los ingenieros han tenido la malicia de no hacer nada hasta el presente... no querer proporcionar el número de obreros necesarios para trabajar con la velocidad requerida a las cosas de las que se han convenido con el señor Orry. ... [Orry no ha enviado ni los planos que le entregó ni el dinero] ... Y estoy muy enojado porque se crea haber previsto todo lo que es necesario en esta importante plaza enviándome solo aquí. Algún gran honor que esta opinión me haga, no me siento suficientemente fuerte para sostenerla, ni sabiendo hacer nada sobrenatural. ... Que vuestra excelencia tampoco espere que se pueda hacer gran cosa para defender la plaza en el estado en que se encontrará. En una palabra, con nada no se hace nada. ${ }^{32}$

30 Madrid, 20 de enero de 1706. AN, MAR/B/4/30, f. 97v.

31 Madrid, 12 de febrero de 1706. AN, MAR/B/4/30, ff. 101r.-103v.

32 Cádiz, 22 de abril de 1706. AN, MAR/B/4/30, ff. 109v.-112r. 
Incluso lo que había llegado a Cádiz, 62 quintales de pólvora (el compromiso era mucho mayor), era de mala calidad. No se había atendido ni lo más básico, como era la provisión de agua para la guarnición y la población. Así pues, el enemigo solo precisaba cortar la comunicación de Cádiz con tierra firme y la ciudad caería sin ser preciso combate alguno. Al no llegar financiación desde Madrid, en mayo Renau solicitó un préstamo personal a un comerciante francés (Jean Stalpaert) por un importe de 2.000 escudos para iniciar los trabajos en la isla de San Sebastián, que era el punto que estimaba más débil y fácil de tomar, e intentar agrandar la batería de Trocadero. De manera sorpresiva afirma que temía menos a la información que la inteligencia extranjera podía obtener sobre la plaza, debido al volumen de foráneos que la habitaban, que al descontento de la oficialidad española por los impagos y constantes atrasos de sus salarios. Convencido de que este problema era insoluble, o que al menos de nada iba a servir que instase a su remedio en Madrid, propuso abiertamente que la defensa de Cádiz recayera completamente sobre Francia, mediante el envío de tres o cuatro batallones y de varios navíos de guerra, lo que reiteró sin éxito. Renau aquí no estaba evaluando la reacción que esto causaría entre la población, sino solo la mejora que implicaría en la defensa gaditana. De hecho, él afirmó en diversas ocasiones que el mayor peligro en una plaza era que entre los habitantes hubiera "gentes mal intencionadas», pues contra eso «todas las fortificaciones no sirven de nada», ${ }^{33}$ y a la de Cádiz la consideraba desleal (ciertamente había individuos que conspiraban a favor del archiduque en la ciudad; CASTRO, 1858: 465-466; BISSO, 1868: 92) y dispuesta a abrir las puertas al enemigo (las tropas eran tan necesarias para defender Cádiz de un ataque aliado como para sofocar cualquier conato de sublevación o revuelta popular interna).

De la escasa afección por los militares franceses tuvo un ejemplo extremo con el encierro en prisión de René Duguay-Trouin ordenado por el gobernador («porque le habían asegurado que si le hubieran cogido el día anterior lo habrían matado en la ciudad») tras un enfrentamiento de marineros franceses con chalupas de la aduana, obligándole a dejar Cádiz con sus naves para calmar los ánimos del pueblo ante el temor de un motín. ${ }^{34} \mathrm{Y}$ esta falta de armonía era extensible, por otras razones, cuando debían combatir juntas tropas españolas y francesas. Entonces el problema fundamental, más allá de en quién recaía el mando, eran las equiparaciones de los grados entre España y Francia, lo que llevó a promulgar un reglamento por parte de Felipe v para evitar más contiendas. ${ }^{35}$ Por otro lado, alertó sobre la circunstancia de que los artilleros en Cádiz eran mayoritariamente catalanes y mallorquines, de cuya lealtad se podía dudar y a lo que tampoco ayudaba mucho que llevaran meses sin cobrar. Para evitar que la fuerza artillera estuviera en manos de súbditos que podían no ser fiables, propuso, e insistirá numerosas veces en el futuro, que los artilleros navales franceses se encargaran de servir los cañones una vez las embarcaciones se encontraran en la rada. La mejor noticia del año fue que la delicada situación de los aliados en Cataluña y Valencia les mantenía ocupados allí, por lo que no había que temer un ataque, de modo que se podía dedicar este tiempo a mejorar las defensas. Ahora bien, advirtió que hasta la fecha afirmar que Cádiz era clave «solo sirve para enviarme aquí, sin

33 Cádiz, 25 de septiembre de 1707. AN, MAR/B/4/32, f. 252r.

34 Cádiz, 6 de junio de 1706; Cádiz, 10 de octubre de 1706. AN, MAR/B/4/30, ff. 117r.-v.; ff. 119r.122r. La cita en f. 121r.

35 Madrid, 7 de febrero de 1707. AN, MAR/B/4/32, ff. 239v.-240r. 
darme ningún medio para remediar nada. Haré con toda seguridad todo lo que pueda, monseñor, pero eso no será suficiente». ${ }^{36}$

En 1707, tras su habitual paso por la Corte de principios de año, regresó a Cádiz con la promesa de 1.000 pistolas mensuales para las fortificaciones. ${ }^{37} \mathrm{Sin}$ embargo, no logró que se le concedieran tropas francesas, por lo que solicitó un regimiento irlandés (obtuvo el Crafcon, pero finalmente se le acordó el Mahony; RECIO, 2004: 12). El 4 de septiembre de este año firmó el único plano que se conserva de todos los que levantó en España, dedicado a la Puerta de Tierra de Cádiz y las obras que proyectaba realizar. Este elemento de las defensas fue erigido en el siglo XVII y finalizado en 1671, pero planteó desde un inicio numerosos problemas, ya que el fuerte viento de Levante y que el terreno fuera un arenal determinó que a los pocos años el foso y la trinchera quedaran cubiertos de arena (FERNÁNDEZ CANO, 1973: 96-97, 122-123; CALDERÓN, 1976; GRANADO, 2016: 17-18). A lo anterior se añadían defectos de diseño, como la reducida altura de la edificación o la debilidad de sus fundamentos. A solventar todos estos problemas se dedicó Renau. Una de las principales tareas consistió en sacar la arena de los fosos, para lo que ideó unas cajas tiradas por bueyes, de los que lamentó su reducido número. ${ }^{38}$ Aunque la historiografía no cita ni el plano ni los trabajos de Renau, afirmando que hay que esperar a la llegada en 1727 de Ignacio Sala como ingeniero director y a sus proyectos (1728-1749), obviamente esto no es así, pues antes de Sala se habían presentado soluciones y, es más, su proyecto es idéntico al de Renau de 1707 (Figuras 4 y 5). Los autores que han estudiado las fortificaciones gaditanas hacen hincapié en que Sala y después Juan Martín Cermeño, a partir de 1751, introdujeron las técnicas de Vauban, cuando uno de sus principales discípulos las proyectó en 1707. Esta afirmación solo puede deberse al desconocimiento del plano de Renau, aunque Sala es evidente que tuvo acceso a alguna copia de este.

Renau estimaba que, por su configuración, la plaza de Cádiz, cuando tuviera finalizadas todas sus fortificaciones, sería una de las más fuertes de Europa y ya no sería posible que fuera tomada por tropas de desembarco, siempre que contara en su interior con una buena guarnición, municiones y víveres. Proyectó perfeccionar la obra coronada con su foso y su camino cubierto y la muralla. Aquí se evidenciaba el discípulo de Vauban. Detalló con minuciosidad la debilidad de cada una de las zonas y cómo se planteaba solventarla. ${ }^{39}$ Ese año llegaron informes de París, que los comunicó a Madrid y la Corte a Cádiz (donde se recibieron también de la capital francesa), que alertaban de que se preparaba un ataque aliado contra la plaza el mes de diciembre o en enero de 1708. Sin embargo, aun con el reconocimiento de la debilidad de la plaza, Renau, por primera vez, no sintió el menor temor, porque tras analizarlo afirmó que se trataba de «una quimera», que si se ponía en ejecución precisaría, para que Cádiz fuera tomada, que ellos fueran "peores que salvajes» para caer en las trampas del enemigo. ${ }^{40}$ Confiaba completamente en su aptitudes tácticas y solo denunció, una vez más, la necesidad de contar con una guarnición numerosa (la evaluaba en 4.000 soldados), que debía dedicar sus fuerzas la mitad para vigilar las cinco puertas de la población y el resto para contener el interior. Siempre le asustó más

36 Cádiz, 9 de mayo de 1706. AN, MAR/B/4/30, f. 116r.-v.

37 Madrid, 7 de febrero de 1707. AN, MAR/B/4/32, f. 238r.

38 Cádiz, 23 de octubre de 1707. AN, MAR/B/4/32, f. 253v.

39 Cádiz, 4 de septiembre de 1707. AN, MAR/B/4/32, ff. 245r.-250v.

40 Cádiz, 25 de septiembre de 1707. AN, MAR/B/4/32, f. 251r.-v. 
el peligro que podía surgir de los habitantes que por parte de los invasores. En ese momento Cádiz solo contaba con 500 hombres, porque los cuatro regimientos de infantería que oficialmente estaban allí destinados se hallaban fuera, en una campaña a las órdenes del duque de Osuna. Esto, ya lo hemos visto, fue una constante: siempre se dispuso de escasas tropas y además se empleaban en fines distintos a los establecidos inicialmente y fuera de Cádiz. Renau siempre receló de las fuerzas que podía enviar Felipe v (por su número o porque solo estarían allí de paso), centrando su esperanza en el envío de navíos franceses («en los cuales se podría confiar»), ${ }^{41}$ que proporcionarían grandes ventajas a ningún coste: los artilleros se harían cargo de las baterías de la ciudad y de los fuertes, y mientras no fuera necesaria su presencia se podrían dedicar al corso en el estrecho, con lo que obtendrían recursos para financiar todos sus gastos y salarios. ${ }^{42} \mathrm{~A}$ finales de año envió una memoria a Madrid sobre el tema de la guarnición precisa para Cádiz y se planteó viajar allí ese invierno, aprovechando la presencia del duque de Orléans y del mariscal de Berwick. En esos momentos se disponía de 2.500 hombres, insuficientes para custodiar las cinco puertas y dar servicio a los cuatro fuertes, en una plaza «muy poblada y la mayor parte extranjeros mal intencionados», ${ }^{43}$ con más de 2.500 metros totalmente abiertos y unas murallas bajas y muy débiles. Para Renau la pérdida de Cádiz supondría la de toda España o alargar la guerra, en cualquier caso un incremento del gasto, por lo que cualquier inversión en esta plaza siempre sería inferior al coste de su captura. ${ }^{44}$ En Madrid, en 1708, obtuvo del duque de Orléans el envío de 10 batallones, con la novedad de que no se podrían sacar de la plaza para otros fines. No obstante, sus quejas sobre la escasez de pólvora (se reducía a 300.000 quintales, cuando eran necesarios 900.000 como mínimo), debido a que se llevaba de Cádiz a otros lugares, sin reemplazarla nunca, no fueron atendidas. Solo le quedaba el recurso de la ironía. Escribió a Pontchartrain que no podía hacer magia y fabricar pólvora sin sus componentes, ni podía hacer servir los cañones sin cureñas ni artilleros, ni hacer plataformas y fortificar sin dinero: «no veo de qué sirvo y os confieso, monseñor, que hace tiempo que querría estar en el fondo de las Indias, condenado a pasar allí mis días». ${ }^{45}$

Fiel a su costumbre, en 1709, por última vez, acudió a la Corte, en esta ocasión acompañado del marqués de Fiennes (teniente general y comandante de las tropas de Francia en España). Presentó un panorama en el cual el deterioro continuaba a marchas forzadas: los cañones no resistirían cuatro disparos sin desmontarse; todas las plataformas precisaban rehacerse; no poseían maderas ni herramientas para las reparaciones; las armas y la pólvora eran más escasas que el año anterior; pero el mayor problema era el derivado de las malas cosechas, pues las reservas de trigo que llegaban por mar solo alcanzaban para ocho días. Esto último le

41 Cádiz, 25 de septiembre de 1707. AN, MAR/B/4/32, f. 253v.

42 Esta idea la reitera en otras cartas. Vid. Cádiz, 21 de noviembre de 1707; Cádiz, 27 de noviembre de 1707. AN, MAR/B/4/32. Madrid, 16 de abril de 1708; Cádiz, 1 de julio de 1708; Cádiz, 2 de septiembre de 1708. AN, MAR/B/4/33.

43 Cádiz, 27 de noviembre de 1707. AN, MAR/B/4/32, f. 258v. La población de Cádiz, muy al contrario, experimenta un decrecimiento entre 1700 (41.000 habitantes) y 1710 (34.500), por causas como la situación económica previa a la guerra y la resultante de esta, así como la fiebre amarilla de 1709. PonCe CORDONES, 1983: $428,429,431$.

44 Madrid, 16 de abril de 1708. AN, MAR/B/4/33, f. 245v.

45 Madrid, 14 de mayo de 1708. AN, MAR/B/4/33, f. $248 \mathrm{v}$. 
llevó a exponer que siempre había temido que los enemigos, de quienes obtenían el trigo, se decidiesen a no exportárselo: «Felizmente, parece que ellos no lo piensan». ${ }^{46} \mathrm{Y}$ así fue, afortunadamente para Cádiz (GARCíA FERNÁNDEZ, 2006: 186201, especialmente 192, gráfico 5-15). No confiaba en los compromisos de la Corte, eran muchos años de palabras incumplidas, y ya no ocultaba su total desafección por la marcha de la guerra en España, pues solo había obtenido el hacerse odioso (así lo afirma) con sus continuas representaciones. Sin embargo, los hechos eran que Felipe $v$ no dedicaba nada desde hacía dos años a las fortificaciones de Cádiz (a estas alturas su única esperanza era el duque de Orléans) y confiesa que se ha dedicado al contrabando (ruega que Francia le excuse por el perjuicio económico que le pueda haber causado) para obtener dinero que destinar a la defensa de la ciudad. Sus palabras anunciaban que se hallaba presto a abandonar definitivamente esta empresa: "No hay uno de nosotros que no quisiera estar a 100.000 leguas y, aunque yo no soy el encargado en jefe de la defensa de esta plaza, os confieso, monseñor, que he estado mil veces a punto de retirarme a algún rincón de la tierra y no pensar más en el mundo». ${ }^{47}$ Solicitó que se diera cuenta de esto a Luis XIV, para que en modo alguno pensara que por su parte había negligencia, sino simplemente manifestación de su desánimo al no contar con el respaldo de la Corte española y la responsabilidad que asumía en solitario, si llegaba a acontecer una desgracia.

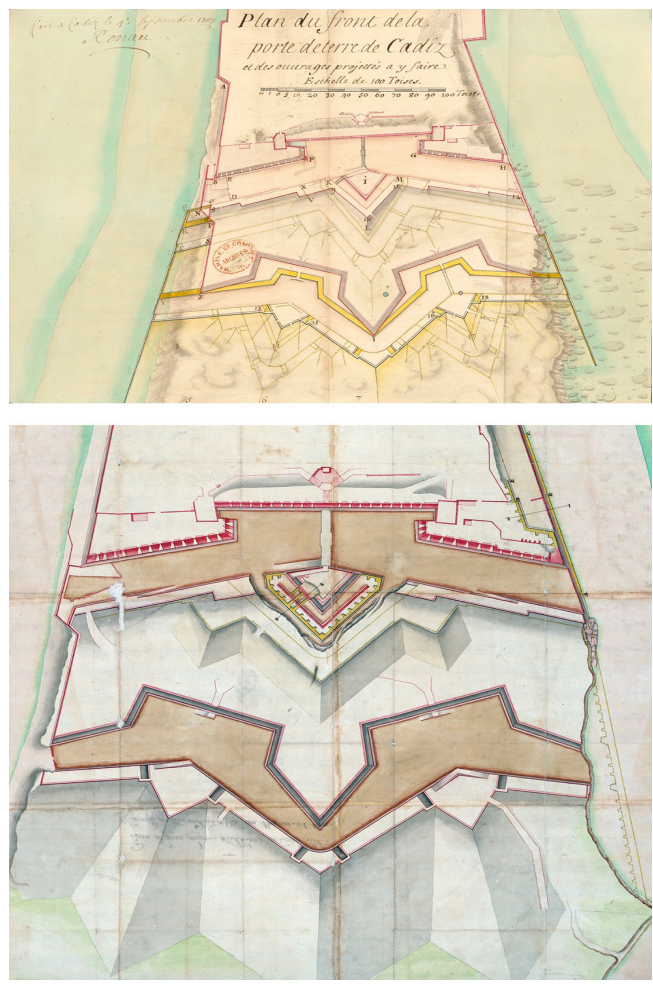

46 Madrid, 18 de marzo de 1709. AN, MAR/B/4/34, f. 114r. 47 Madrid, 18 de marzo de 1709. AN, MAR/B/4/34, f. 117r. 
Figura 4. Renau d'Éliçagaray, Bernard, Plano del frente de la Puerta de Tierra de Cádiz y de las obras proyectadas y a realizar, Cádiz, 4 de septiembre de 1707. Las obras ya efectuadas están marcadas con líneas rojas. AN, MAR/B/4/32. SALA, Ignacio, Plano del Frente de la Puerta de Tierra de Cádiz que con sus perfiles demuestra el estado de la obra del Revellin, Baluarte de S[an]ta Elena y recalzo de la Ala deste Baluarte, Cádiz, 10 de abril de 1730. AGS, MPD, 21, 075.

En su correspondencia informaba sobre algunas personas que había conocido, otras con quienes mantenía amistad, citaba a quienes responsabilizaba de obstaculizar su tarea, en suma, con muy diferente profundidad, dibujaba el carácter y la personalidad de algunos individuos relevantes en la España de la primera década del siglo XVIII. Sus comentarios sobre algunos personajes eran muy breves: de Francisco de Ronquillo (Álvarez, 2018: 43-44) afirma que «es un hombre de mucha capacidad, que conozco muy particularmente». ${ }^{48}$ En Madrid conoció en 1702 al marqués de Villarrocha, que le causó una magnífica impresión por su inteligencia, por sus opiniones sobre la fortificación de Portobelo, por sus proyectos para Panamá o las construcciones de cañones por los esclavos negros. Obviamente, nada sabía Renau ni le iba a relatar Villarrocha de sus andanzas y corruptelas en América (ANDÚJAR, 2017), de modo que para el francés era una víctima que había sido revocado de su cargo de presidente de Panamá «a causa de los lazos que tenía con el señor duque de Harcourt» ${ }^{49}$ (embajador de Francia en España). Claramente, quedó entusiasmado con Villarrocha, pues intentó hablar con el rey sobre él, pero no se hallaba en Madrid, e incluso presionó, sin éxito obviamente, para que fuera enviado de vuelta a Portobelo. Renau, que jamás tuvo la menor mancha en su expediente, y menos en relación con la corrupción, sucumbió ante la personalidad de Villarrocha. Ahora bien, no estuvo solo en su defensa, ya que todo el cuerpo diplomático francés en España hizo todo lo posible para que fuera rehabilitado y regresara a Panamá, aunque en este caso el móvil fueron los intereses económicos franceses en el tráfico de esclavos que Villarrocha favorecía (ANDÚJAR, 2017: 82-83).

Si tenemos en cuenta lo que escribió del marqués de Leganés, podríamos pensar que Renau no captaba precisamente el fondo de las personas, pues realizó una encendida defensa del compromiso del marqués con Felipe v. Pero no era así, sino que actuaba por convicción. De hecho, ya al inicio de su estancia en Cádiz, cuando arribó una flota a las órdenes del mariscal d'Estrées este le comunica la existencia de un complot, en el cual estaría implicado el marqués de Leganés. Renau no le dio ningún crédito a esta noticia y respondió «con su vida» de la lealtad de este. Tras llevar a cabo una labor de espionaje en la casa de juego donde se reunían los confabulados, logró exculpar al marqués y que se le encargase a este el acabar con la conspiración (ELISSAGARAY DE JAURGAIN, 2004: 183). Su sentido de la amistad estaba por encima de todo, además de que la afición a la ciencia del marqués (es de sobra conocido su papel fundamental en el movimiento de los novatores) debió ser otro elemento que les uniría, por lo que no dudó en empuñar la pluma para limpiar su honor:

48 La Coruña, 4 de noviembre de 1703 . AN, MAR/B/4/24, f. 255v.

49 Madrid, 29 de abril de 1702. AN, MAR/B/4/22, f. 336v. 
Durante nuestra estancia el año pasado en Cádiz, el señor marqués de Leganés, tenía excelentes ideas... para la defensa de España. Como sé que ha sido sospechoso e incluso relevado de su empleo por eso, estoy obligado a hacerle justicia habiéndolo visto de cerca más que nadie y deciros que todo lo que he visto en él ha sido de mucha fidelidad y rectitud... Como él va a Francia, si se le da lugar a justificarse, estoy persuadido que lo hará, y si yo estuviera me tomaría la libertad de hablar con el rey, porque creo que la verdad al respecto no será inútil para el servicio del rey de España, siendo un hombre en edad de bien servir y de ofrecer al rey los conocimientos de este país, que no serán inútiles... Yo le he visto penetrado de dolor y desesperación por la desconfianza que se le ha demostrado [tras ser denunciado en 1705 por sus intrigas fue conducido a Pamplona, a continuación a Burdeos y finalmente al castillo de Vincennes, en París, donde falleció en 1711]. ${ }^{50}$

\section{Otro personaje que gozó de su aprecio fue el marqués de Villadarias:}

no he conocido sujeto más celoso, más activo para el servicio y más desinteresado que el señor marqués de Villadarias, hombre de gran valor, ... hombre de piedad en el fondo, sin embargo duro y severo, incapaz de disfraces y poco político, sin reservas cuando cree que se trata del servicio del rey... Tiene muchos enemigos, lo que no es sorprendente después del poco [ilegible] que guarda a los señores ministros. Muchas gentes quieren que sea un gran ladrón, pero no he visto aún una persona a la que él haya tomado nada, ni a la que haya hecho por cinco sueldos asuntos, lo que es muy raro en España. Sus cuentas son sencillas y muy fáciles de examinar. ${ }^{51}$

Finalmente, deseamos citar las palabras que le mereció el duque de Osuna, de quien Renau, de una profunda religiosidad, no realizó juicio alguno sobre su conducta personal, limitándose a dejar constancia de lo que era vox populi, pero subrayando también sus virtudes, sin omitir que su manera de actuar dificultaba cualquier coordinación de la defensa de Cádiz con él:

casi no se molesta [por los escritos en su contra] porque su vida es pública y conocida de todo el mundo. Es un hombre que no quiere esconderse, que llevaba la misma vida en Madrid que aquí, también abiertamente. Cuando salió de Madrid para venir aquí, tenía muchas carrozas cargadas de cantantes y de actrices. Él no marcha sin eso. Es un señor de excelentes cualidades, incapaz de engañar al rey ni a nadie por lo que parece... y por quien daría todas las cosas. Y con todo esto nos hace enfurecer, porque lo hace todo según su cabeza, sin consultar nada, dispone de las tropas como le place. ${ }^{52}$

Salta a la vista que lo que más valoraba en los marqueses de Leganés y de Villadarias y en el duque de Osuna era su absoluta entrega en el servicio a su rey, que no era sino la principal cualidad de Renau, quien dedicó su vida a esto mismo de modo desinteresado, sin obtener más recompensa que grados militares (algunos muy tardíos), la vicepresidencia de la Académie des Sciences en 1714 por un año o la concesión por el duque de Orléans, ya regente, de la gran cruz de la orden de San Luis. Con esto tuvo que paliar una existencia solitaria, alejado de sus hermanos, que siguieron viviendo en las cercanías del lugar en que nacieron (Armendarits, en el departamento de Pyrénées-Atlantiques), y carente

50 Madrid, 29 de abril de 1702. AN, MAR/B/4/22, ff. 338r.-339r.

51 Madrid, 3 de enero de 1707. AN/MAR/B/4/32, ff. 236r.-237r.

52 Cádiz, 2 de septiembre de 1708. AN, MAR/B/4/33, ff. 254v.-255r. 
de recursos, más allá de un inmueble que adquirió en 1698, en el que todo indica que no se alojó nunca, siendo heredado por uno de sus hermanos (ELISSAGARAY DE JAurgain, 2004: 167). Por diversos hechos de su vida sabemos que no tenía el menor apego a los bienes materiales, pero también es cierto que en este aspecto nunca obtuvo premio alguno.

Sus penurias económicas personales se presentaron desde el mismo momento de su llegada a España. El hecho de que no contara con una ordenanza de viaje, que reiteradamente reclamó hasta que la consiguió en julio de $1702,{ }^{53}$ le llevó a informar a finales del invierno de ese año de que había emitido una letra de cambio de 12.000 francos en favor de un comerciante francés sobre sus emolumentos del año anterior, que no había cobrado, a fin de que se le abonaran, y si esto planteaba problemas administrativos solicitó a Pontchartrain que diera las órdenes oportunas, "porque hace ya tiempo que se me ha avanzado este dinero y debo considerablemente». ${ }^{54}$ Aprovechó para añadir que los viajes que debía realizar le resultaban muy gravosos, a lo que se sumaba la pérdida que experimentaba con el cambio de moneda. Dos meses más tarde reiteró su solicitud, e informó de que además de sus gastos debía hacer frente a los de los ingenieros que viajaban con él. Por otro lado, no era la primera vez que su economía se resentía por su servicio a la Corona, ya que su situación había sido también grave tras el viaje que realizó a América en $1699^{55}$ a instancias de Pontchartrain (MoreAu DE SAINT-MérY, 1784: 630-633; PRITCHARD, 2004: 374), que le resultó «extremadamente costoso». ${ }^{56}$

En 1707 su economía había llegado a un punto intolerable. Rogó a París que desde la Secretaría de Marina se le abonasen sus emolumentos en dinero, "porque aquí no quieren para nada los billetes de moneda», pues no recibía su sueldo de teniente general de España más que de modo muy irregular, por lo que no contaba con él. Su situación era crítica: «que he agotado enteramente mi crédito y que estoy endeudado por encima de la cabeza, no sabiendo ya cómo hacer, porque finalmente estoy sin ningún recurso, y sería muy triste salvarme con una bancarrota, como estaré obligado a hacer si usted no tiene esta bondad conmigo». ${ }^{57}$ Solo un mes más tarde repitió los mismos argumentos, aunque incrementó el dramatismo y refirió que había dedicado toda su vida a servir a Luis XIV y que no había solicitado ni ocho días de licencia, ${ }^{58}$ recordó sus numerosos viajes sin descanso, afirmó que temía estar condenado al fracaso, por motivos ajenos a él, y que no quería contribuir a esto ni a defraudar a todos los que habían confiado en él. Estaba solicitando su retorno. Se disculpó porque era consciente de que no eran momentos para pedir, "pero no se puede vivir del aire». ${ }^{59}$ En 1709 su estado era de extrema necesidad. Su correspondencia evidencia su sentimiento de absoluto desamparo material en lo personal y en lo profesional. En sus palabras se aprecia la pérdida del ímpetu y la ilusión, de la actividad frenética de los primeros

53 Madrid, 5 de julio de 1702. AN, MAR/B/4/22.

54 Madrid, 4 de marzo de 1702. AN, MAR/B/4/22, f. 330r.

55 Fue su segunda expedición a América, ya que había visitado las Antillas en corso en abril de 1696 al mando de 1.600 hombres, 4 navíos y 2 fragatas, regresando a Rochefort el 28 de septiembre, con una cuarta parte de la tripulación del Intrépide, que terminó hundido por una vía de agua. LABAT, 1742: 174-176; Bagneux, 1933; SYMCox, 1974: 181, 211, 216; PRITCHARD, 2004: 321.

56 Madrid, 4 de abril de 1702. AN, MAR/B/4/22, f. 341v.

57 Cádiz, 23 de octubre de 1707. AN, MAR/B/4/32, f. 254r.

58 Sí había vuelto a Francia, pues el 10 de abril de 1705 informó de las operaciones en Gibraltar a Luis XIV. VERGÉ-FRANCESCHI, 1991: 395.

59 Cádiz, 27 de noviembre de 1707. AN, MAR/B/4/32, f. 261r. 
tiempos en España. Llevaba tres años viviendo de préstamos al 12\% de interés, buscando quién le respaldase cuando llegara el momento de tener que renovarlos y solicitar otros nuevos, pero sus acreedores le instaban a que hiciera frente ya a sus deudas sin más dilación. Su tesitura era kafkiana, ya que en España no disponía de recursos, pero no le permitían ir a Francia para procurarlos. Mientras tanto su deuda se iba incrementando: «Había solicitado una licencia aquí por un par de meses, para ir a poner orden en mis asuntos y que pareciera al menos a mis acreedores que hacía algunos movimientos para satisfacerles, pero no se me ha permitido alejarme. Juzgad pues, monseñor, en qué pena voy a estar. No sé en absoluto cómo hacer. ... Estoy en la desesperación». ${ }^{60}$ Renau había llegado al límite de su resistencia y obtuvo el permiso para retornar a Francia, adonde llegó a finales de la primavera atravesando el puerto de Roncesvalles, con tan solo una pistola en sus bolsillos, que era todo el caudal acumulado después de ocho años de servicio (FONTENELLE, 1721: 115).

\section{CONCLUSIÓN}

De la lectura de la correspondencia de Renau se podría extraer la idea errónea de que no solo fue el único que se preocupó por Cádiz y su defensa, sino que además solo él llevó a cabo gestiones en la Corte, que sus opiniones y decisiones fueron las más acertadas y que incluso la financiación de los gastos corrió a su cargo, endeudándose personalmente por esto. Es curioso que todas sus referencias se limiten a personas que desempeñaban cargos militares, españoles y franceses, y que no cite ni una sola vez al cabildo gaditano, pues la ciudad de Cádiz contribuyó a los gastos bélicos, hasta el punto de que sus arcas quedaron exhaustas (Bustos, 1984: 147; BENÍTEZ, 2002: 496). Esto es un reflejo del control que van a ejercer los franceses en todos los aspectos de la organización y la financiación de la defensa de la ciudad (BEnítez, 2002: 486-487). Hay una identificación de Renau con la ciudad, hasta el punto de que expresa su pesar por su situación, su tristeza por no encontrar apoyos, hasta su desesperación y decisión de abandonar España, porque considera que tras largos años de esfuerzos persiste su debilidad y no soporta la idea de que su conquista por los aliados se asocie a su nombre. Esto encaja con algunas de las características de su personalidad, pero no se corresponde, claro está, con la realidad de los hechos. Renau tuvo un papel importante, aunque en las historias gaditanas no se le cita, pero no crucial como él expone, pues aunque él obvia sus nombres intervienen muchos otros personajes en los eventos que se viven en Cádiz entre 1701 y 1709.

Renau no actúa de espaldas a las autoridades españolas, que conocen su presencia, sus actividades, y quienes le facultan y respaldan. Ahora bien, aunque tiene contactos con los principales personajes de la Corte y en las ciudades por las que transita y reside, solo responde, se justifica, se explica y obedece a París. Es un agente de Francia que trabaja para la defensa de España simplemente porque es lo que le interesa a la política exterior de Luis XIV. Para él España es solo un elemento al servicio del rey Sol, y cualquier acción se analiza bajo esta premisa de manera permanente. Su labor es detectar los puntos débiles y remediar estos déficits, para que si estalla el conflicto los daños sean ínfimos y se pueda articular la respuesta.

60 Madrid, 18 de marzo de 1709. AN, MAR/B/4/34, ff. 118v.-119r. 
Evidentemente, la duración de la Guerra de Sucesión podría ser contemplada como un fracaso de quienes tenían como cometido primero evitarla y, en caso de que no fuera posible, segundo minimizar su alcance. Sin embargo, no es así. Renau realiza una magnífica labor y sus análisis se evidencian certeros. Serán factores que exceden de su control, y sobre los que había avisado en reiteradas ocasiones, los que van a determinar que el conflicto estalle y se prolongue: entrada de Portugal en la guerra en el bando austracista, conquista de Gibraltar, ínfima formación de las milicias, papel harto mejorable de la nobleza, escasez de recursos económicos y graves carencias de pertrechos.

Las aportaciones de Renau son múltiples y vienen definidas por su personalidad polifacética (militar, científico, navegante), que conjuga el estudio y el análisis del territorio con la puesta en práctica de medidas y acciones que solventen los problemas que detecta. Su mera presencia en España contribuye al trasvase científico (ingeniería, construcción naval) y se plasma en un completo conocimiento de los principales puertos de Galicia y de las fortalezas fronterizas con Portugal (descripciones, proyectos y planos). Su actividad como un agente de campo, que transmite información a Pontchartrain de manera permanente durante casi una década, dibuja la dicotomía de un hombre al servicio de su rey natural que debe adoptar decisiones para que conserve la corona otro monarca nieto del suyo, pero cuyos intereses no siempre serán coincidentes (aquí hay que dejar bien claro que Renau actuará siempre como súbdito de Luis XIV, a quien por otra parte le unía una larga relación). La correspondencia de Renau nos proporciona el testimonio en primera persona de un hombre con un importante bagaje y reputación que llega a España cuando está cercano a los 50 años de edad, tras haber recorrido Francia y sus teatros de guerra de finales del siglo XVII, después de haber llevado a cabo dos expediciones a América (una de ellas como corsario, aunque hay quien le califica de filibustero; De CAUNA, 2002: 153), llegando incluso al actual Senegal, ${ }^{61}$ siempre cumpliendo órdenes, que cambia Rochefort y Versalles por Cádiz y Madrid. Su labor, a sus ojos, fue la de un ingeniero en cuyas manos estaba el modernizar las infraestructuras defensivas españolas, para lo que iba a contar con la financiación procedente de las riquezas americanas. Renau, quien ha sido calificado como «quizás el oficial naval más inteligente de la armada de Luis XIV» (PRITCHARD, 2004: 321), dedicó a Cádiz sus años de madurez, la última etapa de su vida como ingeniero militar. No se sintió siempre arropado en España, pero tampoco podía imaginar él cuando llevó a cabo sus actividades corsarias en 1696 en el Caribe y paralizó la Carrera de Indias, que provocaron que los españoles reaccionaran con virulencia contra los franceses en Cádiz (GIRARD, 2006: 307), que solo cinco años más tarde su misión iba a consistir en fortalecer la clave de bóveda del sistema comercial español que él había intentado derribar y que logró detener durante unos años.

$61 \mathrm{Al}$ volver de América realizó una escala en la isla de Gorea, en el distrito de Dakar, viaje del que se redactó un manuscrito. BoulĖGE, 2013: 348; Journal d'un voyage fait aux Isles de l'Amérique dans l'année 1699 sur un vaisseau du Roy comandé par Mr Renau Ingénieur général de la marine. Université Cheikh Anta Diop de Dakar, Bibliothèque Universitaire, ms. 1. 


\section{REFERENCIAS}

Álvarez y CAÑAS, M.L. (2018): «El comprometido nombramiento de corregidores políticos y militares durante la Guerra de Sucesión. Nobleza y lealtad en Cádiz», en J.I. Fortea Pérez, J.E. Gelabert González, R. López Vela y E. Postigo Castellanos (eds.), Monarquías en conflicto. Linajes y noblezas en la articulación de la Monarquía Hispánica, vol. 2. Comunicaciones, Fundación Española de Historia Moderna, Madrid: 39-49.

ANDÚJAR CASTILLO, F. (2017): «Interpretar la corrupción: el marqués de Villarrocha, Capitán General de Panamá (1698-1717)», Revista Complutense de Historia de América, 43: 75-100.

Apestegui Cardenal, C. (1992): «Aproximación a la vida y obra de Gaztañeta», en Antonio de Gaztañeta 1656-1728, Untzi Museoa / Museo Naval - Sociedad Estatal Quinto Centenario, San Sebastián: 37-102.

BAGNEUX, J. de (1932): «Un basque illustre: Renau d'Elissagaray 1652-1719», Bulletin de la Société des Sciences, Lettres et Arts de Bayonne, 10: 273-292.

BAGneux, J. de (1933): «Expédition de Renau d'Elissagaray aux Antilles en 1696», Bulletin de la Société des Sciences, Lettres et Arts de Bayonne, 11: 197-211.

Benítez Barea, A. (2002): «El impacto de la Guerra de Sucesión en Cádiz», en J.L. Pereira Iglesias (coord.), Felipe v de Borbón (1701-1746). Actas del Congreso de San Fernando (Cádiz), de 27 de noviembre a 1 de diciembre de 2000, Universidad de Córdoba - Ayuntamiento de San Fernando, Córdoba - San Fernando: 479499.

Bernardo Ares, J.M. de (2008): «La clientela austracista de Portocarrero: El III marqués de Leganés», Ariadna. Revista de Investigación, 19: 123-134.

Bernoulli, J. (1695): «Jac. B. Explicationes, annotationes \& additiones adea, quae in Actis sup. anni de Curva Elastica, Isochrona Paracentrica, \& Velaria, hinc inde memorata, \& partim controversa leguntur; ubi de Linea mediarum directionum, aliisque novis», Acta Eruditorum, Prostant apud Joh. Grossii Haeredes \& Joh. Thom. Fritschium, Lipsiae: 537-553.

Bernoulli, J. (1696): «Jac. B. Problema Beaunianum universalius Conceptum, sive Solutio Aequationis nupero Decembri propositae», Acta Eruditorum, Prostant apud Joh. Grossii Haeredes \& Joh. Thom. Fritschium, Lipsiae: 332-337.

BernoulLi, J. (1714): Essay d'une nouvelle théorie de la manoeuvre des vaisseaux, avec quelques lettres sur le même sujet..., J. G. König, Basle.

BERNOULLI, J. (1742): Opera omnia, tam antea sparsim edita, quam hactenus inedita. Tomus secundus, quo continentur ea quae Anno 1714 ad Annun 1726 prodierunt, Sumptibus Marci-Michaelis Bousquet \& Sociorum, Lausannae \& Genevae, «Lettre I de monsieur Bernoulli à monsieur le chevalier de Renau, Contenant quelques Remarques sur son nouveau Mémoire», Basilea, 12 de julio de 1713: 129-144; «Reponse de monsieur le chevalier Renau à monsieur Bernoulli, Contenant des instances \& des difficultés réiterées», París, 15 de septiembre de 1713: 145-152; «Lettre II de Monsieur Bernoulli à monsieur le chevalier Renau, Contenant une ample Solution des instances \& des difficultés faites dans la Réponse précédente», Basilea, 7 de noviembre de 1713: 153-167.

Bisso, J. (1868): Cronica de la Provincia de Cadiz, Editores Rubio, Grilo y Vitturi, Madrid.

Boulège, J. (2013): Les royaumes wolof dans l'espace sénégambien (XIII'-XVIII siècle), Éditions Karthala, Paris. 
BRIOIST, J.-J.; VÉRIN, H. (2008): «Mémoire sur la construction des vaisseaux dans lequel il y a une méthode pour en conduire les façons», Documents pour l'histoire des techniques, 16: 143-168. [En línea] http://journals.openedition. org/dht/1229 [Consulta: 20 de octubre de 2020]

Bustos Rodríguez, M. (1984): «La ciudad de Cádiz y su contribución militar a la Guerra de Sucesión española, 1704-1705», Anales de la Universidad de Cádiz, 1: 139-148.

Calderón Quijano, J.A. (1976): Las defensas del Golfo de Cádiz en la Edad Moderna, Escuela de Estudios Hispano-Americanos, Sevilla.

Castro, A. de (1858): Historia de Cádiz y su provincia desde los remotos tiempos hasta 1814, Imprenta de la Revista Médica, Cádiz.

D'ErLo, J. (1905): Bernard Renau d'Elissagaray, Chef d'escadre, Lieutenant-Général des Armées de Terre, Cie. Fse. des Papiers-Monnaie, Paris.

De Cauna, J. (2002): "Aventuriers et flibustiers basques et gascons de la Caraïbe (XVI ${ }^{\mathrm{e}}-\mathrm{XVII}{ }^{\mathrm{e}}$ siècles)», en S. Requemora y S. Linon-Chipon (eds.), Les Tyrans de la mer. Pirates, corsaires $\mathcal{E}$ flibustiers, Presses de l'Université de Paris-Sorbonne, Paris: $145-162$.

Désos, C. (2016): «Les ingénieurs du roi de France auprès de la couronne d'Espagne (1704-1715)», Vegueta. Anuario de la Facultad de Geografia e Historia, 16: 67-92.

Dubet, A. (2008): Un estadista francés en la España de los Borbones. Juan Orry y las primeras reformas de Felipe $v$ (1701-1706), Biblioteca Nueva, Madrid.

ElissagARAY DE JAURGAIN, R. d' (2004): «Un Basque illustre en son temps et trop oublié: Bernard Renau d'Elissagaray, dit Petit-Renau. Marin, ingénieur, mathématicien et même fiscaliste», Ekaina, 91: 163-195.

Emmanuel, M. (1959): La France et l'exploration polaire. 1. De Verrazano à la Pérouse, 1523-1788, Nouvelles Éditions Latines, Paris.

Etchegoin, J. (1939): "Quelques notes sur Renau d'Éliçagaray», Bulletin de la Société des Sciences, Lettres et Arts de Bayonne, 29: 65-70.

Fernández Cano, V. (1973): Las defensas de Cádiz en la Edad Moderna, Escuela de Estudios Hispano-Americanos, Sevilla.

FERnÁNDEZ GonzÁLEZ, F. (1992): «Gaztañeta, arquitecto naval», en Antonio de Gaztañeta 1656-1728, Untzi Museoa / Museo Naval - Sociedad Estatal Quinto Centenario, San Sebastián: 25-35.

FERrEIRO, L.D. (2007): Ships and Science. The Birth of Naval Architecture in the Scientific Revolution, 1600-1800, The MIT Press, Cambridge (EE.UU.).

Fontenelle, B. de (1721): «Eloge de M. Renau», en Histoire de l'Academie Royale des Sciences. Année M. DCCXIX, Imprimerie Royale: Paris: 101-120.

García Fernández, M.N. (2006): Comerciando con el enemigo: El tráfico mercantil anglo-español en el siglo XVIII (1700-1765), Consejo Superior de Investigaciones Científicas, Madrid.

García Hurtado, M.-R. (2022): «Un comisionado francés en la primera década del siglo XVIII en Galicia: Preparándose para una guerra», Vinculos de Historia, 11.

Girard, A. (2006): El comercio francés en Sevilla y Cádiz en tiempo de los Habsburgo. Contribución al estudio del comercio extranjero en la España de los Siglos XVI al XVIII, Centro de Estudios Andaluces - Renacimiento, Sevilla.

GONZÁLEZ BELTRÁN, J.M. (2003): «El asalto angloholandés de1702 y sus repercusiones en la Bahía de Cádiz», en J.M. González Beltrán (ed.), El asalto angloholandés de 1702 a la bahía de Cádiz. Entre la política internacional y las repercusiones locales, Ayuntamiento de El Puerto de Santa María, El Puerto de Santa María: 75-120. 
Granado Castro, G.; Barrera Vera, J.A.; Aguilar Camacho, J. (2016): «"Las Puertas de Tierra" as a paradigm of fortification systems in Cadiz during the Modern Age: an approach through historical mapping and panoramic drawings», en G. Verdiani (ed.), Defensive Architecture of the Mediterranean XV to XVIII Centuries. Vol. III, Didapress, Firenze: 13-20.

Hamy, E.-Th. (1895): «Les Français au Spitzberg au XVII ${ }^{\mathrm{e}}$ siècle», Bulletin de géographie historique et descriptive du Comité des travaux historiques et scientifiques: 159-182.

Hamy, E.-Th. (1901): «Une croisière française à la côte Nord du Spitzberg, en 1693», Bulletin de géographie historique et descriptive du Comité des travaux historiques et scientifiques: 32-63.

Hanotin, G. (2009): Jean Orry, un homme des finances royales entre France et Espagne (1701-1705), Universidad de Córdoba - CajaSur, Córdoba.

Henrat, Ph. (1984): «French Naval Operations in Spitsbergen During Louis XIV's Reign», Artic, vol. 37, 4: 544-551.

HrodeJ, Ph. (2006): «Les vaisseaux français, un outil au service du Bourbon de Madrid et de l'Empire espagnol d'Amérique (1700-1713)», en Ch. Buchet y M. Vergé-Franceschi (dirs.), La Mer, la France et l'Amérique latine, Presses de l'Université Paris-Sorbonne, Paris: 27-44.

Huygens, C. (1693): «VIII. Remarque de M. Huguens sur le Livre de la Manoeuvre des vaisseaux, imprimé à Paris en 1689 in 8, pag. 117», Bibliothèque universelle et historique, tomo xxv, Chez Abraham Wolfgang, Amsterdam, primera parte: 195-203.

Huygens, C. (1694): «Article V. Replique de Mr. Huguens à la Reponse de Monsr. Renau, Ingenieur General de la Marine en France», Histoire des Ouvrages des Savans, Chez Reinier Leers, Rotterdam: 355-361.

LabAt, J.-B. (1742): Nouveau Voyage aux Isles de l'Amerique... Nouvelle Edition... Tome Sixième, Chez Guillaume Cavelier Pere, Paris.

LEFRANÇOIS DE LALANDE, J.J. (1793): Abrégé de navigation, historique, théorique et pratique, où l'on trouve les principes de la Manoeuvre $\mathcal{E}$ ceux du Pilotage..., Chez l'Auteur, Paris.

Montucla, J.-É. (1758): Histoire des mathematiques, dans laquelle on rend compte de leurs progrès depuis leur origine jusqu'à nos jours, tomo II, Chez Charles Antoine Jombert, Paris.

Moreau de SAINT-Méry, L.-É. (1784): Loix et Constitutions des Colonies Françoises de l'Amérique sous le Vent... Tome Premier, Comprenant les Loix et Constitutions depuis 1550 jusqu'en 1703 inclusivement, Chez l'Auteur - Moutard - Mequignon jeune, Paris.

Odriozola Oyarbide, M.L. (1979): La construcción naval en Gipuzkoa. Siglo XVIII, Diputación Foral de Gipuzkoa, San Sebastián.

Odriozola Oyarbide, M.L. (1998): «La construcción Naval en Gipuzkoa. Siglos XVIXVIII», Itsas Memoria. Revista de Estudios Marítimos del País Vasco, 2: 93-146.

PeÑa IzQuierdo, A.R. (2005): La crisis sucesoria de la monarquía española. El cardenal Portocarrero y el primer gobierno de Felipe v (1698-1705). Tesis doctoral realizada bajo la dirección de Lluís Roura i Aulinas defendida en la Universitat Autònoma de Barcelona el 8 de noviembre de 2005. [En línea] https:/ / www. $\mathrm{tdx}$. cat/handle/10803/4803\#page=1 [Consulta: 10 de noviembre de 2020]

Pітот, H. (1731): La theorie de la manoeuvre des vaisseaux, reduite en pratique ou Les principes et les regles, pour Naviger le plus avantageusement qu'il est possible, Chez Claude Jombert, Paris. 
Ponce Cordones, F.J. (1983): «Dos siglos claves en la demografía gaditana (Breve estudio sobre la evolución de la población de Cádiz en las centurias XVII y XVIII)», Gades, 11: 417-453.

PRITCHARD, J.S. (2004): In Search of Empire: The French in the Americas, 1670-1730, Cambridge University Press, Cambridge - New York.

Quintero GonZÁlez, J. (2020): «Jorge Juan y el arsenal de La Carraca», en M.-R. García Hurtado (ed.), Las innovaciones de la Armada en la España del siglo de Jorge Juan, Consejo Superior de Investigaciones Científicas, Madrid: 599-618.

RAmis y Ramis, A. (1832): Fortificaciones antiguas de Menorca, Imprenta de Pedro Antonio Serra, Mahón.

Recio Morales, Ó. (2004): “"Una nación inclinada al ruido de las armas”. La presencia irlandesa en los ejércitos españoles, 1580-1818: ¿la historia de un éxito?», Tiempos Modernos. Revista Electrónica de Historia Moderna, vol. 4, 10. [En línea] http://www.tiemposmodernos.org/tm3/index.php/tm/article/ view/41/62 [Consulta: 1 de noviembre de 2020]

Renau D'Éliçagaray, B. (1689): De la theorie de la manouvre des vaisseaux, Chez Estienne Michallet, Paris.

Renau D'Éliçagaray, B. (1712): ${ }^{62}$ Mémoire où est démontré un principe de la Mechanique des Liqueurs, dont on s'est servi dans la Theorie de la Manoeuvre des Vaisseaux, $\mathcal{E}$ qui a été contesté par M. Hughens. Par Monsieur Renau, Lieutenant General des Armées du Roy C. de l'Academie Royale des Sciences, s.i., (Paris).

RENAU D'ÉLIÇAGARAY, B. (1713): «Reponse de monsieur le chevalier Renau à monsieur Bernoulli, Contenant des instances \& des difficultés réiterées», París, 15 de septiembre, en J. Bernoulli (1742), Opera omnia, tam antea sparsim edita, quam hactenus inedita. Tomus secundus, quo continentur ea quae Anno 1714 ad Annun 1726 prodierunt, Sumptibus Marci-Michaelis Bousquet \& Sociorum, Lausannae \& Genevae: 145-152.

Resa Moncayo, F.J. (2016): ¿Leal servidor o traidor? El Marqués de Villadarias en la Guerra de Sucesión y su vinculación con la ciudad de Antequera. Tesis doctoral dirigida por Marion Reder Gadow y defendida en la Universidad de Málaga el 8 de enero de 2016.

Richer, A. (1815): "Notice sur Bernard Renau», en Vie du Maréchal de Tourville, Lieutenant-Général des armées navales de France, sous Louis XIV. Quatrième édition, augmentée des Vies du Maréchal d'Estrées et de Bernard Renau ... Tome Second, Chez Volland le jeune, Paris: 127-174.

SAINT-SAUD, A. de (1930): «B. Renau d'Eliçagaray inspecteur de la Marine et la fabrication des bombes en Périgord», Bulletin de la Société Historique et Archéologique du Périgord, septiembre-octubre: 264-272.

SAVÉRIEN, A. (1745): Nouvelle theorie de la manoeuvre des vaisseaux, a la portée des pilotes, Chez la Veuve d'André Knapen - Charles-Antoine Jombert, Paris.

Segura García, G. (2005): «Cádiz, 1702: el asalto aliado durante la Guerra de Sucesión», Revista de Historia Militar, 97: 151-177.

Symcox, G. (1974): The Crisis of French Sea Power, 1688-1697. From the Guerre $d^{\prime}$ Escadre to the Guerre de Course, Martinus Nijhoff, The Hague.

Vergé-Franceschi, M. (1991): Dictionnaire des personnages et des batailles, en P. Le V. Villette-Mursay, Mes campagnes de mer sous Louis XIV, Tallandier, Paris.

62 La Bibliothèque Nationale de France indica como fecha hacia 1690, pero se trata de un error, pues el libro se imprime posteriormente a su regreso de España, ya que en el título indica el grado que le otorgó Felipe v. 
Bernard Renau d’Éliçagaray en España durante la Guerra de Sucesión

VÉRIN, H. (1993): La gloire des ingénieurs. L'intelligence technique du XVI au XVIII siècle, Albin Michel, Paris. 


\title{
Un señorío en la alta Andalucía del siglo XVII: Antonio Álvarez de Bohorques, I marqués de Los Trujillos, o la ambición señorial
}

\author{
A Manor in the High Andalusia of the Seventeenth Century: Antonio Álvarez \\ de Bohorques, 1st Marquis of Los Trujillos, or Manorial Ambition
}

\author{
Francisco Javier Illana López \\ Universidad de Jaén \\ https:/ / orcid.org/0000-0002-0969-0517 \\ fillana@ujaen.es
}

Recibido: 11/01/2021; Revisado: 22/03/2021; Aceptado: 10/05/2021

\section{Resumen}

\begin{abstract}
Las ventas de jurisdicciones en la España de los Austrias permitieron a multitud de acaudalados castellanos medrar en la pirámide social de la Edad Moderna, obteniendo el título de señores de vasallos. Este trabajo analiza el caso de uno de ellos: don Antonio Álvarez de Bohorques, I marqués de los Trujillos, quien trató de construir un gran territorio nobiliario a caballo entre Jaén y Granada a través de la compra de varios señoríos.
\end{abstract}

Palabras clave: Jaén, Granada, ventas de jurisdicciones, señorío, Trujillos.

\begin{abstract}
The Habsburg sale of jurisdictions in Castile allowed a vast number of wealthy men to climb the Early Modern social pyramid by obtaining titles akin to those of feudal lords. This paper analyses the case of Antonio Álvarez de Bohorques, 1st Marquis of Los Trujillos, who tried to build a manorial state by buying up estates between the Kingdoms of Granada and Jaén.
\end{abstract}

Key words: Jaén, Granada, Sale of Jurisdictions, Manors, Trujillos. 
«Yo soy uno de los criados de Su Majestad que con más amor sirven las cosas de su servicio»».

\section{INTRODUCCIÓN²}

En la figura de don Antonio Álvarez de Bohorques, I marqués de los Trujillos, encontramos el ejemplo paradigmático de élite nobiliaria con control político y social sobre las instituciones urbanas de la corona de Castilla, poder aprovechado para saltar a la escala central de la Monarquía. Un oligarca ligado a los oficios concejiles de varias ciudades del reino, especialmente de la alta Andalucía, a la vez que a las instituciones estatales de los Austrias. De Álvarez de Bohorques ha dicho el profesor SorIA (2011) que «quizás sea un auténtico paradigma del pacto tácito que presidía las relaciones entre el centro y la periferia, entre la monarquía y el patriciado urbano entre los siglos XVI y XVIII».

El presente estudio tiene por objetivo central profundizar en una de las muchas facetas que este aristócrata granadino de inicios del siglo XVII ofrece para su estudio: la gestión señorial. El I marqués de los Trujillos, como tantos otros acaudalados de la Castilla moderna, aprovechará las posibilidades ofrecidas por la Monarquía Hispánica para titularse señor de vasallos sobre una serie de poblaciones, engrosando así no solo sus rentas jurisdiccionales, sino también los títulos que acompañarán a su apellido y a linaje. No es tanto nuestro interés profundizar en la figura de Álvarez de Bohorques, como adentrarnos en el proceso de construcción de su señorío, tan extenso como efímero, pues acabará desintegrándose al poco de su muerte, como veremos.

Las fuentes bibliográficas con las que partimos son, de entrada, muy limitadas. Álvarez de Bohorques fue una personalidad influyente en el reinado de Felipe III y Felipe IV, de quien, sin embargo, no disponemos de mucha información, más allá de pistas bibliográficas en diversos trabajos sobre la nobleza antiguorregimental. ${ }^{3}$ Es por ello por lo que las fuentes de nuestro estudio serán mayoritariamente documentales. Contamos con su expediente de caballero de la Orden de Santiago, conservado en el Archivo Histórico Nacional, sección de Órdenes Militares, ${ }^{4}$ como hilo conductor para la reconstrucción de su biografía y linaje. De cara a la constitución de su señorío a caballo entre los reinos de Jaén y Granada, principal objetivo de estudio de este trabajo, disponemos de todos los procesos de venta y privilegios de jurisdicción en el Archivo General de Simancas. ${ }^{5}$

En definitiva, este estudio analizará al I marqués de los Trujillos en su condición señorial, y a su estado nobiliario, encajándolo dentro de ese mecanismo venal que son las ventas de jurisdicciones en tiempos de los Austrias, que dieron posibilidad de ascenso social a tantos linajes en la Castilla moderna.

1 Carta de Antonio Álvarez de Bohorques. Archivo General de Simancas [en adelante AGS], Patronato Real [PTR], leg. 90, doc. 149.2.

2 Esta investigación y el estudio resultante de ella ha sido posible gracias a un contrato predoctoral de Formación de Profesorado Universitario (FPU18/00751), y el Proyecto de investigación PID2019. 110225GB-I00 del Ministerio de Ciencia, Innovación y Universidades.

3 Hablamos de una bibliografía que va desde obras antiguas, tales como ArGOTE (1866) o ESPINALT (1786), hasta obras de reciente cuño como SORIA (2007) O CASEY (2008).

4 En adelante, AHN, OOMM.

5 Las consultas de cara a este estudio se centran en las secciones Escribanía Mayor de Rentas. Mercedes y Privilegios, ventas y confirmaciones -EMR, MER en lo sucesivo- y Dirección General del Tesoro, inventario 24 -DGT, Inv. 24-. 


\section{SEMBLANZA DE ANTONIO ÁLVAREZ DE BOHORQUES, I MARQUÉS DE LOS TRUJILLOS}

En absoluto hemos de encuadrar a don Antonio Álvarez de Bohorques en el seno de una familia de la alta nobleza en el momento de su nacimiento, en la Granada de Felipe II. Antes bien, nuestro personaje constituye el caso paradigmático de oligarca urbano cuyo ascenso social viene aparejado a un constante servicio a la Corona, el cual le reportará múltiples oficios, beneficios y, en última instancia, un marquesado. Al fin y al cabo, cuál era, sino esta, una de las vías parar medrar en la España del Antiguo Régimen.

Era hijo de don Alonso Núñez de Bohorques, ${ }^{6}$ hidalgo, emparentado con los Bohorques sevillanos, del lugar de Villamartín, ${ }^{7}$ quien sentaría las bases de la grandeza de la Casa de los Trujillos al introducirse en la máquina burocrática de los Austrias (SORIA, 2005: 114-115; Martínez y De CARLOS, 1998: 442-443). Tras haber sido colegial y catedrático en el Colegio Mayor de Cuenca de la Universidad de Salamanca, ${ }^{8}$ don Alonso se trasladó a Granada para ser oidor de la Real Chancillería (GAN, 1998: 200), cuyo desempeño durante trece años lo catapultó al Consejo de Castilla en 1581 merced a su afinidad con el «partido castellanista»; y después consejero de La Suprema (1590) y de la Cámara de Castilla (1602), donde sobresale su actuación para paliar los conflictos de jurisdicción entre los consejos de Castilla y de Inquisición (EzQuerRa, 2000: 165). Para el caso concreto de este estudio, resulta interesante su papel en la gestión de pleitos jurisdiccionales con señoríos de encomiendas de las órdenes militares, señalado por EzQUERRA. ${ }^{9}$ Brillante carrera administrativa a la que vino aparejada su tímida introducción en el ámbito señorial, con la compra de la jurisdicción civil del lugar granadino de Beas y sus alcabalas, heredado luego por su hijo (SORIA, 2005: 114).

Igualmente adscrita al régimen señorial -sin gozar de título- estaba su madre, la aristócrata granadina doña Francisca Deza Girón, descendiente de don Diego Girón, señor de la villa de Cardela, y de doña Isabel Ponce de León, emparentada con los señores de Luque, y entre cuya ascendencia encontramos apellidos tales adscritos a la nobleza española moderna. ${ }^{10}$

En este linaje situamos el nacimiento de don Antonio en la Granada de 1574, oriundo de una Casa que, si bien no le otorgó un título nobiliario desde la cuna, queda a todas luces claro que le ofreció posibilidad de alcanzarlo a través de dos vías: el servicio a la Corona iniciado por su padre, y una extensa parentela

6 Como biografía de referencia, véase su entrada en el Diccionario Biográfico Español (LóPEZ, 2011). 7 «Villamartin, lugar de la jurisdicción de Sevilla, que es de los hijosdalgo de este apellido. De los cuales es Alonso Nuñez de Bohorques del Consejo Supremo de Su Magestad. Cuya persona no solo ilustra á aquel lugar, por haber producido a un caballero de tanto valor, mas al Andalucía toda...» (ARGote, 1866: 421).

8 Sobre su paso por el Colegio Mayor de Cuenca en la Universidad de Salamanca, véase CARABíAS (1983: 191).

9 «Confiados sus papeles al licenciado Núñez de Bohórquez, cuatro días después era publicada la sentencia, en la que, entre las medidas arbitradas para mejorar el expediente del tribunal destacaron: la firma indistinta de las ejecutorias por cualquiera de los oidores, la ordenación y encuadernación de las bulas apostólicas, privilegios reales y escrituras concedidas al Consejo y la elaboración de un memorial con los pleitos...» (EzQueRra, 2000: 190-191).

10 Reconstrucción genealógica realizada a partir del expediente de caballero de Santiago de don Antonio Álvarez de Bohorques (1599), localizado en AHN, OOMM, Caballeros, Santiago, Exp. 334. 
señorial por vía materna. ${ }^{11}$ Dice CASEY (2008: 114) que «mediante una serie de matrimonios ventajosos con familias patricias de Granada y Córdoba, padre e hijo se labraron una posición inexpugnable como intermediarios en la sombra entre la corte y dos de las ciudades clave andaluzas». En efecto, nuestro personaje casó con su prima hermana por vía materna doña Juana Jiménez de Góngora, hija de don Alonso Jiménez de Góngora y de su tía doña Beatriz Ponce de León, hermana de su madre. Ello le posibilitó la continuidad en el parentesco con los señores de Luque, sus tíos por vía materna. Si bien, no sería esta la madre de su único hijo y heredero, el cual engendró con su amante doña Jerónima de Benavides, hija de don Cristóbal de Benavides, señor de Almuñán y Cañena, y de doña María de Benavides, descendiente de los condes de Santisteban del Puerto, emparentando así esta casa nobiliaria giennense. ${ }^{12}$

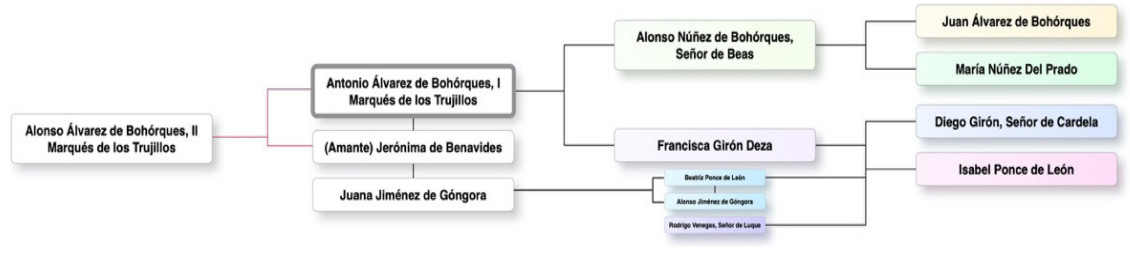

Figura 1. De derecha a izquierda, genealogía de Antonio Álvarez de Bohorques, I marqués de los Trujillos. Fuente: Elaboración propia. ${ }^{13}$

Este es el linaje en que nació el fundador del marquesado de los Trujillos, a caballo entre la aristocracia granadina y cordobesa de final del reinado de Felipe II, y que SORIA (2007: 44) describe como «una de las principales sino la mayor Casa de la nobleza granadina en el siglo XVII». Pasaremos ahora a observar su vertiginoso ascenso en los oficios concejiles de diversas ciudades de Castilla, que lo lanzó hasta otros cargos en la máquina burocrática de Felipe III y Felipe IV.

Podemos adscribir a don Antonio Álvarez de Bohorques dentro de esa media nobleza que componían las élites urbanas, un patriciado con control político y social sobre las instituciones de las ciudades, aprovechado para saltar a la escala señorial; una élite sobre la que nos hablan estudios tales como Soria (2007: 43), Domínguez y Alvar (2005: 103-104) o García (1992: 20-27). La

11 Entre las vías de ascenso social en la España de la Edad Moderna, además de la posesión de una hidalguía o el servicio a la Corona, hemos de aludir otras como las compras de señoríos, las compras de oficios, etc., todas las cuales confluirán en la figura de Álvarez de Bohorques. Estas vías de ascenso social se estudian en DomínguEZ y Alvar (2005: 165-172); también Soria (2007: 213-254).

12 Sobre la casa condal -luego ducal- de Santisteban del Puerto en el reino de Jaén, véanse los estudios de Ribot (2018) y Requena (2007).

13 Para la reconstrucción de este árbol genealógico se ha empleado el expediente de caballero de Santiago del personaje (1599), localizado en AHN, OOMM, Caballeros, Santiago, Exp. 334; así mismo, la biografía de SORIA (2011). 
ocupación de regidurías u otros oficios concejiles es característica fundamental de estas élites, habitualmente adquiridos merced a la posibilidad ofertada por la venta de aquellos promovida por los Austrias. ${ }^{14}$ Del propio Trujillos sabemos que desembolsó elevadas cantidades de dinero a este respecto en diversas ciudades de Castilla, por lo que se ha dicho de él ser la persona que mayor suma pagó por un oficio en la Granada de su tiempo (CASEY, 2008: 57).

En esta línea, a sus 25 años, en 1599, ya ocupaba una veinticuatría en Córdoba recibida como dote al contraer matrimonio a sus dieciocho años, así como el oficio de alguacil mayor de la Inquisición de Granada, tal y como figura en su expediente de caballero de la Orden de Santiago, hábito concedido ese mismo año: «Don Antonio aluarez de bohorques giron alguazil maior de la inquisicion de granada veintiquatro de la cibdad de cordoba, a quien el rey nro sr ha hecho merçed del habito de santiago...». ${ }^{15} \mathrm{Si}$ bien, fue a caballo entre los reinados de Felipe III y Felipe IV cuando nuestro personaje emprendió esa carrera meteórica por distintos cargos y oficios, concedidos o comprados. En esta posibilidad jugó un papel determinante la política de acrecentamiento de oficios promovida por los últimos Austrias, de la que TomÁs y VALIENTE (1982: 169-170) llamó la atención del nacimiento de una burocracia desmesurada que favoreció su entrada a las élites urbanas. A causa de toda esta venalidad de compra y acrecentamiento de oficios, don Antonio se ganó la enemistad de diferentes representantes del patriciado granadino de su tiempo, con largos pleitos que denunciaban tan acusada venalidad. ${ }^{16}$

Corregidor de Guadix, veinticuatro y procurador en Cortes de Córdoba, lo que le aseguró buena posición en la antigua ciudad califal gracias a su provechoso enlace matrimonial; regidor perpetuo de Salamanca; veinticuatro, alguacil mayor de la Inquisición y alférez mayor de su Granada natal y, en última instancia, miembro del Consejo de Hacienda, fueron los oficios y cargos que desempeñó al servicio de la Monarquía Hispánica (FERNÁNDEZ, 2019: 279-280). ${ }^{17}$ Desde todos estos oficios, y especialmente en las ciudades de Granada y Córdoba, sirvió Trujillos a la Corona de Felipe III y Felipe IV. Una intensa correspondencia con el rey entre los años 1619-162018 nos da noticia de la negociación de don Antonio con los cabildos de Córdoba y Granada desde sus oficios de veinticuatro, para conseguir los Servicios de Millones ante las necesidades económicas de la Corona. ${ }^{19}$ Esta intercesión ante los cabildos de las dos ciudades andaluzas le valieron en 1627 el

14 Los estudios dedicados a las ventas de oficios en la Castilla de los Austrias gozan de una situación privilegiada dentro de la historiografía, desde autores clásicos del pasado siglo xx a la actualidad, que han puesto de relieve una tendencia generalizada de venalidad en la Monarquía a vender distintos elementos de patrimonio regio, sobresaliendo los cargos en la administración. Hablamos de estudios tales como Tomás (1980), Domínguez (1985), Andújar y FELICEs (2011), JimÉnez (2012) o AndúJar (2016), entre otros muchos. Para el período concreto de este trabajo, el reinado de Felipe III, véase el trabajo de Marcos (2007).

15 AHN, OOMM, Caballeros, Santiago, Exp. 334, fol. 3r.

16 Sabemos de un largo pleito con los veinticuatros granadinos por la invención del oficio de alcaide mayor honorífico para su hijo Alonso Álvarez de Bohorques, en 1637, el cual estudia con mayor detalle FERNÁNDEZ (2019: 279-280).

17 Así, sabemos de la compra de algunos de estos oficios, como el de alférez mayor de la ciudad de Granada, que adquirido a su pariente don Salvador Egeas Venegas de Córdoba, conde de Luque. Sobre los corregidores andaluces en tiempos de Álvarez de Bohorques, véase el trabajo de FORTEA (2008); sobre los veinticuatro en la Córdoba de esta misma centuria, CASTILlejO (1995).

18 AGS, PTR, leg. 90, docs. 142, 146, 148, 149, 154, 181 y 386.

19 Sobre los Servicios de Millones durante el reinado de Felipe III, véanse los estudios de MARCOS (2009) o FORTEA (1993). 
vizcondado de Caparacena, como premio por conseguir su voto en Cortes (SORIA, 2011). Así hablaba al rey en aquellos años de servicio a las necesidades financieras de la Monarquía:

E procurado persuadir estos dias a la maior parte de los caballeros de el cabildo desta ciudad, mostrandoles el estado en que la Hacienda de su M. se halla las necesidades que en su Casa Real, exercitos, frente de guerra de mar y tierra y fronteras y presidios se padeçen las obligaçiones de gastos que al presente se ofreçen para expeler los moriscos destos reinos y para conservarlos bien defendidos... ${ }^{20}$

Tal fue su trayectoria política, que CASEY lo ha llegado a apodar en sus estudios «el secuaz de Olivares» (2008: 57), o «el braç dret d'Olivares per al govern d'Andalusia» (1989: 220-221), vinculación que también señalan SoriA (2011) o FERNÁNDEZ (2019: 179), este último hablando de un «estrecho contacto que mantuvo con el conde-duque de Olivares». Más recientemente, SÁnchEz-MonTES (2021), en su monografía sobre Felipe IV y Andalucía, hace referencias continuas a Álvarez de Bohórques a lo largo de la obra. Si bien, están todavía por estudiar las intensas relaciones entre Trujillos con el conde-duque, del que tantos autores han llamado la atención. ${ }^{21}$

Un crecimiento político que debe contemplarse en paralelo con el ascenso social que experimentó nuestro personaje y su Casa, igualmente, merced a las posibilidades venales ofrecidas por la Corona. Ya hemos aludido cómo recibió el vizcondado de Caparacena tras conseguir de la ciudad de Córdoba el voto en Cortes por un servicio siendo Trujillos procurador; más, a la muerte de su esposa, sus parientes reclamaron este título para al mayorazgo de los Góngora, por estar aparejado a los oficios que gracias a ellos había recibido en la ciudad califal (SorIA, 2011). Ello no privó a nuestro personaje de persistir en su deseo de adquirir un título nobiliario; para ello, se aprovechó de las posibilidades ofrecidas por la monarquía para comprar la jurisdicción sobre villas, aldeas y lugares, proceso al que luego aludiremos. Al fin y al cabo, la compra de señoríos constituía el paso previo para obtener un título en la España de los Austrias (MARTíNEZ, 2020: 118; SORIA, 1995: 61).

Además de los oficios señalados, Álvarez de Bohorques compró -o intentó adquirir- una importante cantidad de señoríos y rentas enajenadas del patrimonio regio, entre los reinos de Jaén y Granada. Hablamos de los cortijos de Bohorques, Caparacena, Cortes y Trujillos en el reino de Granada; así como las villas de Castillo de Locubín, Los Villares, Valdepeñas, Cazalilla, Guadaortuna, Albolote y Puerta Alta entre los reinos de Jaén y Granada. Algunos de ellos, incluyendo la adquisición de alcabalas y tercias, lo que supuso un importantísimo desembolso para satisfacer sus aspiraciones señoriales. Con estas compras de señoríos no solo logró ennoblecer si linaje, sino también afianzar su ya de por sí elevada posición política (FERNÁNDEZ, 2019: 179). No obstante, al igual que con la adquisición de oficios, la compra de señoríos le granjeó más enemistades en el cabildo granadino, donde entre 1610-1614 algunos capitulares clamaron en contra de la enajenación

20 Carta de Antonio Álvarez de Bohorques. AGS, PTR, Leg. 88, doc. 75, fol. 1r.

21 Pese a que historiadores como los citados han puesto de relevancia esta complicidad, biografías antiguas y actuales del conde duque de Olivares obvian a la figura de Álvarez de Bohorques, lo que pone en evidencia cuan necesaria es una investigación profunda acerca de las relaciones entre ambos personajes. Es el caso de MARAÑón (1956), ElLIOT (2004). 
de lugares jurisdiccionales vendidos a Bohorques (CASEY, 2008: 114-115). Al proceso de compra y a constitución de estos señoríos atenderemos a continuación; de momento, nos basta enunciar que esta costosísima adquisición le valió para conseguir del conde duque de Olivares el título de I marqués de los Trujillos, en 1632.22

A su muerte en 1640, nuestro personaje dejaba un marquesado -y una cuantiosísima deuda por la compra de tantos oficios y señoríos- a su hijo Alonso Álvarez de Bohorques, II marqués de los Trujillos, nacido de su amante Jerónima de Benavides. Sería este el continuador del linaje cimentado por su abuelo de Alonso Núñez de Bohorques, y edificado por su padre Antonio Álvarez de Bohorques.

\section{LAS VENTAS DE SEÑORÍOS EN LA ESPAÑA DEL SIGLO XVII. LAS VILLAS DE DON ANTONIO ÁLVAREZ DE BOHORQUES}

Llegados a este punto, se hace preciso definir estos particulares procesos de ventas de jurisdicciones en el marco de la Corona de Castilla durante la Edad Moderna. Estas no constituyen sino un capítulo más de las enajenaciones y ventas de patrimonio regio llevadas a cabo por los Habsburgo españoles, en línea con las ventas de oficios, hidalguías, privilegios, etc. Un proceso por el que una población realenga -villa, aldea, lugar, cortijo- podía ser enajenada de la Corona o de la Iglesia para ser vendida su jurisdicción. Puestas en marcha por Carlos v y desarrolladas ampliamente por Felipe II, las ventas de señoríos fueron llevadas a su cénit por Felipe IV, como estudió el profesor DomínguEz OrTIz (1964) en su ya clásico trabajo sobre la temática. No constituyen estas ventas de jurisdicciones un caso aislado en Castilla; antes bien, diversos autores lo han puesto en paralelo con otros territorios extrapeninsulares, pertenecientes o no a la Monarquía Hispánica. Es el caso de las ventas de feudos en la Italia española, o las enajenaciones y ventas de las jurisdicciones eclesiásticas en la Inglaterra de los Tudor (DOMínguEZ y Alvar, 2005: 168; NADER, 1990: 1-3).

En estas ventas de señoríos confluyen una serie de intereses comunes. De un lado, la Corona encontró en ello una buena medida para engrosar unas arcas reales exhaustas por las continuas empresas militares de los Austrias, para enfado de las ciudades que, representadas en las Cortes, solicitaron una y otra vez a los reyes el fin de enajenaciones de aldeas y lugares (GELABERT, 2008; MARCOS, 2014). El propio Carlos v lo había establecido así en una cédula de 1554: «hacer villas a los lugares de los dichos nuestros reinos y señoríos y de mandar que se usen todos los arbitrios y cosas necesarias para hacer dineros...» (DELGADO et al., 2009: 88-89). De otro lado, tenemos a unas élites deseosas de ennoblecerse y de acrecentar sus riquezas, encontrando en estas ventas un buen mecanismo, por el que titularse señores de vasallos les posibilitaba el anhelado ascenso social. A este respecto, escribe SORIA (2001: 442) que estas ventas se deben entender como una vía empleada por la Corona para acallar y contentar a esa ambiciosa nobleza antiguorregimental. Por último, tenemos a los vecinos en aquellas poblaciones

22 Del mismo modo que creó el título de marqués de los Trujillos para Álvarez de Bohorques, Olivares también concedió el de condes de Luque para sus parientes por vía materna unos años antes (CASEY, 2008: 75), lo que pone en evidencia el claro favor de la Corona hacia la familia. 
que caen en el régimen señorial, quienes en multitud de ocasiones protestarán contra ello, pagando a la Corona cuantiosas sumas colectivas para exentarse (MARcos, 2014).

Para el período de nuestro estudio, el siglo XVII, las ventas de jurisdicciones -al igual que la totalidad de las enajenaciones de patrimonio regio-fueron llevadas a su extremo en el reinado de Felipe IV. Mientras que Felipe III había frenado las ventas de señoríos, ciñéndose únicamente a los cortijos o heredamientos, ${ }^{23} \mathrm{su}$ sucesor puso en marcha la enajenación de todo tipo de poblamientos, incluyendo aquellas villas que habían pagado por su jurisdicción en el siglo anterior. Tal fue la generalización de estas ventas que ya no era la Real Hacienda la que las tramitaba, sino que las jurisdicciones eran vendidas por los asentistas y factores generales del rey; nombres como Bartolomé Spínola u Octavio Centurión que se repiten en los asientos de venta. ${ }^{24}$ Todo ello encontrará reflejo en las compras del I marqués de los Trujillos.

Como tantos otros oligarcas urbanos de la España moderna, don Antonio Álvarez de Bohorques se aprovechó de estas ventas de señoríos para ennoblecer su Casa a partir de la compra de jurisdicciones. Para ello emprendió la adquisición de una serie de poblaciones a caballo entre los reinos de Jaén y Granada, en el paraje limítrofe llamado hoy de «Los Entredichos», para lo que hubo de endeudarse con elevadísimas sumas de dinero que ni siquiera llegó a pagar en vida. El señorío de Los Trujillos en su vertiente granadina se encuentra estudiado en la ya clásica obra del profesor SoRIA (1995); no tanto así el caso giennense, inédito hasta nuestros días. ${ }^{25}$ Atenderemos en lo sucesivo a la conformación de este señorío jurisdiccional a inicios del siglo XVII, con todas las particularidades que presentan los procesos de venta de cada una de las poblaciones: mientras que algunas ventas prosperarán, otras serán rechazadas, bien por la resistencia vecinal, bien por oposición mostrada por las ciudades.

\subsection{Las compras de jurisdicciones del i marqués de los Trujillos}

En dos grandes bloques de compras, en los años de 1613 y 1629, Álvarez de Bohorques se tituló señor de Albolote, Bohorques, Caparacena, Castillo de Locubín, Cazalilla, Cortes, Guadaortuna, Trujillos, Valdepeñas y Los Villares. En las compras señoriales de Trujillos atendemos a todas las categorías urbanas de la España moderna, desde cortijos o despoblados, aldeas o lugares, e incluso villas «libres» que no pertenecían a la jurisdicción de ninguna ciudad. ${ }^{26}$

Como ya se dijo, Álvarez de Bohorques poseía el título de señor de Beas por

23 En el Antiguo Régimen, se entendía heredamiento como una propiedad rural sin habitantes. Así se describía en el diccionario de Covarrubias justamente en los años del Marqués de los Trujillos: «La possession en el campo de tierras, viñas y arboles, y por ser bienes raizes que estan asidas y pegadas con la tierra se llaman heredades» (Covarrubias, 1611: 466-467).

24 Sobre estos asentistas de la Monarquía Hispánica, véanse los estudios de la profesora SANZ (2015 y 2013).

25 El citado autor llamaba la atención de la inexistencia de obra alguna que se ocupara de las ventas jurisdiccionales en el marco del reino (Soria, 2000: 68). Para el caso giennense, solamente contamos con estudios de casos concretos, como lo son López (1997), Castillo y Delgado (2004), Aponte (2011)

26 Sobre estas categorías urbanas y rurales en la España del Antiguo Régimen, véase el estudio de VELA (2012). 
herencia paterna. Si bien, la carrera señorial de nuestro personaje inició cuando, en 1613, compró a Felipe Iv la jurisdicción sobre sus cortijos de Bohorques, Caparacena y Cortes, en el reino de Granada, pagando a la Real Hacienda 12.800 ducados por todos ellos. ${ }^{27}$ Una compra, la de heredamientos, que va en línea con la política seguida por Felipe III en cuanto a las ventas de señoríos, bajo cuyo reinado mayoritariamente se vendieron jurisdicciones de este tipo de territorios despoblados a sus dueños, más en la línea de conceder mercedes que posibilitaran el ascenso social, antes que por engrosar las arcas reales (LORENZO e IZQUIERDO, 2001: 200; Gallego, 2016: 408). ${ }^{28}$ Es el caso de Álvarez de Bohorques quien, cuando realizó estas primeras compras a la Corona (década de 1610), estaba experimentando ese crecimiento político por las veinticuatrías de las ciudades de Granada y Córdoba, como hemos visto, con lo que esta adquisición de granjeó paralelamente ascenso social al iniciarse en la carrera señorial.

Serían estas compras motivo de conflicto con el cabildo de la ciudad de Granada, cuyos oficiales miraron con recelo, no sólo la enajenación de estos territorios jurisdiccionales de la ciudad, sino el poder que venía adquiriendo don Antonio (CASEY, 2008: 114). Tanto así que fue tras la pérdida de estas poblaciones, en 1614, cuando el concejo de Granada pagó al rey 20.000 ducados por la jurisdicción de todos los cortijos y despoblados de su término, en aras de evitar que continuara la pérdida territorios (SORIA, 1995: 95).

Dos años después, en 1615, adquirió el señorío sobre el cortijo de Trujillos, al norte del reino de Granada, el cual daría nombre a su marquesado dos décadas después. Si bien, no se trata este de un caso de enajenación de patrimonio regio; esto es, no fue una compra efectuada al rey, sino que, al contrario, este señorío fue adquirido a don Juan de Checa Aguilera y su esposa doña Antonia de Velasco, anteriores señores del mismo (SORIA, 1995: 151). La localización geográfica de este cortijo, también llamado de la Puerta Alta de Luchena, limitante con la ciudad de Alcalá la Real, sería determinante para la compra de varias villas y aldeas del reino de Jaén años después, como se verá.

La adquisición de esta serie de jurisdicciones a la Real Hacienda de Felipe III permitió a don Antonio titularse señor de Beas (por nacimiento), Bohorques, Caparacena, Cortes y Trujillos, todos ellos cortijos o territorios meramente despoblados. Con ello, el granadino consiguió del rey la merced de un ascenso social aparejado a la vertiginosa carrera política en que se encontraba inmerso aquellos años.

Muchas más noticias tenemos acerca de las compras efectuadas en tiempos de Felipe IV, a caballo entre los reinos de Jaén y Granada. Su salto al territorio giennense lo dio en 1627, cuando asentó con la Real Hacienda de Felipe IV la compra del lugar de Castillo de Locubín, jurisdicción de la ciudad de Alcalá. ${ }^{29}$ Parece a todas luces claro que, en su interés por esta población, jugó un papel notorio la ubicación de esta: limitante con el reino de Granada, y más aún, con su señorío de Trujillos, lo que nos está anunciando su interés de crear un auténtico estado nobiliario giennense-granadino. Era Castillo una aldea poblada por unos

27 AGS, EMR, MER, leg. 267, fol. 2; AGS, DGT, Inv. 24, leg. 285, fol. 9.

28 «Tal vez por el deseo de minimizar el impacto de las enajenaciones sobre los vasallos, este monarca -al menos en los casos de Ávila y Madrid- se limitó a la venta de jurisdicciones de lugares despoblados, generalmente dehesas y términos redondos sobre los que sus propietarios deseaban obtener jurisdicción» (LORENZO e IZQUIERDO, 2001: 200).

29 AGS, EMR, MER, Leg. 276, Exp. 4. 
400 vecinos y un término de dos leguas y media lo que, a razón del precio habitual de 16.000 maravedís por vecino, supuso un desembolso de 6.400 .000 maravedís que Álvarez de Bohorques se comprometió a pagar:

Que el dho lugar del castillo de locubin y su jurisdicion senorio y vasallage y rentas jurisdicionales aya de quedar y quede obligado e ypotecado por espeçial y espresa ypoteca a la seguridad y complimiento y paga del presçio desta venta y intereses della y a las costas de su cobrança y aunque el dho señor Don Antonio Álvarez de Bohorquez aya tomado la posesion del no sea seruido de transferirsele el dominio hasta que le aya pagado enteramente. ${ }^{30}$

En la compra de Castillo de Locubín nos encontramos con el caso paradigmático de choque entre los intereses del señor, del lugar y de la ciudad de cuya jurisdicción depende este. Pese a los intentos de los vecinos por exentarse de caer en el régimen señorial, nada pudieron hacer estos, pues don Antonio pujó hasta ascender el precio por vasallo a 18.130 maravedís por vecino, lo que hizo aún mas cuantiosa la compra. Al contrario, fue la ciudad de Alcalá la Real la que pujó por la jurisdicción del lugar de Castillo; no es este un caso aislado, pues fueron muchas las ciudades en Castilla que pagaron a la Corona por evitar la pérdida de sus aldeas jurisdiccionales. ${ }^{31}$ El desencuentro entre ciudad y señor no se resolvería hasta dos años después, en 1629:

Se conçerto la dha çiudad de Alcalá la real con el dho marques en que se apartasse del derecho que tenia adquirido a la jurisdicion senorio y vasallaje del dho lugar del castillo de locubin pagando primo y ante todas cossas al dho marques la dha çiudad el dinero que ubiesse pagado (...). E que demas desto le ubiesse de dar la dha ciudad al dho marques en recompensa de la comodidad y benefiçio que ella reçibia consentimiento y permisso para que se pudiere vender al dho marques y el comprar la jurisdiçion de un quarto de legua legal en el termino que tenía la dha ciudad en el alto de cofrida para yncorporarle en la jurisdicion de la dha villa de la puerta alta. ${ }^{32}$

La operación no pudo ser más ventajosa para la Corona: de un lado, la ciudad de Alcalá se hizo cargo del pago que Trujillos había de hacer al rey por el lugar de Castillo de Locubín, que quedó durante las dos centurias sucesivas bajo su jurisdicción; un pago que, entre pujas y averiguación exacta de sus vecindad y término, se elevó a 14.975 .323 maravedís. ${ }^{33}$ De otro, el ya titulado marqués estableció con la Real Hacienda un nuevo asiento de venta de otro territorio despoblado, correspondiente a un cuarto de legua del término de Alcalá la Real, limitante con su heredamiento de Trujillos-Puerta Alta de Luchena y que pasaría

30 AGS, EMR, MER, leg. 276, exp. 4, fol. 6r.

31 Lo veíamos más arriba en la ciudad de Granada que, precisamente tras las enajenaciones del Marqués de los Trujillos, sirvió al rey con una ingente cantidad de maravedís por evitar futuras enajenaciones. También otras ciudades castellanas a lo largo de toda la Edad Moderna, como el caso estudiado por MARCos (2019); cerca de nuestro territorio de estudio tenemos un caso similar, cuando el i conde de Villardompardo trató de comprar el lugar de Jamilena de la encomienda calatrava de Martos, recientemente estudiado en IllaNA (2019). De este tipo de pujas entre señores, aldeas y ciudades por toda Castilla, también llamadas derecho de tanteo, da mucha noticia el estudio de DomínGUEZ (1964); en cualquier caso, habitualmente «estos tanteos se vieron abocados al fracaso porque el señor pujaba con una cantidad superior a la ofertada por los vecinos», (LORENZO e IzQUIERDO, 2001: 220).

32 AGS, EMR, MER, leg. 276, exp. 4.

33 AGS, DGT, Inv. 24, leg. 291, exp. 22. 
a incorporarse a este lugar. ${ }^{34}$ Por ello pagó 2.000 ducados don Antonio al rey, con la condición de que «si alguno vezino de la dha ciudad o del dho lugar del Castillo de Locubin o otra qualquier persona hiciesen contradicion [...] la dha Ciudad de Alcalá la Real le ubiese de poder defender [al marqués]»; ${ }^{35}$ con ello, hábilmente cerraba toda puerta a un nuevo bloqueo de su compra.

Ello no hace sino confirmar lo que apuntábamos con anterioridad: el verdadero interés de Álvarez de Bohorques en estos territorios del sur giennense residía meramente en acrecentar su estado nobiliario granadino hacia Jaén. Tanto es así, que nuestro marqués costeó la elaboración de un plano que recogiera con exactitud la planta de la jurisdicción que había comprado. ${ }^{36}$ Obra del medidor Luis Carducci, ${ }^{37}$ el plano muestra un término en forma de polígono irregular con todo su perímetro perfectamente medido y precisado, y con una serie de topónimos que lo delimitaban. Puntos como la villa de Noalejo, el arroyo de Mures, las lomas de Sancho y de la Cerradura de las Peñas, entre otros, que, gracias al empleo de los Sistemas de Información Geográfica (SIG), nos han permitido ubicar el emplazamiento de este señorío sobre el territorio actual (Figuras 2 y 3 ).

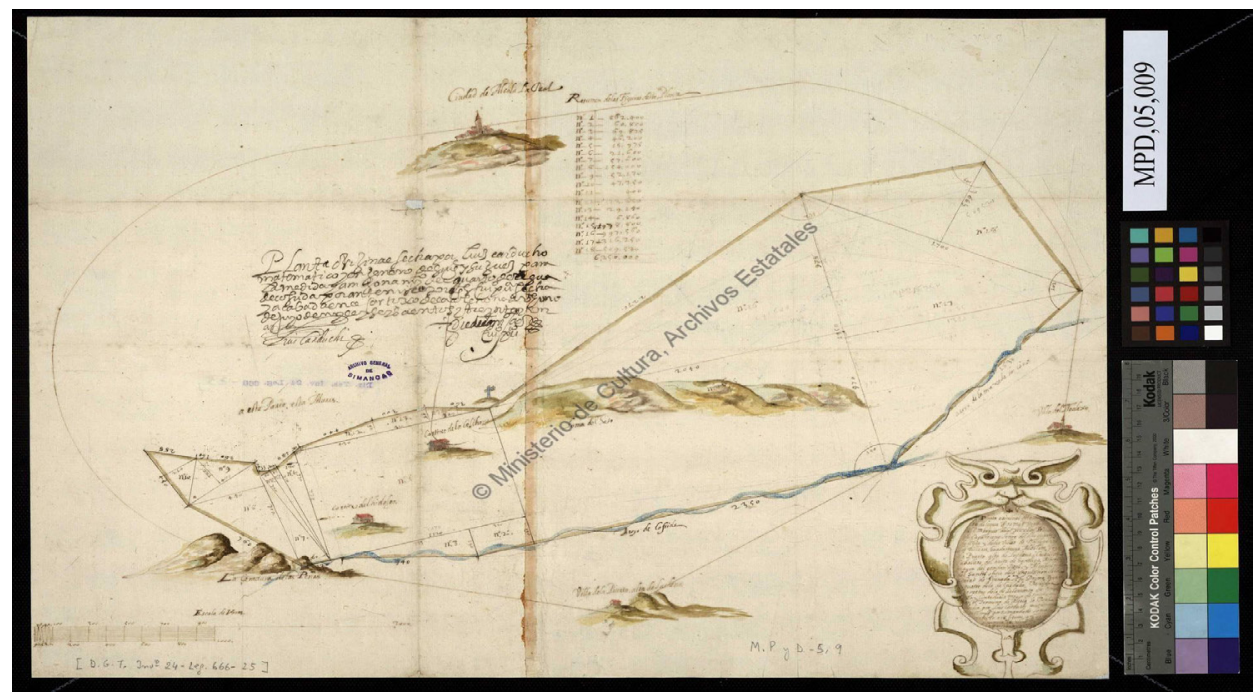

Figura 2. Planta original del quarto de legua q[u]e su Mag[esta]d vendio al Marques de los Truxillos señor de Caparacena.... Luis Carducci, 1631. Escala 1:8.800.000. Dimensiones $43 \times 56,5 \mathrm{~cm}$ (AGS). ${ }^{38}$

34 AGS, EMR, MER, leg. 253, exp. 1.

35 AGS, DGT, Inv. 24, leg. 291, exp. 4, fol. 1r.

36 AGS, Mapas, planos y dibujos [MPD], 05-009.

37 Luis Carduchi, ingeniero y matemático que en tantas ocasiones trabajara para la Monarquía Hispánica en el marco de estas ventas de jurisdicciones, encargado de la medición de los términos de las villas y lugares vendidas a los señores, elaboró también numerosos planos de las mismas características que aquí nos ocupa, destinados a plasmar gráficamente los nuevos señoríos. Véase la entrada de NAVARRO (2011).

38 Ministerio de Educación, Cultura y Deporte, Archivo General de Simancas, MPD, 05-009. 


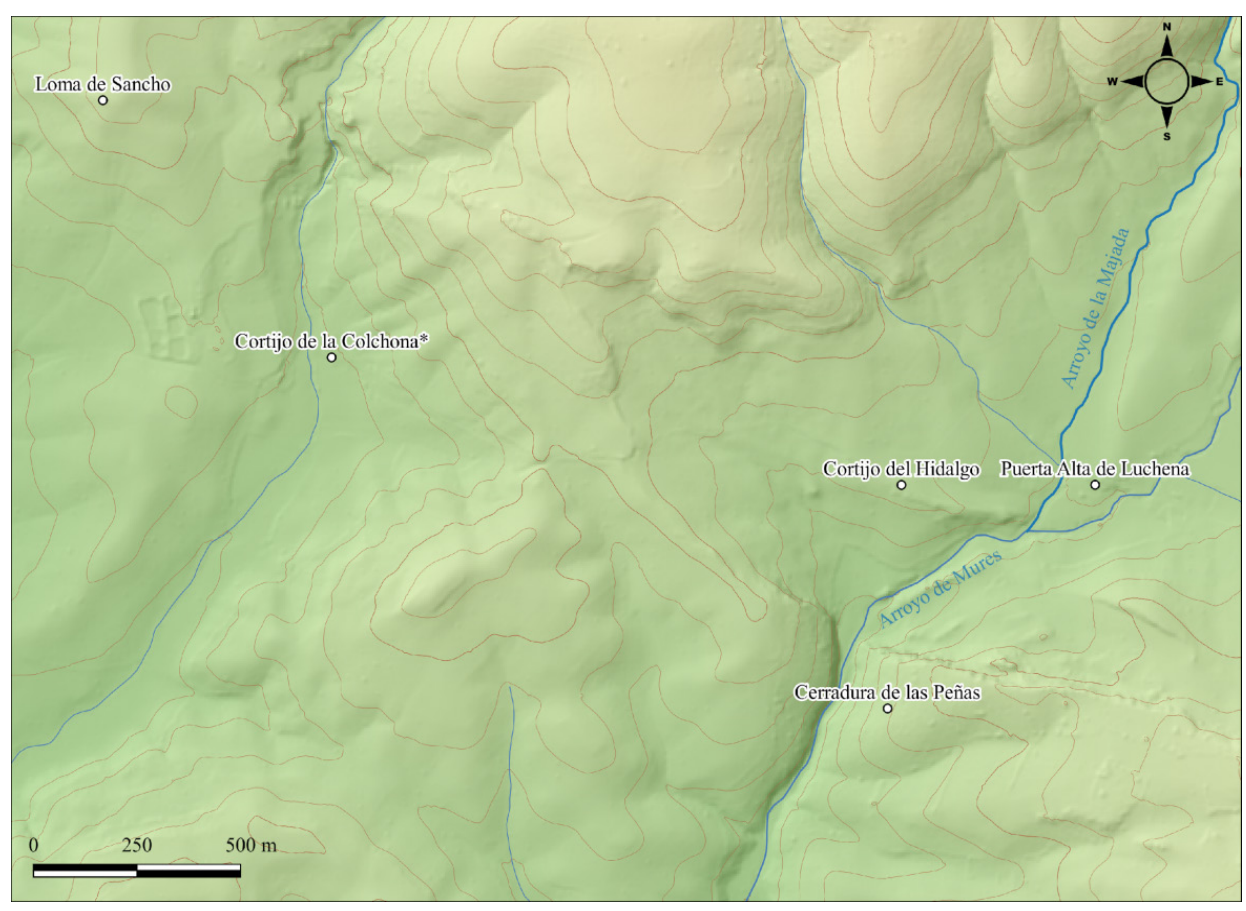

Figura 3. Georreferenciación de la jurisdicción adquirida por Antonio Álvarez de Bohorques sobre el término de Alcalá la Real..$^{39}$

La hipótesis sobre sus intenciones de construir un gran estado señorial entre Jaén y Granada, se refuerza si atendemos a las ventas de 1629, cuando compró en bloque una serie de villas y lugares conectadas entre las capitales de ambos reinos. Así adquirió de la Real Hacienda de Felipe Iv en conjunto los lugares de Los Villares (Jaén) y Albolote (Granada), así como las villas de Valdepeñas, Cazalilla, (eximidas de la ciudad de Jaén en tiempos de Felipe II) y Guadaortuna (segregada también de Granada). ${ }^{40}$ Una transacción de elevadísimo importe, por la compra de tantos señoríos a la vez, algo infrecuente entre estos compradores de vasallos, reservado solamente a altos burócratas de la administración de los Austrias como lo fueron Lerma, Olivares ${ }^{41} \mathrm{o}$, un siglo antes, Francisco de los Cobos. Precisamente este último fue, junto con nuestro Álvarez de Bohorques, el único personaje que compró un lote tan numeroso de villas y aldeas en el reino de Jaén, como se ha estudiado recientemente (ILLANA, 2021). El intento del poderoso marqués de los Trujillos de adquirir este elevado número de jurisdicciones pone en evidencia su

39 Elaboración: Juan Manuel Castillo Martínez, becario de iniciación a la investigación en el Área de Historia Moderna de la Universidad de Jaén.

40 AGS, DGT, Inv. 24, leg. 291, fol. 2.

41 «Adquisiciones en masa solo hicieron Lerma, el Conde Duque y, en menor grado, don Luis de Haro; promovidos a un supremo rango por el favor real, quisieron tener amplios señoríos» (Domínguez, 1964: 174). Las célebres ventas de las «villas de Behetría» al duque de Lerma por Felipe III, modélicas para el siguiente reinado, se estudian en el trabajo de MARcos (2003). 
deseo de equipararse socialmente a aquellos.

De este modo asentó con Bartolomé Spínola, fiador de Su Majestad en tiempos de Felipe IV, la compra de estas villas y lugares al mismo precio que veíamos más arriba: 16.000 maravedís por vecino, o 6.400 ducados por legua legal de término, a convenir con la Real Hacienda qué era más beneficioso para la Corona. Se estimó un total de 680 vecinos entre todas las villas, lo que ascendió a 11.600.000 maravedís que don Antonio se comprometió a pagar en una serie de plazos establecidos en el asiento de venta. Todos estos presupuestos económicos de partida eran muy subjetivos, condicionados al conteo de la vecindad exacta, lo que con frecuencia elevaba el precio al calcularse con exactitud el número de vecinos y la extensión del término.

TABLA 1

Venta de jurisdicciones a Antonio Álvarez de Bohorques, I marqués de los Trujillos

\begin{tabular}{|c|c|c|c|c|c|c|}
\hline Año & Reino & Población & Categoría & Vecindad & $\begin{array}{c}\text { Precio } \\
\text { (maravedís) }\end{array}$ & Prospera \\
\hline 1613 & Granada & Bohorques & Cortijo & - & \multirow[t]{3}{*}{$4.800 .000^{42}$} & Sí \\
\hline 1613 & Granada & Caparacena & Cortijo & - & & Sí \\
\hline 1613 & Granada & Cortes & Cortijo & - & & Sí \\
\hline 1615 & Granada & Trujillos & Cortijo & - & - & Sí \\
\hline 1627 & Jaén & Castillo de Locubín & Lugar & 400 & 6.400 .000 & No \\
\hline 1629 & Granada & Albolote & Aldea & 200 & 3.200 .000 & Sí \\
\hline 1629 & Jaén & Cazalilla & Villa & 160 & 2.560 .000 & No \\
\hline 1629 & Granada & Guadaortuna & Villa & 150 & 2.400 .000 & $\overline{\text { Sí }}$ \\
\hline 1629 & Jaén & Valdepeñas & Villa & 150 & 2.400 .000 & $\overline{\text { Sí }}$ \\
\hline 1629 & Jaén & Los Villares & Lugar & 30 & $1.040 .000^{43}$ & Sí \\
\hline
\end{tabular}

Fuente: Elaboración propia.

Expuestas todas estas ventas, subyace una cuestión: ¿qué fue lo que realmente llevó al I marqués de los Trujillos a hipotecarse con tales cantidades de dinero para comprar señoríos? ¿Hay alguna motivación más allá que su sed de ennoblecimiento y ascenso social? La distribución geográfica de sus señoríos por el territorio despeja toda duda. Si observamos la ubicación de las villas, aldeas y heredamientos del marqués sobre el mapa de los reinos de Jaén y Granada, atendemos a una suerte de eje que conecta las dos capitales (Figura 4). Un itinerario que, no por casualidad, coincide con el camino que se había abierto entre Jaén y Granada en tiempos de Carlos v a través de la Sierra Sur giennense por el emplazamiento de Los Entredichos, con la fundación de una serie de poblaciones

42 Dado que estos tres despoblados se vendieron en conjunto, no conocemos el precio de cada uno de ellos, por lo que nos limitamos al dinero que pagó por el común.

43 Por su baja vecindad, el lugar de Los Villares fue el único que se pagó a razón de su extensión, estimado en una media legua de término. 
como Valdepeñas Campillo de Arenas o Los Villares (Delgado et al., 2013, 2011 y 2009), transitando por la ciudad de Alcalá la Real. En efecto, la compra de estos señoríos supuso un ambicioso proyecto que confería a Álvarez de Bohorques tanto la presencia de su Casa a lo largo de todo este itinerario, como el control sobre el mismo a través de su estado nobiliario.

Buen ejemplo este de que, en muchas ocasiones, las compras de señoríos no solamente trajeron a los señores ventajas sociales -ennoblecimiento- y económicas -a través de las rentas de las poblaciones-, sino que, también pudieron ocultar intereses previos.

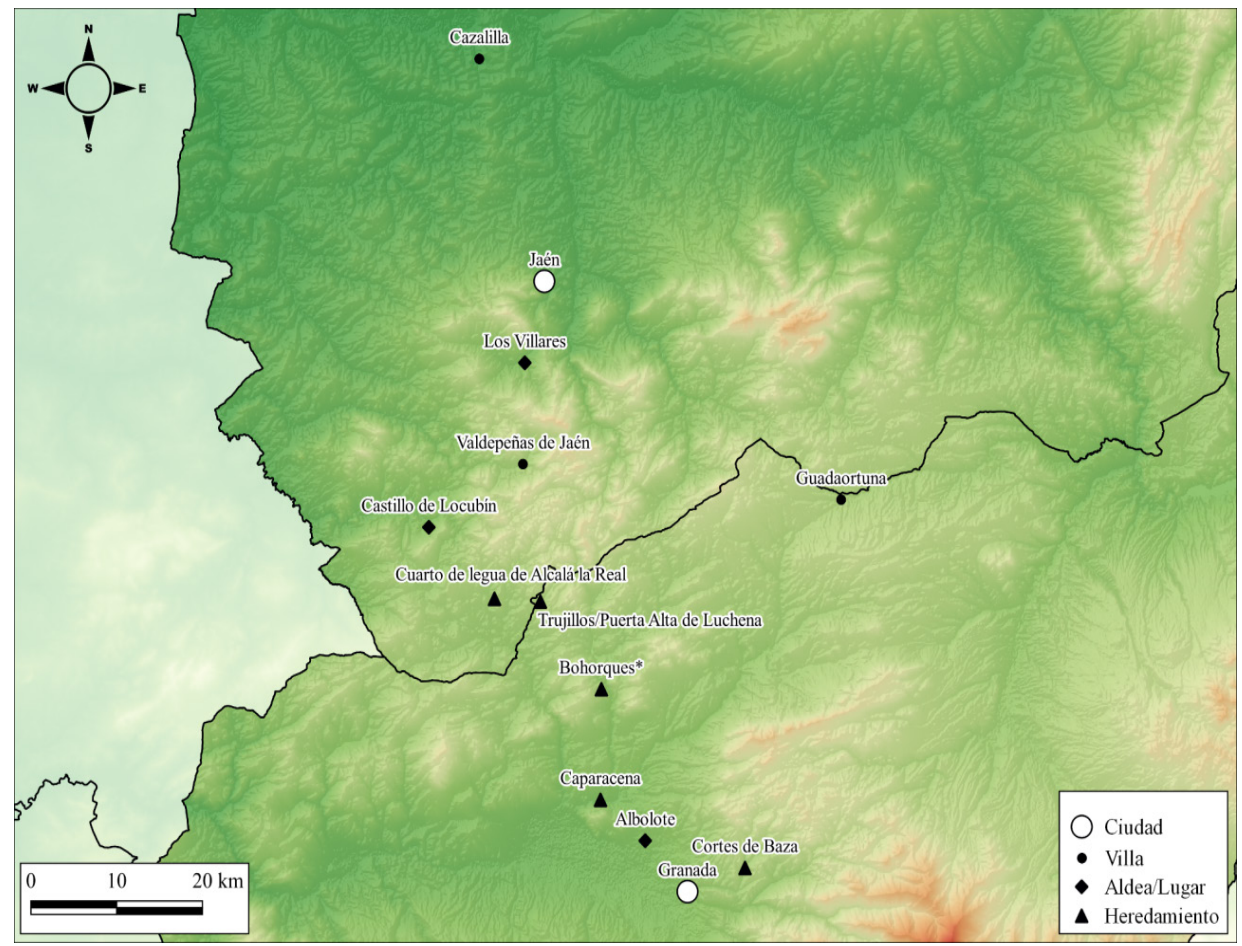

Figura 4. Señorío de Antonio Álvarez de Bohorques, I marqués de los Trujillos, entre los reinos de Jaén y Granada. ${ }^{44}$

\subsection{El ocaso del señorío: la resistencia villana y la ruina de la Casa}

Como punto final a este trabajo, resta atender cómo se frustró el ambicioso proyecto del I marqués de los Trujillos por titularse señor de vasallos. En primer lugar, y sobre todo en las villas que ya gozaban de concejo propio, la vecindad

44 Elaboración: Juan Manuel Castillo Martínez, becario de iniciación a la investigación en el Área de Historia Moderna de la Universidad de Jaén. 
resistió al régimen señorial. Como era frecuente en las ventas de señoríos, el asiento de venta establecía la posibilidad de los vecinos de pujar por su jurisdicción y eximirse de caer en el régimen señorial: «el derecho de tanteo que su magestad reseruo a los dhos lugares, para que para poder ussar del an de tener obligazion de pagar y desembolsar con efecto en moneda de plata doble los lugares cuyo presçio ubiera pagado el sr marqués». ${ }^{45}$ A ello recurrieron dos de las villas: Cazalilla, en el reino de Jaén, antigua aldea de la capital que se había exentado de esta en 1566, alegó poseer su privilegio de villazgo y sus vecinos pujaron subir el precio un dos por ciento de lo pagado por Trujillos, con lo que sirvieron a Felipe IV con 2.636.605 maravedís. ${ }^{46}$ Esto mismo sabemos de Guadaortuna, exentada de la ciudad de Granada igualmente en tiempos de Felipe II, y que, en 1632, solo tres años después de la compra por Álvarez de Bohorques, estaba tramitando con la Real Hacienda su tanteo, como se informaba al marqués: "por auerse tanteado dho lugar de cazalilla (...) y tratarse de tantear el de guadaortuna solamente aueis de pagar si llegase a efecto de tantearse el dho lugar de guadaortuna seis quentos y ochoçientos mill mrs por los otros tres lugares». ${ }^{47}$

De entrada, dos de las cinco poblaciones compradas por don Antonio en 1629 se resistieron a caer en el régimen señorial. Pero el auténtico ocaso del señorío llegó a la muerte de nuestro personaje, cuando su hijo, don Alonso Álvarez de Bohorques, II marqués de los Trujillos, arruinado por las colosales inversiones de su padre, hubo de solicitar a la Corona la remisión de las deudas, así como la cancelación de algunas de las ventas de señoríos. ${ }^{48}$ En 1640, recientemente fallecido su padre, don Alonso solicitaba a Felipe IV la remisión de las alcabalas del lugar de Albolote, así como lo que restaba por pagar del cuarto de legua de Alcalá la Real, en atención a los servicios prestados a la Corona. Una suma que ascendía a 550.817 maravedís, que el rey aceptó a redimir: «teniendo por bien de hazer mrd como por la presente se la hago al dho Don alonso de vorquez marques de los truxillos de remittir y perdonar como por la presente, le remito y perdonó los otros 550.817 mrs de plata que a mí se restan». ${ }^{49}$ Así mismo, rogaba que las villas y lugares de Valdepeñas, Guadaortuna, Los Villares y Albolote fueran reintegradas en el patrimonio real o vendidas a otra Casa, por no poder ejecutar el pago cuyo abono no había completado su padre:

y auiendo fallecido en mi seruicio [Antonio Álvarez de Bohorques] con su falta se halló que montaban mucho mas, que al dho presente allandose el marques su hijo sin medios con que satisfacer, pidio me sirviese destos lugares cediendo en favor de mi real hacienda los 10.000.000 que estauan satisfechos por quenta desta ventas se le concedio su ofrecimiento y se hizo merçed dellos al conde de Santa coloma. ${ }^{50}$

Así es como el señorío creado por el I marqués de los Trujillos se desintegró, y las villas compradas por don Antonio se repartieron entre otras casas nobiliarias que aprovecharon la mala coyuntura de la familia para adquirirlas. Las villas y lugares de Valdepeñas, Guadaortuna, Los Villares, y Albolote fueron de nuevo

45 AGS, DGT, Inv. 24, leg. 291, exp. 2, fol. 5 r-v.

46 DGT, Inv. 24, leg. 291, exp. 23.

47 AGS, DGT, Inv. 24, leg. 291, exp. 2.

48 AGS, DGT, Inv. 24, leg. 291, exp. 4.

49 AGS, DGT, Inv. 24, leg. 291, exp. 4, fol. 2r.

50 AGS, DGT, Inv. 24, leg. 291, exp. 4, fol. $1 \mathrm{v}$. 
vendidos a la Casa del Conde de Santa Coloma, Dalmau de Queralt. ${ }^{51}$ En el patrimonio de la Casa de los Trujillos solamente quedaron aquellas villas, aldeas y cortijos de la vertiente granadina comprados en 1613, ligados a su apellido y título: Trujillos o Bohorques, entre otros, ${ }^{52}$ cuya pérdida hubiera supuesto el revés definitivo a su posición social adquirida. ${ }^{53}$

\section{CONCLUSIONES}

En la figura de don Antonio Álvarez de Bohorques, I marqués de los Trujillos, encontramos al prototípico aristócrata de la España moderna que aprovechará las dos vías principales para medrar socialmente en Antiguo Régimen: el servicio a la Corona, así como el ennoblecimiento, ambas ligadas entre sí. Más allá de los oficios desempeñados por el personaje en la administración de los Austrias, en este estudio hemos atendido a la segunda de estas vías de ascenso social: cómo don Antonio trató de construir un estado nobiliario sobre una serie de territorios de la alta Andalucía.

Para ello se valió de las ventas de señoríos promovidas por los Austrias. Hemos planteado estas ventas como un mecanismo por el que la Corona puso en marcha la enajenación y venta de patrimonio regio -oficios, hidalguías, jurisdicciones, etc.- con el fin de engrosar las arcas reales, a la vez que satisfacer los deseos de ennoblecimiento de tantos poderosos en Castilla. Fue así como Álvarez de Bohorques, que ya había protagonizado un brillante ascenso político merced a su habilidad al frente de las veinticuatrías de Granada y Córdoba, así como en la Real Hacienda, trató de ennoblecerse equiparando su posición social al estatus político. Para ello se hipotecó con la compra de una serie de señoríos a caballo entre los reinos de Granada y Jaén, a cuyas ventas hemos atendido en este trabajo. Unas ventas que, por su dimensión, bien pudieran ponerse en paralelo a las efectuadas por otras personalidades de la España de los Austrias, como puedan serlo Francisco de los Cobos, el duque de Lerma o el conde-duque de Olivares.

La construcción de este extenso señorío en la alta Andalucía enmascara

51 AGS, DGT, Inv. 24, leg. 297, exp. 1. Sobre este II conde de Santa Coloma, García (2011). De Valdepeñas de Jaén sabemos que, tras largos años de pleito por su jurisdicción no resuelto hasta 1650, logró reintegrarse en el realengo, merced al privilegio de villazgo que tenían de 1558 (ILLANA, 2020: 988). Tomando como referencia el Catastro de Ensenada sabemos que, una centuria después, continuaban bajo la jurisdicción de este condado de Santa Coloma algunas de estas poblaciones, como Albolote, de la que se diría que «es de señorio y perteneze al exmo señor conde de santa coloma de queralt» (AGS, Catastro de Ensenada, Respuestas Generales [CE, RG], Leg. 276, fol. 363); otras, como Los Villares, a través de diversos avatares, había pasado a otra Casa: «y aunque hay título de Vizconde de los Villares, solo tiene la propiedad de lo mostrenco de este término, con la sola regalia de aprobar la Justicia, que anualmente se le presenta» (ESPINALT, 1786: 230).

52 De Trujillos, se dice en el Catastro de Ensenada que todavía en el siglo xvIII «es de señorio y su jurisdizion perteneze al Señor don Alonso Alvarez de Boorques Marques de los Truxillos a quien todos los mas lauradores en Cortixos propios de dicho señor pagan sus rentas» (AGS, CE, leg. 302, fol. 59); de Caparacena, se dice que «esta Villa le llaman de caparazena, su jurisdizion del Señor Marques de los Truxillos» (AGS, CE, RG, Leg. 282, fol. 144).

53 Tanto así que, unos años después, lo vemos pleiteando por defender a capa y espada sus privilegios señoriales sobre estas poblaciones granadinas. Lo vemos en un largo pleito, en relación con los lugares granadinos incorporados por su padre al mayorazgo, en Archivo de la Real Chancillería de Granada, leg. 5313, exp. 7. 
una intencionalidad compleja, detrás de su interés por medrar socialmente o por adueñarse de las rentas de aquellos lugares: en la ubicación geográfica de los señoríos de Álvarez de Bohorques, conectando entre ellos las ciudades de Granada y Jaén, se atisba un interés por el control y la presencia de su Casa sobre un itinerario que conectaba ambas urbes a través de la Sierra Sur giennense. Resta profundizar sobre ello, en aras de entrever cuáles eran los intereses de control social sobre este camino que, a buen seguro, iban más allá de imponer la presencia de su marquesado sobre el territorio. En cualquier caso, su prematura muerte y la ruina de su heredero, II marqués de los Trujillos, incapaz de hacer frente a los muchos pagos a que su padre le había hipotecado, frustraron tan ambiciosos planes.

Para construir este discurso nos hemos servido de una serie de fuentes que van desde las primarias -documentación escrita, cartografía histórica-, secundarias -con una bibliografía antigua y actual- hasta las novedosas herramientas proporcionadas por las humanidades digitales y los Sistemas de Información Geográfica (SIG), que nos han permitido mostrar gráficamente la distribución espacial de los territorios del i marqués de los Trujillos. Merced a ello, hemos podido dar solidez la hipótesis planteada: el interés de nuestro personaje por construir un auténtico estado nobiliario giennense-granadino con control sobre el territorio y sobre sus vasallos, como tantos otros compradores de señoríos en Castilla, que no deja de llevar aparejada una intencionalidad política, social y económica. Sirva para arrojar luz sobre la faceta de un personaje poderoso, a la par que desconocido, de la Andalucía de Felipe IV.

\section{REFERENCIAS}

Andújar Castillo, F. (2016): «Cuando el rey delegaba la gracia: las comisiones de ventas de oficios en la Castilla del siglo xVII», en P. POnce Leiva y F. Andújar Castillo (eds.), Mérito, venalidad y corrupción en España y América. Siglos XVII y XVIII, Albatros, Valencia: 135-156.

Andújar Castillo, F.; Felices De la Fuente, M.M. (2011): El poder del dinero. Ventas de cargos y honores en el Antiguo Régimen, Biblioteca Nueva, Madrid.

Aponte Marín, A. (2011): "Antes y después de la exención. Jaén, sus lugares y las villas», en J. M. Delgado Barrado y M. A. López Arandia (coords.), Ciudades de Jaén en la Historia (siglos XV-XXI). Mitos y realidades, Secretariado de Publicaciones de la Universidad de Sevilla, Sevilla: 283-298.

Argote de Molina, G. (1866): Nobleza de Andalucía. Edición de Manuel Muñoz Garnica, Jaén.

Carabías Torres, A. M. (1983): El Colegio Mayor de Cuenca en el siglo Xvi: estudio institucional, Ediciones Universidad de Salamanca, Salamanca.

CAsey, J. (2008): Familia, poder y comunidad en la España moderna. Los ciudadanos de Granada (1570-1739), Publicaciones de la Universidad de Valencia y Publicaciones de la Universidad de Granada, Valencia.

CAsey, J. (1989): «El concepte de família en l'Antic Règim», en VV. AA., L'espai viscut. Colloqui Internacional d'Historia Local, Diputación de Valencia, Valencia.

Castillejo Cuenca, M. I. (1995), «Los caballeros veinticuatros de Córdoba a finales 
del siglo XVII. Riqueza, función y linaje de una élite de poder», Chronica Nova, 22: 29-71.

Castillo Armenteros, J. C.; Delgado Barrado, J. M. (2004): Torredelcampo. De lugar del concejo de Jaén a villa independiente Ayuntamiento de Torredelcampo, Torredelcampo.

Covarrubias Orozco, S. (1611). Tesoro de la Lengua Castellana o Española, Imprenta de Luis Sánchez, Madrid.

Delgado Barrado, J. M., Fernández García, J. y López Arandia, M. A. (2013): Las nuevas poblaciones del Renacimiento. Los Villares (1508-1605), Universidad de Jaén y Diputación Provincial de Jaén, Jaén.

Delgado Barrado, J. M., Fernández García, J. y López Arandia, M. A. (2011): Fundación, repoblación y Buen Gobierno en Castilla. Campillo de Arenas, 15081543, Diputación de Jaén y Universidad de Jaén, Jaén.

Delgado Barrado, J.M.; Fernández García, J.; López Arandia, M.A. (2009): Fundación e independencia. Fuentes documentales para la historia de Valdepeñas de Jaén (1508-1558), Diputación de Jaén y Universidad de Jaén, Jaén.

Domínguez Ortiz, A. (1985): «La venta de cargos y oficios en Castilla y sus consecuencias económicas y sociales», en Instituciones y sociedad en la España de los Austrias, Ariel, Barcelona: 137-184.

Domínguez Ortiz, A. (1964): «Ventas y exenciones de lugares durante el reinado de Felipe IV», Anuario de historia del derecho español, 34: 163-208.

Domínguez Ortiz, A.; Alvar EzQuerra, A. (2005): La sociedad española en la Edad Moderna, Itsmo, Madrid.

Elliot, J. H. (2004): El Conde-duque de Olivares: el político en una época de decadencia, Crítica, Barcelona.

Espinalt, B. (1786): Atlante Español: Descripción general geográfica, cronológica e histórica de España por Reynos, Imprenta de Hilario Santos Alonso, Madrid.

EzQuerra Revilla, I. J. (2000): El Consejo Real de Castilla bajo Felipe II: grupos de poder y luchas faccionales, Sociedad Estatal para la Conmemoración de los Centenarios de Felipe II y Carlos V, Madrid.

FERnÁndez MARTín, J. (2019): «Venalidad de oficios y honores en el concejo granadino durante el primer tercio del siglo XVII: poder, conflicto y ascenso social», Chronica Nova, 45: 259-295.

FORTEA Pérez, J. I. (2008): «Entre la toga y la espada: los corregidores andaluces en el siglo XVII», en VVAA, Homenaje a don Antonio Domínguez Ortiz, Granada, Universidad de Granada: 305-346.

FORTEA Pérez, J. I. (1993): «Reino y Cortes: el servicio de millones y la reestructuración del espacio fiscal en la Corona de Castilla (1601-1621)», en J.I. ForTEA Pérez y C.M. Cremades Griñán (eds.), Política y Hacienda en el Antiguo Régimen. II Reunión Científica de la Asociación Española de Historia Moderna. Vol. 1, Secretaría de Publicaciones de la Universidad de Murcia, Murcia: 53-82.

GAllego LÁzARO, E. (2016): «La reorganización de la Comunidad de Ciudad y Tierra de Segovia durante la Edad Moderna. Las ventas de lugares en el siglo XVII», Studia Histórica. Serie IV Historia Moderna, 38: 387-424.

Gan Giménez, P. (1998): La Real Chancillería de Granada (1505-1834), Centro de estudios históricos de Granada y su reino, Granada.

GARCíA CÁRCEL, R. (2011): «Queralt y Codina, Dalmau de. Conde de Santa Coloma (II)», en Diccionario Biográfico Español, Real Academia de la Historia, Madrid.

García Hernán, D. (1992): La nobleza en la España moderna, Itsmo, Madrid. 
Gelabert GonzÁlez, J.E. (2008): "Ciudades, villas y aldeas», en J. I. Fortea Pérez y J. E. Gelabert González, Ciudades en Conflicto (siglos XVI-XVIII), Marcial Pons Historia y Junta de Castilla y León, Santander: 81-106.

IlLANA López, F.J. (2021): «La señorialización de un territorio en el corazón del reino de Jaén: las villas de Francisco de los Cobos (1537-1548)», en C. Borreguero Beltrán, O.R. Melgosa Oter, A. Pereda lópez y A. Retorillo Atienza, A la sombra de las catedrales: cultura, poder y guerra en la Edad Moderna, Servicio de Publicaciones de la Universidad de Burgos, Burgos: 1941-1957.

IllanA López, F.J. (2020): «De lugares a villas. Las exenciones jurisdiccionales en el reino de Jaén durante la Edad Moderna. El caso de Valdepeñas de Jaén», en J.J. Iglesias Rodríguez e I.M. Melero Muñoz, Hacer Historia Moderna. Líneas actuales y futuras de investigación, Editorial Universidad de Sevilla, Sevilla: 977-989.

ILlANA López, F.J. (2019): «Fernando de Torres y Portugal, conde de Villardompardo, y su intento frustrado de compra del lugar de Jamilena de la encomienda calatrava de Martos (1561)», Historia y Genealogía, 9: 114-127.

JimÉnez Estrella, A. (2012): «Poder, dinero y ventas de oficios y honores en la España del Antiguo Régimen: un estado de la cuestión», Cuadernos de Historia Moderna, 37: 259-272.

López Álvarez, A. (2011): «Núñez de Bohórquez, Alonso», en Diccionario Biográfico Español, Real Academia de la Historia, Madrid.

López Cordero, J. A. (1997): La venta de lugares del término de Jaén en el siglo XVI: el caso de Pegalajar, UNED, Jaén.

Lorenzo Pinar, F. J. e Izquierdo Misiego, J. I. (2001), «Ventas jurisdiccionales abulenses en tiempos de Felipe III y Felipe IV», Studia Histórica. Serie IV Historia Moderna, 23: 199-231.

Marañón, G. (1956): El Conde Duque de Olivares, Espasa Calpe, Madrid.

Marcos Martín, A. (2019): «Resistir la enajenación... Pero pagando. La compra por Talavera de la Reina de los lugares de su tierra y jurisdicción (1587-1594) », Quaderni di L'idomeneo, 42: 435-455.

Marcos Martín, A. (2014): “"Porque siendo villa y teniendo jurisdicción por sí vendrá a aumentarse y ser pueblo muy grande...". Exenciones de lugares y concesiones de villazgos en Castilla en el siglo XVI», en M. CAMPILLO MÉndeZ y J. J. RuIz IBÁÑEZ, Felipe II y Almazarrón: la construcción local de un imperio global. Sostener, gobernar y pensar en la frontera, Universidad de Murcia, Murcia: 2849.

Marcos Martín, A. (2009): «Enajenaciones de patrimonio regio, poder real y condiciones de millones durante el reinado de Felipe III (1598-1621)», en E. Soria Mesa, J.J. Bravo Caro y J.M. Delgado Barrado, Las élites en la época moderna: La Monarquía Hispánica. Vol. I, Servicio de Publicaciones de la Universidad de Córdoba, Córdoba: 113-132.

Marcos Martín, A. (2007): "Las ventas de oficios en Castilla en tiempos de suspensión de las ventas (1600-1621)», Chronica Nova, 33: 13-35.

Marcos Martín, A. (2003): “"Desde la hoja del monte hasta la piedra del río...". La venta al Duque de Lerma de las once villas de Behetría de Castilla la Vieja», Publicaciones de la Institución Tello Téllez de Meneses, 74: 49-113.

Martínez Millán, J.; De Carlos Morales, C.J. (1998), Felipe II (1527-1598). La configuración de la Monarquía Hispana, Junta de Castilla y León, Salamanca.

MARTínez SHAw, C. (2020): Breve historia de la España moderna (1474-1808), Alianza, 
Madrid.

Nader, H. (1990): Liberty in Absolutist Spain. The Habsburg Sale of Towns, 1516-1700, Johns Hopkins University Press, Baltimore and London.

Navarro Brotons, V. (2011): "Carduchi, Luis», en Diccionario Biográfico Español, Real Academia de la Historia, Madrid.

Riвot, L. (2018): «El IX conde de Santisteban (1645-1716). Poder y ascenso de una Casa noble a través del servicio a la Corona», Espacio, tiempo y forma. Serie IV Historia Moderna, 31: 23-42.

Requena Parrilla, M.C. (2007): «El IX conde de Santisteban (1645-1716). Poder y ascenso de una Casa noble a través del servicio a la Corona», en F. ANDÚJAR CAstillo y J.P. DíAz López (coords.), Los señoríos en la Andalucía moderna. El marquesado de los Vélez, Instituto de Estudios Almerienses, Almería: 705-718.

SÁnchez-Montes GonzÁlez, F. (2021): El viaje de Felipe IV a Andalucía en 1624. Tiempo de recursos y consolidación de lealtades, Editorial Universidad de Granada, Granada.

SANZ AyÁn, C. (2015): Un banquero en el Siglo de Oro. Octavio Centurión, el financiero de los Austrias, La Esfera de Libros, Madrid.

SAnZ Ayán, C. (2013): Los banqueros y la crisis de la Monarquía Hispánica de 1640, Marcial Pons Historia, Madrid.

Soria MesA, E. (2011): «Álvarez de Bohorques, Antonio. Marqués de los Trujillos», en Diccionario Biográfico Español, Real Academia de la Historia, Madrid.

SORIA MesA, E. (2007): La nobleza en la España moderna. Cambio y continuidad, Marcial Pons Historia, Madrid.

SORIA MesA, E. (2005): «Burocracia y conversos. La Real Chancillería de Granada en los siglos XVI y XVII», en F.J. ARANDA PéreZ (coord.), Letrados, juristas y burócratas en la España moderna, Universidad de Castilla-La Mancha, Cuenca.

SORIA MesA, E. (2001): «La ruptura del orden jurisdiccional en la Castilla de los Austrias», en F.J. GuILlamón Fernández y J.J. RuIz IBÁÑEZ, Lo conflictivo y lo consensual en Castilla: sociedad y poder político, 1521-1715. Homenaje a Francisco Tomás y Valiente, Universidad de Murcia, Murcia: 439-460.

SORIA MESA, E. (2000): El cambio inmóvil. Transformaciones y permanencia en una élite de poder (Córdoba, ss. XVI-XIX), Díaz del Moral, Córdoba.

Soria Mesa, E. (1995): La venta de señoríos en el reino de Granada bajo los Austrias, Universidad de Granada, Granada.

TomÁs y VAlIENTE, F. (1982): Gobierno e instituciones en la España del Antiguo Régimen, Alianza, Madrid.

TomÁs y VAliENTE, F. (1980): «Venta de oficios públicos en Castilla durante los siglos XVII y XVIII», en Gobierno e instituciones en la España del Antiguo Régimen, Alianza, Madrid: 151-177.

Vela Santamaría, F. J. (2012): «Ciudades, villas y lugares: organización y jerarquía en la Corona de Castilla del Siglo de Oro», en I Congresso Histórico Internacional As Cidades na História: População. Volume III - Cidade Moderna II, Câmara Municipal de Guimarães, Guimarães: 194-220. 
Vegueta. Anuario de la Facultad de Geografía e Historia

$21(2), 2021,59-78$

eISSN: 2341-1112

https://doi.org/10.51349/veg.2021.2.03

\title{
Cartografía digital disidente: El caso de Santiago de Chile durante el estallido social de 2019
}

\author{
Dissident Digital Cartography: \\ The Case of Santiago de Chile during the Social Outburst of 2019
}

\author{
Víctor Jiménez Barrado \\ Pontificia Universidad Católica de Chile \\ Instituto de Geografía \\ https://orcid.org/0000-0001-7064-7465 \\ victor.jimenez@uc.cl
}

Recibido: 02/10/2020; Revisado: 14/12/2020; Aceptado: 11/03/2021

\section{Resumen}

El 18 de octubre de 2019 estalló en Santiago de Chile una de las mayores crisis sociales de la historia reciente del país. En un contexto de represión estatal y de desinformación surgieron múltiples iniciativas dedicadas a reunir colaborativamente información espacial, mayoritariamente apoyadas en las nuevas tecnologías. El objetivo de este trabajo es descubrir su significado y utilidad. Para ello se han identificado y analizado estos registros cartográficos mediante la observación participante no impostada en redes sociales. Los resultados muestran la cartografía digital como una estrategia de cuidado mutuo, un entorno de lucha y un hito fundamental para su continuidad.

Palabras clave: Cartografía colaborativa, Chile, ciudad, lucha social, modelo neoliberal.

\begin{abstract}
On the 18th October 2019, one of the biggest social crises in Chile's recent history broke out in its capital Santiago. Against a backdrop of state repression and disinformation, there emerged multiple collaborative initiatives, largely based on new technologies, to collate spatial information. The objective of this article is to discover this collation's significance and usefulness. As such, these cartographic records have been identified and analysed by way of genuine participatory observation within social networks. The results present digital cartography as a strategy of mutual care, an arena for struggle and a fundamental milestone in its continuity.
\end{abstract}

Keywords: Collaborative Mapping, Chile, The City, Social Struggle, Neo-Liberal Model. 


\section{INTRODUCCIÓN}

\subsection{Indicadores del éxito neoliberal chileno: la cara macroeconómica de La Moneda}

Chile ha sido reconocido internacionalmente como uno de los laboratorios iniciales y, por ende, cancha inaugural del modelo neoliberal (HARVEY, 2007; Stiglitz, 2012). Las recetas de la teoría económica, condensadas en el «ladrillo» de los Chicago Boys (De CASTRO y MéndeZ, 1992), se implantaron forzosamente desde 1973, por un gobierno dictatorial y militar (instrumento sine qua non) con apoyo exterior (HARVEY, 2012; JANOSCHKA e HIDALGO, 2014), hasta 1990. Entre tanto, estos ideales se consolidaron mediante la Constitución política del Estado de 1980, que fue transferida sin solución de continuidad al sistema democrático, quedando, hasta la fecha, vigente con algunas modificaciones.

La Carta Magna es, por lo tanto, pilar fundamental para la reproducción y supervivencia de un sistema que, si bien es hegemónico en el mundo, muestra en Chile trazos singulares de máxima radicalidad.

De ella se descuelga todo un corpus legal que otorga a gran parte de los bienes nacionales de uso público un estatus de "transabilidad» en el libre mercado. Así ocurre con el agua, en cuyo código regulador se establece la propiedad privada del derecho de su aprovechamiento, lo cual no sólo choca con la cosmovisión indígena (Di Giminiani y GonZÁLeZ, 2018), sino además con resoluciones específicas de la ONU que reconocen el derecho humano al agua. ${ }^{1}$ Algo similar ocurre en el acceso a la sanidad, degradada de servicio público a bien de consumo (SAKELlariou y RotAROU, 2017), o con el sistema educativo, que ha fomentado a partes iguales la metamorfosis social temprana en deudor crediticio y las protestas estudiantiles contra el modelo (CinI y GUZMÁN-CONCHA, 2017; INZUNZA ET AL., 2019).

Con estos mimbres, el país andino ha conseguido unos óptimos datos macroeconómicos, particularmente importantes dentro de su contexto regional. Sus logros se condensan en una tasa de desempleo que no sube del $8,5 \%$ en los últimos 9 años (datos de la Encuesta Nacional de Empleo) y su posición cuadragésimo-segunda a nivel mundial como país con mayor Producto Interior Bruto según los datos del Fondo Monetario Internacional, ocupando el mismo lugar en términos del Índice de Desarrollo Humano y el $53^{\circ}$ en cuanto a PIB per cápita. Ejemplo de su fortaleza macroeconómica es que aproximadamente una década atrás, la coincidencia de tres factores (extrema apertura económica debido al modelo neoliberal, amplias reservas de mineral al norte del país -Chile es el país con mayor producción y reservas de cobre a nivel mundial- y el desarrollo productivo-tecnológico de China, principal socio exportador e importador) le permitieron superar rápidamente, a través de su sistema extractivista-exportador, la crisis global iniciada en 2007 (HARVEY, 2019).

Junto con esto, la deuda pública económica es muy baja con relación al PIB $(25,56 \%)$, pero se dispara si atendemos a la deuda de lo público y sus instituciones con la sociedad, entendiendo esto como la obligación del Estado chileno de proveer

1 La Resolución 64/292 de la Asamblea General de las Naciones Unidas reconoció el 28 de julio de 2010 el derecho humano al agua y al saneamiento, haciendo hincapié en la importancia de disponer de agua potable y saneamiento en condiciones equitativas como componente esencial del disfrute de todos los derechos humanos. 
a sus ciudadanos de igualdad de oportunidades (Artículo 1 de la Constitución política de la República de Chile).

El presente artículo se organiza desde la presentación inicial de las causas principales que han promovido el estallido social y por ende, la cartografía estudiada. Se exponen las contradicciones de un modelo que, como ya se ha explicado, es exitoso en el nivel macroeconómico pero que a medida que se aproxima a la escala humana se torna deficitario, teniendo expresiones espaciales claras. Desde ese punto se parte hacia una explicación metodológica para, posteriormente, presentar y discutir los resultados (cartografías, características y protagonistas) y finalmente alcanzar unas conclusiones sobre el significado de esta producción de cartografía digital disidente en Chile.

\subsection{La polarización social y la precariedad: el revés desigual de la moneda.}

El citado triunfo macroeconómico chileno ha obtenido notables resultados, entre ellos la rápida reducción de la pobreza. Según la encuesta CASEN, el porcentaje de personas en situación de pobreza y pobreza extrema en Chile ha pasado de un $16,5 \%$ y $12,6 \%$ respectivamente en el año 2006 a un $6,3 \%$ y un $2,3 \%$ en 2017. Estas cifras reflejan un veloz aumento de la clase media, que se ha convertido en la base social del país. Un grupo socioeconómico que, además de representar una fuerza de trabajo barata, es el grueso de la demanda nacional de bienes y servicios.

El despojo comienza en la institucionalidad. El Estado chileno es un Estado subsidiario, apoyado en la máxima teórica de que éste sólo debe actuar en ausencia de la iniciativa privada, pero que en la práctica obliga a que sea la población la que subsidie sus responsabilidades mínimas (BORGIAS, 2018). Esto se muestra en la labor fiscalizadora de las asociaciones y las ONGs contra los abusos, pero también en el rol que la solidaridad popular ejerce como muleta del neoliberalismo, haciéndose cargo de primeras necesidades en materia de educación o sanidad, siendo la Teletón ${ }^{2}$ un ejemplo paradigmático de la integración de la beneficencia en el sistema neoliberal (HUMERES, 2019). Un sistema basado en el individualismo radical tal y como lo describe De Julios (1995), que necesita de la sumisión y del convencimiento del individuo, actuando éste como célula del organismo neoliberal nacional. Así, el manejo elevado de anglicismos económicos (o relacionados con el consumo masivo) del chileno promedio (Gerding, Fuentes y Kotz, 2012) es un indicio de la primacía de lo económico, aunque este conocimiento no se corresponda con una educación familiar y académica en buenas prácticas (DENEGRI ET AL., 2005), entendiendo como tales el fomento del ahorro y el abandono de un consumo compulsivo apoyado en el crédito. De hecho, según los datos del Banco Central de Chile, la deuda de los hogares aumentó en sólo 4 años (20152019) desde el $65,9 \%$ al $74,3 \%$ del ingreso disponible. Bajo esta dinámica, el ingreso fijo mensual a través de la renta laboral se hace completamente necesario, dependencia que se encona en una etapa crítica como la de jubilación. En ella, los gastos sanitarios aumentan mientras la capacidad financiera se ve muy reducida debido a la insuficiencia económica que genera el actual sistema de pensiones privado, obligatoriamente gestionado por las Administradoras de Fondos de

2 Inspirado en el evento televisivo estadounidense Telethon, presentado por Jerry Lewis. 
Pensiones (AFP) ${ }^{3}$ (VIVEs et al., 2016).

Así, en un contexto de libre empresa y protección a ultranza de la propiedad privada, sin mero atisbo de su función social, se gesta el caldo de cultivo de la polarización socioeconómica. Chile es, junto con México, el país con mayor desigualdad de la OCDE (KeELeY, 2018). Un coeficiente de Gini por sobre 0,45 desvela que el reparto de la riqueza y la reducción de la brecha social son materias pendientes del modelo y del país. Esto coincide con los informes de CEPAL (2019), los cuales indican que el 1\% más acaudalado de la población chilena concentra más de un cuarto de la riqueza $(26,5 \%)$, mientras que la mitad más pobre de la población sólo retiene un 2,1\% de la riqueza.

El modelo neoliberal extractivista de los recursos naturales (basado en la minería, principalmente de cobre), ${ }^{4}$ también lo es de su proletariado, compuesto por una amplia base de clase media endeudada. Es decir, un estrato socioeconómico cuya capacidad de consumo se sustenta en el crédito más que en sus rentas salariales.

Por supuesto, este expolio no se refiere a los recursos retraídos por el Estado del salario a través de la vía impositiva, que con un $7 \%$ en promedio son -por mucho- los más bajos de la $\mathrm{OCDE},{ }^{5}$ sino a la diferencia en términos de plusvalía que le otorga al sector privado un nivel de salarios mensuales promedio en 2018 de 652.397 pesos chilenos. Esta cifra esconde una realidad más depredadora y precarizada, puesto que el ingreso mediano se sitúa en 411.100 pesos chilenos, dentro de un contexto de servicios públicos básicos (educación, sanidad y pensiones) privatizados y un coste de la canasta básica de alimentos de 43.091 pesos chilenos por persona (10,48\% del ingreso mediano mensual).

\subsection{El canto de la moneda: territorio y ciudad, voceros de la desigualdad.}

Espacialmente la inequidad se muestra sin tapujos en Chile, con una amplia disparidad regional en cuanto a PIB per cápita (Figura 1), indicador que, por otro lado, sesga la realidad individual. El país está desprovisto de políticas e instrumentos redistributivos en lo espacial, tales como una Política Nacional de Ordenación del Territorio y una planificación territorial regional -Planes Regionales de Ordenamiento Territorial- (MATURANA et al., 2017). Esta ausencia deja a los territorios (y sus pobladores) a la deriva, a la vez que ahonda, aún más, en las problemáticas consecuencias de la grave inequidad y segregación socioespacial chilena.

\footnotetext{
3 El sistema de AFP, creado en 1980 por José Piñera (hermano del actual presidente de la República) es una de las 7 famosas modernizaciones que la Junta Militar dictatorial implantó en Chile para consolidar el modelo neoliberal. A esta medida le acompañan otras como un nuevo plan laboral, la reforma educativa, sanitaria y judicial, el reordenamiento de la propiedad privada agrícola y la reforma administrativa para adelgazar el Estado.

4 En atención a los datos del Banco Central de Chile, sólo en el año 2017, las exportaciones del sector minero chileno alcanzaron un precio de 68.306,1 millones de dólares americanos, lo que significó multiplicar por 7 las exportaciones del sector primario para el mismo periodo.

5 El promedio de la OCDE en el año 2017 es del 25,5\%. El registro más aproximado a nivel nacional procede del otro país latinoamericano integrante de la OCDE, México (11,2\%).
} 

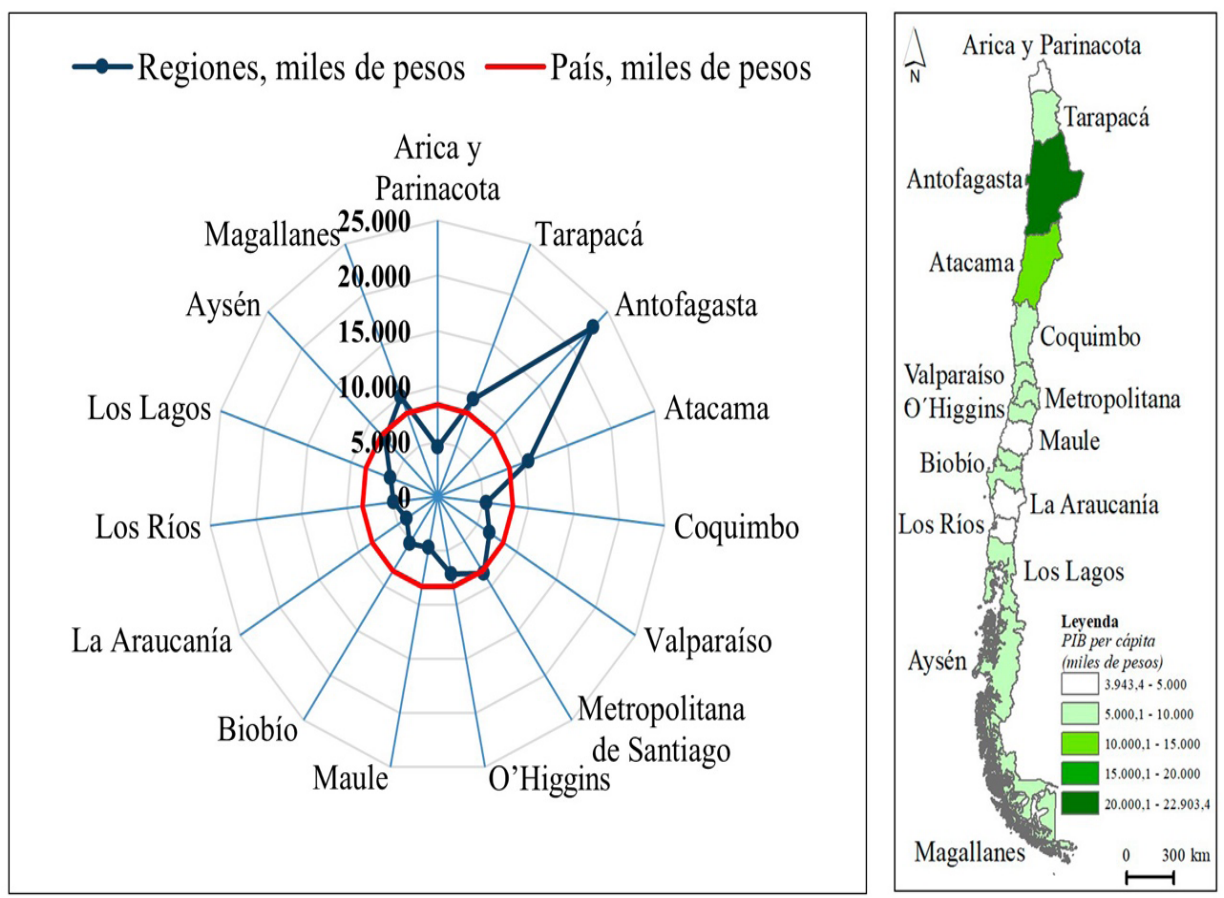

Figura 1. PIB per cápita en las regiones chilenas. Elaboración propia. 2019

Dentro de una agenda político-normativa liberal y centralista esto supone la explotación sin fin de la naturaleza en regiones (tales como Antofagasta, rica en recursos minerales) y la concentración de capitales públicos y privados en Santiago, a la que sigue una corriente demográfica. Este actuar centrípeto se mantiene aun cuando existen recientes medidas "descentralizadoras» (Ley $\mathrm{N}^{\circ}$ 21.074 para el fortalecimiento de la regionalización del país), por cuanto éstas no comportan una autonomía presupuestaria en dichas escalas que proporcione libertad de acción a sus gobiernos.

Por su parte, las políticas urbanas en Chile han estado altamente ideologizadas durante los últimos 50 años (NAvarrete-Hernández y Toro, 2019). Se han combinado periodos dónde se primaba la búsqueda de la igualdad (1952-1973) o donde sólo el mercado guiaba los criterios de ocupación del suelo (1973-1989), seguidos de otro donde se trataba de mitigar, con giros improvisados (Román y BARTON, 2018), la segregación socio-espacial (1990-2010), para final y recientemente volver a una hegemonía economicista.

Así, el status quo aúpa a la capital a una macrocefalia donde se sintomatiza de forma más clara (por su proximidad) la desigualdad (Figura 2). El «cono de alta renta ${ }^{6}$ es parte del lenguaje e imaginario social, a la vez que muestra y vector

6 El sector con mayor nivel socioeconómico en Santiago de Chile está conformado por las comunas 
que explica el patrón espacial de segregación socio-espacial en la capital. Según el reciente índice PICSA (2019), referido a esta variable, la gran metrópoli chilena ocupa el puesto $93^{\circ}$ a nivel mundial, la sexta en el contexto latinoamericano.

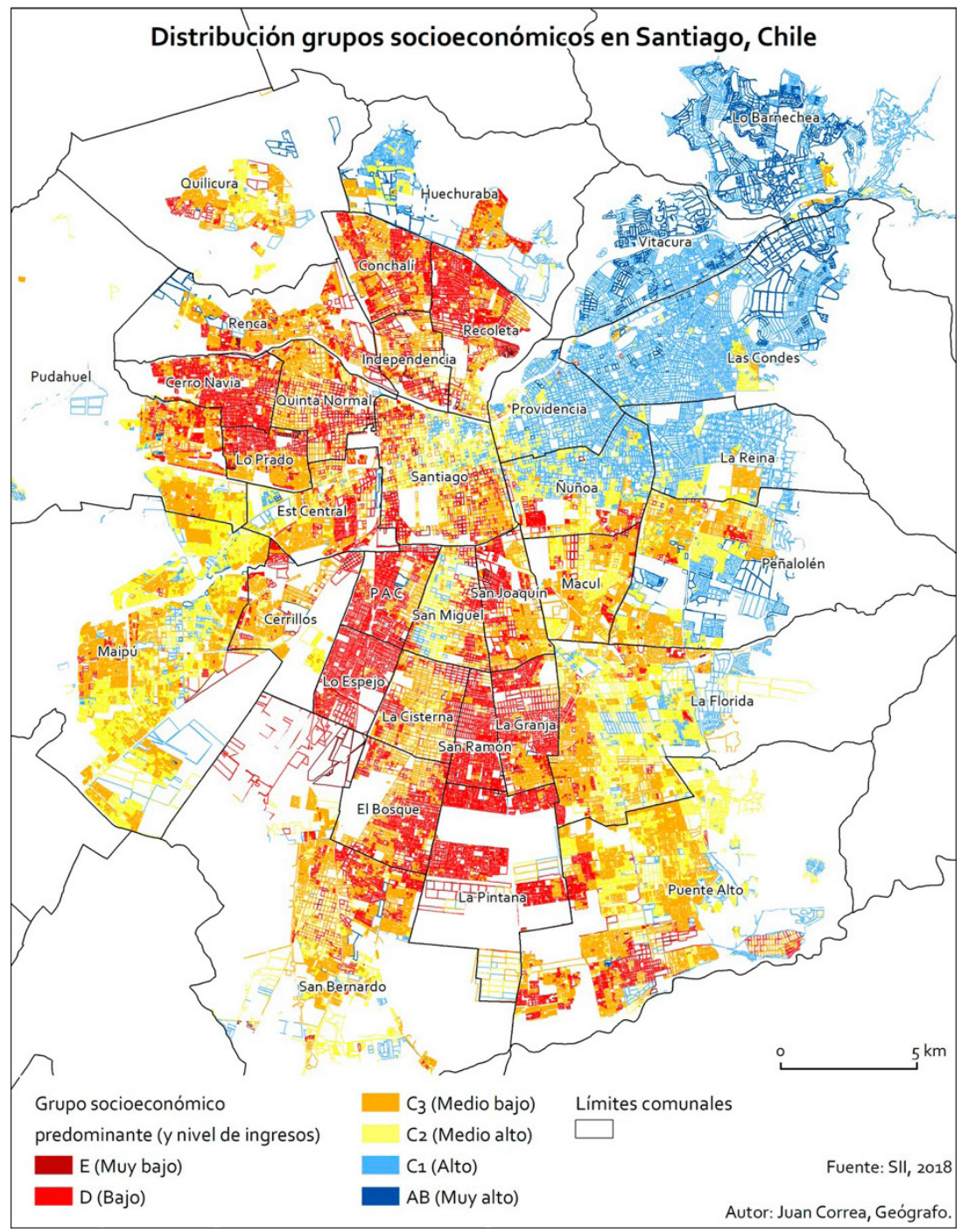

Figura 2. Distribución espacial de los grupos socioeconómicos en Santiago de Chile (CORREA, 2018). ${ }^{7}$

orientales de Providencial, Vitacura, Lo Barnechea y Las Condes, principalmente. A este se suman las comunas de La Reina y Ñuñoa, por la pujanza de sus secciones más septentrionales y orientales. 7 CorreA, J. [@Juanizio_C]. 2018. [Twitter]. 
En ella, comunas del citado "cono de alta renta" (ubicado al noreste), como Vitacura, exhiben un nivel de ingresos promedio más de cinco veces superior al de comunas como Pedro Aguirre Cerdá (PAC), situada a apenas 8,5 kilómetros en línea recta. Tal diferencia se llega a conceptualizar como otro signo más de «violencia estatal» (ANIÑIR y CANDINA, 2020; PIZARro, 2020) que alimenta levantamientos populares como el ocurrido. Junto a esta disparidad, tanto el Censo más reciente (2017) como la encuesta CASEN ofrecen un panorama capitalino muy polarizado en el que ese grupo de sólo seis comunas presenta un perfil muy diferente del resto. Esto alcanza a cuestiones tales como el tipo de actividad predominante, con una clara hegemonía del sector terciario, pero también a los perfiles profesionales que habitan este espacio (gran concentración relativa de intelectuales y profesionales relacionados con las altas instituciones políticas, judiciales, educativas y empresariales). Este retrato socioeconómico afecta finalmente a cuestiones materiales como una menor dificultad de acceso a servicios básicos (educación, sanidad, habitabilidad, etc.), lo que en síntesis divide la ciudad en un espacio privilegiado y otro, más amplio, que queda relegado en múltiples dimensiones.

Por lo tanto, Santiago es paradigma de la ciudad neoliberal gracias a un modelo que lejos de reconocer el derecho a la ciudad, no garantiza si quiera el derecho a la vivienda digna (BRUEY, 2012). De hecho, cuando éste se ha provisto de manera subsidiada por el Estado, se ha realizado de nuevo bajo un paradigma individualista y competitivo, disfrazado de mecanismo participativo y autogestionado, tal y como lo concibe MuÑOz (2007). La realidad es que las políticas de "rostro humano" (Atria, 2013; Hidalgo, Alvarado y Santana, 2017; TAPIA, 2018) han estado más preocupadas de salvar objetivos cuantitativos que cualitativos, resultando analgésicas. Por esta razón, la producción de viviendas sociales fue un éxito de cara a subsanar el déficit habitacional (Hidalgo, 1999), aunque cimentó las bases de un modelo urbanístico guettificado. Sustancial en el entendimiento de esta configuración metropolitana son también las operaciones traumáticas como las erradicaciones de poblaciones, la densificación urbana en gran altura, y la reestructuración del transporte público y las autovías urbanas (GARRETON, 2017).

En consecuencia, la liberalización del suelo, instrumentalizada y normalizada (JIMÉNEZ et al., 2018), permite a las élites elegir preferentemente la ubicación y la morfología urbana, mientras que las clases populares se resignan a un nuevo TINA (There Is No Alternative), puesto que sus condiciones pretéritas son mucho más precarias, como las tomas o los campamentos. Bajo estas condiciones, existe una clara estigmatización social fundamentada en el lugar de residencia (MÉNDEZ y OTERO, 2018), en el que las unidades barriales se enclaustran y compiten entre ellas (LETELIER et al., 2019), alejando el desarrollo integral e integrado de la ciudad, que carece de gobierno metropolitano.

Existen certezas de que esta desigualdad social repercute en una crisis de representatividad, que aleja del juego democrático particularmente a las clases sociales más perjudicadas (también las más numerosas) por el sistema (FERNÁNDEZ, MANUEl-NAVARRETE y TorRes-SALINAS, 2016), y que se ve agravada por una histórica falta de diálogo entre el Estado y su sociedad (GuTIÉRREZ, 2020). En este clima de angustia individual, descontento popular y falta de representatividad estalló en Santiago un movimiento social que, como se ha expuesto, no es atribuible en exclusiva al alza de 30 pesos en el billete de metro, sino a 30 años en los que 
se apuntalan las condiciones explicadas. Las protestas sociales comenzaron de forma incipiente durante los días 17, 18 y 19 de octubre de 2019, siendo la jornada del viernes 18 la de mayor movilización social de la historia reciente de Chile, con epicentro en la céntrica Plaza Baquedano de la capital y replicada en la mayor parte de las ciudades del país. Desde ese momento, la lucha se extendió temporal y espacialmente, sin un abanderado o interlocutor político. Durante meses (sin interrupción diaria) y en todos los rincones del país, las formas de protesta más comunes fueron la evasión de los pasajes de metro, las caceroladas diurnas en las calles y nocturnas en las casas, las concentraciones en la vía pública (masivas los días viernes), la celebración de cabildos (asambleas populares autoconvocadas) y foros vecinales de participación trasversal, etc. Pero en los primeros días y semanas, las protestas también incluían luchas en las calles entre civiles y cuerpos policiales, lo que provocó inseguridad tanto por sus características, como por la represión violenta de Carabineros (cuerpo nacional de policía) y el ejército, que conllevó fallecidos civiles. Es en este peligroso escenario cuando y donde aparece la cartografía colaborativa del estallido social.

El presente trabajo toma como objetivo principal conocer las características principales de esta cartografía novedosa apoyada en las nuevas tecnologías, tratando de, esencialmente, descubrir su origen y significado. Si bien la causa inmediata de este hecho histórico fue la, en principio nimia, subida de los pasajes de metro, la consecuencia más relevante será la creación de un nuevo marco constitucional para Chile, de ahí la importancia de estudiar todos los elementos que ayudaron a crear esta coyuntura refundacional y modernizadora del país.

\section{METODOLOGÍA}

El proceso metodológico responde a las características específicas de la cartografía motivada por el estallido social en Chile y producida entre el 18 de octubre y el 30 de noviembre de 2019, así como a las circunstancias del investigador durante los acontecimientos. Consiguientemente, la observación participante no estructurada ni inducida se erige como el método más adecuado y factible. La espontaneidad, inmediatez y novedad de la cartografía, al igual que su potencial fugacidad, impide una recopilación de datos y fuentes etapizada y ordenada previamente. Además, la condición de académico, geógrafo y residente santiaguino del autor, lo sitúa en una posición no impostada, preexistente e integrada en redes profesionales, académicas y sociales vinculadas a la producción cartográfica, lo cual ha facilitado el acceso a la información.

La eventualidad provoca que los datos no tengan fuentes precisas, acotadas ni anteriormente reconocidas. Por ello, el primer paso es identificar y acceder a las mismas. Esto se realizó por dos vías; una marginal, a través de notificaciones en redes profesionales y/o académicas (vía correo electrónico), las cuales dieron aviso de iniciativas cartográficas al respecto (algunas de ellas surgidas desde la propia casa académica); y otra, general, mediante el seguimiento de redes sociales (RRSS) hasta el final de noviembre. Para esto último se simuló la actividad diaria de un usuario de Twitter durante los acontecimientos (con mayor intensidad de consultas durante la semana del 18 al 25 de octubre), reportando información espacial derivada de la búsqueda por eventos y localizaciones que, por experiencia 
vivencial o aparición en medios de comunicación, eran relevantes. Adicionalmente, se hizo uso durante todo el proceso del listado de tendencias en Chile (Trending Topics), realizando búsquedas sobre las publicaciones asociadas a etiquetas (hashtags) más recurrentes, aun cuando habían perdido la condición de «tema más comentado» según el listado que ofrece la propia red social. Entre ellas destacan las referidas a lugares específicos (\#PlazaDignidad, \#barricadas, estaciones de metro, etc.), eventos concretos (\#toquedequeda; \#EstadoDeExcepcion) o generales (\#RenunciaPiñera; \#EvasionMasivaTodoElDia; \#LaMarchaMasGrandedeChile) e, incluso, algunas que coincidentemente fueron útiles (\#30DayMapChallenge).

Para ampliar la base de datos, esta búsqueda fue replicada en términos, periodo y cadencia en Instagram. Cuando las etiquetas coincidían con lugares exactos, se procedía a realizar una búsqueda de publicaciones geolocalizadas.

$\mathrm{Si}$ bien este procedimiento genera incertidumbre ante la representatividad de la muestra, sí es prueba de que lo aquí examinado compone el grueso y parte más accesible (y, por consiguiente, utilizada por la población) de la cartografía generada a tenor de la crisis social.

Esta búsqueda entregó resultados directos sobre cartografía en muy pocas ocasiones, aunque ha resultado útil para identificar los mapas más relevantes, pero fundamentalmente, las fuentes y usuarios más activos (asociaciones, colectivos y personas), cuyos procesos y/o productos cartográficos se servían adicional o exclusivamente en otras plataformas como Google Maps y sus derivados. Estos mismos resultados han propiciado un posterior muestreo en «bola de nieve», que ha permitido localizar nuevos agentes que ayudaban a cartografiar lo ocurrido, encontrando coyunturalmente experiencias de otras ciudades chilenas o que rebasan la escala urbana, las cuales han sido depuradas mediante Sistemas de Información Geográfica (conversión de capas KML o KMZ a formato shapefile y selección y examen de datos referidos en particular a Santiago).

Finalmente, una vez acotadas las fuentes y cartografías, en este trabajo se muestra una relación de ellas, ${ }^{8}$ acompañadas de un examen sobre su origen, disponibilidad, medios de promoción y difusión. Junto con esto, se indaga en su contenido y su potencial significado y utilidad durante o después de las protestas.

\section{RESULTADOS}

La resistencia popular chilena atesora una gran tradición que hunde sus raíces de lucha contemporánea en las Jornadas Nacionales de Protesta celebradas durante los años 80, retomadas periódicamente en democracia para seguir haciendo frente al modelo neoliberal (alza en el coste de los servicios, sistemas privados de salud, educación y pensiones, sobre-explotación de la naturaleza, discriminación a los pueblos indígenas y otras minorías, etc.).

Los acontecimientos de octubre y noviembre de 2019 encuentran notables paralelismos con las citadas jornadas, tanto en las formas de las protestas (barricadas, saqueos y masivas manifestaciones pacíficas) como en los métodos represivos por parte del Estado (BRAVO, 2012). Entre estos métodos se incluyen

8 Aquellas cartografías en construcción o en constante producción han sido examinadas según su estado a 30 de noviembre de 2019, independientemente de que se refieran a un periodo temporal concreto o no. 
la declaración del Estado de Emergencia y toque de queda, miles de detenidos, decenas de muertes civiles y violaciones a los derechos humanos por parte de cuerpos policiales y militares (ACNUDH, 2019).

Al igual que en el año 2006 con el movimiento pingüino, la reivindicación de octubre de 2019 parte de los estudiantes secundarios (DISI, 2018), aunque esta vez gatillados por una cuestión que no les afecta directamente en lo inmediato, ${ }^{9}$ sino movidos por la solidaridad intergeneracional.

Al margen de estas similitudes, en la actualidad, la presencia extendida de dispositivos móviles con acceso a internet en Chile ha significado un elemento diferenciador clave a la hora de oponer resistencia. Los avances tecnológicos facilitan la organización popular y le aportan sencillez, a la vez que ayudan a contrarrestar el discurso oficialista en un ámbito global. En términos cartográficos esto significa que el proceso "mapeador» nace y se instala en la resistencia al oficialismo, sin una de las principales limitaciones para su éxito, es decir, las dificultades de acceso a la red o los dispositivos que la proveen (SULLIVANWiley, Short y Casellas, 2019; Nicolosi, French y Medina, 2019). Todo proceso cartográfico de este tipo requiere de «información geográfica voluntaria», con la particularidad de que en Chile los "prosumidores» (RITZER y JURGENSON, 2010) lo han sido en directo.

Así, una de las cartografías más relevantes y útiles fue la promovida por el "Colectivo de Geografía Crítica Gladys Armijo», que recopiló y publicó prácticamente en tiempo real sucesos durante los momentos más álgidos del estallido. Se trata de una cartografía de tipo colaborativo a la que se suman aportes voluntarios captados en RRSS (Twitter e Instagram), utilizadas también como medio de difusión. La información espacial se aloja en los servidores de Google, de acceso y uso gratuito, a través de su herramienta multiplataforma «My Maps». La Figura 3 muestra una síntesis del tipo de contenidos recopilados entre las jornadas del día 18 de octubre y 24 de octubre de 2019 en la ciudad de Santiago.

9 Los estudiantes secundarios chilenos, popularmente denominados pingüinos por su vestimenta, disponen de una Tarjeta Nacional Estudiantil (TNE) que los beneficia con una tarifa reducida en el transporte público. 


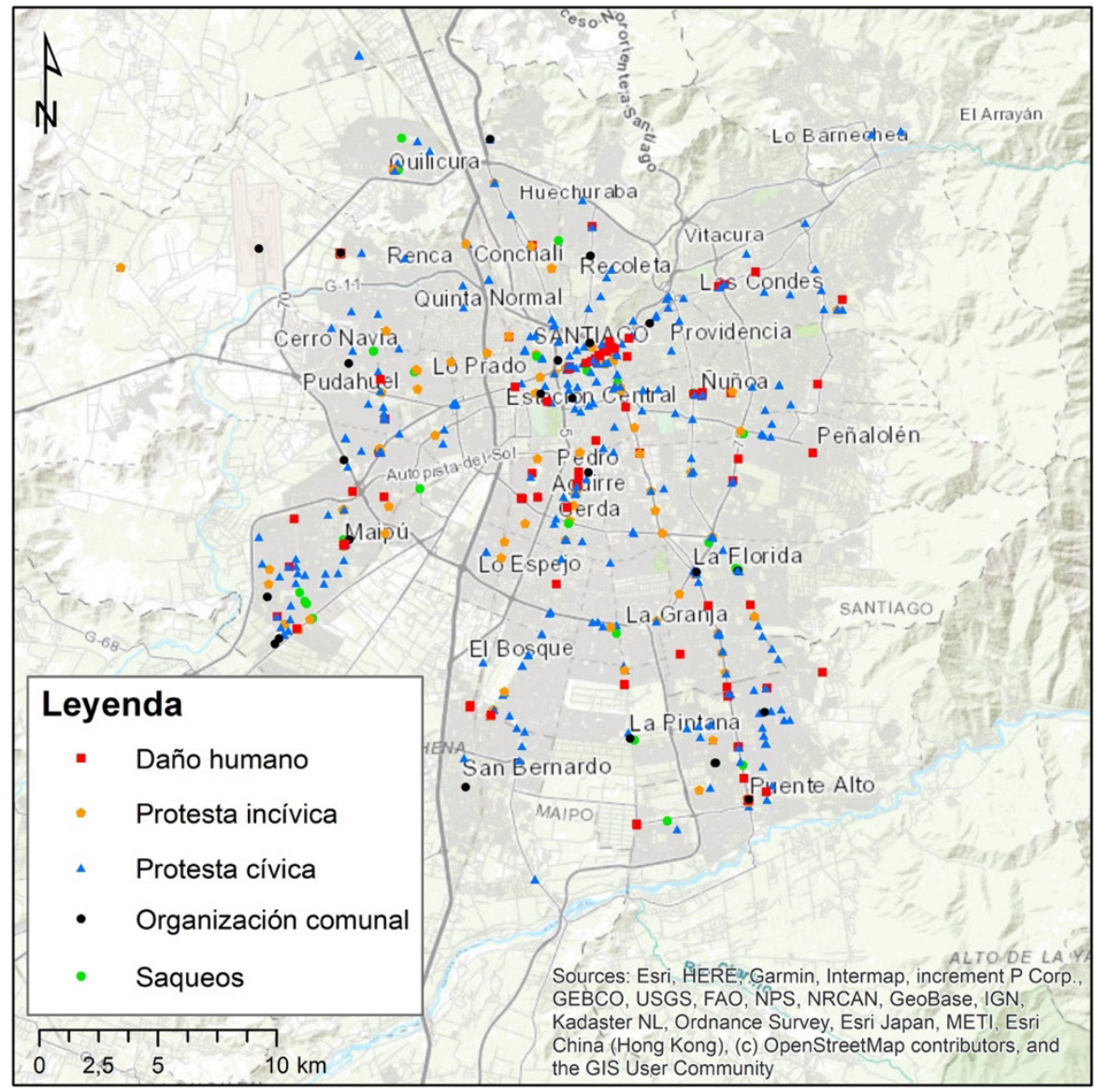

Figura 3. Información espacial colaborativa del estallido social. Elaboración propia a partir de Geografía Crítica Gladys Armijo. 2019

La información, que es descargable, se presenta mayoritariamente en topología de puntos (existen topologías de líneas para representar marchas y otras formas de resistencia) y se compartimenta fundamentalmente por periodos temporales y espacios (escala urbana, nacional e internacional), aunque también existen algunas dedicadas a temáticas específicas (muertes, daños oculares y movilizaciones). Su fácil e intuitiva leyenda y manejo facilita su comprensión y transversalidad social, lo que, combinado con su viable consulta en dispositivos móviles, potencia su uso.

Entre los mapas referidos a la capital destacan el de las jornadas del 18 y 19 de octubre, así como las del 20, 21, 22, 23 y 24 del mismo mes (incluidas dentro del periodo de toque de queda declarado), teniendo estas últimas cuatro fechas una cobertura nacional. Su contenido varía, ampliándose y reduciéndose (Tabla 1) en función del propósito declarado del colectivo en su web: «la difusión de la 
protesta en el mapa tiene por objetivo visibilizar situaciones que la prensa está ocultando».

Este «mapa dinámico» se convierte así en una herramienta que, según definen sus creadores, lucha contra la criminalización de la protesta popular generada por el gobierno y los grandes grupos mediáticos. Esto se combina con su utilidad para la ciudadanía, basada en el libre acceso, pero impidiendo su aprovechamiento por las fuerzas policiales al resguardar el anonimato de lo reportado y sus protagonistas, así como de los informantes. De este modo, los muy mediatizados daños en las estaciones de metro dejan de referirse, para incluir progresivamente otros registros menos expuestos a la opinión pública como muertes, represión policial, centros de torturas, así como nuevas formas de protesta y organización (huelgas y cabildos).

En esta última línea avanza otra iniciativa, esta vez constituida ex profeso por un conjunto de geógrafos agrupados bajo el nombre de "Geo Constituyente», en la que se determina la fecha, hora y lugar de celebración de cabildos, a lo que se suma la entidad o grupo de personas convocantes. Al igual que el anterior, es un mapa colaborativo de acceso libre que utiliza la plataforma de Google My Maps, aunque esta vez restringe a Instagram su forma de captar y difundir la información.

Su razón de ser es el fomento (a través de la publicitación centralizada) de la participación en estos enclaves y eventos de representación de la soberanía popular, en contestación a la inacción gubernamental.

TABla 1

Contenido de la cartografía colaborativa del Colectivo Geografía Crítica Gladys Armijo

\begin{tabular}{|l|c|c|c|c|c|c|c|}
\hline 18 y 19 octubre & \multicolumn{2}{|c|}{20 octubre } & 21 y 22 octubre & \multicolumn{2}{|c|}{23 y 24 octubre } \\
\hline Evento & Magnitud & $\mathrm{E}$ & $\mathrm{M}$ & $\mathrm{E}$ & $\mathrm{M}$ & $\mathrm{E}$ & $\mathrm{M}$ \\
\hline $\begin{array}{l}\text { Estaciones de } \\
\text { metro con daños }\end{array}$ & 31 & & & & & & \\
\hline Cacerolazos & 89 & & 23 & & 78 & & 50 \\
\hline $\begin{array}{l}\text { Recuperaciones/ } \\
\text { Saqueos }\end{array}$ & 31 & & & & & & 5 \\
\hline $\begin{array}{l}\text { Disparos: Balas/ } \\
\text { Perdigones }\end{array}$ & 14 & & 11 & & 16 & & 21 \\
\hline $\begin{array}{l}\text { Resistencia al } \\
\text { toque de queda }\end{array}$ & 60 & & 20 & & 53 & & 2 \\
\hline Quema de buses & 6 & & & & & & \\
\hline $\begin{array}{l}\text { B a r r i c a d a s / } \\
\text { Quemas }\end{array}$ & 46 & & 7 & & & & \\
\hline $\begin{array}{l}\text { In m u e b 1 e s } \\
\text { incendiados }\end{array}$ & 6 & & 4 & & & & \\
\hline
\end{tabular}


Víctor Jiménez Barrado

\begin{tabular}{|c|c|c|c|c|c|c|c|}
\hline & & $\begin{array}{c}\text { Situaciones } \\
\text { emergentes }\end{array}$ & 6 & & 11 & & 2 \\
\hline & & & $\begin{array}{c}\text { Centro de } \\
\text { torturas }\end{array}$ & 2 & & 1 \\
\hline & & & & $\begin{array}{c}\text { Represión } \\
\text { policial }\end{array}$ & 31 & & 4 \\
\hline & & & & & $\begin{array}{c}\text { Huelga } \\
\text { Nacional }\end{array}$ & 7 \\
\hline & & & & & & $\begin{array}{c}\text { Convocatoria } \\
\text { de cabildo }\end{array}$ & 11 \\
\hline
\end{tabular}

Fuente: Geografía Crítica Gladys Armijo. Elaboración propia.

Según la consulta del 3 de noviembre de 2020 a esta cartografía, en Chile habían sido convocados hasta 416 cabildos, de los cuales 193 tenían como sede la capital. Con esta labor que aún continúa (Figura 4), no sólo se favorece la participación sino también la continuidad de la protesta y la discusión acerca de la Constitución, tema inicialmente rechazado por el gobierno nacional.

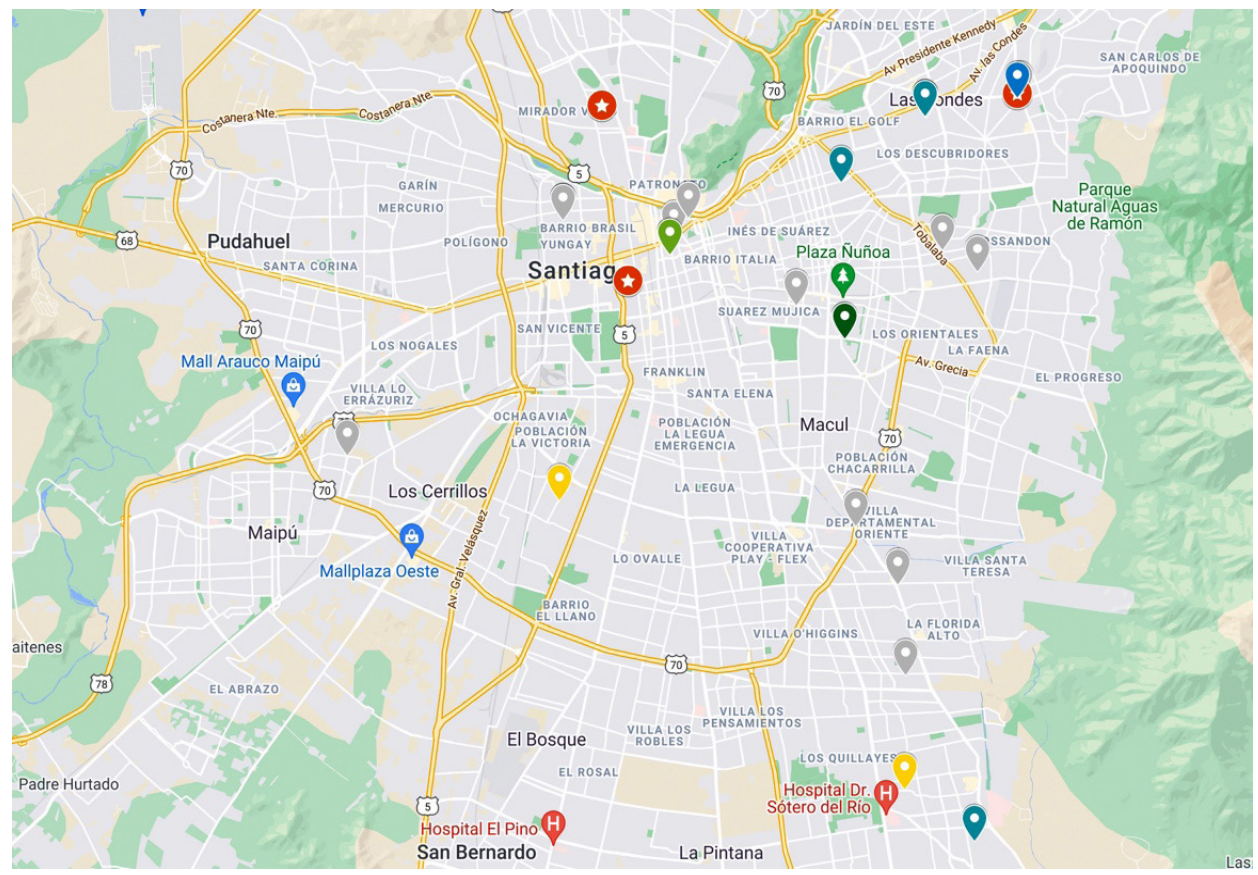

Figura 4. Mapa colaborativo de cabildos y asambleas autoconvocadas en Chile.

Geo Constituyente. 2018 
Esto demuestra que la cartografía responde a una orfandad social con respecto al gobierno, la cual se recrudeció en momentos críticos como el toque de queda. En ese contexto, el 23 de octubre aparece un mapa de apoyo a la población civil generado y publicitado por el medio local de comunicación alternativo «La Voz de Maipú», como forma de "servicio social» ante los problemas para abastecerse. Por ello, en él se reportan, de nuevo a través de Google My Maps, todos los almacenes y negocios en Maipú, comuna integrante de la capital. En un espectro parecido se podría incluir también el mapa de semáforos fuera de servicio (Figura 5) que el 4 de noviembre ofreció Emol en la misma plataforma de Google, aunque bajo un argumento más próximo al relato gubernamental que abogaba por «una vuelta a la normalidad».

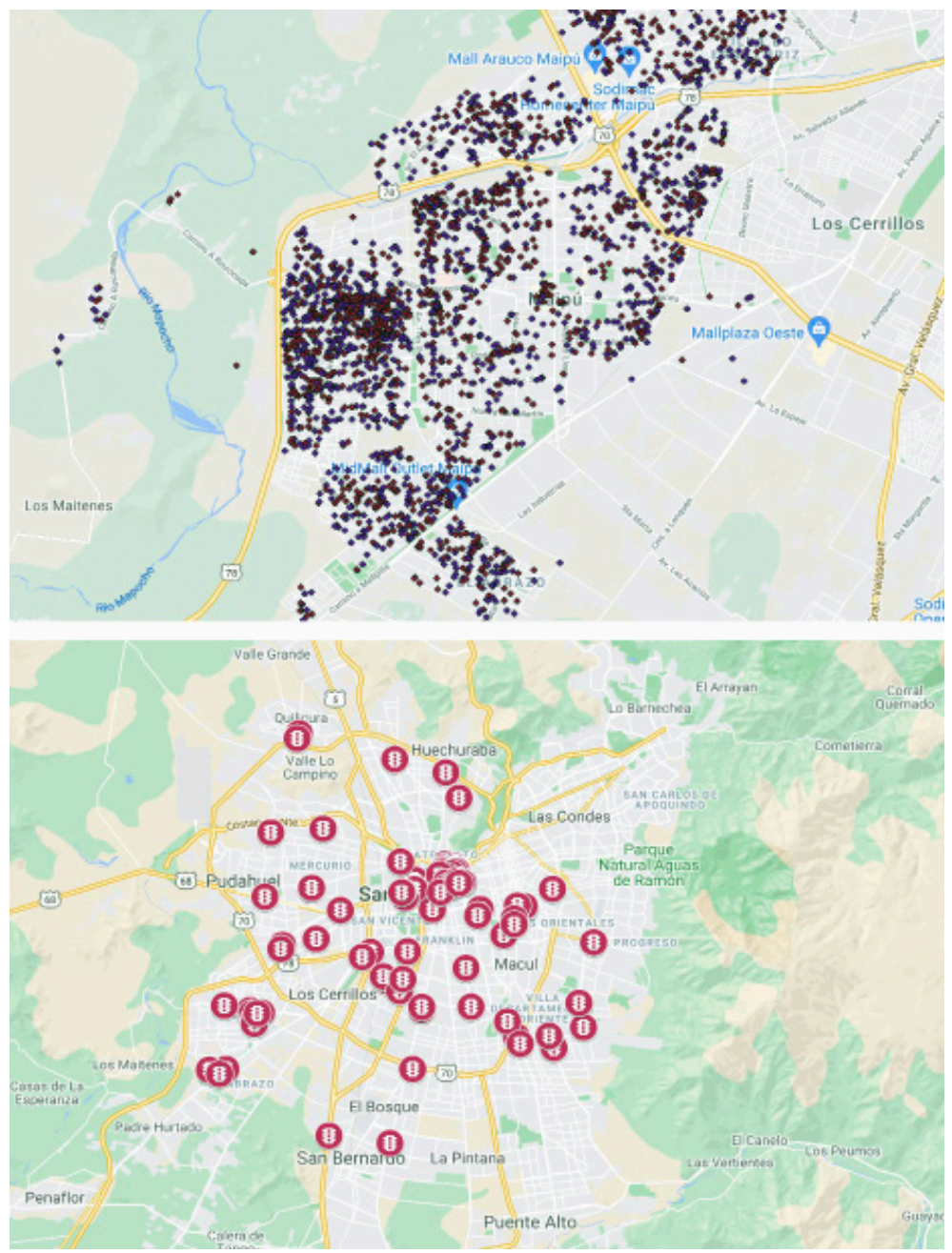

Figura 5. Cartografía sobre almacenes y negocios en Maipú (arriba) y sobre semáforos fuera de servicio en Santiago de Chile (abajo). La Voz de Maipú y Emol. 2019 
Durante el toque de queda, rápidamente se pasó del sentimiento de desamparo al de inseguridad. La represión policial llevó aparejadas violaciones a los derechos humanos que el colectivo «Desclasificación Popular» ha llamado a georreferenciar (fundamentalmente a través de las RRSS) bajo el proyecto «Cartografías de la represión", con el fin de "constatar la producción de espacios represivos como parte de una política de Estado». Iniciativas parejas surgieron en la academia, desde una actividad similar del colectivo estudiantil «Piquete geográfico» de la Pontificia Universidad Católica de Valparaíso hasta la celebración de talleres de cartografía organizados por diversas organizaciones de geógrafos e institutos de la Pontificia Universidad Católica de Chile.

A esta última institución también pertenecen otras actividades, esta vez atribuibles al Centro de Desarrollo Urbano Sustentable (CEDEUS), que puso a disposición del público su herramienta cartográfica colaborativa "Mi ciudad». En ella, se pueden construir de forma anónima y libre mapas de puntos de temática abierta, complementados con descripciones y fotografías. Gracias a esta herramienta han aparecido mapas relacionados con el estallido social que georreferencian desde marchas pacíficas hasta saqueos y disparos de la policía.

En una lucha por el relato, la Corporación de Fomento de la Producción (CORFO), agencia gubernamental, ha elaborado una cartografía siguiendo la misma metodología y plataforma dominante entre la resistencia civil (Google My Maps). En ella se realiza un catastro de las pequeñas y medianas empresas (Pymes) «afectadas por la contingencia nacional», incluidas presumiblemente por sus propietarios en la base de datos. Este mapa, publicitado a través del hashtag \#elijopyme, presenta una serie de registros en bloque no contrastables debido a que, a diferencia de los ejemplos vistos anteriormente, la información no es descargable.

Esta disputa adquiere su culmen a la hora de dominar un espacio, y parte de esta dominación recae en la capacidad de darle nombre. Durante este proceso se han vivido cambios espontáneos en la toponimia de la ciudad en un intento de construir una nueva imagen referente, forma a través de la cual ejercer apropiación y acción sobre el espacio geográfico (NúÑEZ, ZAMBRA y ALISTE, 2017). El más notable de entre ellos es el que afecta al epicentro físico de las protestas, oficialmente denominado como Plaza Baquedano (en honor al general y presidente efímero de Chile durante 1891), y que en su origen, según DE RAMón y Gross (1985), fue nombrado Plaza La Serena (1875-1892), para pasar a designarse Plaza Colón (en la conmemoración del cuarto centenario de la llegada de los europeos a América) y más recientemente (1910-1928), Plaza Italia. La cuarta nominación tras la original y consecuente resignificación se produjo el 11 de noviembre de 2019, cuando las etiquetas de Google Maps fueron modificadas en un ejercicio de "ciberactivismo" o "activismo virtual», para renombrar este lugar como «Plaza de la Dignidad». Esto, que aún no ha alcanzado oficialidad, adquirió materialidad dos días después mediante un grafiti de gran formato en el asfalto de la misma plaza.

Este hecho responde a un imaginario social (nuevo y ampliamente compartido) de este espacio, que lo interpreta como puesto de resistencia cívica ante la dura represión estatal. No en vano, en este sector han tenido lugar continuas movilizaciones, siendo la del 25 de octubre de 2019, la más multitudinaria. Ese día, tras el llamado a realizar "La marcha más grande de Chile», se reunieron 1,2 millones de personas según las cifras de la Intendencia Metropolitana.

De hecho, este registro ha sido fruto de controversia, por lo cual han 
aparecido varias respuestas desde la academia (particularmente por el profesor Pablo Guzmán del Instituto de Estudios Urbanos y Territoriales de la Pontificia Universidad Católica de Chile) y otros expertos profesionales del campo de la ingeniería que, si bien no se han plasmado todavía en estudios científicos publicados, sí fueron dados a conocer en las RRSS.

De esta forma, la producción cartográfica no sólo ha tenido un carácter colaborativo y guiado por asociaciones y colectivos, sino que parte de ella ha sido fruto de un trabajo individual. Estas cartografías han aprovechado toda la potencialidad de las RRSS y la coincidencia con hashtags no relacionados con la protesta, como \#30DayMapChallenge, para difundir su mensaje, en muchas ocasiones contrario al oficialismo. En ellas predomina una participación académica y con formación especializada, que combinada con la producción de cartografía colaborativa aísla el discurso del oficialismo.

\section{DISCUSIÓN}

El desarrollo tecnológico y su democratización ha sido un componente diferenciador con respecto al papel de la cartografía y su incidencia en este tipo de procesos. Los nuevos mapas han sido eficaces por 4 ventajas comparativas, todas ellas consecuencias del progreso técnico e interrelacionadas.

En primer lugar, la gratuidad y su amplia difusión. El acceso libre a un entorno digital a través de una extensa gama de dispositivos móviles ha permitido transversalidad social y la multiplicación de los actores implicados en la producción cartográfica y en la recepción del resultado. Esta influencia ha resultado mayor si se considera que los agentes participantes son en su mayoría nativos digitales, o bien cuentan con un alto grado de inmersión.

En segundo lugar, la anulación de las limitaciones espaciales (y temporales). Durante un contexto crítico y de inseguridad, así como de suspensión de derechos de movimiento y reunión, la generación de la información al igual que su transmisión y recepción ha estado garantizada por las redes móviles. Este esquema ha permitido, además, un reemplazo en la fuente de datos, es decir, de los informantes que mayoritariamente se encontraban en las calles. Gracias a esto ha aumentado la resiliencia de un movimiento que ha avanzado mediante una dinámica de enjambre (SÁNCHEZ, 2012), que sorteaba e inutilizaba los esfuerzos del gobierno por reestablecer el orden público en determinados enclaves urbanos para sofocar las protestas.

Seguidamente, la inmediatez, consecuencia de los dos elementos anteriores. La producción cartográfica se ha realizado mayoritariamente con aportes voluntarios y masivos, que han reducido a la mínima expresión el proceso de captación de datos y su publicación. El mapeo digital y en tiempo real, como en otros movimientos sociales recientes ocurridos globalmente (15-M en Madrid, Ocuppy Wall Street en Nueva York o el 15-O de 2011 a nivel mundial), ha permitido la consolidación y reproducción "viral" del estallido, aportándole inmediata visibilidad nacional e internacional (NOFRE, 2013). Por esta razón y la naturaleza de sus contenidos, estos mapas son eminentemente una cartografía de uso (durante los eventos) y no de análisis. Su objetivo se asemeja parcialmente a las cartografías del peligro (HENDEL, 2020) y los mapas feministas topofóbicos (TORO y OCHOA, 2017) por cuanto expone espacios peligrosos, pero difieren de 
estos por su escasa latencia. Por lo tanto, esta es una cartografía de alarma (DE Sото, 2014), que además de servir como vector de reproducción del movimiento por su capacidad para localizar eventos y aglutinar personas, se utiliza en Santiago durante momentos críticos como un mapa de resguardo y cuidado (generando movimientos de repliegue). Su trasversalidad social y rapidez, da buena cuenta del carácter espontáneo de lo producido, lo que contrarresta el mensaje oficialista que defiende la confluencia de estrategias premeditadas en su contra.

Por último, resulta principal su intercomunicación. Esto redunda en un mayor orden y capacidad evolutiva. El avance en paralelo de distintas iniciativas con diferentes orígenes, pero cuyos resultados eran de acceso público e inmediato, ha impedido la existencia de duplicidades. Cuando estas eran detectadas, los contenidos de los mapas variaban. Otro factor que ha introducido cambios ha sido el mensaje gubernamental y mediático, contrarrestado desde la cartografía. Esto ha provocado que cada cartografía se convierta rápidamente en referencia dentro de la temática que aborda y en contraparte del oficialismo.

\section{CONCLUSIONES}

La cartografía generada en Chile debido al estallido social vivido el 18 de octubre de 2019 ha sido parte esencial del mismo y elemento fundamental para su pervivencia en el tiempo. Esta resistencia ha resultado a su vez indispensable para cosechar logros tan importantes como el plebiscito constitucional pactado para el 26 de abril de 2020, aunque pospuesto hasta el 25 de octubre del mismo año a tenor de la crisis sanitaria desatada por el Covid-19, y del que se ha originado un nuevo proceso constituyente a tenor de un $78,28 \%$ de sufragios favorables a la redacción de una nueva Constitución para Chile.

Los mapas generados han sido consumidos por la sociedad desde sus hogares y las calles con distintos propósitos, que eran cambiantes según las necesidades y la evolución del conflicto. La adaptación del resultado cartográfico es fruto de esta retroalimentación.

Tal y como indican Moral y Merino (2018:271) este tipo de mapas «nacen en un contexto efímero con una voluntad de documento registral, organizativo y de difusión de ideas - tácticas que definan una nueva ciudad", y en este caso específico, pretenden alcanzar un nuevo modelo-país.

Prueba del éxito e influencia de la cartografía colaborativa es que desde el gobierno se ha intentado replicar su metodología e, incluso, se han utilizado sus mismos canales de captación y difusión. Esto demuestra lo afirmado por LACOSTE (1977) sobre la importancia del espacio, la geografía y su representación gráfica, esto es, los mapas, en la confrontación entre partes, anunciada para Chile por el Presidente de la República. ${ }^{10}$ Así, en la cancha de juego chilena de un lado se encuentra el gobierno y su ponderación del orden público, y de frente, la cartografía socialmente construida, con apoyos puntuales e individuales desde la academia y otros sectores, en defensa de los derechos humanos.

Este tipo de eventos y análisis demuestran que el estudio de la meta-cartografía en un entorno y coyuntura digital como la actual debe ser tenido muy en cuenta

10 Tras tres días desde el estallido social, el 21 de octubre, y momentos antes de declarar el estado de emergencia y toque de queda, el presidente Sebastián Piñera declaró: «estamos en guerra contra un enemigo poderoso». 
por la geografía humana. Tan importante es el resultado final como la forma de construirlo, el modo de publicarla, el tipo de acceso y las características, origen y número de sus productores y usuarios. La cartografía, que fue patrimonializada por el poder institucional cada vez se muestra más "democratizada», lo cual implica oportunidades pero también nuevos riesgos que deben ser examinados.

\section{REFERENCIAS}

ACNUDH. (2019): Informe sobre la misión a Chile "30 de octubre-22 de noviembre de 2019". Disponible online.

ANIÑIR, D.; CANDINA, A. (2020): «Estallido social: elementos para una genealogía de las violencias», Meridional. Revista Chilena de Estudios Latinoamericanos, 14: 241-246. doi: 10.5354/0719-4862.2020.57136

Atria, F. (2013): Neoliberalismo con rostro humano: veinte años después, Catalonia, Santiago de Chile.

BorgiAS, S.L. (2018): “"Subsidizing the State:" The political ecology and legal geography of social movements in Chilean water governance», Geoforum, 95: 87-101. doi: https://doi.org/10.1016/j.geoforum.2018.06.017

BRAVO, V. (2012): «Neoliberalismo, protesta popular y transición en Chile 19731989», Politica y Cultura, 37: 85-112.

Bruey, A.J. (2012): "Limitless Land and the Redefinition of Rights: Popular Mobilisation and the Limits of Neoliberalism in Chile, 1973-1985», Journal of Latin American Studies, 44 (3): 523-552. doi: https://doi.org/10.1017/ S0022216X12000399

CEPAL (2019): Panorama social de América Latina, CEPAL-ONU, Santiago de Chile.

CinI, L.; GuZMÁn-ConCHA, C. (2017): «Student movements in the age of austerity. The cases of Chile and England», Social Movement Studies, 16 (5): 623-628. doi: https://doi.org/10.1080/14742837.2017.1331122

Denegri, M.; Palavecinos, M.; Gempr, R.; CAPRILe, C. (2005): «Socialização econômica em famílias chilenas de classe média: educando cidadãos ou consumidores?», Psicologia E Sociedade, 17 (2): 88-98.

DisI, R. (2018): «Sentenced to Debt: Explaining Student Mobilization in Chile», Latin American Research Review, 53 (3):448-465. doi: https:/ / doi.org/10.25222/ larr.395

De Julios, A. (1995): «Individualismo y modernidad. Una lectura alternativa», Anuario de Filosofía del Derecho, 12: 239-268.

De Soto, P. (2014): «Los mapas del \#15M: el arte de la cartografía de la multitud conectada», en E. Serrano, A. Calleja, A. Monterde y J. Toret (eds.), 15MP2P. Una mirada transdisciplinar del 15M, Universtitat Oberta de Catalunya, Barcelona: 362-387.

Di Giminiani, P.; GonzÁlez, M. (2018): «Who Owns the Water? The Relation as Unfinished Objectivation in the Mapuche Lived World", Anthropological Forum, 28 (3): 199-216. doi: https:/ / doi.org/10.1080/00664677.2018.1495060

Fernández, I.C.; Manuel-Navarrete, D.; Torres-Salinas, R. (2016): «Breaking Resilient Patterns of Inequality in Santiago de Chile: Challenges to Navigate towards a More Sustainable City", Sustainability, 8: 820. doi: https://doi. org/10.3390/su8080820 
GARRETON, M. (2017): "City profile: Actually existing neoliberalism in Greater Santiago", Cities, 65:32-50. doi: http:/ / dx.doi.org/10.1016/j.cities.2017.02.005

Gerding, C.; Fuentes, M.; Kotz, G. (2012): "Anglicismos y aculturación en la sociedad chilena», Onomázein, 25: 139-162.

GutiéRreZ, Ó. (2020): «Razones del levantamiento social en Chile. Necropolítica como paradigma de Estado», Universum, 35 (1): 104-126.

HaRveY, D. (2007): Breve historia del Neoliberalismo, Akal, Madrid.

HarveY, D. (2012): El enigma del capital y las crisis del capitalismo, Akal, Madrid.

Harvey, D. (2019): Marx, El capital y la locura de la razón económica, Akal, Madrid.

Hendel, V. (2020): "Cartografías del peligro. Desplazamientos, migración, fronteras y violencias desde la experiencia de los jóvenes en un barrio del Gran Buenos Aires, Argentina (2018-2019)», Historia y Sociedad, 39: 184-212. doi: http:/ / dx.doi.org/10.15446/hys.n39.82576

Hidalgo, R. (1999): «La vivienda social en Chile: La acción del Estado en un siglo de planes y programas», Scripta Nova, 3 (45). Disponible online.

Hidalgo, R.; Alvarado, V.; Santana, D. (2017): «La espacialidad neoliberal de la producción de vivienda social en las áreas metropolitanas de Valparaíso y Santiago (1990-2014): ¿hacia la construcción ideológica de un rostro humano?», Cadernos Metrópole, 19 (39): 513-535. doi: http://dx.doi.org/10.1590/22369996.2017-3907

Humeres, M. (2019): “"Gane usted y ayude a la Teletón”: mecanismos neoliberales en la gestión del bienestar», Convergencia. Revista de Ciencias Sociales, 81: 1-24. doi: https:/ / doi.org/10.29101/crcs.v26i81.11641

InZunZA, J., Assael, J., CoRnejo, R., y Redondo, J. (2019): «Public education and student movements: the Chilean rebellion under a neoliberal experiment», British Journal of Sociology of Education, 40 (4): 490-506. doi: https:/ / doi.org/1 0.1080/01425692.2019.1590179

JANOSCHKA, M.; HidALGO, R. (2014): «La ciudad neoliberal: estímulos de reflexión crítica», en R. HidALGo y M. JANOSCHKA (eds.), La ciudad neoliberal. Gentrificación y exclusión en Santiago de Chile, Buenos Aires, Ciudad de México y Madrid, Serie GeoLibros, Santiago de Chile: 7-32.

Jiménez, V.; Hidalgo, R.; Campesino, A.J.; Alvarado, V. (2018): «Normalización del modelo neoliberal de expansión residencial más allá del límite urbano en Chile y España», EURE, 44 (132): 27-46. doi: http:/ /dx.doi.org/10.4067/ s0250-71612018000200027

KeELEY, B. (2018): Desigualdad de ingresos. La brecha entre ricos y pobres, OCDE, París. LACOSTE, Y. (1977): La geografía: un arma para la guerra, Anagrama, Barcelona.

LetelieR, L. F.; TAPIA, V.C.; IRAZÁBAL, C.; BoyCo, P. (2019): «Políticas de fragmentación vs. prácticas de articulación: limitaciones y retos del barrio como dispositivo de planificación neoliberal en Chile», Boletín de la Asociación de Geógrafos Españoles, 81: 1-38. doi: http:/ / dx.doi.org/10.21138/bage.2698

MÉndeZ, M.L.; OTERO, G. (2018): «Neighbourhood conflicts, socio-spatial inequalities, and residential stigmatisation in Santiago, Chile», Cities 74: 7582. doi: https:/ / doi.org/10.1016/j.cities.2017.11.005

Maturana, F.; Fuenzalida, M.; ArenAs, F.; HenríQuez, C. (2017): «La planificación territorial en Chile y el proceso de descentralización», en C. VIAL y J. Hernández (eds.), ¿Para qué descentralizar? Centralismo y políticas públicas en Chile: Análisis y Evaluación por Sectores, Instituto Chileno de Estudios 
Municipales y Universidad Autónoma de Chile, Santiago de Chile: 181-208.

Moral, F.; Merino, E. (2018): «Cartografías urbanas: la representación gráfica del conflicto en los espacios públicos», Polipapers, 23 (32): 262-273. doi: https:/ / doi.org/10.4995/ega.2018.7973

MuÑoz, C. (2007): «Vivienda progresiva, un programa del sector público que se potenció en el hábitat rural chileno", Revista INVI, 22 (59): 132-150.

Navarrete-Hernández, P.; Toro, F. (2019): «Urban Systems of Accumulation: Half a Century of Chilean Neoliberal Urban Policies», Antipode, 51 (3): 899-926. doi: https://doi.org/10.1111/anti.12504

Nicolosi, E.; French, J.; Medina, R. (2019): «Add to the map! Evaluating digitally mediated participatory mapping for grassroots sustainabilities», The Geographical Journal, 185: 1-14. doi: https:/ / doi.org/10.1111/geoj.12315

Nofre, J. (2013): “Cartografías de la indignación», Ar@cne, 169: 1-20.

NúÑEZ, A.; ZAMBRA, A.; Aliste, E. (2017): «El poder de los mapas, los mapas del poder: la construcción del saber geográfico de Patagonia-Aysén», Universum, 32 (2): 149-162.

Pizarro, R. (2020): «Chile: rebelión contra el Estado subsidiario», El trimestre económico, 87 (346): 333-365. doi: 10.20430/ete.v87i346.1055

ROMÁN, Á.; BARTON, J.R. (2018): «Los supuestos del pensamiento urbano en Chile: justicia y equidad en la planificación de las ciudades», en F. ENCINAS, A. Wechsler, W. Bustamante, y F. Díaz (eds.), Intersecciones: II Congreso Interdisciplinario de Investigación en Arquitectura, Diseño, Ciudad y Territorio, Ediciones ARQ, Santiago de Chile: 14-27.

SAKELLARIOU, D.; ROTAROU, E.S. (2017): «The effects of neoliberal policies on access to healthcare for people with disabilities», International Journal for Equity in Health, 16(199): 1-8. doi: https:/ / doi.org/10.1186/s12939-017-0699-3

SÁNCHEZ, R. (2012): «El 15M como insurrección del cuerpo-máquina», Anthropos: Huellas del conocimiento, 234: 216-224.

Stiglitz, J. (2012): El precio de la desigualdad, Taurus, Madrid.

TAPIA, V. (2018): "Geografías de la contención: el rol de las políticas de escala barrial en el Chile neoliberal», Scripta Nova, 22 (592).

De Castro, S.; Méndez, J.C. (1992): El ladrillo. Bases de la Política Económica del Gobierno Militar Chileno, Centro de Estudios Públicos, Santiago de Chile.

De Ramón, A.; Gross, P. (1985): Santiago de Chile: Características histórico-ambientales, 1891-1924, Monografías de Nueva Historia, Londres.

PICSA. (2019): Creating an Inclusive Prosperity Cities Index. Background and Methodology, Disponible online.

Ritzer, G. y JuRgenson, N. (2010): «Production, Consumption, Prosumption: The nature of capitalism in the age of the digital 'prosumer'», Journal of Consumer Culture, 10(1): 13-36. doi: https:/ / doi.org/10.1177/1469540509354673

Sullivan-WileY, K.A.; SHort, A.G.; CASELlas, J.P. (2019): «Mapping vulnerability: Opportunities and limitations of participatory community mapping», Applied Geography, 105: 47-57. doi: https:// doi.org/10.1016/j.apgeog.2019.02.008

ToRO, J.; OcHOA, M. (2017): «Violencia de género y ciudad: cartografías feministas del temor y el miedo», Sociedad y economía, 32: 65-84.

Vives, A.; MolinA, A.; GrAY, N.; GonZÁLEZ, F. (2016): «Envejecimiento y trabajo en Chile: propuesta para el monitoreo de la salud laboral», en I. IRARRÁZAVAL, E. Piña, y M. Letelier (eds.), Propuestas para Chile, Centro UC Políticas Públicas, Santiago de Chile: 17-50. 


\title{
La transcripción del alfabeto líbico-bereber canario: el ejemplo de El Hierro
}

\section{The Alphabetic Transcription of Canarian Libyco-Berber Script: The Case of El Hierro}

\author{
Irma Mora Aguiar \\ Universidad de La Laguna \\ Cátedra Cultural de Estudios Bereberes \\ https:// orcid.org/0000-0002-6259-6685 \\ irmamora7@gmail.com
}

Recibido: 22/03/2021; Revisado: 26/04/2021; Aceptado: 10/05/2021

\begin{abstract}
Resumen
Se aborda la transcripción del alfabeto líbico-bereber canario desde una perspectiva de análisis morfofonológica. Para ello, se parte del corpus epigráfico herreño y se compara con el conjunto continental. A través de este estudio, se constata la presencia de múltiples morfemas del líbico de Numidia en las inscripciones herreñas. A su vez, se detectan rasgos lingüísticos de los dialectos bereberes meridionales, confirmándose el vínculo del alfabeto canario con la variedad presahariana, descendiente del líbico oficial númida. Finalmente, se advierten diferencias ortográficas entre el norte y el sur de la Isla que podrían reflejar variedades diatópicas, diacrónicas y diastráticas.
\end{abstract}

Palabras clave: Transcripción alfabética, análisis morfofonológico, líbico-bereber, Canarias, El Hierro.

\begin{abstract}
This study aims to transcribe the Canarian Libyco-Berber alphabet, employing a morpho-phonological analysis approach and comparing the corpus of inscriptions from the island of El Hierro with the continental one. The study demonstrates that the inscriptions from El Hierro contain multiple morphemes also present in the oldest Libyco-Berber alphabet from Numidia. In addition, the island inscriptions exhibit linguistic features of the Southern Berber dialects, confirming the link between Canarian and pre-Saharan alphabets. Finally, epigraphic analysis shows differences between the north and south of El Hierro. This orthographic disparity could signify diatopic, diachronic and sociocultural variation.
\end{abstract}

Key words: Alphabetic Transcription, Morpho-Phonological Analysis, Libyco-Berber, Canary Islands, El Hierro. 


\section{INTRODUCCIÓN}

Según ciertos lingüistas, como Ignace Gelb (1976 [1952]: 84) y Louis-Jean CALVET (1996: 222), cualquier escritura desconocida resulta más fácil de transcribir cuando se conoce la lengua que refleja. Tal fue el caso, por ejemplo, de la lineal B: una escritura silábica micénica que el doctor Michael Ventris y el filólogo John CHADWICK (1962 [1958]) acabaron descodificando tras concluir que representaba un dialecto arcaico del griego. Previamente, la arqueóloga Alice E. Kober había reconocido las marcas de género y otros morfemas flexivos que Ventris identificó con las desinencias casuales (СHADWICK, 1962 [1958]: 52). Este procedimiento minucioso ${ }^{1}$ ofreció mayor solidez a su hipótesis que las meras conjeturas que ofrecían algunos de sus predecesores.

También, la traducción de los antiguos textos egipcios se apoyó en el conocimiento de la lengua copta. ${ }^{2}$ Previamente, se habían descifrado sus grafías a partir de la piedra de Rosetta: una inscripción bilingüe greco-egipcia; cuyo texto egipcio fue redactado en dos variedades gráficas: jeroglífica y demótica. Las labores de transcripción de François CHAMPOLLION (1822) se iniciaron a partir del antropónimo regio reconocible en la versión griega (Ptolemaios). Así, el carácter conservador que posee la onomástica en las lenguas fue aprovechado por Champollion para establecer paralelismos entre ambos códigos.

El desciframiento del alfabeto líbico oriental o númida no distó mucho de los ejemplos expuestos. Su transliteración fue posible gracias a una estela bilingüe púnica-líbica: la inscripción de Aṭban. Al igual que sucedió con las escrituras egipcias, la transcripción de la númida conllevó décadas de estudio por parte de diferentes autores, entre los que destacó SAULCY (1843) por descodificar la mitad del alfabeto a mediados del siglo XIX. A comienzos del siglo XX, se produjo el hallazgo de una segunda inscripción bilingüe en la ciudad de Dougga: la dedicatoria a Masinisa, que favoreció la transliteración del resto del alfabeto (MARCY, 1936; СНАвот, 1939, 1940). En cuanto a la traducción de estas inscripciones bilingües y, en general, del conjunto númida, los epigrafistas se han sustentado en lenguas del phylum afroasiático, especialmente en el bereber, ya que el libio parece reflejar una de sus variedades diacrónicas (JudAs, 1863; HALÉvY, 1874; MARCY, 1936; ChABOT, 1940; RÖSsler, 1958; CHAKeR, 1985; GALAND, 2002; etc.).

Con respecto al alfabeto líbico-bereber canario, se ha observado cierta

1 «Dos son los métodos que pueden seguirse. Uno consiste en el análisis metódico, (...); el otro procede por conjeturas más o menos justificadas. La intuición inteligente debe, por supuesto, desempeñar un papel en el primer caso; pero existen grandes diferencias entre un desciframiento basado en un cuidadoso análisis interno y otro obtenido mediante el ensayo y el error. De este último puede obtenerse el resultado correcto, pero será necesario confirmarlo por aplicación al material virgen, ya que por su origen no tiene fuerza probatoria alguna. Es preciso asimismo un criterio seguro para discriminar entre lo que es probable o improbable que un texto contenga. De esta facultad carecían visiblemente quienes comprometieron su reputación con el método conjetural» (СHADWICK, 1962 [1958]: 41-42).

2 No obstante, los egiptólogos del siglo XIX cometieron errores de traducción al equiparar el copto al egipcio antiguo, siendo realmente dos estados de la lengua bien diferenciados (CERVELLó, 2016: 269270). 
homogeneidad (SPRINGER, 2017) y un mayor parecido con las inscripciones númidas (SPRINGER, 1994, 2001: 166-171). No obstante, la variedad canaria contiene una serie de grafemas característicos de otros alfabetos, que están ausentes en el líbico oriental (SPRINGER, 2019). Tal y como concluimos en nuestra tesis doctoral, esas similitudes con el alfabeto oriental de Dougga se explican porque este constituyó la norma que se extendió por el norte de África tras la reunificación de Numidia (162 y 111 a. n. e.). Obviamente, con el debilitamiento de la dinastía masilia, la escritura evolucionó, adaptándose a las distintas variedades geográficas y sociales, así como a las funciones y soportes empleados por sus usuarios. Ello parece explicar la presencia en Canarias de grafemas ajenos al corpus oriental. Aparentemente, estos caracteres pertenecen a una modalidad líbica meridional que se distribuyó a lo largo de la franja esteparia durante los primeros siglos de nuestra era y, más tarde, hacia al Sáhara central. ${ }^{3}$ Probablemente, la difusión de dicho alfabeto estuvo relacionada con la romanización, pues esta propició un aumento demográfico, el empuje poblacional hacia el sur y la dinamización del comercio caravanero (EuZENNAT, 1985: 170; BÉNABOU, 1976: 167-175; Gsell, 1927: V, 4; Lhote, 1975: 164, 1982: 58; Demougeot, 1960: 219; CAmps, 1978: 161). Así, a través de la célebre Ruta de los Chotts o de los Lagos Salados (Trousset, 1982), la escritura líbico-bereber acabaría arribando a las inmediaciones del río Guir, Tafilalt, valles del Sous y Draa. Estas regiones concentran las inscripciones más similares a las canarias, por lo que se deduce que la escritura llegaría a las Islas con sus primeros pobladores desde las costas meridionales del actual Marruecos a partir de los siglos II-III d. n. e. (MorA, 2021), periodo que coincide con la mayoría de las dataciones canarias más antiguas (VELASCO et al., 2020). Dada la probada líbico-berberofonía de los antiguos habitantes de las Islas (AcostA, 2017, 2019a) y los parecidos de la escritura líbico-bereber canaria con la númida, resulta tentador transcribir sus inscripciones recurriendo en exclusiva a esta modalidad alfabética. No obstante, como apuntaba CHADWICK (1962 [1958]: 41-42), este procedimiento basado en «el ensayo y el error» solo proporcionaría conjeturas de obligada demostración. Además, permanecerían sin transcribir aquellos grafemas ajenos a la norma númida, que tendrían que estudiarse necesariamente a partir de otros alfabetos líbico-bereberes.

\section{METODOLOGÍA}

Para el análisis del alfabeto canario, hemos seleccionado el corpus de la isla de El Hierro. Ello se debe a que sus 114 paneles suponen más de la mitad de los aproximadamente doscientos estimados por SPRINGER (e. p.) para el conjunto canario. Por lo tanto, se trata de una muestra bastante representativa del líbicobereber de las Islas. Obviamente, las conclusiones extraídas deben extrapolarse con cautela al resto del Archipiélago, ya que, como apuntábamos, se observa una

3 La inscripción líbico-bereber más antigua del Sáhara central es, de momento, la hallada sobre un bloque del monumento funerario de Abalessa (Tamanghaset, Argelia), cuyos restos arqueológicos datan de los siglos Iv-v d. n. e. (vid. CAMPs, 1978: 61). 
clara uniformidad alfabética, pero también ciertas diferencias en las frecuencias de algunos caracteres (SPRINGER, 2017).

El corpus herreño ha sido comparado con 1389 inscripciones norteafricanas pertenecientes a estelas y paneles de diversos alfabetos antiguos y medievales (líbico oriental, occidental, meridional y líbico-bereber de transición) distribuidos desde la franja septentrional norteafricana hasta el Sáhara occidental. ${ }^{4}$ Así pues, al igual que han hecho nuestros predecesores para las escrituras indescifradas o poco conocidas, consideramos que los ensayos de transcripción no pueden evadir el análisis interno, fundamentalmente porque no está demostrada la existencia de inscripciones bilingües en Canarias. ${ }^{5}$

En este análisis, nos hemos apoyado en el método que desarrolló RössLER (1958) para desentrañar la morfología del líbico oriental, seguido principalmente por CHAKer $(1985 a, 1988)$ y JONGELING $(1984,1994)$. Más tarde, El KHAYARI (2004) lo aplicó para interpretar el líbico occidental. Este análisis trata de localizar segmentos permutables y conmutables entre pares mínimos que comparten la misma raíz léxica. Cuando carecíamos de pares mínimos para identificar estos morfemas, hemos recurrido al principio del triliterismo de la raíz (Rössler, 1958: 108). Según este principio, aplicable a otras lenguas afroasiáticas, las raíces se constituyen originalmente por un máximo de tres consonantes. ${ }^{6}$ Por consiguiente, todo signo adicional debería de reflejar un morfema gramatical. Además de en la epigrafía herreña, este procedimiento ya se ha aplicado al estudio de su toponimia aborigen (AсоsтA, 2019a: 205).

\section{CORPUS ALFABÉTICO}

En este apartado analizamos los grafemas líbico-bereberes herreños, ordenándolos según su supuesto lugar de articulación. Estos se representan atendiendo a su posición en los renglones, mayoritariamente verticales y leídos de abajo hacia arriba. Asimismo, exponemos su comportamiento en los alfabetos estudiados, centrándonos en El Hierro con el fin de advertir su hipotético valor fonológico y, si lo tuviera, morfológico.

4 Hemos desarrollado este trabajo en nuestra tesis doctoral La contextualización arqueológica y epigráfica de las inscripciones líbico-bereberes de El Hierro, defendida en la Universidad de La Laguna en 2021.

5 En Lanzarote y Fuerteventura se han documentado inscripciones bialfabéticas líbico-bereberes y líbico-canarias. Por los parecidos formales de estas últimas, algunos autores (PICHLER, 2003; FARRUJiA et al., 2009; BELMONTE et al., 2019: 223; PERERA y JiméneZ, 2020) han concluido que se trata de escritura latina, llegando incluso, en ocasiones, a clasificarla como cursiva pompeyana. Además, sin respaldarse en ningún método solvente de transcripción, PERERA y JiMÉNEz (2020:3) han defendido la existencia de paneles que contenían «(...) las mismas voces con caracteres de los dos tipos de alfabeto documentados en Fuerteventura (líbico-bereber y líbico-latino)». A pesar de ello, ningún latinista ha concluido aún que se trate verdaderamente de este alfabeto (RAMíreZ, 2010). Tampoco se ha pronunciado académica y públicamente al respecto la comisión de especialistas (ninguno de ellos en escritura líbico-bereber) invitada al encuentro privado Las voces de las palabras escritas. Escritura líbico-bereber y líbico-canaria, celebrado en Lanzarote en octubre de 2017. Por lo tanto, consideramos aventurada la transcripción de un alfabeto poco conocido (el líbico-bereber) a partir de una grafía enigmática (la líbico-canaria). 6 Las raíces bilíteras y monolíteras se explican por el debilitamiento y la consecuente vocalización de los radicales correspondientes a semiconsonantes y consonantes posteriores (PRASSE, 1972: I-III, 104106). 


\subsection{Orden labial}

\section{El grafema $\bigcup$}

Se trata de un alógrafo del signo original X (Álvarez, 1964: figura 54; GALAND, 1976: 76; SPRINGER 2001: 169), que en el alfabeto líbico oriental representó el fonema */f/. Esta variante cuadrangular $(\forall)$ o redondeada $(\forall)$ es común en las inscripciones canarias realizadas mediante piqueteado. Igualmente, se documenta en algunos yacimientos ${ }^{7}$ de Draa-Tafilalt (Marruecos) y de Río de Oro-La Güera (Sáhara occidental) que contienen inscripciones líbico-bereberes medievales o de transición, lo que sugiere que era una variante relativamente tardía.

$\mathrm{Al}$ igual que en los alfabetos norteafricanos, en El Hierro el uso de $\forall$ fue escaso (2,19\% del corpus) y no se constata una pauta indicativa de su función morfológica. Debido a este comportamiento y a que la /f/ carece de función gramatical $^{8}$ en las lenguas líbico-bereberes, resulta verosímil que plasmara el mismo valor fonológico en las inscripciones herreñas. ${ }^{9}$ Por lo tanto, descartamos que anotase el fonema */g/, como sucede en el tifinagh de Ahaggar (Argelia), ya que, además, como se verá en el apartado 3.3, esta velar se representó mediante otro signo.

\section{El grafema $\odot$}

Tampoco es una letra especialmente frecuente en el corpus herreño $(2,08 \%)$ ni se observa ninguna función morfológica para ella. Tanto en el líbico oriental como en el occidental, representó el fonema */b/ (CHABOT, 1940: v; KHAYARI, 2004: 95) y, si bien carecía de valor gramatical, su presencia era elevada debido al uso de la fórmula BNS 'su estela, su lápida'. Como la escritura se empleó mayoritariamente en Canarias sobre soportes rupestres ajenos a los usos funerarios, es predecible la ausencia de esta fórmula. Igualmente, la frase 'su lápida' no sería aplicable para el chajasco de la necrópolis del Hoyo de Los Muertos (Guarazoca, Valverde), ya que se trata de un tablón de madera.

En definitiva, es más verosímil que el signo $\odot$ representase la */b/, como en los alfabetos líbicos, que la */s/, como en los tuaregs ${ }^{10}$ (vid. Aghali-ZaKara y Drouin, 2007: 28). De no ser así, observaríamos un comportamiento diferente para este grafema (i.e., frecuencia más elevada, combinación con otros caracteres, etc.), puesto que la consonante /s/ desempeña diversas funciones morfológicas en las lenguas líbico-bereberes, tal y como expondremos más adelante.

7 Hajart, Wiggane, Foum Chenna (Rodrigue y Pichler, 2007), Laghchiwat (Ewague, 2016), Monolito de Gleibat Ensur y Leyuad (GALAND, 1973a).

$8 \mathrm{El}$ valor gramatical de esta consonante se restringe actualmente a las preposiciones bereberes af(ella) y eyaf'sobre' (vid. NAÏT ZERRAD, 2011).

9 Es probable que, en cierto estado de la lengua aborigen herreña, este grafema se realizara *[p], ya que así se conserva en la toponimia herreña de origen bereber, según ACOSTA (2019a: 230).

10 En los alfabetos tifinagh parece haberse producido una confusión entre los valores de la letras líbicas $\odot(* / b /$ en líbico y /s/ en tuareg) y $\Phi(* / s /$ en líbico y /b/ en tuareg), seguramente, motivada por sus similitudes gráficas. 


\subsection{Orden dental}

El grafema +

Es habitual en el corpus herreño (4,92 \%) y parece ejercer varias funciones gramaticales advertidas en el conjunto norteafricano. A esto hay que añadir que, tanto en los alfabetos líbicos antiguos como en los tuaregs actuales, representó el fonema */t/ (Снавот, 1940: v; Galand, 1966: 21; Aghali-ZaKara y Drouin, 2007: 28), por lo que resulta especialmente verosímil que en Canarias poseyera el mismo valor.

La *t de El Hierro parece haber representado mayormente dos morfemas característicos que marcan el género femenino en las lenguas líbico-bereberes: el prefijo verbonominal $(t-)$ y el circunfijo singular $(t-\ldots-t)$.

Con respecto al prefijo verbonominal $(t-)$, hemos hallado dos pares mínimos que demostrarían su existencia. Así, observamos que la supuesta raíz ${ }^{*} R N$ (La Cueva de Las Chivas 1.2 y Arenas Blancas 1.1) lleva prefijada esta * $t$ (*TRN) en el panel 1.1 de la Cueva del Agua. Además, la *t parece permutar con la desinencia masculina de $3 .^{\mathrm{a}}$ persona singular $\left({ }^{*} \mathrm{YRN}\right)$ en la inscripción 1.1 del Barranco del Cuervo. Asimismo, hallamos la conmutación de *t en la supuesta raíz *FM: *TFM (Barranco del Cuervo 9.5B) frente a * FM(-N) (La Candia 1.2).

El circunfijo singular $(t-\ldots-t)$ es una marca nominal líbico-bereber que parece haberse inscrito en las secuencias *TDKT (La Caleta 5.5) y *TKNT (Hoyo Blanco 1.2). Sin embargo, no contamos con pares mínimos que lo confirmen, ni tampoco podemos recurrir al triliterismo de la raíz para establecer tal valor. No obstante, en bereber, la / $t$ / muy rara vez tiene un valor de tercer radical, por lo que es bastante probable que se trate del sufijo nominal femenino.

\section{El grafema つ}

Es otro de los caracteres que comparte su valor */d/ en los alfabetos líbicos y en los tifinagh de Ghat (Libia) y Ahaggar (Argelia) (GALAND, 1966: 32; KHAYARI, 2004: 95-97; Aghali-Zakara y Drouin, 2007: 28). Tanto en las inscripciones norteafricanas como en las herreñas (donde suma el 3,28 \% del corpus) parece representar radicales léxicos. Además, tuvo un empleo reducido como conjunción copulativa, sobre todo en las estelas oficiales de Dougga, donde se enumeran diversos personajes. También en El Hierro pudo haberse usado como tal, pues se sitúa entre dos líneas (*SMS y *ML) de la inscripción 1.1 de El Tejal. Asimismo, la encontramos prefijada en la tercera línea desde la izquierda en el panel 1.4 de La Cueva de Don Gabino ( $\left.{ }^{*} \mathrm{DWHB}\right)$. Quizá, esta palabra estaba constituida por la conjunción y una raíz trilítera, o bien por un patronímico: *w $\mathrm{Hb}$ ¿'el hijo de $\mathrm{Hb}^{\prime}$ ? 
El grafema

Se trata de uno de los signos más complejos del corpus herreño (4,70\%), ya que se comporta de manera diferente a su equivalente númida $(* / \delta /)$. En efecto, en El Hierro, este grafema suele escribirse a final de palabra: un patrón que también observamos en Gran Canaria, ${ }^{11}$ Lanzarote, ${ }^{12}$ Fuerteventura ${ }^{13}$ y en algunas inscripciones rupestres de La Cabilia ${ }^{14}$ (Argelia) y de Draa-Tafilalt. ${ }^{15}$ Por lo tanto, probablemente $\amalg$ representó un morfema. Dado que la $/ \mathrm{J} /$ es poco productiva, teniendo únicamente una función expresiva en bereber (KossmanN, 1999: 2019; NAÏT-ZERRAD, 2002a: 356), habría que descartar que plasmara esta consonante. Seguramente, la clave para descifrar este signo esté en otro gráficamente próximo perteneciente a la norma oficial númida: la *t de Dougga $(\epsilon)$. Dicha letra podría ser su antecesora, ya que se observa una progresiva pérdida de su apéndice lateral, ${ }^{16}$ que le hace adquirir una forma parecida a $\ni$ (lectura horizontal sinistrorsa). Asimismo, este grafema representa la dental faringalizada en los actuales alfabetos tifinagh de Ahaggar y Ghat (vid. Aghali-ZaKara y Drouin, 2007: 28), de manera que parece muy probable que también descienda de la * $t$ de Dougga.

Su función morfológica se confirma a partir del triliterismo de la raíz, ya que encontramos la letra $\amalg$ sufijada a series triconsonánticas en La Candia 1.3 $\left({ }^{*} \mathrm{MNRT}\right)^{17}$ y 1.4 ( $\left.{ }^{*} \mathrm{NTTST}\right)$. Además, también la hallamos al final de las palabras *YZNKT (La Candia 1.4) y *WDDMT (La Caleta 5.2), que aparentemente están formadas por un prefijo $\left({ }^{*} y-\mathrm{y}{ }^{*} w-\right.$, respectivamente), una raíz trilítera y la supuesta ${ }^{*} t$.

En principio, sorprende que esta consonante correspondiera a un morfema, siendo más habitual esta función para su correlato no faringalizado. Quizá, la explicación radique en una supuesta realización $\left[\mathrm{t}^{\mathrm{f}}\right] \mathrm{de} / \mathrm{t} /$ en posición final. Un comportamiento similar se ha documentado en algunos dialectos cenetes meridionales actuales donde se faringaliza tanto la $t$ final como la inicial. Concretamente, en las regiones de Matmata (Gabes, Túnez) (Provotelle, 1911: 12) y, Touat y Gourara (Adrar, Argelia) (BASSET, 1885: 388-392). Consideramos esclarecedor que estas hablas se sitúen en los extremos del área de expansión

11 Durante la primera fase dedicada a Gran Canaria del Inventario de Inscripciones alfabéticas (proyecto dirigido por la Dra. Renata Springer en 2014), observamos este comportamiento en los siguientes paneles: Montaña de Birbique 1.1, Barranquillo del Cardón 1.1, Barranco del Roque 1.3, Roque de Cuevas del Rey 1.1, Lomo de las Tablas 1.1. Además, este patrón se repite en el Barranco de la Angostura, la Necrópolis de Arteara, el Barranco de Balos, Bandama y la Hoya de Toledo (vid. C.H.E.C., 1988; GarCía Navarro et al., 2004; Cuenca, 1996; Springer, 1996; Rodrigue y Pichler, 2007; Martín et al.,2008).

12 Concretamente, se inscribió en la Peña de Luis Cabrera, el Barranco de las Piletas, la Peña Juan del Hierro, Femés, Montaña Ortiz, (vid. Ulbrich, 1996; Rodrigue y Pichler, 2007).

13 Este signo se halla en posición final en el Morro de la Montaña Blanca y en el Morro de la Galera (vid. RODRIGUe y PICHLER, 2007).

14 Ifigha, Falaise de Roui y Azrou Bourzou (vid. SPRINGER, 1994: 215-235).

15 El Ghoula 2.3 y Rehris 2.5 (vid. Rodrigue y Pichler, 2007).

16 Contamos con dos ejemplos ilustrativos en las estelas de la Torre oeste y del Monumento de los nichos, recientemente descubiertas (vid. GHAKI, 2000: 1662, 2011: 5).

17 No obstante, la * $m$ inicial podría corresponder también al prefijo de nomen agentis. 
del antiguo alfabeto líbico meridional, variedad que seguramente se implantó en Canarias (MorA, 2021: 55). Igualmente, Acosta (2019a: 231) ha contemplado la posibilidad de que a la Isla arribara un habla cenete meridional.

\subsection{Orden alveolar}

El grafema $\ominus$

Se trata del alógrafo de la * s/ númida más habitual en El Hierro, resultante de la evolución de la forma original $\mathbb{Z}$. Esta última variante está también presente en la Isla, especialmente en las inscripciones realizadas mediante incisión. Ambas formas ascienden al 6,56\%: un porcentaje elevado que coincideconla productividad de la /s/ en las lenguas líbico-bereberes. De hecho, en las inscripciones herreñas distinguimos algunos morfemas con */s / característicos de la onomástica líbica, que han sido estudiados por numerosos autores (LETOURnEUX, 1878; СНАBOT, 1940; FÉVRIER, 1956; PrASSE, 1974; JONGELING, 1984; CHAKER, 1985a). Nos referimos al prefijo de nomen instrumenti, de causativo y factitivo (s-), así como a los pronombres enclíticos oblicuos de $3 .^{a}$ persona $(-s,-s n)$.

El prefijo de nomen instrumenti (s-) se suele encontrar adherido al de nomen agentis $(m-)$, formando el prefijo adjetivador denominal * $m s-$ (GALAND-PERNET y GALAND, 1995), que es especialmente habitual en la antroponimia númida (СНАвот, 1940: хIX) y aún lo conserva el habla tuareg de Mali (HeAtH, 2005: 552). Aparentemente, el prefijo adjetivador se empleó también en El Hierro, tal y como se deduce de su conmutación en los siguientes pares mínimos: *YN (El Tejal 1.2 y Barranco de Tejeleita 2.6 B) frente a *MSYN (Barranco de Tejeleita 2.6) y *WRN (Barranco del Cuervo 8.2) frente a ${ }^{*} \operatorname{MSWRN}_{1}$ (La Cueva de Don Gabino 1.2 G).

Los pronombres enclíticos oblicuos de $3 .^{\text {a }}$ persona $(-s,-s n)$ son frecuentes en el corpus líbico oriental y poseían dos funciones descritas por diversos especialistas (RÖssler, 1958: 112; Jongeling, 1984: 89; CHAKeR, 1985a: 487-488, 492-493). En primer lugar, la de adjetivo posesivo, cuando acompañaban a sustantivos, como se observa claramente en la fórmula funeraria númida bn-s 'su estela' (LETOURNEUX, 1878: 71). En cambio, ejercía la función de complemento indirecto cuando va acompañado de verbos, como, por ejemplo, señalaba CHAKER (1985a: 492) para el antropónimo YZGGSN (RIL ${ }^{18}$ 1109): "Y-ZGG (a)sen, de *ZGG (?)+(a)sen "a ellos" $\rightarrow$ "Él les..."».

En El Hierro se documenta la forma plural del pronombre oblicuo de 3. ${ }^{a}$ persona en las siguientes líneas: *NŠHSN (Barranco de Tejeleita 2.3), *YDRSN (Barranco del Cuervo 7.1), *TTTṬN (La Cueva de Don Gabino 1.1) y *ŠG SN (La Caleta 2.3 y 3.2). En los tres primeros ejemplos se segmenta el pronombre -sn a partir del principio del triliterismo de la raíz, aunque la ${ }^{*} n$ - y la * $y$ - iniciales podrían corresponder, respectivamente, a las desinencias verbales de 1 . $^{\mathrm{a}}$ persona

18 La sigla RIL hace referencia al Recueil des Inscriptions Libyques de CHAвот (1940), que contiene el corpus más amplio de estelas epigráficas líbicas. 
del plural y $3 .^{\text {a }}$ del masculino singular. Por consiguiente, el pronombre oblicuo equivaldría al complemento indirecto en estos casos. En cambio, la línea *TTTTSN parece formada por un sustantivo acompañado del posesivo, a saber: *titt (a)sen ¿'su (de ellos) ojo, su fuente' ? $^{19}$ Por último, observamos que los propios autores de la inscripción segmentaron con un punto el pronombre oblicuo del supuesto sustantivo en *ŠG SN: 'su (de ellos) šg'.

\section{El grafema $\mathrm{H}$}

Aparentemente, anotaba la */ $\mathrm{z}^{\varsigma}$ / en el líbico oriental (Снавот, 1940: V; cf. KossmanN, 2020: 877). No obstante, pudo haber plasmado la */z/ en el occidental y en el meridional para evitar confusiones con la ${ }^{*} n$ tras su rotación. ${ }^{20}$ Esta idea se apoya también en los alógrafos tuaregs de $z(\neq, \nvdash, \nVdash, \#)$, que resultan de la evolución o la duplicación de I.

Igualmente, el signo $H$ pudo plasmar el fonema */z/ en el líbico-bereber herreño, dado que este grafema parece descender del líbico meridional y, al igual que sucede en el vecino continente, de su análisis tampoco se infiere ninguna función morfológica. A pesar de ello, poseyó un uso más elevado (3,17 \%) que en otras regiones norteafricanas, probablemente debido al léxico empleado, o bien a aspectos fónicos como la sonorización de $s$ - en posición intervocálica o ante consonantes sonoras.

\section{El grafema $\top$}

Es un signo escaso en las inscripciones continentales, ya que parece haber plasmado la sibilante faringalizada $* / \mathrm{s}^{\uparrow} /$ : un fonema poco productivo en las lenguas líbico-bereberes. Igualmente, es minoritario en El Hierro $(0,77 \%)$, por lo que sería admisible que compartiera el mismo valor fonológico.

\subsection{Orden palatal}

\section{El grafemau}

Se trata del alógrafo más habitual, aunque también se documenta su forma original $w$ (con valor * $/ \int /$ en Dougga) en las inscripciones incisas herreñas, así como su variante diacrónica tardía $\Omega \Omega^{21}$ en algunas piqueteadas. Todos los

19 El sustantivo pan-bereber tițt designa 'ojo' y por extensión, 'fuente' (HADDADOU, 2006: 221).

$20 \mathrm{La}{ }^{*} n$ y la ${ }^{*} z$ númidas se representan, respectivamente, a través de una barra vertical y horizontal. No obstante, en el líbico occidental (GALAND, 1966: 25) y en el meridional parece abandonarse esta regla ortográfica, teniendo que adoptar una forma diferente para la */z/ (MORA, 2021).

21 Esta variante resultó del alargamiento de $\boldsymbol{\sim}_{\mathrm{y}}$ es aparentemente posterior a la forma original ${ }^{\text {}}$. Así mismo, se ha documento un alógrafo más tardío en Foum Chenna, generado tras el estiramiento de 几 . Las inscripciones de Foum Chenna se enmarcan en el líbico-bereber de transición (PICHLER, 2008: 187), por lo que podrían ser medievales o, incluso, posteriores. 
alógrafos suman el 2,95 \% con respecto al total del corpus. Las dos variantes redondeadas se localizan también en las estelas del antiguo limes tingitano ${ }^{22}$ y en los paneles rupestres de Draa-Tafilalt y Sous-Masa (Marruecos). ${ }^{23}$

Al ser el único grafema en este orden, probablemente no constituía una consonante relevante para el sistema fonológico líbico-bereber, tratándose quizá de un alófono con valor expresivo, tal y como se documenta en bereber (KossMANN, 1999: 219; NAÏT-ZERRAD, 2002a: 356) y en algunos guanchismos (AcostA, 2017: 24). De hecho, en la antroponimia númida ${ }^{24}$ se observa la variación libre de $s$ y š en el pronombre enclítico oblicuo plural ${ }^{25}$ (alomorfos -sn y -šn) y en el prefijo nominal ${ }^{26}$ (alomorfos $m s-$ y $m \check{s}$-), por lo que seguramente fueron alófonos para los autores de estas estelas. Asimismo, en la actualidad, se ha señalado la palatalización ocasional de la $s$ en cinco dialectos bereberes meridionales. ${ }^{27}$

Según nuestro análisis epigráfico, El Hierro no fue ajeno a este comportamiento, pues aparentemente la palatalización de la *s se produjo en los mismos morfemas, dando lugar a los correspondientes alomorfos. En primer lugar, la observamos en el supuesto prefijo adjetivador de las líneas *NMŠșG ( $\left.{ }^{*} n m s ̌ s ̧ g ~ ¿ ' d e ~ m s ̌ s ̧ g ' ?\right)$, *YNMŠGL (*yan mšgl i'un mšgl'?) (Los Saltos 1.1), *YNMŠKL (“yan mškl i'un $m s ̌ k l$ ?') (Los Letreros 13.2) y, quizá, en *GSNMŠN ( ${ }^{*} g s n$ mšn) (La Candia 1.2). Y, en segundo lugar, se advierte lo mismo en el supuesto pronombre oblicuo de 3 . ${ }^{a}$ persona del plural de *S ¿F?GŠN (La Candia 2.6) y * ¿YW?MNŠN (Barranco del Cuervo 1.1).

\subsection{Orden velar}

\section{El grafema in}

Se trata de una variante característica del alfabeto líbico meridional (MORA, 2021: 47-48), a su vez procedente de la $k$ asimétrica de Dougga (RIL 1) (JuDAs, 1863: 11-12; MARCY, 1936a: 24, 1932: 19; Álvarez, 1964: figura 52; CAMPS, 1978: 158; cf. GALAND, 1966: 33, 1973b). En El Hierro se ha registrado este alógrafo en las inscripciones incisas y su forma redondeada en las piqueteadas. En total, la

22 IAM (Inscriptions Antiques du Maroc) 20, 25 (Galand, 1966: 67, 73) y Thamusida 1 (Ait Ali, 2012: 424). 23 Msemrir 1.4, Ouaremdaz 1.9 y Taouz 1.7 (Rodrigue y PICHLER, 2007).

24 En los epitafios líbicos orientales se adoptó el alógrafo cuadrangular $\amalg$, en lugar de ${ }^{\star}$ (presente en las oficiales de Dougga y en las estelas occidentales o mauretanas). En la escritura púnica, la forma ш es también un alógrafo de la šin $\left(* / \int /\right)$ que parece generalizarse a partir del siglo IV a. n. e. (vid. CunCHILlOS y ZAMORA 1997: 168-170).

25 BRŠN (RIL 186), variante de BRSN (RIL 914); BTŠN (RIL 817); YBLŠN (RIL 571) y KNYŠN (RIL 89), posible variante de KNYSWN (RIL 7: 3).

26 MŠHRNL (RIL 1071); MŠGT (RIL 251); MŠKWR (RIL 476); MŠRT (RIL 413), variante de MSRT (RIL 290); MŠTH (RIL 337), variante de MSTH (RIL 87, 513, 589, 671, 674, 676, 689, 723, 810 y 1033); MŠṬHT (RIL 76); MŠTRT (RIL 284 y 473); MŠW (RIL 139), variante de MSW (vid. Chabot, 1940: XV) y MŠWNT (RIL 447), que podría ser la variante de MWSN (RIL 26 y 915).

27 Concretamente, en el zenaga (TAINe-CHeIKH, 1999: 318), el tetserret (Lux, 2013: 133), el tuareg de Ahaggar (Prasse, 1972: I, 45), así como en Ouargla (Delheure, 1987: 3) y Auyila (Putten, 2014: 14). 
presencia de este grafema representa el 2,95 \%: una cifra cercana a la registrada para la * $k$ líbica meridional.

En cuanto a su valor morfológico, se ha documentado el prefijo $\mathrm{kn}$ - en la antroponimia líbica (Снавот, 1940: хviII; Yoyotтe, 1958: 24; Colin, 1999: 16), que, según nuestro criterio, refleja un sintagma formado por el antiguo artículo ${ }^{28}$ y la preposición 'de'. Además, se ha registrado el sufijo - $k n$ (Colin, 1996: 51-53; JoNGELING, 1984: 60-61, 1994: XVII), que identificamos con el pronombre enclítico de acusativo de 2 a $^{\text {a }}$ persona del plural. Los pronombres de acusativo realizan la función de sujeto en los verbos de cualidad (GALAND, 2002: 273-283; ACOSTA, e.p.) y la de complemento directo en los verbos transitivos (CHAKER, 1985a: 487).

En El Hierro no se detecta la prefijación de *KN, seguramente por la propia evolución de la lengua, aunque quizá sí su sufijación. De hecho, advertimos la conmutación del supuesto pronombre enclítico * $k n$ en el par mínimo ${ }^{*} \mathrm{~N}_{1} \mathrm{RKN}$ (La Caleta 2.1) y *NR (Lomo de Tejeleita 1.3). Asimismo, pudo haberse empleado su singular $(-k)$, dada la conmutación de esta consonante en el par *LMNK (El Tejal 1.4) y *LMN (Rivera 1.2).

\section{El grafeman}

A priori, esta letra resultaba difícil de reconocer por su forma, ya que podría haberse confundido con la ${ }^{*} s_{1}$ de Dougga o con una * $m$ invertida (vid. Снавот, 1940: v). No obstante, a partir del estudio del corpus herreño, hemos constatado que se trataba de un alógrafo redondeado de $\Lambda$, a su vez variante de la letra original 1 con valor */g/ en los alfabetos oriental (СНАвот, op. cit.: ibidem) y occidental (KHAYARI, 2004: 103). Por lo tanto, este grafema parece haber evolucionado de la misma manera que la * $k$, experimentando una ligera inclinación de su ductus, un alargamiento del trazo corto y, finalmente, un redondeamiento de su ángulo. Igualmente, según se extrae de la consulta del RIL (СНАBOT, op. cit.), la *g númida llegó a experimentar los dos primeros pasos, aunque mantuvo su forma aguda. ${ }^{29}$

Hemos comprobado que las diferentes variantes de este grafema $(4,16$ $\%$ en total) se llegaron a emplear para secuencias idénticas. En primer lugar, registramos cinco veces la palabra *GZL en La Caleta, escrita con el alógrafo redondeado (paneles 5.4 y 5.6) y con el anguloso (paneles 4.15 y 5.6). Por otro lado, se advierten las mismas oscilaciones gráficas para la *NG en distintos paneles a principio de línea, que quizá reflejaba la preposición pan-bereber nnig 'sobre,

\footnotetext{
28 En las inscripciones líbicas orientales se observa una vacilación de la velares * $k$ y ${ }^{*} g$, especialmente en los epitafios (en general, posteriores a las oficiales de Dougga). Por ejemplo, encontramos la variante GNSLN (RIL 677) del antropónimo KNS 1 LN, habitual en Dougga (RIL 2, 3, 5, 7 y 11). Probablemente, esto se explique a partir del debilitamiento de la * $k$, que quizá representaba una labiovelar, produciéndose, por tanto, la siguiente evolución: ${ }^{*} / \mathrm{k}^{\mathrm{w}} />* / \mathrm{g}^{\mathrm{w}} />/ \mathrm{w} /$. Ello podría reflejar los resquicios de un orden labiovelar proto-líbico-bereber, tal y como ha propuesto AcosTA (2019a: 165).

29 El mantenimiento de la forma aguda en las inscripciones líbicas parece deberse a que la técnica empleada era mayoritariamente la incisión, tras antes haber realizado un esbozo piqueteado (СНABOT, 1940: 230). Dada la ausencia de metales en Canarias, se recurrió al instrumental lítico, que no resultaba igual de eficaz para ejecutar incisiones prolijas y profundas. Quizá, por ello se prefirió la técnica del piqueteado, ya que favorecía la precisión, permanencia y visualización de los trazos.
} 
encima de' (DALLET, 1982: 553; TAÏFI, 1991: 474; KossmANN, 1999: 148), documentada en la teonimia canaria según Provotelle ${ }^{30}$ (1911: 13). Hemos reconocido esta supuesta preposición a partir de la segmentación del texto con el punto ( ${ }^{*} \mathrm{NG} \cdot \mathrm{RY}$ en La Caleta 2.5) y a través del principio del triliterismo de la raíz en *NGTDT y *NGNRN (La Caleta 5.9). Asimismo, también pudo haberse inscrito en las líneas *NGDBNK (La Candia 2.5) y *NGWSYN (La Caleta 2.1).

\section{El grafemaH}

Se trata de uno de los caracteres propios del alfabeto líbico meridional (MorA, 2021: 50), que más tarde se generalizó en los primeros alfabetos saharianos. Según Aghali-ZaKara y Drouin (2009: 9) y CASAjus (2015: 188-190), representó la consonante $\gamma$ en estas inscripciones antiguas. Es posible que tanto en el líbico meridional como en El Hierro equivaliera también a esta velar faringalizada (*/ $\mathrm{k}^{\varsigma} /$ ), ya que no se documenta su equivalente de Dougga $(\stackrel{\bullet}{\cdot})$. Además, tampoco el grafema $\equiv$ es tan frecuente como para haberlo anotado, tal y como podría haber sucedido en los epitafios orientales. ${ }^{31}$ Por otro lado, este signo tiene una frecuencia muy baja $(0,55 \%)$ : rasgo característico de los fonemas faringalizados del bereber.

A priori, resulta complejo afirmar que $\mathrm{H}$ equivaliera a la desinencia de $1 .^{\mathrm{a}}$ persona del singular $(-\gamma)$, como señalaron AGHALI-ZAKARA y Drouin (2009: 9) para los textos saharianos. Aun así, quizá poseyó un valor gramatical en dos ejemplos en los que se sitúa a final de palabra. La primera, ${ }^{*} \mathrm{HMBQ},{ }^{32}$ corresponde al panel 2.11 del Barranco del Cuervo y deducimos que se trataba de un sufijo al estar precedido por tres consonantes. Por último, se observa su permutación con la * $t$ en el panel 1.1 del Barranco de Tejeleita: *WRYNT WRYNQ :

\subsection{Orden glotal}

El grafemalll

Es un signo relativamente escaso (1,97\%) comparado con su equivalente de los epitafios orientales (10 \%). En cambio, la supuesta */h/ herreña registra una pauta más cercana a la norma oficial de Dougga, donde esta letra comenzaba a alternar con la $t_{1}$ a final de palabra. En las inscripciones herreñas, la glotal aparece

30 «Une particularité qui m’a paru intéressante à signaler à part est le nom que les Sendi donnent à Dieu: Ou gounnej, c'est-à-dire, à proprement parler, celui qui est au-dessus. (...) Ce qui m'a frappé c'est la ressemblance étrange qui existe entre le nom de Dieu chez les anciens Guanches, d'après Viana et Galindo, et le nom qu'emploient les Sendi. Viana donne Hucanech (lisez sans doute Ou-k-anech), Galindo Achucana. N'est-ce pas là le même mot que notre Ou-g-ounnej?» (Provotelle, 1911: 13).

31 El grafema III $(* / \mathrm{h} /)$ quizá acabó reemplazando también a $\div$ en el líbico oriental funerario debido a una supuesta relajación en la articulación del fonema $* / \mathrm{k}^{\varsigma} /$. Sirva de ejemplo actual, la realización [ћ] de la velar faringalizada entre los bereberes de Achtouken (Sous, Marruecos) (LaOust, 1921: 55).

32 Como se verá, empleamos la letra $q$ para representar esta velar, siguiendo la tradición instaurada por Снавот (1940: v). Sin embargo, desconocemos si su realización era sorda o sonora, siendo este un rasgo impertinente para las consonantes faringalizadas de las lenguas afroasiáticas (MARTINET, 1983: 239; ACOSTA, 2019b: 51). 
solo siete veces ${ }^{33}$ en posición final, siendo por el contrario mucho más habitual la ${ }^{*} t$ (14 líneas $)^{34} \mathrm{y}$, sobre todo, su correlato faringalizado: ${ }^{*} t$ (22 líneas). ${ }^{35}$

La diferencia con la ${ }^{*} h$ de los epitafios orientales quizá apunte a cuestiones dialectales, ya que en Numidia se produjo un debilitamiento de la *t final $\left({ }^{*}[\mathrm{t}]>\right.$ $\left.{ }^{*}[\theta]>*[\mathrm{~h}]\right)$, tanto en la lengua líbica como en la púnica, a partir del siglo II a. n. e. (Jongeling, 1984: 83; PutTEN, 2017: 347). En cambio, según se desprende de nuestro estudio epigráfico y de la toponimia (AcostA, 2019a: 199, 211), ese fenómeno no afectó a la modalidad que arribó a El Hierro, seguramente porque provenía de la periferia meridional líbico-bereber. También es posible que la * $h$ final de Canarias no procediera necesariamente del debilitamiento de la * $t$, como se ha propuesto para el líbico oriental. Además, el comportamiento de la *h herreña no es extrapolable al conjunto archipelágico, ya que en otras islas, como Fuerteventura, se observa que la * $h$ final es más habitual. ${ }^{36}$ Quizá, ello se explique porque no representaba realmente una glotal etimológica, sino una vocal, siguiendo el mismo patrón de los epitafios funerarios númidas (de época romana en su mayoría) (MoRA, 2017: 7-8) y de la actual escritura tuareg (Drouin, 2007: 6-7). Dado que, en la escritura líbicobereber, la vocalización es una práctica que suele asociarse al contacto con otras lenguas (AGHALI-ZAKARA, 2014: 5), quizá los autores de las inscripciones majoreras estuvieron más influidos por la romanización. En cualquier caso, se trata de un planteamiento que requiere mayor profundidad y cuyo estudio revelará, con toda seguridad, más datos sobre las gentes que poblaron el Archipiélago.

\subsection{Líquidas}

En aras de la sistematicidad, abordamos aparte el estudio de estos caracteres, ya que se sitúan fuera de la correlación principal. Resulta llamativo que estos grafemas compartan formas ${ }^{37}$ y valores en los alfabetos líbicos (СНАвОт, 1940;

33 * GH (La Caleta 4.2, *NH (Barranco del Cuervo 9.5B), *TTHH (El Tejal 1.2), *WQNFH (Barranco del Cuervo 2.7), *YMRH (La Candia 1.3), *YWDGRH (Camino Ancho 1.1) y *ZK YYNH (Hoyo Blanco 2.3). 34 *GZLSR-T (La Caleta 5.4), *NMṬ ¿T? (Hoyo Blanco 1.2), *NRT (Barranco del Cuervo 1.3), *NRWT (La Caleta 4.14), * N S SRT (Barranco del Cuervo 9.6), *NȚNN 1 T (Barranco del Cuervo 7.1), * RNWNRT (Barranco del Cuervo 9.6), *ȘB ¿FT? (Hoyo Blanco 1.3), *TDKT (La Caleta 5.5), *TKNT (Hoyo Blanco 1.2), * WRYNT (Barranco de Tejeleita 1.1), *WRYT · (La Caleta 5.6), *WYR-T (La Caleta 3.2) y * ¿W?YR-T (La Caleta 2.3)

35 * ¿B?R-TMṬ (La Candia 2.1), *KTṬ (Lomo de Tejeleita 2.6), *LBT • (La Caleta 2.1), *M¿G?TDṬ (La Caleta 5.1), *MNBHṬ (La Caleta 4.4), *MNRṬ (La Candia 1.3), *MSNMGWṬ (Los Letreros 9.4), *NGTDṬ (La Caleta 5.9), *NN ȚGYLṬ (Los Saltos 1.2), *NȘȚȘYDṬ (Los Letreros 11.26), *NṬSṬ (La Candia 1.4), * ¿RH?MGWṬ (La Cueva de Don Gabino 1.2 F), * SŠṬ (Lomo de Tejeleita 3.1), *ŠDṬ (Los Letreros 4.1), *TNGSṬ (La Caleta 5.1), *WDDMṬ (La Caleta 5.2), *WRFDṬ (Camino Ancho 1.1), *WRTFṬ (El Barranquillo 1.1), *YMSṬ (La Caleta 5.1), *Y ¿SṬ? (La Cueva de Don Gabino 1.2 B), *YZNKT (La Candia 1.4) y *¿Z?YTMNT (Barranco del Cuervo 0.0 A).

36 Este grafema aparece en posición final en nueve paneles majoreros: Montaña Blanca 1.6, Cuchillete de Buenavista 1.5, Barranco del Cavadero 1.1 y 2.1, Morro de La Galera 1.1, Montaña del Sombrero 1.1, $1.2,1.4$ y 1.5. En cambio, la *t final solo se inscribió en dos paneles: Montaña Blanca 1.1 y Morro de La Galera 1.2 (vid. Rodrigue y PiCHLeR, 2007).

37 No obstante, hay que aclarar que la semiconsonante $w$ ha experimentado un ligero cambio en los alfabetos tuaregs, simplificando sus dos barras por dos puntos. 
Galand, 1966; Khayari, 2004) y tifinagh (Aghali-ZaKara y Drouin, 2007: 28), lo cual parece deberse a su valor morfemático.

\section{El grafemaU}

$\mathrm{Al}$ igual que en las inscripciones norteafricanas, se observa que este signo poseyó una frecuencia elevada $(8,10 \%)$ y que acostumbraba a situarse a comienzo de palabra, tal y como se observa en 24 líneas. ${ }^{38}$ Por lo tanto, seguramente representó también la consonante */m/ en El Hierro, que en las lenguas líbico-bereberes y otras del phylum afroasiático funciona como prefijo adjetivador, de nomen agentis y de nomen loci. El agentivo es habitual en el corpus líbico, empleándose para los títulos, los nombres de funciones y los etnónimos. Igualmente, algunos topónimos bereberes presentan este prefijo, en cuyo caso designa su carácter locativo o una cualidad asociada al terreno. Aunque seguramente la ${ }^{*} m$ - inicial equivalía a tal prefijo en la mayoría de las inscripciones herreñas, solo advertimos un par mínimo donde parece conmutar: *NY (Barranco de Tejeleita 0.1) frente a *MNY (Camino Ancho 1.1).

Por otro lado, cabe recordar que documentamos también el agentivo unido al prefijo de nomen loci, causativo y factitivo (s-) para formar el prefijo adjetivador denominal *ms-. Por consiguiente, las palabras que lo contienen quizá designaban antropónimos, títulos, cualidades, etc.

\section{El grafema-}

Se trata del signo más abundante del corpus herreño (15,21 \%). Seguramente, ello se debía a las múltiples funciones de la consonante representada $(* / n /)$. Asimismo, consideramos que los caracteres - $\left({ }^{*} n\right)$ y $\mid\left({ }^{*} n_{1}\right)$ son variantes, tal y como parece haber sucedido en el líbico occidental (GALAND, 1966: 25), donde se produjeron oscilaciones de su posición (vid. Ait Ali, 2012: 573). De hecho, en seis inscripciones herreñas ${ }^{39}$ advertimos una norma ortográfica característica del líbico: ${ }^{40}$ la inclinación o rotación de la * $n$ cuando acompaña a otra ${ }^{*} n$ o a un signo formado por barras, con el fin de evitar su confusión con la * $l$ o la * $h$ rotada.

Con respecto al comportamiento de este grafema, observamos su alta

38 *M[...]¿L? (La Caleta 4.6), *M[...]NFȘ (Los Letreros 9.4), *MBK (La Caleta 4.6), *M¿G?TDṬ (La Caleta 5.1), ${ }^{*}$ M?HFGN (Barranco del Cuervo 0.17), *MKYN $i$ D? (Barranco del Cuervo 9.5A), *ML (El Tejal 1.1), *MMLiR? (Piedra del Cabildo), *MN (Hoyo Blanco 2.1), *MNBHT (La Caleta 4.4), *MN ${ }_{1} \mathrm{~L}_{(\mathrm{Los}}$ Saltos 4.1), *MNM (Los Letreros 6.4), *MNRṬ (La Candia 1.3), * MNY (Camino Ancho 1.1), *MRMNYW (La Caleta 4.10), * $\mathrm{MRN}_{1}$ (Barranco del Cuervo 6.2), *MSM (Los Letreros 5.8), *MSNMGWṬ (Los Letreros 9.4), *MSRYN (La Caleta 4.10), *MṬL (La Caleta 5.6), *MZG (La Cueva de Don Gabino 1.3) y ${ }^{*}$ MR-TW (La Caleta 5.9).

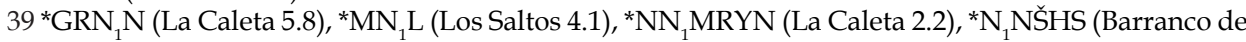
Tejeleita 2.6), *NN $N_{1}$ TGYLṬ (Los Saltos 1.2) y *NȚNN 1 T (Barranco del Cuervo 7.1).

40 En las palabras NFRTLN y FS LN $_{1}$ (RIL 6 de Dougga) se observa que las $n(I)$ se trazaron inclinadas junto a la $l(\|)$. Asimismo, se observa el mismo comportamiento para las ${ }^{*} n$ de las inscripciones occidentales RIL 839 y 853. 
frecuencia a principio y final de línea. Por lo tanto, la letra - cumplió seguramente varias funciones características del líbico y de las lenguas bereberes como expondremos a continuación.

La * $n$ inicial pudo equivaler al alomorfo alveolar del prefijo agentivo * $m$ - ante radicales labiales, patente en el líbico oriental (RössLER, 1958: 102-103) y el bereber (Prasse, 1974: 67, 1972: 159; Heath, 2005: 552) o a la preposición de genitivo $n$ 'de', muy habitual en las inscripciones del limes tingitano, según El KHAYARI (2004: 104).

En El Hierro parece constatarse ambos comportamientos. En primer lugar, se observan dos ejemplos en los que el supuesto alomorfo agentivo se prefijó a raíces triconsonánticas con radical labial: *NMDL (Barranco del Cuervo 6.4) y ${ }^{*} \mathrm{~N}_{1} \mathrm{MRZ}$ (Barranco del Cuervo 1.1). Además, encontramos un par mínimo donde pudo haber conmutación: *NMRN (Barranco de Tejeleita 0.1) frente a * ${ }^{*} \mathrm{~N}_{1}$ (Barranco del Cuervo 6.2). En segundo lugar, el valor preposicional de ${ }^{*} n$ se evidencia a través de su conmutación en el par mínimo * ${ }_{1}$ NSSHSN (Barranco de Tejeleita 2.6) frente a *NŠHSN (Barranco de Tejeleita 2.3). En este caso, descartamos que la ${ }^{*} n$ equivalga al prefijo de nomen agentis, ya que no existen consonantes labiales en la supuesta raíz ( $\left.{ }^{*} \mathrm{NSS} H\right){ }_{,}^{41}$ cosa que no podemos hacer en los tres ejemplos anteriores, pues cabría la posibilidad de que ${ }^{*} n$ - reflejara la preposición de genitivo ante sustantivos agentivos que comienzan por ${ }^{*} m$ -

$\mathrm{La}^{*} n$ final es especialmente habitual en las inscripciones líbicas, tal y como señaló LETOURNEUx (1878: 65) por primera vez. Igualmente, este comportamiento parece haberse trasladado a la escritura herreña. Quizá, la * $n$ final respondía a dos funciones distintas: un sufijo verbonominal de plural y un sufijo adjetival. La marca de plural está claramente presente en los pronombres oblicuos de $3{ }^{a}{ }^{a}$ persona $(-s n)^{42}$ que abordamos en el orden alveolar. No obstante, desconocemos si las ${ }^{*} n$ finales de los casos siguientes representaron un plural verbonominal o un sufijo adjetival: ${ }^{43}{ }^{*} \mathrm{FRRN}$ (La Cueva de Las Chivas 1.5), ${ }^{*} \mathrm{GRN}_{1} \mathrm{~N}$ (La Caleta 5.8), *MSYN (Barranco de Tejeleita 2.6), *MSRYN (La Caleta 4.10), *NBṬSMN (La Candia 1.2), *NFZYN (Barranco de Tejeleita 2.3), *NGWSYN (La Caleta 2.1), *NTZMN (La Candia 1.2), *ŠFZRN (Hoyo Blanco 1.2), *TSNRN (La Cueva del Agua 1.1), ${ }^{*}$ WLRMN (Lomo de Tejeleita 1.6) y *ZYZYN (Barranco del Cuervo 2.4).

\section{El grafema $=$}

Corresponde a la */1/ en los alfabetos conocidos y, quizá, también en el herreño, donde posee una presencia idéntica a la númida funeraria: ${ }^{44} 4 \%$.

41 Excluimos de la raíz la terminación * $\mathrm{SN}$ porque parece corresponder al pronombre enclítico oblicuo de 3 . $^{\text {a }}$ persona del plural.

42 Este pronombre está compuesto por la -s de $3 .^{a}$ persona singular del oblicuo y la $-n$ del plural.

43 CHAKER (1985b: 5) describió tres patrones adjetivales bereberes constituidos de la siguiente manera: «(a)ccan, (a)cc can, (a)cvcan». No obstante, su identificación en las inscripciones es más compleja debido a la ausencia de vocales.

44 La variedad de Dougga presenta la frecuencia más elevada para la consonante $l(6,25 \%)$, ello se debe al empleo reiterado de la palabra gld 'rey'. 
Aparentemente, no desempeñó ninguna función gramatical, aunque JoNGELING (1994: XIX) señaló que era muy frecuente a final de palabra en la onomástica líbica, patrón que hemos observado en diecisiete inscripciones herreñas. ${ }^{45}$

En definitiva, la función de esta consonante parece haber sido fundamentalmente léxica, revelando algunas raíces pan-bereberes habituales. Concretamente, destacaríamos las contenidas en las palabras *GZL e *YGLD.

La secuencia *GZL se inscribió cinco veces en tres paneles de La Caleta (4.15, 5.4 y 5.6) y parece corresponder a la raíz GZL 'ser corto' (NAÏT-ZERRAD, 2002b: III, 931-932). Por lo tanto, podría tratarse de un antropónimo, apodo o de un etnónimo, quizá vinculado a los guezulas: una extensa tribu senhaya que VycicHL (1955) identificó con los antiguos gétulos ${ }^{46}$ y que, durante el medievo, ya se habían extendido hasta el Sáhara occidental (CAMPS, 1999). No obstante, el análisis epigráfico per se solo nos ofrece esta hipótesis de partida que merece un estudio histórico exhaustivo antes de extraer conclusiones definitivas de esta índole.

La palabra *YGLD (Barranco del Cuervo 0.17) estaba formada aparentemente por la desinencia verbal de 3. a persona masculina singular ( $y$-) más una raíz trilítera *GLD, que parece ser la misma que la del título gld 'rey' (PRASSE, 1972: I-III, 158) de las inscripciones oficiales de Dougga. De ser así, habría diferencias de conjugación entre ambas regiones. Así, el caso herreño se basaría en la de los verbos activos, mientras que en la ciudad númida parece haberse seguido la de los verbos de estado y cualidad. ${ }^{47}$ Este tipo de conjugación, hoy en desuso, consiste en sufijar a la raíz los pronombres personales de acusativo (GALAND, 2002: 273-283). Por otro lado, también cabría la posibilidad de que la secuencia *YGLD estuviera formada por la preposición bereber y ‘a, para' y un sustantivo gld. Desde nuestro punto de vista, la segunda hipótesis resulta menos convincente, ya que no se ha documentado este tipo de fórmulas en el corpus líbico, ni tampoco dicha preposición.

\section{El grafema $\bigcirc$}

Este signo común en los alfabetos transcritos representaba el fonema * $\mathrm{f}$ / y poseía una frecuencia relativamente elevada en las inscripciones norteafricanas, especialmente en las estelas del limes y en las rupestres meridionales. En El Hierro, observamos un patrón similar, teniendo una presencia del 9,74 \%.

45 *GL (Hoyo Blanco 1.7), *GZL (La Caleta 4.15, 5.4 y 5.6), *HR-TRTL (La Cueva de Don Gabino 1.2 A), *LL (Barranco del Cuervo 5.1), * M[...]¿L? (La Caleta 4.6), * ML (El Tejal 1.1), * MN 1 L (Los Saltos 4.1), ${ }^{*}$ MȚL (La Caleta 5.6), *NMDL (Barranco del Cuervo 6.4), *RL (Piedra del Cabildo), *[...]SML (Guarazoca), *ك̌ $\cdot \mathrm{L}$ (La Caleta 4.4), "WMBYW-RL (La Candia 1.2), *WZWRL (La Candia 1.2), *YDKL (Hoyo Blanco 1.2), *YNMŠGL (Los Saltos 1.1) y *YNMŠKL (Los Letreros 13.2).

46 Cabe señalar que los gétulos conformaban un conjunto heterogéneo de pueblos nómadas y seminómadas que se situaban en la franja presahariana, limítrofe con el imperio romano (DESANGES, 1962). Dicha franja correspondía al ámbito de extensión del alfabeto líbico meridional (MorA, 2021).

47 Se trata de un modelo de conjugación arcaico que se mantiene de forma dispar en algunos dialectos bereberes, difiriendo en los aspectos y personas verbales. En el habla de los Ayt Ziyan (Pequeña Cabilia) se observa la pauta más conservadora (GALAND, 2002: 273-283). 
Tanto en el continente como en Canarias, ${ }^{48}$ este grafema acostumbraba a escribirse tras la ${ }^{*} w$, sobre todo a principio de palabra. ${ }^{49}$ Por consiguiente, parecía corresponder al adverbio de negación *wr. De hecho, podemos confirmar su carácter morfemático a partir de la segmentación del texto mediante el punto en *WR ·NS (Lomo de Tejeleita 1.7) y *WR ·TZ (La Caleta 5.7).

El empleo de este adverbio a comienzo de palabra es habitual en la antroponimia y la teonimia líbico-bereberes desde la Antigüedad hasta hoy. En efecto, su existencia se retrotrae a algunos nombres de los jefes libios ${ }^{50}$ recogidos en las inscripciones jeroglíficas egipcias (YOYOTTE, 1958: 23; CoLIN, 1996: II, 14). También entre los númidas, contamos con significativos ejemplos de antropónimos ${ }^{51}$ y teónimos ${ }^{52}$ que comienzan por este adverbio (CAMPS, 1990: 144145; JonGELING, 1994: 14). Durante el medievo, la tradición se trasladó además a los gentilicios, ya que muchos se gestaron a partir de patronímicos. Finalmente, esta costumbre se ha conservado entre los tuaregs, quienes usan nombres personales construidos por el adverbio de negación más un sustantivo ('sin ...') o más un verbo en 3. ${ }^{a}$ persona ${ }^{53}$ ('él/ella no...) (CHAKER, 1985a: 488). En definitiva, resulta congruente que los aborígenes canarios portaran este tipo de antropónimos, pues, al fin y al cabo, poseían el mismo bagaje cultural.

\section{El grafema}

Este signo parece haber representado un morfema debido a su alta frecuencia $(7,33 \%)$, a su comportamiento y al ejemplo norteafricano, donde posee valor * $y$ $(* / \mathrm{j} /)$. Por lo tanto, seguramente equivalió también a la desinencia de $3 .^{a}$ persona del masculino singular ( ${ }^{*} y$-). En efecto, observamos varios pares mínimos que lo confirmarían. En primer lugar, se advierte su conmutación en *YNM (La Cueva de Don Gabino 1.2 B) frente a *NM (La Caleta 5.6). Por otro lado, además de la

48 Además de en El Hierro, se documenta esta sucesión en Gran Canaria (La Angostura, Barranco de Balos y Hoya de Toledo), Lanzarote (Peña de Luis Cabrera y Femés) y Fuerteventura (Montaña Blanca) (vid. C.H.E.C., 1988; Cuenca, 1996; Springer, 1996; Ulbrich, 1996; Rodrigue y Pichler, 2007).

49 En El Hierro distinguimos las siguientes líneas con la secuencia *WR: *WR (La Candia 2.7), ${ }^{*} W R$.NS (Lomo de Tejeleita 1.7), *WR TZ (La Caleta 5.7), *WRFDT (Camino Ancho 1.1), *WRKYS (La Cueva Don Gabino 1.4), *WRLBR (Barranco de Tejeleita 4.1), *WRN (Barranco del Cuervo 8.2), *WRN (La Candia 1.3), *WRTFT (El Barranquillo 1.1), *WRYNQ (Barranco de Tejeleita 1.1), * WRYNT (Barranco de Tejeleita 1.1), *WRYT (La Caleta 5.6), *WZWRL (La Candia 1.2), * YTRWRN (La Candia 1.2), *MSWRN 1 (La Cueva de Don Gabino 1.2) y *ŠNŠWRN (La Cueva del Agua 1.1).

$50 \mathrm{Tal}$ es el caso de $W r$ ? $m r$ : «L'un des grands personnages libyens dont ses compatriotes constatent, dans le récit de la campagne de l'an 5 de Ramsès III, qu'ils ont été anéantis par le roi» (CoLIN, 1996: II, 20).

51 En las inscripciones líbicas orientales encontramos los siguientes antropónimos: $\mathrm{WRS}_{1} \mathrm{~K}_{1} \mathrm{~N}$ (RIL 1: 5), WR[...] (RIL 932), WRH (RIL 180), WRGDHN (RIL 117), WRMRSN (RIL 262), WRMRT (RIL 802), WRMZ (RIL 286, 318, 319, 397. 421 y 942), WRMH[Z] (RIL 230), WRT (RIL 945), WRZ[F] (RIL 523) y WRZR[F] (RIL 670).

52 CAMPS (1990: 144-145) extrajo de las inscripciones latinas los siguientes nombres de divinidades que contenían este prefijo adverbial: VARRICCALA, VARSis, VARSisSima y VARSUTINA.

53 «Wer-Ilemmed 'Il n'apprend pas' < du verbe elmed 'apprendre'; Wer-tenezzu 'elle n'est pas à vendre' < du verbe enz 'vendre / acheter'» (AgHALI-ZAKARA, 2003: 221) . «Our-iekkoul ('il ne prend pas souci'), Our-toukil ('elle n'est pas perdue')» (FOUCAULD y BASSET, 1940: 329-331). 
conmutación de la desinencia, vemos la permutación por su equivalente femenina ( ${ }^{*} t$-) ante la supuesta raíz * $R N$ en las líneas siguientes: *YRN (Barranco del Cuervo 1.1), * RN (La Cueva de las Chivas 1.2), * $\mathrm{RN}_{1}$ (Arenas Blancas 1.1) y * $\mathrm{TRN}_{1}$ (La Cueva del Agua 1.1).

Cabe señalar que esta letra poseía diversos alógrafos $(\varkappa, \backsim, 2$, etc.), siendo el de trazos cuadrangulares el más habitual en El Hierro. Esta variante se documenta en las estelas del limes de la Mauretania Tingitana (IAM $\left.{ }^{54} 20\right)$ y en algunas inscripciones rupestre ${ }^{55}$ del Draa-Tafilalt y el Sáhara occidental.

\section{El grafema $\|$}

Al igual que el signo anterior, parece representar una semiconsonante, en este caso la velar */w/. Nuevamente, nos apoyamos en su elevada frecuencia $(6,13$ $\%)$, su comportamiento y en la comparación con los alfabetos norteafricanos. En efecto, este grafema era habitual en las inscripciones líbicas porque representaba el sustantivo * $w$ 'hijo' con el que se construía el patronímico del personaje homenajeado o fallecido, por ejemplo: MSNSN GLDT WGYY (RIL 2: 6) ‘Masinisa rey, hijo de Gaya'. En segundo lugar, se encuentra también en menor cantidad en el adverbio de negación *wr del que ya hablamos, tanto en El Hierro como en el norte de África. Por último, la *w inicial podría, además, explicarse a partir del artículo masculino bereber wa/wi que, por el contrario, no parece haberse empleado en las estelas líbicas. En efecto, CHAKER (1985a: 487) señaló la ausencia del artículo y del sintagma wan/win 'el de, lo de'. Por el contrario, se registran numerosos antropónimos númidas con los prefijos $k$ - y kn- que, según nuestro criterio, podrían corresponder, respectivamente, a un estado arcaico de wa/wi y wan/win.

En El Hierro existen numerosos ejemplos de la *w a comienzo de palabra, ${ }^{56}$ por lo que quizá se trate del sustantivo en aposición 'hijo', o bien de un estado reciente del artículo bereber, ${ }^{57}$ pues no documentamos el prefijo ${ }^{*} k n \sim{ }^{*} g n$. De hecho, advertimos la función morfemática de *w- a partir de su conmutación en los ejemplos siguientes: *WYṬ (La Candia 2.4) frente a *YṬT (Barranco de Tejeleita 2.6) e *YṬNWW ${ }^{58}$ (El Tejal 1.2). No obstante, habría que desarrollar un estudio más complejo antes de decantarnos por la función que desempeñó la *w inicial en cada caso.

54 La sigla IAM alude a la obra Inscriptions Antiques du Maroc (GALAND, 1966), que contiene gran parte del corpus líbico occidental.

55 Nos referimos a las inscripciones marroquíes de Hayart 1.8, Oudraz 1.4 y Taouz 1.1 y 1.3 (RODRIGUE y Pichler, 2007) y a las saharianas occidentales de Leyuad VI y Assaig Bedrag 1 y 2 (GALAND, 1976).

56 *WDDMT (La Caleta 5.2), *WKSN (La Caleta 4.2, 5.4 y 5.5), *WLRMN (Lomo de Tejeleita 1.6), *WMBYW-RL (La Candia 1.2), *WMK (Barranco del Cuervo 2.6), * $\mathrm{WN}_{1}$ (La Caleta 1.1), *WQNFH (Barranco del Cuervo 2.7), *WS Q ?S (La Caleta 2.3), *WSRF (Camino Ancho 1.1), *WYR-T (La Caleta 2.3 y 3.2), *WYT (La Candia 2.4) y *WZWRL (La Candia 1.2).

$57 \mathrm{El}$ artículo wa parece haberse generalizado en el medievo, según se desprende de la antroponimia (CHAKER, 1985a: 489). Quizá, ello se debía a la culminación del debilitamiento de la * $/ \mathrm{k}^{\mathrm{w}} /$.

58 Esta línea parece estar formada por * YṬ más *GNW, que localizamos también en *SRGNW (La Candia 1.3). 


\subsection{Los dígrafos}

Estos signos corresponden a uniones de dos consonantes, por lo que no se incluyen dentro del sistema fonológico. Los dígrafos o ligaduras no se han documentado en los antiguos alfabetos líbicos septentrionales, por lo que parecen ser relativamente modernos (PrASSE, 1972: I-III, 147). Ciertamente, son bien conocidos en los alfabetos tifinagh actuales, especialmente en Níger y Mali, estando en desuso en Ahaggar (SAVAGE, 2012: 116). Dado que estos signos se registran también en algunas inscripciones rupestres meridionales y en Canarias, parece tratarse de un recurso, además de tardío, originario del ámbito presahariano.

Tradicionalmente, el empleo y la comprensión de los dígrafos están reservados a los usuarios y lectores más experimentados. Su uso indica la ausencia de vocal entre las dos consonantes ligadas, las cuales, consiguientemente, forman un grupo tautosilábico ${ }^{59}$ (cuando las consonantes pertenecen a la misma sílaba) o heterosilábico (cuando las consonantes pertenecen a sílabas distintas). Por lo tanto, indirectamente, tales grupos indican también que las demás consonantes contienen vocales. Los dígrafos se emplean fundamentalmente para desambiguar aquellas palabras que poseen las mismas consonantes, pero una vocalización diferente, por ejemplo: $+[\oplus$ [tămárt] 'barba' frente a +[O+ [témərit] 'mujer amable' (SAVAGE, op. cit.).

\section{El dígrafo $\oplus$}

Este signo representa la ligadura $r t$ en la escritura tuareg (PRASSE, 1972: 157; Drouin, 2011: 9). Además, lo encontramos en las inscripciones rupestres antiguas ${ }^{60}$ de Sous-Masa y Draa-Tafilalt, así como en el líbico-bereber de transición o medieval. Se desconoce si este carácter representó siempre el mismo valor en toda su área de influencia. No obstante, a continuación, nos ceñiremos al análisis del corpus de El Hierro.

El signo $\oplus$ tuvo un uso anecdótico en la escritura herreña, concentrándose en la mitad septentrional de la Isla ${ }^{61}$ y representando únicamente el $0,77 \%$ del total. Además, en La Caleta (2.1, 2.4, 3.2 y 5.4) y el Barranco del Cuervo (1.1 y 2.3), se documenta el signo $\oplus$ que parece ser un alógrafo, ya que ambas variantes se emplearon para la misma secuencia: *WYR-T (La Caleta 2.3 y 3.2).

Con respecto a su valor fonológico, pensamos que pudo representar también la ligadura $r t$ (que anotamos * $\mathrm{R}-\mathrm{T}$ ) por las razones que a continuación exponemos. Primeramente, encontramos este signo en la línea *TMR-TN (La Cueva del Agua 1.2), donde la ${ }^{*} t$ de la ligadura parece corresponder a la del pronombre enclítico de $3^{\text {a }}$ persona plural de acusativo $(-t n)$. En cuanto a la ${ }^{*} r$, quizá era un radical de la

59 La ligadura tautosilábica es menos frecuente y se sitúa a final de palabra, adecuándose a la silabación tuareg (SAVAGE, 2012: 100).

60 Estas inscripciones se encuentran en los yacimientos marroquíes de Taouz, Iourarhane y Ouaremdaz (Rodrigue y PichleR, 2007).

61 Se documenta en el Barranco del Cuervo (9.6), La Cueva del Agua (1.2), La Cueva de Don Gabino (1.2), La Caleta (2.3 y 5.9), La Candia (2.1) y en el tablón del Hoyo de los Muertos (Guarazoca). 
raíz * $M R$, abundante en el conjunto epigráfico insular y que, igualmente, parece documentarse en la secuencia *MR-TW (La Caleta 5.9). Por otro lado, el valor * $r$ puede explicarse a partir de otras palabras reconocibles en el corpus herreño. Así, la línea *GZLSR-T (La Caleta 5.4) parece formada por las palabras *GZL (La Caleta 4.1 y 5.6) y *SRT (recogida aisladamente en el Barranco del Cuervo 9.6). Finalmente, la *t de este dígrafo quizá correspondía al prefijo verbonominal de género femenino $t$ - en las siguientes líneas: *BR-TMT (La Candia 2.1), *HR-TRTL (La Cueva de Don Gabino 1.2), *GR-TNK (La Caleta 2.4), *NR-TNWN (Barranco del Cuervo 2.3), *NR-TRN (La Caleta 2.1), *NR-TWLN (Barranco del Cuervo 1.1) y, quizá, *R-TNS (La Cueva de Don Gabino 1.2).

\section{El dígrafo $\mathbb{D}$}

Posee un uso muy restringido en el norte de África, concretamente en las inscripciones rupestres de Ifigha (Tizi Ouzzou), donde se han registrado cuatro recurrencias (vid. Poyto y Musso, 1969). Aparentemente, el alfabeto empleado en este abrigo de La Cabilia pertenecía a la modalidad meridional, a pesar de situarse en pleno Tell argelino. ${ }^{62}$ También en Canarias es un signo poco común, pues además de contabilizarse dos ejemplares en Gran Canaria ${ }^{63}$ y Lanzarote, ${ }^{64}$ se documentan solamente cuatro en El Hierro (La Candia 1.2, Barranco de San Juan 1.1 y Los Letreros 4.1), que suponen el 0,44\% del corpus insular.

Al igual que el signo anterior, creemos que $\mathbb{D}$ representó una ligadura, concretamente *wr. Nuestra conclusión no solo se apoya en la forma del grafema, sino también en la frecuencia del supuesto adverbio de negación líbico-bereber wr. Quizá, la habitualidad de este morfema llevó a los usuarios de la escritura a crear este dígrafo para representarlo o, por el contrario, para señalar que no se trataba de este adverbio. Dado que entre las consonantes ligadas no existe vocal, en el caso de que reflejara la negación, la secuencia posterior podría corresponder a un sintagma verbal, ya que CHAKER (1985a: 488) precisó que los tuaregs empleaban la forma wr ante verbos, reservando su variante vocalizada war ante sustantivos. Por otro lado, si nos atenemos al patrón tradicional, las ligaduras tautosilábicas deberían situarse únicamente a final de palabra (SAVAGE, 2012: 100). Sin embargo, el dígrafo solo ocupa esta posición en una de las cuatro líneas herreñas. ${ }^{65}$ Por lo tanto, para los casos restantes, habría que considerar la posibilidad de que la ligadura contuviera un grupo heterosilábico, como concluimos para la $\oplus$ en

62 Durante la Antigüedad, los montañeses del Tell argelino llevaron a cabo una economía nómada que aprovechaba las diferencias climáticas latitudinales del territorio norteafricano: montaña, llanura y desierto. Así, durante el invierno, descendían a la llanura para beneficiarse de los pastos y sembrar en las inmediaciones de los ríos. Por el contrario, cuando las lluvias no eran propicias, se desplazaban con el ganado hacia las regiones saharianas anexas (BÉNABOU, 1976: 72). Es probable que estas migraciones estacionales expliquen la presencia del alfabeto líbico meridional en la Cabilia, así como cierta influencia cenete en su dialecto (SOUAG, 2017).

63 El grafema 4 está en el denominado panel n. 3 del Barranco de Balos (SPRINGER, 1996: 415).

64 UlbRich (1996: 355) calcó este signo en el panel A2 de la Peña de Luis Cabrera.

65 *KRŠ ¿W-R? (Los Letreros 4.1), ${ }^{*}{ }^{*} N_{1}$ ?WW-RZRN (La Candia 1.2), *WMBYW-RL (La Candia 1.2) y *YQW-RSTS (Barranco de San Juan 1.1). 
la Isla. En este supuesto, la *w quizá correspondía al sustantivo 'hijo', o bien al artículo, mientras que la ${ }^{*} r$ podría ser el radical inicial de un antropónimo ${ }^{66} \mathrm{o}$ cualquier otro sustantivo. En definitiva, para el comportamiento de esta ligadura, barajamos diferentes explicaciones en las que habría que profundizar antes de decantarnos por la más verosímil.

\section{PROPUESTA DE SISTEMA FONOLÓGICO}

Tras el análisis del corpus alfabético herreño, exponemos nuestra propuesta de sistema fonológico de tres series y seis órdenes. Esta organización parte de los estudios del bereber (AcostA, 2019a: 195, 2019b: 47) y de otras lenguas del phylum afroasiático (MARTINET, 1983: 242; CANTINEAU, 1960: 21). De ellos se desprende la correlación, dentro de cada orden, de las series sorda, sonora y faringalizada ${ }^{67}$ que pudo estar motivada, en origen, por una oposición gradual en la apertura de la glotis (ACOSTA, 2019b: 40). Finalmente, para garantizar la sistematicidad, hemos representado aparte las consonantes líquidas.

Este sistema fonológico coincide en su práctica totalidad con el diasistema bereber de André BASSET (1952: 5) y Galand (1960: 1217) ( $c f$. Kossmann, 1999: 249). Debe tenerse en cuenta que los sistemas solamente reflejan valores fonológicos, prescindiendo de las realizaciones efectivas de cada uno de los fonemas a lo largo de la dilatada historia de la lengua líbico-bereber insular (ca. siglos II-XV d. n. e.). Tales datos solo son accesibles a través del estudio sistemático de la onomástica y del léxico aborígenes, siendo necesario un análisis histórico-comparativo que considere el contacto con las lenguas románicas de los siglos XV al XVII.

TABLA 1

Propuesta de sistema fonológico del líbico-bereber herreño (correlación principal)

\begin{tabular}{|c|c|c|c|c|c|c|c|c|c|c|c|c|}
\hline & \multicolumn{2}{|c|}{ Labial } & \multicolumn{2}{|c|}{ Dental } & \multicolumn{2}{|c|}{ Alveolar } & \multicolumn{2}{|c|}{ Palatal } & \multicolumn{2}{|c|}{ Velar } & \multicolumn{2}{|c|}{ Glotal } \\
\hline Sorda & $* / f /$ & $\forall$ & & + & $* / s /$ & $\theta$ & & $\omega$ & & In & $* / \mathrm{h} /$ & || \\
\hline Sonora & $* / b$ & $\odot$ & $* / d$ & {[} & & $\mathrm{H}$ & & & $* / g /$ & n & & \\
\hline Faringalizada & & & $*|t| t \mid$ & ш & $* / s^{s} /$ & $\mathrm{T}$ & & & $* / \mathrm{k}^{\mathrm{s}}$ & $H$ & & \\
\hline
\end{tabular}

Fuente: Elaboración propia.

66 No obstante, los antropónimos líbicos que comienzan por esta consonante no son muy habituales (vid. СНАвот, 1940: ххI).

67 Además, hay que sumar la oposición consonántica laxa-tensa que aquí no hemos incluido, dado que la escritura líbico-bereber no representa la geminación. 
TABLA 2

Propuesta de sistema fonológico del líbico-bereber herreño (líquidas)

\begin{tabular}{|c|c|c|c|c|c|c|c|c|}
\hline & \multicolumn{2}{|c|}{ Labial } & \multicolumn{2}{|c|}{ Alveolar } & \multicolumn{2}{|c|}{ Palatal } & \multicolumn{2}{|c|}{ Velar } \\
\hline Nasal & $* / \mathrm{m}$ & $\sqcup$ & $* / \mathrm{n} /$ & - & & & & \\
\hline Lateral & & & $* / 1 /$ & $=$ & & & & \\
\hline Vibrante & & & $* / \mathrm{r} /$ & 0 & & & & \\
\hline Semivocal & & & & & $* / \mathrm{j} /$ & ப & $* / \mathrm{w} /$ & $\|$ \\
\hline
\end{tabular}

Fuente: Elaboración propia.

\section{CONCLUSIONES}

Frente a la disparidad de las «transcripciones» apriorísticas del líbico-bereber canario, proponemos un estudio basado en un método solvente y falsable, aplicado con anterioridad a la epigrafía líbica (RössLER, 1958; CHAKER, 1985a; JoNGELING, 1984, 1994; KHAYARI, 2004; etc.). Tal y como recomendaba СHADWICK (1962: 41-42) para la descodificación de las escrituras desconocidas, este procedimiento se ha fundamentado en el análisis interno de las inscripciones. Para ello, nos hemos apoyado en la morfología gramatical líbico-bereber, pues esta constituye un inventario cerrado de unidades mínimas con significado invariante.

A partir del análisis interno del corpus herreño, hemos obtenido diversas conclusiones. En primer lugar, se detectan morfemas gramaticales característicos de las lenguas líbico-bereberes, como los afijos verbonominales, pronombres personales, adverbios, preposiciones y conjunciones. Además, la mayoría de ellos se documenta en las estelas líbicas orientales, lo que indica un innegable parentesco histórico con Numidia: foco cultural líbico-bereber por excelencia. Como estos morfemas son reconocibles en la onomástica númida, es posible que muchas de las inscripciones herreñas contuvieran antropónimos y, quizá, también etnónimos. Por otro lado, se observa un vínculo evidente con la periferia meridional norteafricana que trasciende del contexto rural y del soporte rupestre. En efecto, la epigrafía insular revela rasgos lingüísticos de los actuales dialectos bereberes meridionales, como la variación libre de $* / s / \sim^{*} / \int / \mathrm{y} \mathrm{de} * / t / \sim^{*} / \mathrm{t}^{\mathrm{t}} /$. Cabe destacar que esta oscilación se ve más acentuada en el sur de El Hierro, quizá por su aislamiento de la costa de Valverde, donde se concentran las inscripciones. Asimismo, tal disparidad podría estar motivada por la propia evolución de la 
lengua durante este largo periodo histórico, o bien por diferencias socioculturales. En este sentido, cabe señalar que en la franja septentrional se registran más ligaduras, cuyo conocimiento supone un dominio de la escritura.

Los resultados del análisis morfofonológico casan con nuestra propuesta clasificatoria del líbico-bereber canario. Según esta hipótesis, el alfabeto que se trasplantó en el Archipiélago procedía de una variedad presahariana tardía, descendiente, a su vez, de la norma oficial de Dougga. Dada la concentración de estos marcadores alfabéticos en Tafilalt, valles del Sous y Draa y en el Sáhara occidental, los primeros pobladores de las Islas debieron de venir desde la vecina costa norteafricana (MorA, 2021). Asimismo, debido a la homogeneidad alfabética que presentan las inscripciones líbico-bereberes canarias (SPRINGER, 2017), este ensayo de transcripción del corpus herreño puede servir como punto de partida para la investigación del conjunto canario.

En definitiva, el estudio de la escritura nos está desvelando tímida, pero consistentemente, los únicos testimonios directos de los aborígenes canarios. De esta manera, la epigrafía nos proporciona una valiosa información sobre este periodo de la historia canaria y norteafricana, difícilmente perceptible a través de otras disciplinas.

\section{REFERENCIAS}

Acosta Armas, J. (2017): «Notas sobre la aspiración en los guanchismos», Revista de Filología, 35: 9-49.

Acosta Armas, J. (2019a): «Gramática de la toponimia herreña de origen bereber», en J. J. BAtista RodríGuez (ed.), Estudios sobre toponimia canaria prehispánica. Sobre guanchismos, topónimos guanches y lingüística bereber, Academia Canaria de la Lengua, Santa Cruz de Tenerife: 151-222.

Acosta Armas, J. (2019b): «Notas sobre la espirantización de */t/ bereber en los guanchismos», Revista de Filología, 39: 13-70.

Acosta ARMAS, J. (en prensa): «Aproximación a la génesis del sistema pronominal personal bereber», en VII Coloquio de Lingüística del Instituto Universitario de Lingüística Andrés Bello.

Aghali-ZaKara, M. (2003): «Anthroponymie touarègue. Dénominations multiples des individualités», Nouvelle revue d'onomastique, 41-42: 221-229.

Aghali-ZaKara, M. (2014): «À propos de la vocalisation des néo-tifinagh», La lettre du RILB, Répertoire des Inscriptions Libyco-Berbères, 20, EPHE-Ive Section, Paris: $5-10$.

Aghali-ZaKara, M. y Drouin, J. (2007): Inscriptions rupestres libyco-berbères Sahel Nigéro-Malien, Droz, Ginevra.

Aghali-Zakara, M. y Drouin, J. (2009): «Station du Bonhomme et les messages écrits», La lettre du RILB, Répertoire des Inscriptions Libyco-Berbères, 15, EPHEIVe Section, Paris: 2-10.

Ait Ali YAHIA, S. (2012): Étude comparative entre les stèles à inscriptions libyques de la 
Berbèrie Centrale (Algérie) et de la Berbèrie Occidentale (Maroc) (Thèse de doctorat), Université Mouloud Mammeri, Tizi Ouzou.

Álvarez Delgado, J. (1964): Inscripciones líbicas de Canarias. Ensayo de interpretación líbica, Universidad de La Laguna, La Laguna.

Basset, A. (1952): La Langue Berbère, Oxford University Press, London-New YorkToronto.

BASSET, R. (1885): Notes de lexicographie berbère, Quatrième série: Vocabulaire du Touat et du Gourara, Argot du Mzab, dialectes des Touaregs Aouelimmiden, Imprimerie Nationale, Paris.

Belmonte Avilés, J. A. et al. (2019): «Calendario, signo y símbolo: tres claves para una aproximación al poblamiento del archipiélago canario», en Un periplo docente e investigador. Estudios en homenaje al profesor Antonio Tejera Gaspar, Universidad de La Laguna: 207-232.

BÉNABOU, M. (1976): La résistance africaine à la romanisation, Maspero, Paris.

CAlvet, L.J. (1996): Historia de la escritura, Paidós, Barcelona.

Cervelló Autuori, J. (2016): Escrituras, lengua y cultura en el Antiguo Egipto, Universitat Autònoma de Barcelona.

CAMPS, G. (1978): «Recherches sur les plus anciennes inscriptions libyques de l'Afrique du Nord et du Sahara», Bulletin archéologique du Comité des Travaux Historiques et Scientifiques, 10-11: 143-166.

CAMPS, G. (1990): «Qui sont les Dii Mauri ?», Antiquités africaines, 26: 131-153.

CAMPs, G. (1999): «Gudâla/Guezula», en Encyclopédie berbère, 21, Edisud, Aixen-Provence [en línea], publicado el 1 de junio de 2011, URL: http:// encyclopedieberbere.revue.org/1788 [Consulta: 01/05/2019].

Cantineau, J. (1960): Études de linguistique arabe, Klincksieck, Paris.

CAsajus, D. (2015): L'alphabet touareg. Histoire d'un vieil alphabet africain, CNRS, Paris.

Снавот, J.-B. (1939): «Sur quelques signes de l'alphabet libyque», Journal asiatique: ou recueil de mémoires d'extraits et de notices relatifs à l'histoire, à la philosophie, aux sciences, à la littérature et aux langues des peuples orientaux, CCXXXI, JeanMarie Durand, Paris: 117-124.

Cнавот, J.-B. (1940): Recueil des Inscriptions Libyques, Imprimerie Nationale, Paris. CHADwick, J. (1962 [1958]): El enigma micénico, Taurus, Madrid.

Chaker, S. (1985a): «Onomastique berbère ancienne (Antiquité/Moyen Age): rupture et continuité», Bulletin archéologique du CTHS, serie 9, fascículo 19B: 483-497.

ChaKer, S. (1985b): «Adjectif», en Encyclopédie berbère, 2, Edisud, Aix-en-Provence [en internet], publicado el 1 de diciembre de 2012, https://journals. openedition.org/encyclopedieberbere/857 [Consulta: 01/05/2019].

CHAKer, S. (1888 [1986]): «Terminologie libyque des titres et fonctions», Annali del'Istituto Universitario Orientale di Napoli, 46/4: 541-562.

Champollion, F. (1822): Lettre à M. Dacier relative à l'alphabet des hiéroglyphes phonétiques, Imprimerie de Firmin Didot, Paris.

C.H.E.C. (1988): «Nuevos grabados alfabetiformes aborígenes», La Provincia, 08/11/1988. 
Colin, F. (1996): Les Libyens en Egypte (xve siècle a. C. -IIe siècle p. C). Onomastique et histoire, vol. I- II, Université Libre de Bruxelles.

Colin, F. (1999): «Le vieux libyques dans les sources égyptiennes du Nouvel Empire à l'époque roman», Bulletin archéologique du Comité des travaux historiques et scientifiques, nouvel série, Afrique du Nord, fasc. 25: 13-18.

Cuenca SANABria, J. (1996): «Las manifestaciones rupestres de Gran Canaria», en A. Beltrán (ed.), Manifestaciones rupestres de las Islas Canarias, Dirección General de Patrimonio Histórico, Santa Cruz de Tenerife: 133-22.

Cunchillos, J.L.; Zamora, J.A. (1997): Gramática fenicia elemental, Consejo Superior de Investigaciones Científicas, Madrid.

DALLET, J.-M. (1982): Dictionnaire kabyle-français, SELAF, Paris.

DelHeure, J. (1987): Dictionnaire Ouargli-Français, SELAF, Paris.

Demougeot, É. (1960): «Le chameau et l'Afrique du Nord romaine», Annales. Economies, sociétés, civilisations, 15, 2: 209-247.

Desanges, J. (1962): Catalogue des tribus africaines de l'antiquité classique à l'ouest du Nil, Université de Dakar, Faculté des Lettres et Sciences Humaines, Dakar.

Drouin, J. (2007): «Le signe $\vdots$ / h/ est-il une mater lectionis dans les inscriptions Libyco-Berbères ?», La lettre du RILB, Répertoire des Inscriptions LibyqueBerbères, 15, EPHE- Ive Section, Paris: 6-7.

Drouin, J. (2011): «Fonctions et usages des signes composites, les tifinagh aqqânnin», La Lettre du RILB, Répertoire des Inscriptions Libyco-Berbères, 17, EPHE- IVe Section, Paris: 9-12.

Euzennat, M. (1985): «L'olivier et le limes», Bulletin archéologique du CTHS, serie 9, fascículo 19B: 161-171.

Ewague, A. et al. (2016): "Laghchiwat, nouveau site rupestre au sud d'Es Smara (Sahara marocain)», Lettre internationale d'informations sur l'art rupestre,75: 5-11.

FARrujia de LA Rosa, A. J. et al. (2009): «Las escrituras líbico-bereberes y latinocanaria en la secuenciación del poblamiento de las Islas Canarias», El Museo Canario, 64: 9-50.

FÉvrIER, J. G. (1956): «Que savons-nous du libyque ?», Revue Africaine. Centenaire de la Société Historique Algérienne 1856-1956, Jourdan, Alger: 263-273.

FoucAuld, Ch. y BASSET, A. (1940): Dictionnaire abrégé touareg-français de noms propres: dialecte de l'Ahaggar, Larose, Paris.

GALAND, L. (1960): «Berbères», en Encyclopédie de l'Islam, I, A-B, Brill, Leiden: 12081222.

GALAND, L. (1966): «Inscriptions libyques», en Inscriptions Antiques du Maroc, CNRS, Paris: 1-80.

GALAND, L. (1973a): «L'inscription libyco-berbère de Loma de Aasli (Seguiet elHamra)», Almogaren, 4: 81-90.

Galand, L. (1973b): «L'alphabet libyque de Dougga», Revue des mondes musulmans et de la Méditerranée, 13-14: 361-368.

GALAND, L. (1976): «Inscriptions berbères du Sahara occidental», Almogaren, 7: 7579.

Galand, L. (2002): Études de linguistique berbère, Peeters, Leuven-Paris. 
GAlAnd-Pernet, P. y GALAND, L. (1995): «Notes d'onomastique et de vocabulaire berbères», L'homme méditerranéen. Mélanges offerts à Gabriel Camps, Publications de l'Université de Provence. Aix-en-Provence: 265-270.

García Navarro et alii (2004): «Nueva estación de grabados rupestres localizada en la necrópolis de Arteara, San Bartolomé de Tirajana. Gran Canaria», Tabona: Revista de Prehistoria y de Arqueología, 12: 119-136.

GeLb, I. J. (1976 [1952]): Historia de la escritura, Alianza, Madrid.

GHAKI, M. (2000): «Stèles libyques et néopuniques de Tunisie», en L'Africa romana: lo spazio marittimo del Mediterraneo occidentales: atti del 14. Convegno di studio, 7-10 dicembre 2000, Sassari, Carocci, Roma: 1661-1678.

GHAKI, M. (2011): «Une nouvelle inscription libyque officielle à Dougga», en Parcours Berbères Mélanges offerts à P. Galand-Pernet et L. Galand pour le 90 eme anniversaire, Berber Studies, 33, Rüdiger Köppe, Köln: 1-5.

Gsell, S. (1927): Histoire ancienne de l'Afrique du Nord, Libraire Hachette, Paris.

Halévy, J. (1874): «Essai d'épigraphie libyque», Journal asiatique ou Recueil de mémoires d'extraits et de notices, serie 7, tomo IV, Imprimerie Nationale, Paris.

Heath, J. (2005): A Grammar of Tamashek (Tuareg of Mali), Part 1, Mouton de Gruyter, Berlin - New York.

Jongeling, K. (1984): Names in Neo-Punic inscriptions, University of Groningen.

JoNGELING, K. (1994): North-African names from Latin sources, Research School CNWS, Leiden.

JudAs, A.-C. (1863): Sur l'écriture et la langue berbères dans l'antiquité et de nos jours, Imprimerie de Pillet fils aîné, Paris.

Haddadou, M. A. (2006): Dictionnaire des racines berbères communes, HautCommissariat à l'Amazighité, Alger.

KHAYARI, A. el (2004): «Considérations sur l'épigraphie libyque du Maroc», en M.H. FANTAR y A. SirAJ (eds.), Débuts de l'écriture au Maghreb, Fondation du roi Abdul-Aziz Al-Saoud pour les Études Islamiques et les Sciences Humaines, Casablanca: 91-113.

Kossmann, M. (1999): Essai sur la phonologie du proto-berbère, Rüdiger Köppe, Köln. Kossmann, M. (2020): «Sibilants in Libyco-Berber», Journal of the American Oriental Society, 140 (4): 875-888.

Laoust, E. (1921): Cours de Berbère Marocain, Dialectes du Sous du Haut et de l'AntiAtlas, Challamel, Paris.

Letourneux, A. H. (1880 [1878]): «Du déchiffrement des inscriptions libycoberbères», en Atti del IV Congresso Internazionale degli Orientalisti, 1, Firenze: 57-75.

Lhote, H. (1975): Hacia el descubrimiento de los frescos del Tasili. La pintura prehistórica del Sahara, Ediciones Destino, Barcelona.

Lhote, H. (1982): Les chars rupestres sahariens. Des Syrtes au Niger par les pays des Garamantes et des Atlantes, Hespérides, Toulouse.

Lux, C. (2013): Le tetserret, langue berbère du Niger. Berber Studies, Rüdiger Köppe, Köln.

Marcy, G. (1932): «La Pierre écrite d" Ain Jema'a», Bulletin de la Société de préhistoire du Maroc, 6, Société de préhistoire du Maroc, Casablanca: 14-22. 
Marcy, G. (1936): Les inscriptions bilingues de l'Afrique du Nord, Imprimerie Nationale, Paris.

MARTín RodrígueZ et alii (2008): «Nuevas investigaciones en torno a los grabados rupestres del Barranco de Balos (Agüimes, Gran Canaria)», Tabona: Revista de Prehistoria y de Arqueología, 16: 193-218.

Martinet, A. (1983): «La palatalización "espontánea" de G en árabe"», Evolución de las lenguas y reconstrucción, Gredos, Madrid: 235-249.

Mora Aguiar, I. (2017): «Historia de los alfabetos líbico-bereberes a través del

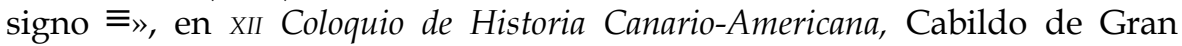
Canaria, Las Palmas de Gran Canaria: 1-17.

Mora Aguiar, I. (2021): «La dispersión de la escritura líbico-bereber desde Numidia hasta Canarias», en N. Moncunill y M. Ramírez-SÁnchez (eds.), Aprender la escritura, olvidar la escritura: Nuevas perspectivas sobre la historia de la escritura en el Occidente romano, Universidad del País Vasco, Vitoria-Gasteiz: 37-62.

NaïT-Zerrad, K. (2002a): «Les préfixes expressifs en berbère», Articles de linguistique berbère, Mémorial Werner Vycichl, L'Harmattan, Paris: 349-372.

NAÏT-ZerRAD, K. (2002b): Dictionnaire des racines berbères (formes attestées), III, Peeters, Paris-Louvain.

NAÏT-ZeRrad, K. (2011): Mémento grammatical et orthographique de berbère. KabyleChleuh-Rifain, L'Harmattan, Paris.

Perera Betancort, M.A.; Jiménez GonZÁlez, J.J. (2020): «Manifestaciones rupestres y estructuras arqueológicas de Montaña Jaifa, Fuerteventura», en XXIII Coloquio de Historia Canario-Americana (2018), Cabildo de Gran Canaria, Las Palmas de Gran Canaria: 1-17.

Pichler, W. (2003): Las inscripciones rupestres de Fuerteventura, Cabildo de Fuerteventura, Puerto del Rosario.

PICHLER, W. (2008): «The Libyco-Berber inscriptions of Foum Chenna/Morocco», Sahara, 19, Pyramids, Segrate: 184-191.

Poyto, R.; Musso, J.-C. (2001 [1969]): «Ifira», en Encyclopédie berbère, 24, Ida Issamadanen, Edisud, Aix-en-Provence: 3643-3644.

Prasse, K.-G. (1972): Manuel de grammaire touarègue (tăhăghart), I-III, Forlag, Copenhague.

Prasse, K.-G. (1974): Manuel de Grammaire Touarègue (tăhăghart), IV-v, Forlag, Copenhague.

Provotelle, P. (1911): Étude sur la Tamazir't ou Zénatia de Qalaât Es-Sened (Tunisie), Ernest Leroux, Paris.

Putten, M. van (2014): A Grammar of Awjila (Libya). Berber Studies, Rüdiger Köppe, Köln.

Putten, M. van (2017): «Are Libyco-Berber horizontal $\underline{T}$ and vertical $H$ the same sign?», en L. Nehmé y AL- A. Jallad (eds.), To the Madbar and Back AgainStudies in the languages, Archaeology, and Cultures of Arabia Dedicated to Michael C.A. Macdonald, Brill, Leiden: 346-357.

Ramírez Sánchez, M. (2010): "Tres décadas de debate sobre las supuestas inscripciones latinas de Lanzarote y Fuerteventura», en VII Congreso de Patrimonio Histórico: Inscripciones rupestres y poblamiento del Archipiélago 
canario, Cabildo insular de Lanzarote, Arrecife: 393-417.

Rodríguez, A.; Pichler, W. (2007): Libyco-Berber inscriptions database, Institutum

Canarium, Wien, [en internet], URL: http:/ / www.institutum-canarium.org/ lbi-project/ [Consulta: 01/05/2019].

Rössler, O. (1958): «Die Sprache Numidiens», Sybaris: Festschrift Hans Krahe,

Harrassowitz, Wiesbaden: 94-120.

SAUlCY, F. DE (1843): «Sur l'inscription bilingue de Thougga», Journal asiatique, 4 (1): 85-126.

SAVAGE, A. (2012): «Structure syllabique de la langue touarègue nouvel éclairage sur les voyelles schwa et 'a bref'», Études et Documents Berbères, 31: 95-135.

SPRINGER BUNK, R.A. (1994): Las inscripciones líbico-bereberes de las Islas Canarias, tesis doctoral inédita, Universidad de La Laguna

SPRINGER BunK, R.A. (1996): «Las inscripciones alfabéticas líbico-bereberes del archipiélago canario», en A. BELTRÁN (ed.), Manifestaciones rupestres de las Islas Canarias, Dirección General de Patrimonio Histórico, Santa Cruz de Tenerife: 393-417.

Springer BunK, R.A. (2001): Origen y uso de la escritura líbico-bereber en Canarias, Centro de la Cultura Popular Canaria, La Laguna.

SPRINGER BUNK, R.A. (2017): «La escritura líbico-bereber de las Islas Canarias: ¿uno o varios alfabetos?», Tabona, revista de Prehistoria y Arqueología, 21: 29-46.

SPRINGER BunK, R. A. (2019): «El alfabeto líbico-bereber canario: la distribución geográfica de los signos en el Norte de África y Sáhara», Vegueta: anuario de la Facultad de Geografía e Historia, 19: 759-772.

SPRINGER BunK, R.A. (en prensa): «Características de los yacimientos de grabados rupestres canarios y los signos empleados en las inscripciones alfabéticas», Études et Documents Berbères.

SouAG, L. (2017): «La diffusion en berbère: Réconcilier les modèles», Diffusion: Implantation, Affinités, Convergence, 24, Peeter, Paris: 88-107.

TAÏFI, M. (1991): Dictionnaire tamazight-francais (parlers du Maroc central), L'Harmattan-Awal, Paris.

TAINE-CHeiKH, C. (1999): «Le zénaga de Mauritanie à la lumière du berbère commun», en M. LAmberti y A. Tonelli (eds.): Afroasiatica Tergestina, Hal, Trieste: 299-324.

Trousset, P. (1982): «Le franchissement des chotts du Sud tunisien dans l'Antiquité», Antiquités africaines, 18, CNRS, Paris: 45-69.

Ulbrich, H.-J. (1996): «Neue Felsbildstationen auf der Kanareninsel Lanzarote (II)». Almogaren, 27: 285-358.

Velasco VÁzQUEZ, J. et al. (2020): «Poblamiento, colonización y primera historia de Canarias: C14 como paradigma», Anuario de Estudios Atlánticos, 66: 1-24.

Vycichl, W. (1955): «Les gétules de la Mauritanie», Bulletin de l'Institut français d'Afrique noire, Série B, Sciences humaines, 17: 163-167.

YoyotTe, J. (1958): «Anthroponymes d'origine libyenne dans les documents égyptiens», Comptes rendus du Groupe Linguistique d'Études Chamito-Sémitiques (GLECS), Geuther, Paris: 22-24. 


\title{
La toponimia como recurso didáctico para la enseñanza de la Geografía. Una propuesta a partir de tres salidas de campo en la Huerta de València (España)
}

\section{Toponymy as a Didactic Resource for Teaching Geography: A Proposal Based on Three Field Trips to Huerta de Valencia (Spain)}

\author{
Álvaro Francisco Morote Seguido* \\ Universitat de València \\ https:/ / orcid.org/0000-0003-2438-4961 \\ alvaro.morote@uv.es \\ Joan Carles Membrado Tena \\ Universitat de València \\ http:/ / orcid.org/0000-0001-6961-1449 \\ joan.membrado@uv.es
}

Recibido: 01/12/2020; Revisado: 03/04/2021; Aceptado: 10/05/2021

\begin{abstract}
Resumen
El objetivo de este trabajo es presentar una propuesta didáctica para el profesorado de Educación Primaria sobre el uso de la toponimia a partir de 3 salidas de campo en la Huerta de València (España). Ante la falta de trabajos sobre educación, toponimia y geografía en el área de estudio, este trabajo aportará significativamente al conocimiento sobre la didáctica de la geografía con el uso de salidas de campo en relación con la toponimia, pero también servirá de paradigma para la comunidad docente, ya que podrá aplicarlo a su territorio de referencia.
\end{abstract}

Palabras clave: Toponimia, propuesta didáctica, salida de campo, geografía, Huerta de València.

\section{Abstract}

This research makes a didactic proposal to Primary School teachers regarding the use of toponymy, based upon three field trips to Huerta de Valencia (Spain). Given the scarcity of scholarly work at the

*Autor de correspondencia / Corresponding author. 
nexus of pedagogy, toponymy and geography, this study significantly contributes to the teaching of geography through toponymy based on field trips, but it also serves as a paradigm for the wider teaching community, as it may be applied to other areas.

Keywords: Toponymy, Didactic Proposal, Field Trips, Geography, Huerta de Valencia.

\section{INTRODUCCIÓN ${ }^{1}$}

La toponimia hace referencia a los nombres de lugar y describe las características humanas y físicas del territorio (sustrato geológico, vegetación, topografía, sistemas de ocupación, fauna, etc.) (Gómez et al., 2015). El estudio de la toponimia se basa principalmente en tres disciplinas humanas (o sociales) claramente definidas como son la historia, geografía y la lingüística (DoRION, 1984). De esta forma se generan especialidades mixtas, como la geografía histórica, la historia de la lengua y las peculiaridades léxicas del lenguaje geográfico (ARROYO, 2018). De carácter plural e interdisciplinario (ORDINAS, 2014), la toponimia es, por tanto, un recurso plausible en el análisis territorial (FERNÁNDEZ et al., 2019) que, sin embargo, había sido poco tratada desde la geografía hasta finales del s. xx. Al respecto, DARBY (1957) ya advirtió de la limitación que suponía no tener en cuenta la vertiente geográfica de esta disciplina y dejar únicamente su estudio a la filología. Por su parte WEST (1954) ya indicaba que la clasificación y distribución de los topónimos pertenecía al campo de la geografía, mientras que el estudio de su etimología correspondía al mundo de la filología. Teniendo en cuenta estas cuestiones, esta investigación cobra un notable interés debido a varios motivos. El primero de ellos es la utilidad de la toponimia como recurso didáctico para la enseñanza de la geografía. Esto se hace más evidente en la etapa de Educación Primaria (objeto de estudio) debido a la escasa formación geográfica y percepción de limitada utilidad de esta ciencia, incluso por parte de los/as futuros/as maestros/as (PARRA y Morote, 2020). El segundo de ellos es el área de estudio donde se inserta esta propuesta (la Huerta de València, España), un espacio socio-cultural y ambiental que ofrece multitud de posibilidades para enseñar a interpretar el territorio y lograr un aprendizaje significativo. Y, en tercer lugar, la escasez de estudios sobre toponimia y didáctica de la geografía realizados en el área de estudio. Por tanto, este trabajo aportará una contribución a la temática de didáctica de la geografía en relación con la toponimia, pero también será un ejemplo para la comunidad docente, ya que puede ser fácilmente tomado como referencia a su territorio.

Respecto a la enseñanza de la geografía, ORDINAS y Binimelis (2018) destacan la importancia del binomio toponimia-geografía. Esto también ha sido indicado por diferentes autores que han demostrado que esta disciplina resulta de enorme interés para entender e interpretar el entorno (LUISA DE TORT, 2004). Sin embargo,

1 Esta investigación se inserta en el proyecto «Las representaciones sociales de los contenidos escolares en el desarrollo de las competencias docentes (PGC2018-094491-B-C32)» financiado por el Ministerio de Ciencia, Innovación y Universidades y cofinanciado con fondos FEDER de la UE. 
uno de los problemas con los que se ha enfrentado esta disciplina ha sido su utilización en la enseñanza asociada a un aprendizaje exclusivamente memorístico (ORDINAS y BINIMELIS, 2018). Diferentes autores han puesto de manifiesto que este aprendizaje y estudio, asociado a la geografía regional, ha conllevado al abuso de la memorización y de ejercicios de repetición y reproducción de topónimos (Ballantyne, 1996; Morote, 2020). Según Comes y Dantí (2003) tener en cuenta la toponimia que se asocia a la experiencia o al contexto vital de los discentes, y la propuesta de actividades orientadas a analizar su sentido o significado, puede estimular el interés por estudiar esta ciencia. Por ello, y como afirman Gómez et al. (2015), la oportunidad de fomentar el análisis aplicado de la toponimia en los programas educativos debe apoyarse en la relevancia del saber cotidiano, donde se inserta también el conocimiento de los topónimos, para la comprensión de la sociedad actual y pasada y del medio en el que se asienta (EsTePA et al., 2011).

Algunas de las propuestas que se pueden implementar en didáctica de la geografía en relación con la toponimia deberían vincularse con la enseñanza activa, por ejemplo, con metodologías de aprendizaje por descubrimiento a través de procedimientos (Gómez-RUIZ, 2010; MARRón, 2011), la obtención de toponimia a partir de nuevas Tecnologías de la Información Geográfica (TIG) como Iberpix (Crespo, 2019; Sebastián y De Miguel, 2017), o la importancia del aprendizaje fuera del aula (De LÁZARO et al., 2014; MARRón, 2013). En esta última línea, cobran un notable protagonismo y utilidad de la toponimia las salidas de campo, uno de los recursos clásicos de la geografía. En este sentido, en un trabajo reciente llevado a cabo por Morote (2019) se ha realizado un análisis de la evolución en las últimas décadas de las temáticas y autores sobre las salidas de campo en geografía. Este autor ha demostrado como en los últimos años han cobrado protagonismo los trabajos vinculados con las TIC y con los estudios de caso. Por ejemplo, de estos últimos, donde se insertaría la propuesta aquí presentada, destacan las contribuciones de Crespo (2012), Delgado et al., (2013), Gómez et al. (2017), Fernández (2017) o López-Fernández y Peral (2017).

En relación con los trabajos vinculados con la toponimia, la mayoría de los estudios se han centrado en aspectos semánticos, filológicos, etimológicos e históricos, pero también geográficos. En España, entre estos últimos cabe mencionar los realizados por MEMBRAdo $(2017 ; 2018)$ o GARCíA DE Celis et al. (2018). En el panorama internacional son reseñables trabajos toponímicos desde la geografía como los de Seidl (2018), AldERMAn (2016), Siwei et al. (2016) o CoNEDERA et al. (2017).

En España, respecto a los trabajos sobre didáctica de la geografía y toponimia, de los años noventa destacan publicaciones sobre propuestas didácticas (MAs, 1999; TORRES, 1995), y sobre problemas, métodos y enseñanza de la toponimia (FrAGo, 1991). En el s. XXI han sido publicadas diferentes investigaciones sobre la utilidad de la toponimia para la enseñanza de la geografía, como la de ORDINAS (2014) acerca del redescubrimiento para el colectivo docente de su utilidad y de su enseñanza mediante técnicas y aplicaciones renovadas. Otras se vinculan con las aportaciones que puede tener esta disciplina para la didáctica y la propuesta de recursos del entorno (espacios vulnerables) (GómEz et al., 2015). También 
destacan investigaciones que tratan sobre experiencias para la enseñanza del paisaje natural como la de ORDINAS y BinIMELIS (2018). Estos últimos definen la valiosa información obtenida de los nombres de lugar sobre múltiples aspectos del territorio como «función pedagógica de la toponimia», que constituye una importante contribución a la consolidación de la conciencia territorial, base esencial de la cohesión y la coherencia social (OrdinAs y Binimelis, 2018: 389). Por su parte, ORDINAS (2014) añade que la enseñanza basada en la toponimia permite la consecución de objetivos como la identificación del entorno físico y humano, a partir de su denominación, y el impacto de las actividades antrópicas sobre el medio, al igual que las transformaciones producidas a lo largo del tiempo, que deben ser cualidades que conviene que sean conocidas por las nuevas generaciones. De ahí, como expresan ORDINAS y BINIMELIs (2018) el interés por mostrar la utilidad de esta disciplina en las clases de geografía y/o ciencias sociales.

Un trabajo reciente sobre la utilidad de la toponimia es el de Domínguez et al. (2020) donde se evalúa y analiza la realización de una práctica de aula sobre el análisis de la toponimia del callejero con perspectiva de género en las diferentes asignaturas del área. Por tanto, el objetivo principal de este trabajo es conocer la utilidad de la toponimia, su aplicación, así como su efectividad en cuanto a introducción de la perspectiva de género. Otros trabajos en el contexto español ponen de manifiesto la importancia que adquiere la toponimia como fuente de conocimiento para la interpretación del territorio como los de RIESCO (2010) o LUISA DE TORT (2014). En el ámbito internacional, destacan referencias sobre toponimia y revalorización del paisaje (ALDERMAn y Reuben, 2020; MEMBRAdo e IRANZO, 2017; 2018), y sobre toponimia, pedagogía e interpretación del paisaje (HeIKKILA, 2008; AldERMAN, 2016). También, cabe indicar algunas contribuciones llevadas a cabo en el ámbito latinoamericano como las relacionadas con la propuesta de recursos didácticos (cartografía) en Argentina (GILIO, 2015), o la utilidad didáctica que tiene la toponimia para enseñar geografía como pone de manifiesto VALENZUELA (2010) en México.

El objetivo de este trabajo es presentar una propuesta didáctica para el profesorado de Educación Primaria sobre el uso de la toponimia a partir de 3 salidas de campo en la Huerta de València (España). Por tanto, lo que se pretende es, por un lado, mostrar ejemplos de cómo interpretar («leer») el territorio a partir de la toponimia a modo de estudio de caso y, por otro, ofrecer a la comunidad docente un ejemplo de cómo utilizar la toponimia para la enseñanza y que fácilmente se puede adaptar a otras áreas de estudio.

\section{2. ÁREA DE ESTUDIO}

El área de estudio es la Huerta de València (España), un paisaje cultural testimonio de la actividad agrícola de sus moradores a lo largo de los últimos dos mil años y un paradigma de las llanuras mediterráneas con un rico paisaje agrario basado en el aprovechamiento hidráulico (IRANZO, 2014). Con $621 \mathrm{~km}^{2}$ y más de 
1,5 millones de habitantes (cerca 2.500 hab./ $\mathrm{km}^{2}$ ), la Huerta de València (Horta de València, en valenciano) es también el nombre de la comarca más poblada de la Comunitat Valenciana, en la que se encuentra su capital y principal ciudad (València) pero, también varias poblaciones que superan los 50.000 habitantes (Torrent, Paterna) y 30.000 habitantes (Mislata, Burjassot, Manises) (Figura 1). Un rasgo característico de esta área es la pérdida de espacio agrario debido a la expansión de los usos urbanos. El crecimiento urbanístico descontrolado de València y su entorno a partir de 1960 provocó su progresiva reducción y degradación. Hubo dos momentos especialmente críticos de sellado de los suelos agrícolas: 1) durante el desarrollismo franquista (1960 a 1975), momento de crecimiento continuo (compacto y en altura), industrialización y construcción del Plan Sur (nuevo cauce del río Turia); y 2) durante la burbuja inmobiliaria española (19972007), en el que predominó el crecimiento urbano discontinuo (urban sprawl) y de las infraestructuras de servicios (comerciales, logísticos portuarios, sanitarios, educativos).

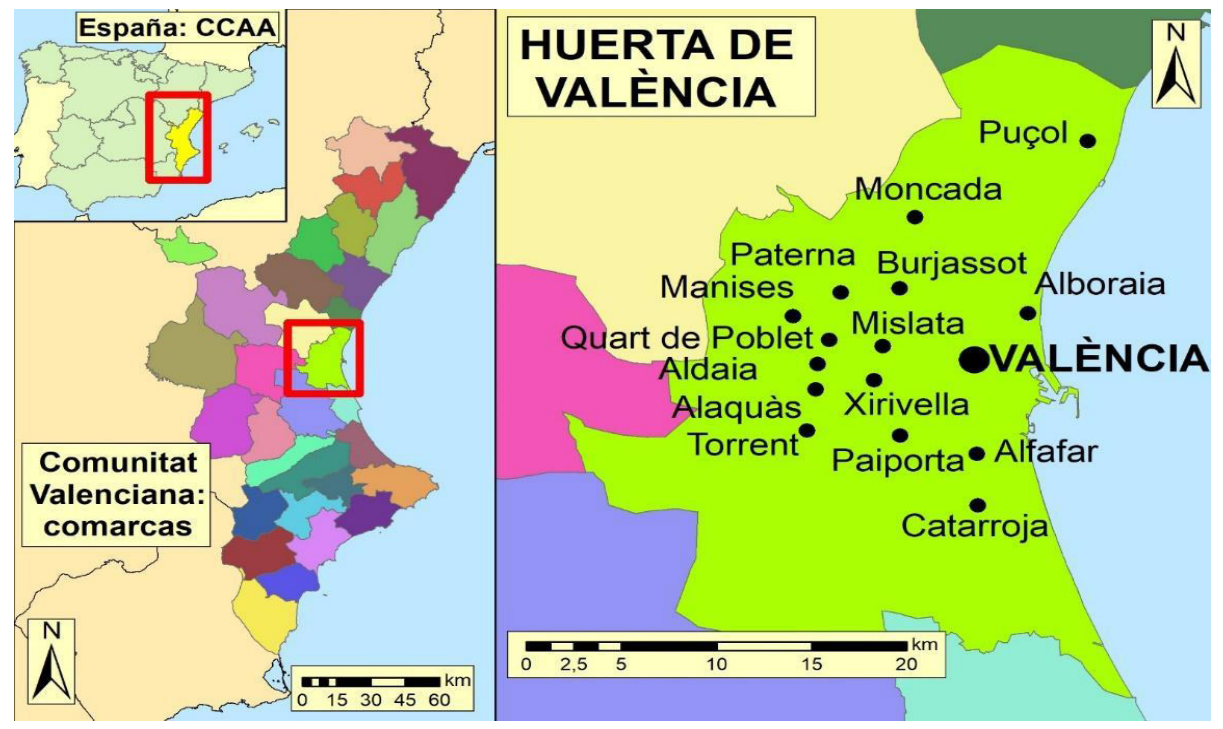

Figura 1. Área de estudio. Comarca de l'Horta o Huerta de València Elaboración propia con datos del ICV (Institut Cartogràfic Valencià).

El crecimiento urbano durante el último medio siglo a lo largo de las principales vías de acceso a la ciudad de València provocó la desconexión entre sí de su huerta tradicional, y creó bolsas de cultivos hortícolas aisladas donde la estructura y funcionamiento del paisaje agrario quedaba notablemente truncada. Entre 1956 y 2015 la huerta pasó de 15.000 a 6.000 ha (una reducción del 60\%) (SORIANO, 2015). Solo durante 1990 y 2009, en plena burbuja inmobiliaria, la huerta 
en la comarca se redujo de 10.000 a menos de 7.000 ha: si el ritmo de destrucción del periodo 1990-2009 se hubiera mantenido estable, este espacio habría desaparecido por completo en solo 63 años (MEMBRADO, 2014).

La crisis económica iniciada en 2008 puso freno al proceso regresivo hortícola y, a pesar de las medidas de protección tomadas por el Consell de la Generalitat Valenciana para su protección institucional (aprobación del Plan de Acción Territorial de la Huerta en 2018), el futuro de lo que queda de la Huerta de València es incierto, ya que el relevo generacional entre los agricultores no está garantizado dada la escasa rentabilidad de los cultivos y el alto valor inmobiliario del suelo («barbecho social»), por su proximidad a la ciudad de València.

Uno de los elementos patrimoniales mejor preservados de este deteriorado espacio es su toponimia, debido al carácter arcaizante propio del lenguaje de los nombres de lugar. En este trabajo se muestra un ejemplo didáctico de análisis toponímico del paisaje, centrado en el espacio hortícola entre la Universitat de València (Campus dels Tarongers), la Universitat Politècnica de València (Campus de Vera), el límite nordeste del término de València y el sur del de Alboraia. Se trata de un espacio donde una parte de la huerta sobrevive de manera más o menos precaria y otra que desapareció hace ya décadas y puede ser reconstituida virtualmente gracias a los nombres de lugar que aún persisten. Desde el punto de vista didáctico, el análisis de la toponimia huertana, sobre un entorno que hoy en día está en gran parte sellado, confirma el predominio histórico de este paisaje agrícola. Este paisaje, gran parte del cual sobrevive solo gracias a sus topónimos, forma parte de la identidad comarcal y, como rasgo identitario, es prioritaria su revalorización, tras décadas de destrucción, degradación y abandono.

\section{MATERIAL Y MÉTODOS}

La propuesta didáctica que aquí se expone, se realiza en el Grado en Maestro/a en Educación Primaria (Facultad de Magisterio, Universitat de València, España), concretamente en la asignatura de «Didáctica de las Ciencias Sociales. Aspectos aplicados» (código 33651). Esta asignatura, obligatoria y de carácter teórico-práctico ( 4,5 créditos) se imparte en el $4^{\circ}$ curso. En relación con el Plan de Estudios del Grado en Maestro/a en Educación Primaria cabe indicar que, junto a la asignatura de «Didáctica de las Ciencias Sociales. Aspectos básicos» $\left(3^{\circ}\right.$ curso) son las únicas materias de carácter obligatorio en las que se insertan contenidos geográficos. La asignatura de $3^{\circ}$ tiene el objetivo de enseñar qué contenidos sobre ciencias sociales se pueden tratar en la Educación Primaria, mientras que la de $4^{\circ}$, donde se realiza esta propuesta, tiene la finalidad de cómo enseñar ciencias sociales. Por tanto, esta propuesta sirve para mostrar cómo se pueden enseñar estas ciencias, y más concretamente en relación con contenidos geográficos a partir de la toponimia que se puede explicar con la realización de salidas de campo y teniendo como marco geográfico (en parte desaparecido) de la Huerta de València.

En cuanto al currículo vigente de Ciencias Sociales, si se tiene en cuenta 
el Decreto del Consell de la Generalitat Valenciana (108/2014 de 4 de julio), los contenidos que se explican durante las salidas de campo se enmarcan principalmente en el Bloque 2 «El mundo en que vivimos: estudio del espacio geográfico, desde lugares próximos hasta regiones que tienen una dimensión global». En este bloque se estudia la distribución y localización de los elementos que configuran el medio físico y su interacción con la acción humana que da lugar a una diversidad de paisajes. Dicha interacción se plantea también desde desafíos que han de superar las sociedades como es el logro del desarrollo sostenible y que requieren un conocimiento de los elementos y sus conexiones que configuran el espacio geográfico en una variedad de escala. En este bloque se concretan aspectos procedimentales apuntados en el bloque anterior.

Además, cabe insistir que, durante las salidas de campo, la toponimia es un recurso complementario que ayuda a entender determinados contenidos dentro de las ciencias sociales. En este sentido, dentro del contexto de la asignatura, el objetivo de las salidas es enseñar al futuro profesorado de Educación Primaria la potencialidad que ofrece el entorno más próximo para explicar aspectos histórico-geográficos. Especialmente, se priorizan determinados elementos que puedan dar lugar al debate y reflexión sobre los problemas sociales y ambientales relevantes en relación con la economía, demografía, urbanización, agricultura, paisaje, patrimonio, historia, toponimia, riesgos naturales y cambio climático (entre otros). La toponimia no es, por tanto, el objetivo principal de las salidas de campo que se desarrollan en la asignatura (pero sí del actual trabajo), sino que se trata de un recurso complementario para llevar a cabo una mejor interpretación, lectura y explicación del territorio. Por ello, en relación con la enseñanza, uno de los objetivos del profesorado que implementa estas salidas de campo es que los discentes valoren la toponimia como un recurso didáctico y que sepan explicar sus potencialidades sobre cualquier área de estudio cuando tengan que llevar a cabo su labor docente. En este sentido, aunque no es objetivo de analizar en esta contribución, el resultado de la realización de estos itinerarios es notablemente positivo, tanto por las opiniones mostradas por el alumnado, como por las propuestas de salidas de campo que realizan en una de las prácticas entregables de la asignatura.

En cuanto a los materiales para las salidas de campo se facilitan al alumnado 3 dossiers donde quedan reflejados los itinerarios. Dentro de estos se incluyen diferentes mapas y fotografías aéreas donde se puede observar una evolución cronológica del área de estudio y los topónimos que se explican. En primer lugar, se incorpora la cartografía catastral de los Bosquejos Planimétricos mandados formar por la Ley de 24 de agosto de 1896 que, para el caso de la ciudad de València, finalizaron en 1902. Estos mapas destacan porque fue la primera cartografía catastral que cubrió todo el territorio nacional (1:25.000), siendo el precedente del actual Mapa Topográfico Nacional (MTN). Esta cartografía es interesante, además, por el gran número y variedad de topónimos, especialmente los que se refieren a infraestructuras (vías de comunicación), viviendas y actividades económicas. En segundo lugar, se añade una captura de imagen de la fotografía aérea del Ejército del Aire (1956), también conocida como la del Vuelo Americano. Le sigue 
la fotografía aérea de 1978 y una actual procedente del visor del Institut Cartogràfic Valencià (ICV). Finalmente, el dossier concluye con un mapa topográfico del área de estudio donde se recogen los topónimos actuales (ICV). Además, para el caso de la segunda salida de campo se añade una cartografía de zonas inundables del Plan de Acción Territorial sobre prevención de Riesgos de Inundaciones de la Comunidad Valenciana (PATRICOVA) (accesible también desde el ICV).

\section{PROPUESTA Y DESCRIPCIÓN DE LAS SALIDAS DE CAMPO}

\subsection{Salida de campo 1. Configuración y evolución histórica de la Huerta de València}

La primera salida de campo tiene el objetivo de dar a conocer al alumnado los diferentes elementos geográficos que se pueden explicar sobre la Huerta de València en relación con la vegetación, actividades económicas, usos urbanos y patrimonio hidráulico (Figura 2). En la primera parte del itinerario se presta especial atención al proceso histórico de la configuración de este espacio agrícola y de los principales problemas a los que se enfrenta: la urbanización, la contaminación de las aguas de riego (Figura 3), el problema del relevo generacional de los agricultores y la rentabilidad de los cultivos.

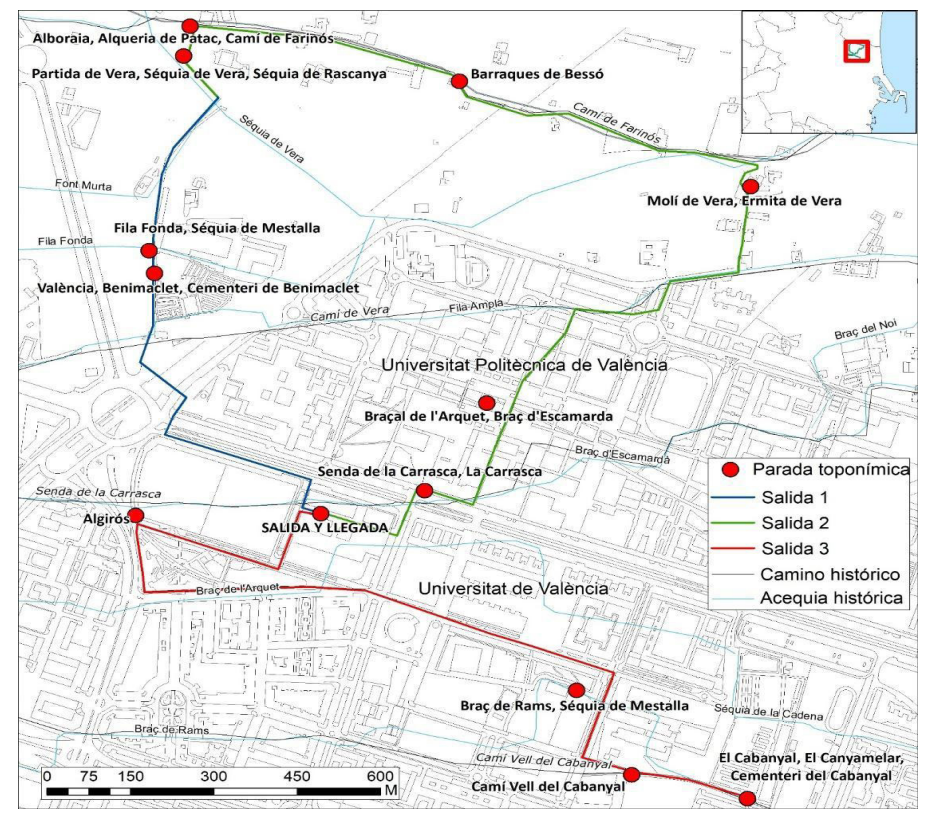

Figura 2. Itinerario de las 3 salidas de campo. Elaboración propia con datos del Institut Cartogràfic Valencià (ICV). ${ }^{2}$

2 En este mapa se han recogido todos los topónimos que se explican. Como «parada toponímica» se 
En cuanto la toponimia, durante este primer recorrido, los nombres de lugar se utilizan para explicar la configuración y transformación histórica y del sistema de regadío de la Huerta de València. Respecto a la primera cuestión, se explica el origen y significado de València que, hace referencia a una colonia romana fundada en el 138 a. C. Su explicación durante el itinerario sirve para comprender el proceso histórico de la configuración de esta ciudad y del territorio de la Huerta ya desde época romana. Se trataba de un espacio fértil que, a lo largo de más de dos milenios, ha sido transformado por la actividad humana tras el paso de diferentes culturas y sociedades. $\mathrm{Al}$ respecto, cuando el recorrido transcurre junto al barrio de Benimaclet, se explica el origen y significado árabe de este nombre de lugar (Tabla 1). Este topónimo también sirve para explicar los procesos de urbanización de la huerta a raíz del crecimiento urbano de la ciudad. También en este punto se explican determinados usos urbanos y servicios públicos, al referirse al Cementeri de Benimaclet, creado a final del siglo XIX (1896-1899) debido a las epidemias de cólera y como medida higiénica para sustituir el cementerio anterior que se encontraba en el centro del barrio junto a la iglesia (antiguo pueblo de Benimaclet). Otro de los topónimos que hacen mención a asentamientos humanos es la Partida de Vera, del latín varius 'color grisáceo' (Tabla 1), tal vez por ser una zona endorreica y de marjal, donde la población vive diseminada en casas rurales (alquerías).

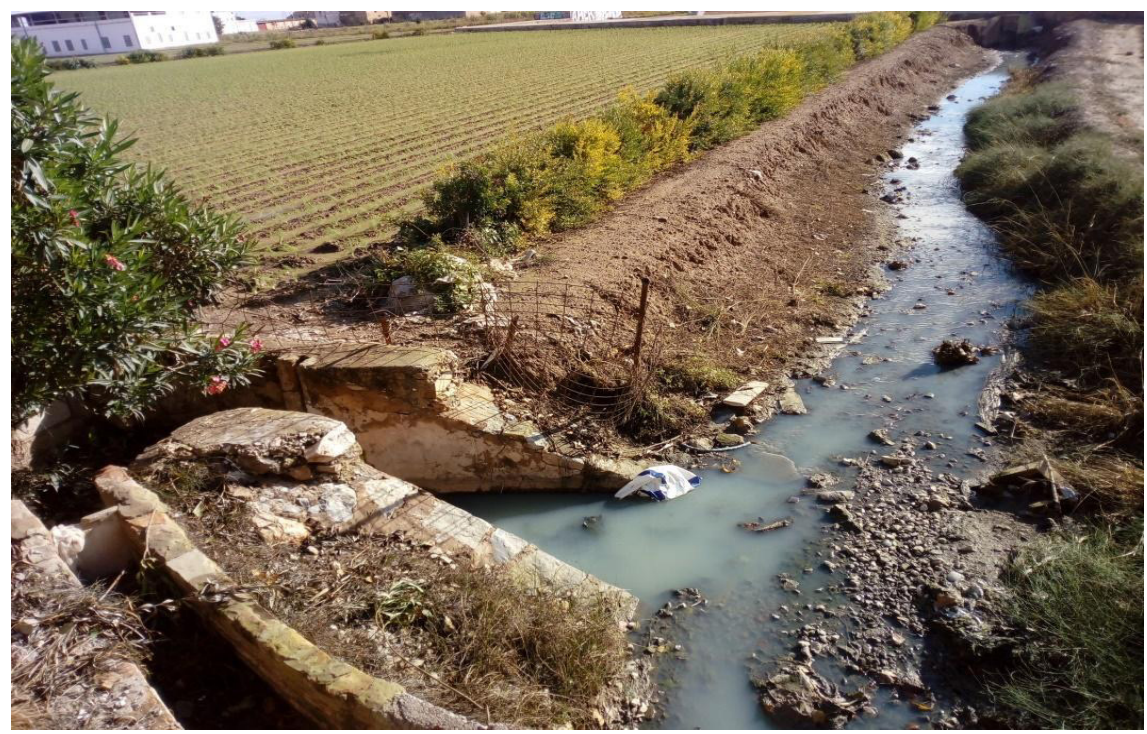

Figura 3. Aguas contaminadas en una de las acequias de la Partida de Vera (Benimaclet). Fotografía de los autores (2019). ${ }^{3}$

entiende como aquellas paradas que se realizan durante las salidas en la que se explican contenidos que tienen que ver con el significado del nombre del lugar (toponimia).

3 En la imagen se puede apreciar un partidor para distribuir las aguas de riego. El agua procede de la Acequia de Mestalla. 
TABLA 1

Topónimos que se explican durante la salida de campo 1

\begin{tabular}{|c|c|}
\hline \multicolumn{2}{|r|}{ València } \\
\hline Origen lingüístico & $\begin{array}{l}\text { Latín valens -entis 'que vale, que tiene valor, que es fuerte' (CASANOvA, } \\
\text { 2011: 285). }\end{array}$ \\
\hline Contenido semántico & $\begin{array}{l}\text { 1. Geografía Humana: asentamiento urbano. } \\
\text { 2. Geografía Humana: topónimo propagandístico (para atraer } \\
\text { colonos). }\end{array}$ \\
\hline Tipo de topónimo & $\begin{array}{l}\text { Nombre de una colonia romana fundada por colonos romanos en } 138 \\
\text { a.C. (según datos de Tito Livio en Ab Urbe Condita). }\end{array}$ \\
\hline Continuidad semántica & $\begin{array}{l}\text { Continúa siendo una urbe. Se trata de una de las grandes ciudades } \\
\text { más antiguas de Europa, ya que ha pervivido ininterrumpidamente } \\
\text { durante más de } 2 \text { milenios }\end{array}$ \\
\hline $\begin{array}{l}\text { Interés didáctico para la } \\
\text { enseñanza de las ciencias } \\
\text { sociales }\end{array}$ & $\begin{array}{l}\text { Ayuda a entender el proceso histórico de la configuración de esta } \\
\text { ciudad y el contexto de la Huerta de València ya desde época romana. } \\
\text { Se trataba de un espacio fértil y que desde hace } 2000 \text { años ha sido } \\
\text { transformado por la actividad humana y tras el paso de diferentes } \\
\text { civilizaciones. }\end{array}$ \\
\hline \multicolumn{2}{|r|}{ Séquia de Mestalla } \\
\hline Origen lingüístico & $\begin{array}{l}\text { Latín tardío mixta (femenino de mixtus) 'mezcla' + sufijo -alla } \\
\text { (Coromines, 1989-1997, v: 289). }\end{array}$ \\
\hline Contenido semántico & Geografía Humana: infraestructura de riego para la huerta. \\
\hline Tipo de topónimo & $\begin{array}{l}\text { Acequia para riego de la huerta. } \\
\text { Mezcla de aguas, porque describe un azud donde unas aguas siguen } \\
\text { por el río y otras se incorporan a la acequia de Mestalla. }\end{array}$ \\
\hline Contin & $\begin{array}{l}\text { Desde su creación funciona como azud y acequia, aunque hoy es más } \\
\text { conocida por dar nombre a un barrio y al campo de fútbol del Valencia } \\
\text { C.F. }\end{array}$ \\
\hline $\begin{array}{l}\text { Interés didáctico para la } \\
\text { enseñanza de las ciencias } \\
\text { sociales }\end{array}$ & $\begin{array}{l}\text { Sirve para explicar el patrimonio hidráulico y las peculiaridades del } \\
\text { sistema de regadío de la Huerta de València. }\end{array}$ \\
\hline \multicolumn{2}{|r|}{ Séquia de Rascanya } \\
\hline Origen lingüístico & $\begin{array}{l}2 \text { opciones } \\
\text { 1. árabe rizq 'bien, propiedad, beneficio' + Ain, 'fuente', el beneficio } \\
\text { que nos aporta la fuente (CoRomines, 1989-1997, vi: } 343 \text { ). } \\
\text { 2. latín resecare 'cortar, recortar' > tardolatino o mozárabe: riscare, } \\
\text { 'terreno recortado, riscoso, peña' (de donde proviene el castellano } \\
\text { risco). }\end{array}$ \\
\hline Contenido semántico & Geografía Humana: infraestructura de riego para la huerta. \\
\hline
\end{tabular}




\begin{tabular}{|c|c|}
\hline Tipo de topónimo & $\begin{array}{l}\text { Actual: acequia para riego de la huerta. } \\
\text { Anterior: } \\
\text { 1. Topónimo propagandístico referido a una acequia, que aporta } \\
\text { riqueza ya que riega los campos y produce alimentos. } \\
\text { 2. Se refiere a los riscos o peñas (en el término de Paterna) cercanos al } \\
\text { azud de Rascanya, de donde parte esta acequia. Aguas arriba de este } \\
\text { azud hay otro azud cuyo topónimo está definido por las mismas peñas } \\
\text { (azud de Tormos, "peñas"). }\end{array}$ \\
\hline Continuidad semántica & $\begin{array}{l}\text { Desde su creación funciona como azud y acequia, aunque hoy es } \\
\text { también conocida para dar nombre a un barrio y a un distrito de la } \\
\text { ciudad de València. }\end{array}$ \\
\hline $\begin{array}{l}\text { Interés didáctico para la } \\
\text { enseñanza de las ciencias } \\
\text { sociales }\end{array}$ & $\begin{array}{l}\text { Sirve para explicar el patrimonio hidráulico y las peculiaridades del } \\
\text { sistema de regadío de la Huerta de València. }\end{array}$ \\
\hline \multicolumn{2}{|r|}{ Fila Fonda } \\
\hline Origen lingüístico & $\begin{array}{l}\text { Catalán/valenciano fila 'canal secundario en el sistema de regadío de } \\
\text { la huerta de Valencia' (cf. reguero, hijuela) (AVL, 2016). }\end{array}$ \\
\hline Contenido semántico & Geografía humana: infraestructura de riego para la huerta. \\
\hline Tipo de topónimo & Acequia menor para riego de la huerta (Figura 3). \\
\hline Continuidad semántica & Desde su creación funciona como acequia de tercer nivel (hijuela). \\
\hline $\begin{array}{l}\text { Interés didáctico para la } \\
\text { enseñanza de las ciencias } \\
\text { sociales }\end{array}$ & $\begin{array}{l}\text { Sirve para explicar el patrimonio hidráulico y las peculiaridades del } \\
\text { sistema de regadío de la Huerta de València. }\end{array}$ \\
\hline \multicolumn{2}{|r|}{ Benimaclet } \\
\hline Origen lingüístico & $\begin{array}{l}\text { Árabe: ibn 'familia, hijos, clan' + mahlad 'linaje árabe' (BARCELó, 2010: } \\
\text { 96). }\end{array}$ \\
\hline Contenido semántico & Geografía humana: propiedad rústica (alquería). \\
\hline Tipo de topónimo & $\begin{array}{l}\text { Antigua alquería. Posteriormente convertida en pueblo (entre el siglo } \\
\text { xvı y 1878) y actualmente barrio de la ciudad de València. }\end{array}$ \\
\hline Continuidad semántica & $\begin{array}{l}\text { Continúa siendo uno de los barrios más conocidos y peculiares de } \\
\text { València y que aún mantiene cierta vida de pueblo. Este barrio tiene } \\
28.718 \text { habitantes (AYUNTAMIENTO DE VALĖNCIA, 2020). }\end{array}$ \\
\hline $\begin{array}{l}\text { Interés didáctico para la } \\
\text { enseñanza de las ciencias } \\
\text { sociales }\end{array}$ & $\begin{array}{l}\text { Sirve para explicar el asentamiento humano por parte de la cultura } \\
\text { islámica en la Huerta de València. También se utiliza para explicar los } \\
\text { procesos de urbanización de la huerta con el crecimiento urbanístico } \\
\text { de la ciudad de València. Se aprovecha la ocasión para explicar los } \\
\text { diferentes amenazadas de este espacio agrícola. }\end{array}$ \\
\hline \multicolumn{2}{|r|}{ Cementeri de Benimaclet } \\
\hline Origen lingüístico & 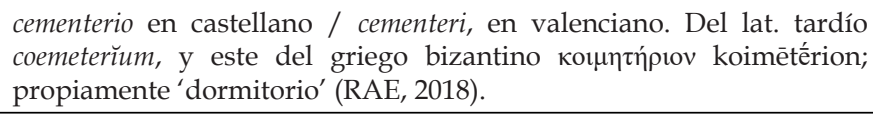 \\
\hline Contenido semántico & Geografía Humana: infraestructura para uso humano. \\
\hline Tipo de topónimo & Lugar para enterramiento de difuntos. \\
\hline
\end{tabular}




\begin{tabular}{|c|c|}
\hline Continuidad semántica & $\begin{array}{l}\text { Desde que se creó a finales del siglo xIx (1896-99) ha funcionado } \\
\text { como lugar de enterramiento de difuntos. Las terribles epidemias } \\
\text { de cólera de finales del siglo xIx provocaron su construcción, ya que } \\
\text { anteriormente el cementerio estaba dentro del pueblo de Benimaclet, } \\
\text { al lado de su iglesia. }\end{array}$ \\
\hline $\begin{array}{l}\text { Interés didáctico para la } \\
\text { enseñanza de las ciencias } \\
\text { sociales }\end{array}$ & $\begin{array}{l}\text { Sirve para explicar los usos urbanos y servicios públicos, así como } \\
\text { la causa de su construcción (epidemias de cólera de finales del siglo } \\
\text { xIx) y el crecimiento demográfico. Se aprovecha también para explicar } \\
\text { el proceso de urbanización ya que se encuentra actualmente en las } \\
\text { afueras del barrio de Benimaclet. }\end{array}$ \\
\hline \multicolumn{2}{|r|}{ Partida de Vera } \\
\hline Origen lingüístico & $\begin{array}{l}\text { Vera podría derivar del latín varius 'color grisáceo' (CoROMINES, 1989- } \\
\text { 1997, vII: 459). } \\
\end{array}$ \\
\hline Contenido semántico & Partida cuya tierra presenta un color grisáceo. \\
\hline Tipo de topónimo & $\begin{array}{l}\text { Tal vez se refiera a los pantanos que cubrían históricamente esta área, } \\
\text { antes de que fueran bonificados para cultivar la huerta. }\end{array}$ \\
\hline Continuidad semántica & $\begin{array}{l}\text { Sus áreas pantanosas (marjales) han desaparecido ya desde hace } \\
\text { siglos. Continúa siendo actualmente una partida agrícola, pero } \\
\text { amenazada por el crecimiento urbano de la ciudad de València y zona } \\
\text { costera (Playa la Patacona, en Alboraia) y vías de comunicación. }\end{array}$ \\
\hline $\begin{array}{l}\text { Interés didáctico para } \\
\text { enseñanza de las ciencias } \\
\text { sociales }\end{array}$ & $\begin{array}{l}\text { Esta área geográfica sirve de marco para explicar diferentes elementos } \\
\text { geográficos, desde la urbanización, agricultura, configuración } \\
\text { histórica de la Huerta de Valencia, hasta el riesgo de inundación. No } \\
\text { hay que olvidar que esta zona era un área pantanosa, de marjal. }\end{array}$ \\
\hline \multicolumn{2}{|r|}{ Séquia de Vera } \\
\hline Origen lingüístico & $\begin{array}{l}\text { Vera podría derivar del latín varius "color grisáceo" (CoROMINES, 1989- } \\
\text { 1997, VII: 459). }\end{array}$ \\
\hline Contenido semántico & Geografía humana: infraestructura de riego para la huerta. \\
\hline Tipo de topónimo & $\begin{array}{l}\text { Se refiere a la acequia que nace de la acequia de Rascanya y que riega } \\
\text { la partida de Vera, cuya tierra presentaría un color grisáceo por sus } \\
\text { marjales. Esta acequia marca el límite entre los actuales términos de } \\
\text { València y Alboraia (antiguamente entre Benimaclet y Alboraia). }\end{array}$ \\
\hline Continuidad semántica & La acequia se creó como canal de riego y así continúa. \\
\hline $\begin{array}{l}\text { Interés didáctico para la } \\
\text { enseñanza de las ciencias } \\
\text { sociales }\end{array}$ & $\begin{array}{l}\text { Sirve para explicar el patrimonio hidráulico y las peculiaridades del } \\
\text { sistema de regadío de la Huerta de València. }\end{array}$ \\
\hline
\end{tabular}

Fuente: Elaboración propia.

Un segundo grupo de topónimos hace referencia al sistema de regadío tradicional de la Huerta de València. En esta parte de la salida de campo se explica el Tribunal de las Aguas, entidad que se encarga históricamente de dirimir los conflictos por el agua de riego entre los agricultores de 7 comunidades de regantes que componen las acequias del Turia (Quart-Benàger-Faitanar, Tormos, Mislata, Mestalla, Favara, Rascanya y Rovella). De estas 7 acequias, cabe indicar que 2 regaban o aun riegan campos de cultivo por donde discurren las 3 salidas de campo que aquí se exponen (acequias de Mestalla y Rascanya) (Tabla 1). A 
continuación, se explica el funcionamiento y jerarquía de las infraestructuras hidráulicas tradicionales: en primer lugar, se destacan los 7 azudes o presas del río Turia, desde donde derivan, respectivamente, cada una de las siete acequias principales citadas (séquia mare); posteriormente, el agua se ramifica a través de los llamados braços (brazos) y braçals (brazales); y, finalmente, en un tercer nivel se encuentran las llamadas files (filas, hijuelas) (Figura 4). De manera general, esta sería la jerarquización de la distribución de las aguas desde el río Turia. También, cabe indicar que el nombre de acequia puede hacer mención indistintamente a braços, braçals o files: es decir, se trata de un nombre general para mencionar a una infraestructura que deriva y transporta agua de riego. Además, cabe remarcar la complejidad de este sistema de riego, ya que hay acequias de entrada de agua a los campos de cultivo ('aguas vivas') y de salida, que recogen las aguas sobrantes ('aguas muertas') hacia el mar. Cabe indicar que antes de su evacuación al mediterráneo, estos mismos caudales pueden ser utilizados hasta en 6 o 7 bancales (Figura 5). Junto a la explicación del sistema de regadío de la Huerta de València se explica el origen y significado de este segundo grupo de topónimos (Tabla 1).

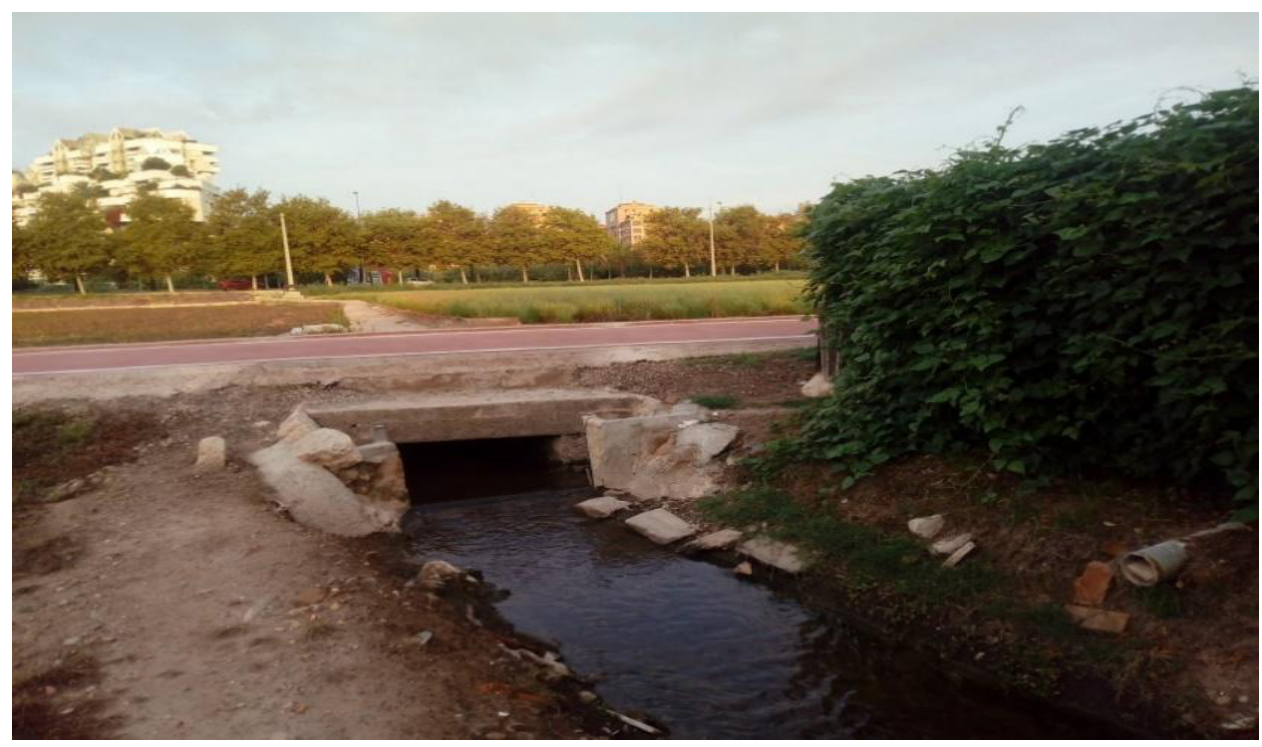

Figura 4. Fila Fonda (Partida de Vera). Fotografía de los autores (2018). ${ }^{4}$

4 En esta imagen se puede observar de fondo la parte nueva del barrio de Benimaclet, concretamente la Cooperativa de Edificios Espai Verd. El agua procede de la acequia de Mestalla. 


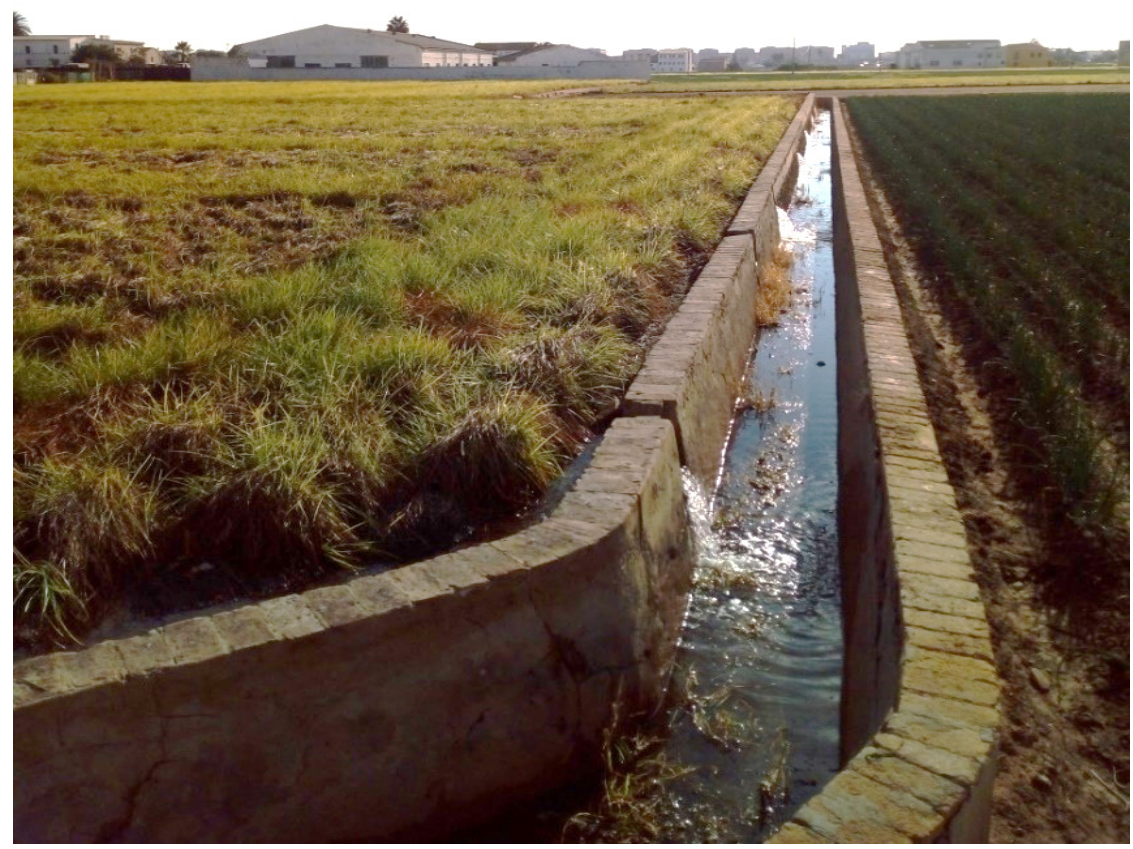

Figura 5. Riego de campos de cultivo de chufa (Alboraia). Fotografía de los autores (2018). ${ }^{5}$

\subsection{Salida de campo 2. Ocupación y adaptación del ser humano al medio}

La segunda salida de campo comienza en el mismo punto donde finaliza la primera (Figura 2). El tema general de este itinerario es mostrar cómo se ha producido la ocupación del territorio y la adaptación del ser humano a un territorio inundable. Esta temática (el riesgo de inundación) debe tratarse en la Educación Primaria como corrobora la normativa para el caso de las ciencias sociales en el Bloque 2, concretamente en el curso $3^{\circ}$ donde uno de los contenidos a tratar son las «Consecuencias de las sequías y las inundaciones para la vida de los seres humanos». En el comienzo de esta jornada se retoma la información de la salida de campo anterior y se vincula el área de estudio con su proceso de configuración y se introduce que antiguamente era una zona de marjal (se pregunta nuevamente por el topónimo de Vera). En cuanto al interés didáctico de la toponimia, los nombres que se explican son aquellos que tienen que ver con

5 En esta imagen se puede observar la salida de las aguas sobrantes ("aguas muertas"). El agua procede de la acequia de Rascanya. 
asentamientos humanos que han ocupado esta zona inundable (Partida de Vera). La idea es que el alumnado intente interpretar este territorio como una zona de riesgo, pero que el ser humano la ha bonificado y ocupado tradicionalmente. Por tanto, que entienda que se ha pasado de una relación de «riesgo-recurso» a «recurso-riesgo».

Por destacar algunos nombres, cabe citar el origen y definición del municipio de Alboraia, del árabe al-burayyaj 'la torrecilla' (BARCELó, 2010: 78) (Tabla 2). En su origen fue una torre de vigilancia musulmana que, tras la conquista cristiana, perdió su funcionalidad y a su alrededor se fueron agregando alquerías. Una de las construcciones típicas de la Huerta de València es la barraca, que pone de manifiesto la adaptación al medio por parte del ser humano con el uso de materiales y recursos disponibles en su entorno, como el barro y las cañas (se presta nuevamente atención a este espacio inundable). Por el recorrido de las 3 salidas de campo, tan solo en esta se pueden observar este tipo de construcciones, antaño muy habituales. Sin embargo, están desapareciendo por la pérdida de su funcionalidad (lugar de residencia tradicional o espacio para guardar apeos de labranza). En el dossier que se facilita al alumnado se indican varios nombres de estas viviendas y se hace especial atención a las Barracas del Bessó (Bessó es un linaje catalán/valenciano que significa 'gemelo') (Figura 6). Además de estos asentamientos también se explica la articulación del territorio a partir de caminos y sendas como el Camí del Farinós, del catalán/valenciano farinós ('harinero'). La finalidad de la explicación de este topónimo es vincular este espacio con la actividad agrícola ya que esta vía de comunicación era la que utilizaban los agricultores para transportar el trigo al Moli de Vera, edificio anexo a la Ermita de Vera. Finalmente, el recorrido de la segunda salida de campo concluye en la zona conocida como La Carrasca. Esta especie arbórea era un hito en el paisaje agrícola valenciano, ya que proporcionaba sombra (además de bellotas para el ganado). De la carrasca que hubo en el pasado y dio nombre al topónimo se desconoce su ubicación y debió desaparecer hace décadas posiblemente con la construcción de la Universitat Politècnica de València. 


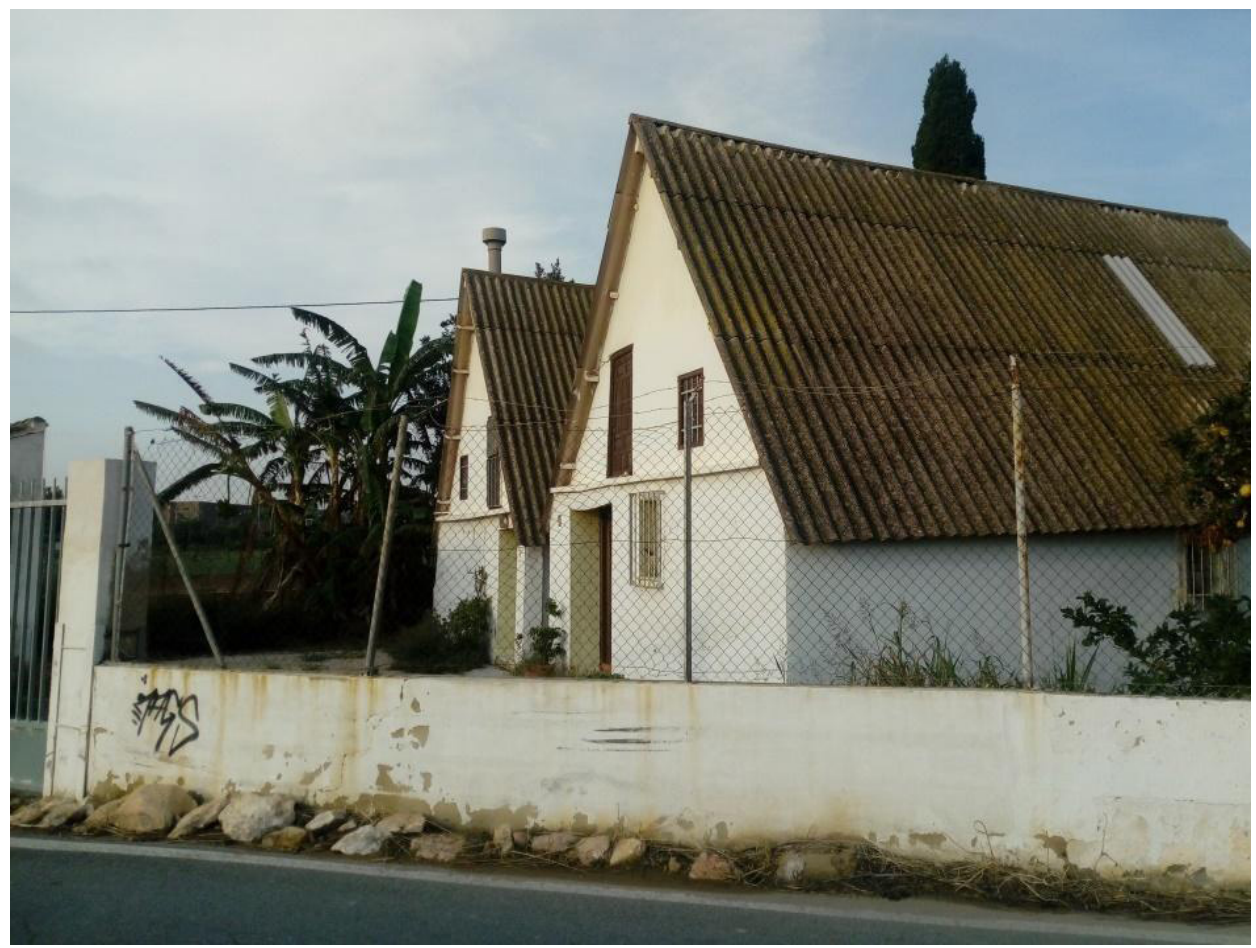

Figura 6. Barracas del Bessó (Camino del Farinós, Partida de Vera).

Fotografía de los autores (2019). ${ }^{6}$

TABLA 2

Topónimos que se explican durante la salida de campo 2

\begin{tabular}{|l|l|}
\hline \multicolumn{2}{|c|}{ Alqueria de Patac } \\
\hline Origen lingüístico & $\begin{array}{l}\text { Alqueria (val.) Alquería (cas.): árabe alqaríyya 'casa de labor con finca } \\
\text { agrícola'. } \\
\text { Patach: Valenciano patac, (patach suena 'patac', con la h muda) de la forma } \\
\text { valenciana pataca “patata". Es un apodo en referencia a una persona que } \\
\text { se dedicaba al cultivo de este tubérculo. }\end{array}$ \\
\hline Contenido semántico & Geografía Humana: propiedad rústica (alquería). \\
\hline Tipo de topónimo & $\begin{array}{l}\text { Hace referencia a una alquería (agrupación de casas) en el término } \\
\text { municipal de Alboraia. }\end{array}$ \\
\hline Continuidad semántica & $\begin{array}{l}\text { Desde su construcción en el siglo xvi, la alquería de Patac se usó con } \\
\text { fines agrícolas. Dada la escasa rentabilidad de las tareas agrícolas, en la } \\
\text { actualidad se ha reconvertido en lugar de celebración de todo tipo de } \\
\text { eventos. }\end{array}$ \\
\hline
\end{tabular}

6 Se puede observar como el tejado tradicional de cañas ha sido sustituido por otro de fibrocemento. Actualmente, la fachada de la barraca de la derecha se encuentra derrumbada. 


\begin{tabular}{|c|c|}
\hline $\begin{array}{l}\text { Potencialidad didáctica } \\
\text { para la enseñanza de } \\
\text { las ciencias sociales }\end{array}$ & $\begin{array}{l}\text { Su finalidad es vincular la actividad agrícola y los tipos de cultivo } \\
\text { característicos de la Huerta de València y ver cómo esto ha quedado } \\
\text { reflejado en la toponimia. Otros nombres vinculados con 'pataca' es el } \\
\text { de la playa de la Patacona (Alboraia). }\end{array}$ \\
\hline \multicolumn{2}{|r|}{ Alboraia } \\
\hline Origen lingüístico & Árabe: al-burayyaj ‘la torrecilla’ (BARCELÓ, 2010: 78). \\
\hline Contenido semántico & Geografía Humana: torre de vigilancia costera. \\
\hline Tipo de topónimo & Torre de vigilancia costera para defenderse de ataques cristianos. \\
\hline Continuidad semántica & $\begin{array}{l}\text { Tras la Reconquista, dejó de ser una torre y pasó a ser una partida. Luego } \\
\text { se convirtió en una alquería, y finalmente en pueblo. Actualmente es un } \\
\text { municipio con } 24.454 \text { habitantes (INE, 2020). }\end{array}$ \\
\hline $\begin{array}{l}\text { Interés didáctico para } \\
\text { la enseñanza de las } \\
\text { ciencias sociales }\end{array}$ & $\begin{array}{l}\text { Sirve para explicar el proceso de configuración histórica de la Huerta } \\
\text { de València (pasado musulmán). También se aprovecha este topónimo } \\
\text { para explicar uno de los cultivos genuinos de esta parte de la Huerta de } \\
\text { València (la chufa, para la elaboración de horchata). }\end{array}$ \\
\hline \multicolumn{2}{|r|}{ Camí del Farinós } \\
\hline Origen lingüístico & Catalán/valenciano: farinós ('harinero'). \\
\hline Contenido semántico & Geografía humana: infraestructura para uso humano. \\
\hline Tipo de topónimo & $\begin{array}{l}\text { Es un molino que sirve para moler del grano del cereal y convertirlo en } \\
\text { harina. }\end{array}$ \\
\hline Continuidad semántica & $\begin{array}{l}\text { Todavía existe este molino, pero ha dejado de funcionar como tal (Molí } \\
\text { de Vera) debido a las inundaciones de la Riuá de 1957. En la actualidad } \\
\text { es un museo etnográfico perteneciente a la Universidad Politécnica de } \\
\text { Valencia. }\end{array}$ \\
\hline $\begin{array}{l}\text { Interés didáctico para } \\
\text { la enseñanza de las } \\
\text { ciencias sociales }\end{array}$ & $\begin{array}{l}\text { La finalidad de la explicación de este topónimo es vincular este espacio } \\
\text { con la actividad agrícola ya que esta vía de comunicación era la que } \\
\text { utilizaban los agricultores para transportar el trigo al molino de Vera. }\end{array}$ \\
\hline \multicolumn{2}{|r|}{ Barraques del Bessó } \\
\hline Origen lingüístico & $\begin{array}{l}\text { Catalán/valenciano: Bessó 'linaje catalán o valenciano que significa } \\
\text { gemelo'. }\end{array}$ \\
\hline Contenido semántico & Geografía Humana: antropónimo. \\
\hline Tipo de topónimo & $\begin{array}{l}\text { Se refiere a unas barracas (vivienda construida con barro y cañas) que } \\
\text { eran propiedad de una familia que se apellidaba Bessó. }\end{array}$ \\
\hline Continuidad semántica & $\begin{array}{l}\text { Actualmente son de las pocas barracas que quedan en uso en la Partida } \\
\text { de Vera (Figura 5). }\end{array}$ \\
\hline $\begin{array}{l}\text { Interés didáctico para } \\
\text { la enseñanza de las } \\
\text { ciencias sociales }\end{array}$ & $\begin{array}{l}\text { Sirve para explicar el patrimonio etnológico y la vinculación y } \\
\text { adaptación de este territorio por la sociedad. Principalmente se explica } \\
\text { la función de estas construcciones y los materiales de construcción } \\
\text { (cañas y barro) que, son materiales que se pueden encontrar en esta área. } \\
\text { No cabe olvidar que esta es una zona de marjal, donde las cañas es una } \\
\text { de la vegetación natural característica. }\end{array}$ \\
\hline \multicolumn{2}{|r|}{ Ermita de Vera } \\
\hline Origen lingüístico & $\begin{array}{l}\text { Vera podría derivar del latín varius 'color grisáceo' (COROMINES, 1989- } \\
\text { 1997, vII: 459). } \\
\end{array}$ \\
\hline Contenido semántico & Geografía Humana: infraestructura para uso humano. \\
\hline
\end{tabular}


La toponimia como recurso didáctico para la enseñanza de la Geografía

\begin{tabular}{|c|c|}
\hline Tipo de topónimo & $\begin{array}{l}\text { La Partida de Vera poseía un poblamiento diseminado notable y su } \\
\text { centro de culto era esta ermita y que venera a la Inmaculada Concepción. }\end{array}$ \\
\hline Continuidad semántica & $\begin{array}{l}\text { El origen de la ermita se remonta al siglo } \mathrm{xV} \text {, aunque el actual templo es } \\
\text { del siglo xviII. Sigue funcionando como ermita. }\end{array}$ \\
\hline $\begin{array}{l}\text { Interés didáctico para } \\
\text { la enseñanza de las } \\
\text { ciencias sociales }\end{array}$ & $\begin{array}{l}\text { Sirve para explicar la ocupación humana de este espacio, la Partida de } \\
\text { Vera, un espacio rural donde residían los agricultores en diseminado y } \\
\text { donde este edificio de culto religioso articulaba esta partida. }\end{array}$ \\
\hline \multicolumn{2}{|r|}{ La Carrasca } \\
\hline Origen lingüístico & $\begin{array}{l}\text { Catalán/valenciano carrasca ('encina') (Quercus ilex ssp. rotundifolia) } \\
\text { (castellano carrasca). Etimología prelatina. }\end{array}$ \\
\hline Contenido semántico & Geografía Física: árbol. \\
\hline Tipo de topónimo & $\begin{array}{l}\text { La carrasca era un hito en el paisaje agrícola, ya que proporcionaba } \\
\text { sombra (además de bellotas para el ganado). De la carrasca que hubo } \\
\text { en el pasado y dio nombre al topónimo se desconoce su ubicación, } \\
\text { debió desaparecer hace décadas posiblemente con la construcción de la } \\
\text { Universitat Politècnica de València. }\end{array}$ \\
\hline Continuidad semántica & $\begin{array}{l}\text { En la actualidad la carrasca ha sobrevivido como un topónimo que } \\
\text { nombra a un barrio de la ciudad de València. Este barrio incluye los dos } \\
\text { mayores campus universitarios de la ciudad, Universitat Politècnica de } \\
\text { València y Campus de Tarongers (Universitat de València) y una popular } \\
\text { parada de tranvía (muy concurrida por alumnado universitario). }\end{array}$ \\
\hline $\begin{array}{l}\text { Interés didáctico para } \\
\text { la enseñanza de las } \\
\text { ciencias sociales }\end{array}$ & $\begin{array}{l}\text { Sirve para explicar este tipo de vegetación mediterránea. En el área } \\
\text { litoral solía asociarse a antiguas casas de campo. }\end{array}$ \\
\hline \multicolumn{2}{|r|}{ Senda de la Carrasca } \\
\hline Origen lingüístico & $\begin{array}{l}\text { Catalán/valenciano carrasca ('encina') (Quercus ilex ssp. rotundifolia) } \\
\text { (castellano carrasca). Etimología prelatina. }\end{array}$ \\
\hline Contenido semántico & Geografía Humana: odónimo. \\
\hline Tipo de topónimo & $\begin{array}{l}\text { Se refiere a una senda que comenzaba en la actual avenida del Primat } \\
\text { Reig (norte de la ciudad de València) y que seguía hacia el mar a través de } \\
\text { la huerta donde actualmente se localizan los dos campus universitarios. }\end{array}$ \\
\hline Continuidad semántica & $\begin{array}{l}\text { Dejó de funcionar como senda. Hoy su trama (enterrada bajo el asfalto) } \\
\text { es irreconocible. }\end{array}$ \\
\hline $\begin{array}{l}\text { Interés didáctico para } \\
\text { la enseñanza de las } \\
\text { ciencias sociales }\end{array}$ & $\begin{array}{l}\text { Se vincula con el topónimo de la Carrasca y sirve para explicar las } \\
\text { antiguas vías de comunicación de esta parte de la Huerta de València, } \\
\text { hoy desaparecidas por la ocupación urbana. }\end{array}$ \\
\hline
\end{tabular}

Fuente: Elaboración propia.

\subsection{Salida de campo 3. La destrucción de la Huerta de Valencia. Urbanización y antiguos espacios agrícolas relictos}

La última salida de campo tiene el objetivo de enseñar a los discentes el proceso de urbanización del antiguo espacio de la Huerta de València en el área que ocupa la antigua partida de Algirós (hoy barrio) e inmediaciones de los barrios 
de El Cabanyal y El Canyamelar. Durante el recorrido se presta especial atención a determinadas construcciones e infraestructuras que se han ido edificando desde 1960 hasta la actualidad. También, se visitan algunos lugares y patrimonio típico de la huerta que aún se puede observar y que refleja la economía tradicional de este espacio singular. Respecto a la toponimia, los nombres que se describen durante este tercer itinerario son los que tienen que ver con el sistema de regadío, los asentamientos humanos y las vías de comunicación (Tabla 3). En cuanto a los primeros, cabe destacar el nombre de Algirós, del árabe (al-jarux, canalización). Se trata, por tanto, de una antigua área donde el sistema de regadío (articulado por la acequia de Mestalla) era de tal importancia que dio lugar a este topónimo (Tabla 3). Algunas de las ramificaciones de la acequia de Mestalla y que en la actualidad se encuentran soterradas son el Braçal de l'Arquet (del catalán/valenciano arquet, 'arquillo') (AVL, 2016), el Braç d'Escamarda (relacionado con un antropónimo), y el Braç de Rams (de Rams, apellido propio de Catalunya y València), cuyo trazado se sitúa bajo el Campus de Tarongers (Universitat de València) y conduce el agua que riega algunas huertas residuales de este espacio.

TABLA 3

Topónimos que se explican durante la salida de campo 3.

\begin{tabular}{|l|l|}
\hline \multicolumn{2}{|c|}{ Algirós } \\
\hline Origen lingüístico & Árabe: al-jarux 'canalización'. \\
\hline Contenido semántico & Geografía Humana: infraestructura de riego para la huerta. \\
\hline Tipo de topónimo & Se refiere a una canalización o acequia para el riego de época islámica. \\
\hline Continuidad semántica & $\begin{array}{l}\text { En la actualidad existe todavía la acequia de Algirós, pero este topónimo } \\
\text { es más conocido por designar un distrito de València que recibe su } \\
\text { nombre. Este barrio tiene censados 36.711 habitantes (AYunTAMIENTo DE } \\
\text { VALĖNCIA, 2020). }\end{array}$ \\
\hline $\begin{array}{l}\text { Potencialidad didáctica } \\
\text { para la enseñanza de } \\
\text { las ciencias sociales }\end{array}$ & $\begin{array}{l}\text { Este topónimo se utiliza para explicar la vinculación de esta parte de la } \\
\text { ciudad de València con el sistema de regadío tradicional. Se trata de una } \\
\text { antigua partida rural que ha sido urbanizada desde los años setenta. }\end{array}$ \\
\hline \multicolumn{2}{|c|}{ Braçal de l'Arquet } \\
\hline Origen lingüístico & $\begin{array}{l}\text { Catalán/valenciano: braçal ('ramal de acequia') (AVL, 2016). } \\
\text { Catalán/valenciano: arquet ('arquillo') (AVL, 2016). }\end{array}$ \\
\hline Contenido semántico & Geografía Humana: infraestructura de riego para la huerta. \\
\hline Tipo de topónimo & $\begin{array}{l}\text { Braçal se refiere a un ramal que deriva del Braç (ramal principal de } \\
\text { acequia) de Rambla, y este, a su vez, del Braç de Rams y este último, de } \\
\text { la acequia de Mestalla. } \\
\text { Arquet se refiere a un pequeño arco que describía la acequia seguramente } \\
\text { para superar algún desnivel natural o artificial. }\end{array}$ \\
\hline
\end{tabular}




\begin{tabular}{|c|c|}
\hline Continuidad semántica & $\begin{array}{l}\text { Hoy su uso para riego es residual (ha perdido su funcionalidad) y su } \\
\text { trazado está enterrado bajo el Campus de Tarongers de la Universitat de } \\
\text { València. }\end{array}$ \\
\hline $\begin{array}{l}\text { Potencialidad didáctica } \\
\text { para la enseñanza de } \\
\text { las ciencias sociales }\end{array}$ & $\begin{array}{l}\text { Sirve para explicar el pasado agrícola y el sistema de regadío de esta } \\
\text { parte de la ciudad de València. }\end{array}$ \\
\hline \multicolumn{2}{|r|}{ Braç d'Escamarda } \\
\hline Origen lingüístico & Árabe: probable antropónimo. \\
\hline Contenido semántico & Geografía Humana: antropónimo. \\
\hline Tipo de topónimo & $\begin{array}{l}\text { Actualmente se refiere a un braç (ramal de acequia) que, a su vez, deriva } \\
\text { del Braç de Rams, y este de la acequia de Mestalla. }\end{array}$ \\
\hline Continuidad semántica & $\begin{array}{l}\text { En la actualidad su trazado está enterrado bajo el campus universitario } \\
\text { de Vera (Universitat Politècnica de València). Continúa más allá de esta y } \\
\text { riega algunas huertas cercanas a la línea de costa (Playa de la Patacona, } \\
\text { Alboraia). }\end{array}$ \\
\hline $\begin{array}{l}\text { Potencialidad didáctica } \\
\text { para la enseñanza de } \\
\text { las ciencias sociales }\end{array}$ & $\begin{array}{l}\text { Sirve para explicar el pasado agrícola y el sistema de regadío de esta } \\
\text { parte de la ciudad de València. }\end{array}$ \\
\hline \multicolumn{2}{|r|}{ Braç de Rams } \\
\hline Origen lingüístico & $\begin{array}{l}\text { Catalán/valenciano: braç (ramal de acequia) y Rams (apellido propio de } \\
\text { Catalunya y València). }\end{array}$ \\
\hline Contenido semántico & Geografía humana: antropónimo. \\
\hline Tipo de topónimo & $\begin{array}{l}\text { Actualmente se refiere a un braç (ramal de acequia) que, a su vez, deriva } \\
\text { de la Acequia de Mestalla. }\end{array}$ \\
\hline Continuidad semántica & $\begin{array}{l}\text { En la actualidad su trazado está enterrado bajo el Campus de Tarongers } \\
\text { de la Universitat de València. Continúa más allá y riega algunas huertas } \\
\text { residuales del entorno de este campus (Figura 6). }\end{array}$ \\
\hline $\begin{array}{l}\text { Potencialidad didáctica } \\
\text { para la enseñanza de } \\
\text { las ciencias sociales }\end{array}$ & $\begin{array}{l}\text { Sirve para explicar el pasado agrícola y el sistema de regadío de esta } \\
\text { parte de la ciudad de València. }\end{array}$ \\
\hline \multicolumn{2}{|r|}{ El Cabanyal } \\
\hline Origen lingüístico & $\begin{array}{l}\text { Catalán/valenciano: cabanya 'construcción rústica' (castellano cabaña) } \\
+ \text { sufijo colectivo - al. }\end{array}$ \\
\hline Contenido semántico & Geografía Humana: infraestructura para vivienda. \\
\hline Tipo de topónimo & $\begin{array}{l}\text { Su origen se remonta al siglo xIII, cuando un grupo de pescadores } \\
\text { comenzaron la edificación en primera línea de playa (a } 4 \mathrm{~km} \text { del centro } \\
\text { de la ciudad de València) de cabañas, que acabaron dando nombre al } \\
\text { actual barrio del Cabanyal, citado por primera vez en } 1422 \text { (SANCHIS, 2009: } \\
\text { 16). A su alrededor se desarrolló un núcleo urbano que actualmente } \\
\text { forma el barrio del Cabanyal (antiguo municipio de Poble Nou de la Mar). }\end{array}$ \\
\hline Continuidad semántica & $\begin{array}{l}\text { En la actualidad no quedan restos de las cabañas originales. El nombre } \\
\text { de Cabanyal está asociado a uno de los barrios con mayor personalidad } \\
\text { de la ciudad de València. }\end{array}$ \\
\hline
\end{tabular}




\begin{tabular}{|c|c|}
\hline $\begin{array}{l}\text { Potencialidad didáctica } \\
\text { para la enseñanza de } \\
\text { las ciencias sociales }\end{array}$ & $\begin{array}{l}\text { Sirve para explicar la vinculación entre la sociedad rural-pesquera con } \\
\text { el territorio. Se trata de un barrio que se adaptó a las condiciones físico- } \\
\text { ecológicas (en paralelo a la línea de costa) y viviendas de construcción } \\
\text { muy primarias (principalmente barro y cañas) que eran los recursos } \\
\text { disponibles y accesibles para su construcción. }\end{array}$ \\
\hline \multicolumn{2}{|r|}{ El Canyamelar } \\
\hline Origen lingüístico & $\begin{array}{l}\text { Catalán/valenciano: canyamel ('Planta perenne') (Saccharum officinarum), } \\
\text { de la que se extrae el azúcar"' (castellano cañamiel o caña de azúcar) + } \\
\text { sufijo colectivo -ar. }\end{array}$ \\
\hline Contenido semántico & Geografía Humana: cultivo. \\
\hline Tipo de topónimo & $\begin{array}{l}\text { Se sabe que hacia el siglo xv (antes de la pequeña edad de hielo) el Reino } \\
\text { de València producía azúcar para Barcelona, como lo testifican varios } \\
\text { documentos, entre los cuales, uno de } 1415 \text { se refiere a algunas posesiones } \\
\text { de cañamiel en las huertas de València y de Castelló (SALICRU, 1995: 189). } \\
\text { Quizá, algunas de estas posesiones dieron nombre a Canyamelar. }\end{array}$ \\
\hline Continuidad semántica & $\begin{array}{l}\text { Han desaparecido los cultivos de caña de azúcar y hoy el Canyamelar } \\
\text { configura un barrio anexo al Cabanyal. De hecho, el nombre del actual } \\
\text { barrio es Cabanyal-Canyamelar. }\end{array}$ \\
\hline $\begin{array}{l}\text { Potencialidad didáctica } \\
\text { para la enseñanza de } \\
\text { las ciencias sociales }\end{array}$ & $\begin{array}{l}\text { Sirve para explicar la vinculación del ser humano con el medio, en este } \\
\text { caso la actividad rural. }\end{array}$ \\
\hline \multicolumn{2}{|r|}{ Camí Vell del Cabanyal } \\
\hline Origen lingüístico & Catalán/valenciano: camí vell ('camino viejo'). \\
\hline Contenido semántico & Geografía humana: odónimo. \\
\hline Tipo de topónimo & $\begin{array}{l}\text { Se refiere a un camino que discurría desde el centro de la ciudad de } \\
\text { València hasta el barrio del Cabañal. }\end{array}$ \\
\hline $\begin{array}{l}\text { La continuidad } \\
\text { semántica }\end{array}$ & $\begin{array}{l}\text { Sobre la parte occidental de este camino se superpuso la avenida Blasco } \\
\text { Ibánez y solo sobrevive en su parte oriental, yuxtapuesto en parte al } \\
\text { Campus de Tarongers de la Universitat de València en las cercanías del } \\
\text { cementerio del Cabanyal (Figura 6). }\end{array}$ \\
\hline $\begin{array}{l}\text { Potencialidad didáctica } \\
\text { para la enseñanza de } \\
\text { las ciencias sociales }\end{array}$ & $\begin{array}{l}\text { Sirve para explicar cómo el proceso urbano de la ciudad de València } \\
\text { prácticamente ha hecho desaparecer las antiguas vías de comunicación } \\
\text { que enlazaban con la ciudad y los antiguos poblados marítimos. Este } \\
\text { topónimo se relaciona con el del barrio y el cementerio del Cabanyal. }\end{array}$ \\
\hline \multicolumn{2}{|r|}{ Cementeri del Cabanyal } \\
\hline Origen lingüístico & 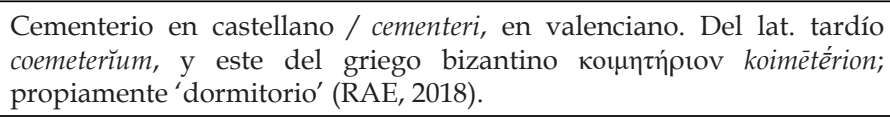 \\
\hline Contenido semántico & Geografía Humana: infraestructura para uso humano. \\
\hline Tipo de topónimo & Lugar para enterramiento de difuntos. \\
\hline Continuidad semántica & $\begin{array}{l}\text { Hasta } 1867 \text { los entierros se realizaban junto a la Parroquia del pueblo } \\
\text { (Cabanyal), pero luego se construyó un cementerio a las afueras, junto al } \\
\text { Camino Viejo del Cabanyal. }\end{array}$ \\
\hline
\end{tabular}




\begin{tabular}{|l|l|}
\hline $\begin{array}{l}\text { Potencialidad didáctica } \\
\text { para la enseñanza de } \\
\text { las ciencias sociales }\end{array}$ & $\begin{array}{l}\text { Al igual que el Cementerio de Benimaclet, sirve para explicar los usos } \\
\text { urbanos y servicios públicos, así como la causa de su construcción } \\
\text { (epidemias de cólera definales del sigloxix) y el crecimiento demográfico. } \\
\text { Se aprovecha también para explicar el proceso de urbanización ya que } \\
\text { se encuentra actualmente insertado en la trama urbana de la ciudad de } \\
\text { València. }\end{array}$ \\
\hline
\end{tabular}

Fuente: Elaboración propia.

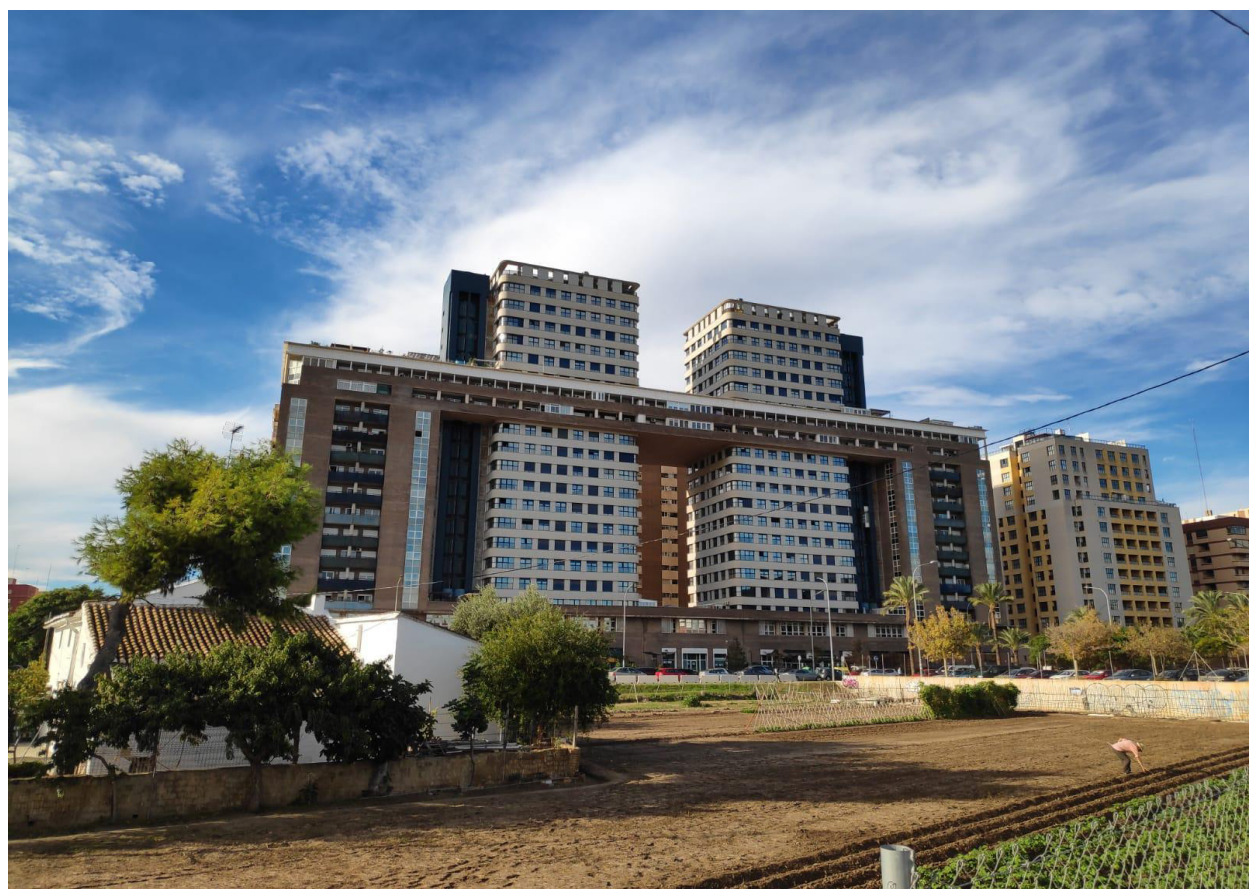

Figura 7. Panorámica y contraste entre el espacio urbanizado y antiguas huertas (Camí Vell del Cabanyal, Algirós). Fotografía de los autores (2018). ${ }^{7}$

En vinculación con segundo grupo de topónimos (asentamientos humanos y vías de comunicación) se explica El Cabanyal (del catalán/valenciano cabanya 'construcción rústica' -castellano cabaña) + sufijo colectivo -al). Su origen se remonta al siglo xIII, cuando un grupo de pescadores comenzó la edificación de cabañas en primera línea de costa (a $4 \mathrm{~km}$ del centro de la ciudad de Valencia), que acabaron dando nombre al actual barrio de El Cabanyal, citado por primera

7 Nota: en la imagen se observa a uno de los pocos agricultores que aún mantienen estas huertas residuales. 
vez en 1422 (SANCHIS, 2009). A su alrededor se desarrolló un núcleo urbano que actualmente forma el barrio del Cabanyal (antiguo municipio de Poble Nou de la Mar). Un segundo topónimo que se describe es El Canyamelar (del catalán/valenciano canyamel 'planta perenne (Saccharum officinarum), de la que se extrae el azúcar' (castellano cañamiel o caña de azúcar) + sufijo coletivo -ar). De este nombre se sabe que hacia el siglo xv (antes de la pequeña edad de hielo) el Reino de València producía azúcar para Barcelona, como lo testifican varios documentos, entre los cuales, uno de 1415 se refiere a algunas posesiones de cañamiel en las huertas de València y de Castelló (SALICRú, 1995). Quizá, alguna de estas posesiones dio nombre a El Canyamelar. Finalmente, durante el itinerario se discurre por el casi desaparecido Camí Vell del Cabanyal, que comunica con el cementeri del Cabanyal. Cabe indicar que este punto se caracteriza por la presencia de alguna huerta relicta y casa de labor, solares y edificios de viviendas de las décadas 1980 y 1990, y da una imagen de contraste, fruto del intenso proceso urbanizador que sigue amenazando la Huerta de València (Figura 7).

\section{DISCUSIONES}

Con este trabajo se ha expuesto una propuesta de cómo enseñar e interpretar el territorio con el uso de la toponimia. El marco geográfico seleccionado (la Huerta de València), sin duda, es un espacio de interés por los cambios acaecidos durante las últimas décadas, así como la toponimia vinculada con el patrimonio agrícola, hidráulico, cultural, social y/o ambiental. Como se ha recogido en las tablas, todos los topónimos identificados y que se explican durante las salidas de campo tienen un interés didáctico que permite explicar determinados procesos que afectan a la Huerta de València. Esta utilidad de los nombres de lugar, también ha sido explicada como sostienen ORDINAS y BINIMELIS (2018) ya que tradicionalmente, la toponimia constituye una herramienta pedagógica de gran valor, a pesar de haber sido ignorada y criticada por ser obsoleta y fundamentada en el abuso del ejercicio memorístico. Al respecto, Ordinas (2014) indica que con la toponimia no solo se aprende geografía y otras ciencias sociales, sino que también en diferentes aspectos de la vida cotidiana permiten obtener una formación integral, al experimentar la interdisciplinariedad tanto en el manejo de contenidos como de técnicas auxiliares. Por su parte, FrIERA (1992) indica que los nombres de lugar ofrecen en el proceso de enseñanza-aprendizaje una enorme utilidad en el conocimiento del medio, tanto en la adquisición de conceptos y terminología, como en procedimientos y valores en la didáctica de las ciencias sociales.

En cuanto a la interpretación del territorio a partir de los nombres de lugar, ORDINAS (2014) se refiere a las ventajas del uso de la toponimia a la hora de interpretar el espacio geográfico, que consisten en: 1) familiarización con el territorio y las fuentes cartográficas y documentales; y 2) descubrimiento de la historia y la geografía regionales y mejora del conocimiento del medio. Respecto a este último, ORDINAS y BINIMELIs (2018) explican que el análisis de los nombres de 
lugar no solo desvela las claves para la interpretación del paisaje (actual y pasado), sino que también facilita la observación directa del territorio, donde el trabajo de campo (con la ayuda de fuentes cartográficas, orales y documentales) resulta imprescindible. Respecto a lo anterior, Мовоте (2014) afirma que la toponimia es el ADN de un territorio, de ahí su utilidad a la hora de explicar geografía.

ORDINAS (2014) hace hincapié en el proceso de la recuperación de la toponimia como recurso didáctico para la enseñanza de esta ciencia. Este autor explica que Canadá y Estados Unidos recuperaron en su enseñanza el interés por su tesoro toponímico. Por ejemplo, la Comisión de Toponimia de Canadá ofrece todo tipo de recursos para el mundo de la enseñanza relacionados con este recurso, al igual que el británico Ordnance Survey que, a través de la toponimia vehicula informaciones culturales y geográficas con enlaces dirigidos a la búsqueda y visualización cartográfica. Para el caso de Australia, la Comisión de Nombres Geográficos, ofrece posibilidades con todo tipo de recursos vinculados con la toponimia del país, al igual que la difusión de documentales donde se hace hincapié al valor patrimonial y la necesidad de preservar las formas autóctonas de sus nombres de lugar (PAReLla, 2008).

En España, el trabajo de Gómez et al. (2015), para el caso de la Educación Primaria, tiene el objetivo de demostrar el potencial didáctico de la toponimia para enseñar la diversidad de un área de estudio y hacer emerger territorios vulnerables o sometidos a riesgos. Estos autores argumentan que los nombres de lugar ofrecen un valor singular como recurso complementario para el análisis territorial y son susceptibles de uso como herramienta didáctica en los procesos de enseñanza-aprendizaje de las ciencias sociales. Por su parte, ORDINAS y BiNIMELIS (2018) se centran en sistematizar las diversas áreas temáticas del medio natural que se pueden tratar desde el estudio de la toponimia que caracteriza un determinado territorio. También en España, un estudio reciente elaborado por Domínguez et al. (2020) pone de manifiesto que la toponimia destaca por su eficacia para la educación en igualdad, pese a las dificultades manifestadas por el alumnado, como el escaso número de calles con nombre de mujeres o la dificultad para acceder a sus biografías. Estas autoras han llegado a la conclusión de que se observa en positivo que el alumnado sienta interés por realizar actividades con perspectiva de género, así como los aprendizajes conseguidos. Otras notables referencias dentro de la literatura española son las de Riesco (2010) y las de Membrado e Iranzo $(2017 ; 2018)$, que tratan sobre los topónimos como fuente de conocimiento y de valoración del territorio. Por su lado, el trabajo de LUISA DE TORT (2014) pone el énfasis en como el paisaje, a través de sus topónimos, se convierte en una herramienta pedagógica fundamental para el estudio y el conocimiento geográfico.

En el ámbito latinoamericano, en Argentina, la investigación de Gilio (2015) tiene la finalidad de introducir, desde una visión antropológica, el uso de la cartografía y los nombres de lugar como herramientas didácticas en la interpretación del territorio, concebido como una construcción socio-histórica. Para ello, utiliza como recurso didáctico la cartografía antigua y moderna, así como diversos nombres para un mismo territorio. En México, Valenzuela (2010) 
ha puesto de manifiesto que la riqueza lingüística, tomando en consideración la cantidad de las lenguas nativas americanas, de la población que las habla y de los topónimos existentes, es motivo para su conservación, estudio y divulgación. Este autor ha estudiado algunos nombres de lugar en lengua náhuatl para corroborar su vinculación con aspectos de la geografía física o humana. En relación con la geografía como ciencia y disciplina escolar, este autor indica que puede contribuir de diferentes formas, no solo para contabilizar y ubicar a los grupos indígenas, sino a través del estudio de la forma en que el espacio geográfico influye en las características socio-culturales y económicas. Por ejemplo, VAlenzuela (2010) muestra como la influencia del espacio geográfico, sin que se perciba de forma aparente, está presente en el significado del nombre de muchos lugares.

En el ámbito anglosajón destacan diferentes referencias sobre pedagogía y toponimia como las de Alderman y Reuben (2020), donde desarrollan un marco pedagógico para transformar las aulas en espacios toponímicos donde el estudiantado pueda intervenir en la política de renombrar sus propias instituciones educativas. Por su parte, HeIKKILA (2008) lleva a cabo un método de enseñanza a través de la toponimia para recuperar antiguos nombres indígenas en un territorio de la Columbia Británica y educar a la vez sobre dicho territorio y sobre su lengua e historia oral. En el caso del estudio de ALDERMAN (2016), este autor interpreta las connotaciones de los topónimos que designan paisajes culturales y su papel como armas de poder político.

\section{CONCLUSIONES}

Como conclusión, con la presentación de esta propuesta del uso de la toponimia a partir de salidas de campo en la Huerta de València, se ha puesto de manifiesto el potencial didáctico de los nombres de lugar para explicar geografía, especialmente en la vertiente que relaciona el ser humano con el medio a lo largo de la historia (Ciencias Sociales). Por tanto, la toponimia, aunque suele obviarse para explicar este tipo de relación, debería tener un mayor protagonismo, tanto en el campo teórico como en las salidas de campo. La propuesta que aquí se expone va más allá del caso de estudio presentado, ya que puede servir de paradigma para enseñar ciencias sociales utilizando un recurso patrimonial y vinculándolo a cualquier territorio. Respecto a la formación del profesorado (no sólo de Educación Primaria, sino en todas las etapas), la toponimia es un recurso que debe estar presente durante su labor docente a la hora de describir cualquier territorio, sea en el aula o fuera de ella.

En cuanto a los retos de investigación, se pretenderá en el fututo analizar si el profesorado en formación incorpora la toponimia como recurso didáctico en las salidas de campo que deben plantear en la asignatura (práctica que se les pide tras la realización de los 3 itinerarios). Para finalizar, cabe añadir que el análisis de los nombres de lugar permite obtener unos resultados que confirman el predominio histórico de unos nombres de lugar que describen un paisaje agrícola fosilizado en 
sus topónimos, pero transformado en la realidad. Este análisis permite descubrir la enorme riqueza patrimonial que oculta la toponimia, y no solo es útil para la enseñanza de la geografía, sino que, además, desde una perspectiva identitaria, permite a las personas que residen o frecuentan el área de estudio redescubrir, aunque solo sea virtualmente, un paisaje cultural hoy desaparecido.

\section{REFERENCIAS}

Academia Valenciana de la Lengua (AVL) (2016): Diccionari normatiu valencià, Publicacions de l'Acadèmia Valenciana de la Llengua, València.

Alderman, D. (2016): «Place, naming and the interpretation of cultural landscapes», en B. Graham y P. Howard (eds.), Heritage and Identity, Routledge, London: 195-213.

Alderman, D.H.; Reuben, R.R. (2020): «The classroom as "toponymic workspace": towards a critical pedagogy of campus place renaming», Journal of Geography in Higher Education, 44 (1): 124-141.

Arroyo, F. (2018): «La toponimia como patrimonio cultural inmaterial», Boletín de la Real Sociedad Geográfica, 153: 33-60.

Ayuntamiento de ValènCia (2020): Estadística. Demografía [En línea].

BALLANTYNE, R. (1996): «Factors affecting student choice of geography as a senior secondary school subject in Queensland», International Research in Geographical and Environmental Education, 5 (3): 172-185.

BARCELó, C. (2010): Noms aràbics de lloc. IIFV-Bromera, València.

Casanova, E. (2011): «Comunidad Valenciana». A: Toponimia hispánica. Origen y evolución de nuestros topónimos más importantes», Denes, València: 257292.

Conedera, M., Vassere, S., NefF, C., Meurer, M. y Krebs, P. (2007): «Using toponymy to reconstruct past land use: a case study of 'brüsáda'(burn) in southern Switzerland», Journal of Historical Geography, 33 (4): 729-748. doi: 10.1016/j. jhg.2006.11.002

COMES, P. y DANTí, J. (2003): «Rastres. Una eina pedagógica per al coneixement de la historia local i comarcal», Ponències. Revista del Centre d'Estudis de Granollers, 11-25.

Coromines, J. (1989-1997): Onomasticon Cataloniae. Els noms de lloc i noms de persona de totes les terres de llengua catalana, VIII vol. Curial Edicions Catalanes, Barcelona.

CRespo, J.M. (2012): «Un itinerario didáctico para la interpretación de los elementos físicos de los paisajes de la Sierra de Guadarrama», Didáctica Geográfica, 13: 15-34.

CRespo, J. M. (2019): «El visualizador Iberpix 4 del Instituto Geográfico Nacional: un recurso didáctico para la interpretación de los componentes físicos del paisaje», Enseñanza de las ciencias de la tierra: Revista de la Asociación Española para la Enseñanza de las Ciencias de la Tierra, 27 (2): 182-191. 
DARBY, H.C. (1957): «Place names and geography», The Geographical Journal, 123: 387-392.

De LÁZARo, M.L.; Crespo, J.M.; GómeZ, M.L. (2014): «Los paisajes agrarios de España en la Nube», en R. Martínez-Medina (coord.), Nuevas perspectivas conceptuales y metodológicas para la educación geográfica, 2: 319-334.

Delgado, B.; Torres, F.J.; García, A.; OJedA, J.F. (2013): «El viaje como aprendizaje significativo y pertinente. Crónica de una experiencia andaluza», en P. PANEQUe y J.F. OJEDA (eds.), El viaje en la geografía moderna, Universidad Internacional de Andalucía, Sevilla: 429-444.

Domínguez, A.; Ortuño, B.; DíEZ, R. (2020): «Mujeres en los callejeros. Una estrategia para incluir la perspectiva de género en las asignaturas de Didáctica de las Ciencias Sociales», en R. RoIg (coord.), La docencia en la Enseñanza Superior: Nuevas aportaciones desde la investigación e innovación, Universidad de Alicante, Alicante: 952-961.

Dorion, H. (1984): Les relations entre la toponymie et les autres sciences sociales. 450 ans de noms de lieux française en amerique du nord, Les publications du Québec, Québec.

Estepa, J.; CuenCA, J.M.; MartíN, M.J. (2011): «Enseñar y aprender las Sociedades Actuales e Históricas a través del Patrimonio en la Educación Primaria», en R. López, L. Velasco, V.M. Santidrián y X.A. Armas (coords.), Pensar históricamente en tiempos de globalización: actas del I Congreso Internacional sobre enseñanza de la historia, Universidade de Santiago de Compostela, Santiago de Compostela: 243-254.

FERNÁNDEZ, J. (2017): «La salida de campo como recurso didáctico para conocer el espacio geográfico: El caso de la ciudad de Valladolid y de Soria», Didáctica Geográfica, 18: 91-109.

FERNÁNDEZ, R.; Gómez, A.; LuENGO, M.Á. (2019): «Aprendiendo a interpretar el territorio: estudio de la fitotoponimia en la provincia de Salamanca», Boletín de la Asociación de Geógrafos Españoles, 82: 1-33. doi: http:/ /dx.doi.org/10.21138/ bage. 2816

FraGo, J.A. (1991): «Problemas, métodos y enseñanzas de la toponimia», en A. Líbano y H. ZumalacárRegui (coord.), Actas de las I Jornadas de onomástica, toponimia, Vitoria-Gasteiz, abril de 1986 = I Onomastika jardunaldien agiriak toponimia, Gasteiz: 199-220.

FrIERA, F. (1992): «Utilidad de la toponimia para el conocimiento del entorno», Lletres asturianes: Boletín Oficial de l'Academia de la Llingua Asturiana, 45: 35-44.

García de Celis, A.; Martínez, L.C.; Prieto, I. (2018): «Patrimonio cultural inmaterial en las Reservas de la Biosfera cantábricas: la recuperación de la toponimia en los Valles de Omaña y Luna (León)», Estudios geográficos, 79: 191-208.

GILIO, B. (2015): «El uso de la cartografía y la toponimia como recursos didácticos en la enseñanza secundaria de geografía: análisis de una experiencia áulica», Informe Científico Técnico UNPA, 7 (1): 121-143.

Gómez-Ruíz, M.L. (2010): «El tratamiento de la información a partir de fuentes cartográficas como procedimiento esencial de la enseñanza-aprendizaje de la Geografía en el bachillerato», en M.J. MARRóN, (coord.), Geografía, educación y 
formación del profesorado en el marco del espacio europeo de educación superior, Vol. 1, AGE, Madrid: 329-344.

Gómez, A.; Sevilla, J.; Fernández, R. (2015): «Hacer emerger la diversidad de espacios y los lugares vulnerables a través de un recurso de escasa visibilidad en el currículo de la educación primaria: la toponimia», en A.M. HERNÁNDEZ, C.R. García y J.L. De la Montaña (coord.), Una enseñanza de las ciencias sociales para el futuro: Recursos para trabajar la invisibilidad de personas, lugares y temáticas, Universidad de Extremadura, Cáceres: 183-192.

Gómez, A., Corrochano, D. y PARRA, G. (2017): «Itinerarios didáctico-naturales en Educación Primaria: el noroeste de Zamora», Didáctica Geográfica, 18: 111-131. HeIKKILA, K. (2008): Teaching through toponymy: using indigenous place-names in outdoor science camps. VDM Publishing.

Institut CARTogràfic VAlencià (ICV) (2020): Visor cartográfico. 2020 [En linea].

Instituto Nacional de Estadística (INE) (2020): Padrón municipal. 2020 [En linea].

IRANZO, E. (2014): «La Huerta de Valencia. Incertidumbre para un paisaje cultural ancestral», en F. Molinero, F. (coord.), Atlas de los paisajes agrarios de España, Ministerio de Agricultura, Alimentación y Medio Ambiente, Madrid: 512532.

López-Fernández, J.A. y PerAL, A.J. (2017): «Las Vías Verdes: escenario para trabajar el medio rural en Educación Primaria», Didáctica Geográfica», 18: 171192.

LUISA DE TORT, J. (2014): «El paisaje como pedagogía del territorio», Didáctica geográfica, 6: 133-153.

MARRón, M.J. (2011): «Enseñar y aprender Geografía a partir de distintos lenguajes: una experiencia de trabajo por proyectos para estudiar el clima de España a partir de los refranes», Anales de geografía de la Universidad Complutense, 31 (1): 107-123.

MArrón, M.J. (2013). «Tratamiento interdisciplinar de la Geografía, la Historia y el Arte con estudiantes del Grado de Magisterio. Una propuesta de enseñanza activa a través de un itinerario didáctico», en R. De Miguel y M.L. De LÁzARo, Innovación en la enseñanza de la geografía ante los desafios sociales y territoriales, Institución Fernando el Católico, Zaragoza: 331-352.

Mas, A. (1999): «Introducció a la Toponímia. Anàlisi i proposta didàctica», Revista del Vinalopó, 2 :7-25.

Membrado, J. C. (2014): «L'expansió urbana a costa de l'horta», en La Universitat de València i els seus entorns naturals: L'Horta de València, el Massís del Caroig, el Carrascal de la Font Roja i la Serra de Mariola, Universitat de València, Valencia: 20-23.

Membrado, J. C. (2017): «La relación entre toponimia urbana y topografía en la Ciutat Vella de Valencia: análisis mediante métodos cuantitativos y cualitativos», Boletín de la Asociación de Geógrafos Españoles, 74: 361-386. doi: https://doi.org/10.21138/bage.2458

Membrado, J. C. (2018): «El papel de la geografía en el análisis del contenido semántico de los topónimos. El caso de Alicante», Anales de geografía de la Universidad Complutense, 38 (1): 35-60. doi: https://doi.org/10.5209/ 
AGUC.60468.

Membrado, J. C. e Iranzo, E. (2017). «Los nombres de lugar como elementos evocadores del paisaje histórico. Análisis de la toponimia de los núcleos de población de la cuenca del Vinalopó», Investigaciones Geográficas, 68: 191-207.

Membrado, J. C. e Iranzo, E. (2018). «Anàlisi toponímica de l’Horta de València. Integració dels enfocaments clàssic i crític per a la reconstitució i revaloració del seu paisatge», Documents d'Anàlisi Geogràfica, 64(2): 247-269.

Morote, A.F. (2014): La toponimia de San Vicente del Raspeig a partir de los Bosquejos Planimétricos de 1898. Ayuntamiento de San Vicente del Raspeig, Concejalía de Cultura, San Vicente del Raspeig.

Morote, A.F. (2019): «Las salidas de campo en España como recurso didáctico para la enseñanza de la Geografía. Una revisión bibliográfica», Geographicalia, 71: 27-49.

Morote, A.F. (2020): «Recuerdos y experiencias de la Geografía Escolar. Caso de estudio de la asignatura de Geografía de las Regiones del Mundo (Universidad de Alicante)», en R. Roig-ViLA (ed.), La docencia en la Enseñanza Superior. Nuevas aportaciones desde la investigación e innovación educativas, Octaedro, Barcelona: 333-342.

Ordinas, A. (2014): «El potencial didáctico de la toponimia en la enseñanza de la Geografía», en R. Martínez-Medina y E.M. Tonda-Monllor (coords.), Nuevas perspectivas conceptuales y metodológicas para la educación geográfica, Vol. 2: 521532.

OrdinAS, A.; Binimelis, J. (2018): «Los nombres de lugar: un recurso didáctico en la enseñanza geográfica del paisaje natural», Anales de Geografía de la Universidad Complutense, 38(2): 385-408. doi: http:/ / dx.doi.org/10.5209/AGUC.62485.

Parella, M. (2008): «Informació toponímica: tendències actuals i futures en un context internacional», Revista Catalana de Geografia, Jornada de treball: Toponímia cartogràfica. Tendències actuals i futures: XII, 34.

Parra, D.; Morote, A.F. (2020): «Memoria escolar y conocimientos didácticodisciplinares en la representación de la educación geográfica e histórica del profesorado en formación», Revista Interuniversitaria de Formación del Profesorado, 95 (34.3): 11-32. doi: https:/ / doi.org/10.47553/rifop.v34i3.82028.

Real Academia Española (RAE) (2018): Diccionario de la lengua Española [En linea].

RiEsCO, P. (2010): «Nombres en el paisaje: la toponimia, fuente de conocimiento y aprecio del territorio», Cuadernos Geográficos, 46: 7-34.

SALICRÚ, R. (1995): El tràfic de mercaderies a Barcelona segons els comptes de la lleuda de Mediona (febrer de 1434), I. Barcelona: CSIC (Milà i Fontanals).

SANCHIS, A. (2009): Historia del Cabanyal. Poble Nou de la Mar (1238-1897). L'Oronella, València.

Sebastián, M. y De Miguel, R. (2017): «Educación geográfica 2020: Iberpix y Collector for ArcGis como recursos didácticos para el aprendizaje del espacio», Didáctica Geográfica, 18: 231-246.

SEIDL, N.P. (2018): «Engraved in the Landscape: The Study of Spatial and Temporal Characteristics of Field Names in the Changing Landscape», Names, Vol. 67 (1): 1-14. Doi.: 10.1080/00277738.2017.1415539. 
SiWEI, Q.; MEngJun, K.; Min, W. (2016): «Toponym mapping: a case for distribution of ethnic groups and landscape features in Guangdong, China», Journal of Maps, 12: 546-550. doi: 10.1080/17445647.2016.1201017.

SORIANO, V. (2015): La huerta de Valencia: Un paisaje menguante. CreateSpace, Charleston.

TORRES, M. (1995): «Toponímia i escola: una proposta didàctica», Eivissa, 26: 20-23.

VALENZUELA, E. (2010): «¿Es posible aprender Geografía a través de la toponimia?», Investigación Universitaria Multidisciplinaria: Revista de Investigación de la Universidad Simón Bolívar 9: 16-26.

West, R.C. (1954): "The Term "Bayou" in the United States: A Study in the Geography of Place Names», Annals of the Association of American Geographers, 44 (1): 63-74. 


\title{
La Catedral de la Inmaculada Concepción de Kansas City (Missouri). Un recurso patrimonial en un escenario de diversidad religiosa
}

\section{The Cathedral of the Immaculate Conception in Kansas City, Missouri: A Heritage Asset in a Scenario of Religious Diversity}

\author{
Margarita Novo Malvárez* \\ Universitat de les Illes Balears \\ https://orcid.org/0000-0001-8372-8088 \\ m.novo@uib.es \\ Joseph R. Hartman \\ University of Missouri- Kansas City \\ https://orcid.org/0000-0003-3376-2135 \\ hartmanjr@umkc.edu
}

Recibido: 02/03/2021; Revisado: 16/04/2021; Aceptado: 10/05/2021

\section{Resumen}

En Estados Unidos no hay religión oficial, ni confesionalismo, ni Iglesia de Estado, pero la religión tiene un peso superior a otros países occidentales. La ciudad más poblada de Missouri, Kansas City, es un ejemplo de diversidad religiosa, en cuyo escenario destaca una catedral católica. Estudiamos la evolución del edificio y modelo de gestión patrimonial a partir de una metodología cualitativa y de la realización de entrevistas a religiosos y gestores culturales. Un modelo que puede transformarse como consecuencia de los procesos de recentralización y gentrificación que están afectando al Power and Light District, el barrio donde ésta se localiza.

Palabras clave: gestión del patrimonio; patrimonio religioso; Catedral de la Inmaculada Concepción; Kansas City; diversidad religiosa.

*Autora de correspondencia / Corresponding author. 


\begin{abstract}
In the United States, there is no official religion, no confessionalism and no Church representative of the State. Nonetheless, religion plays a more influential role than in other Western countries. The most populous city of Missouri is Kansas City, and it is an example of religious diversity, with a Catholic cathedral standing out against its urban background. This article examines the building's evolution and model of heritage management, based on a qualitative methodology and interviews with religious figures and cultural managers. It is a model that might see changes as a result of the process of recentralization and gentrification currently undergone by the Power and Light District, the neighbourhood where the Cathedral is located.
\end{abstract}

Key words: Heritage Management, Religious Heritage, Cathedral of the Immaculate Conception, Kansas City, Religious Diversity.

\title{
1. INTRODUCCIÓN ${ }^{1}$
}

El escenario religioso mundial está cambiando a un ritmo acelerado, entre otros motivos, por los movimientos migratorios internacionales (ANDRADE, 2002). En Estados Unidos la diversidad es especialmente significativa porque, durante décadas, ha recibido inmigrantes de múltiples lugares que han traído con ellos sus rituales. La cuestión inmigratoria marca la pauta al modificar los diferentes ámbitos de la vida urbana, entre los que se incluyen nuevos comportamientos religiosos, que también establecen variaciones sobre el patrimonio.

El estudio del comportamiento religioso de la ciudad más poblada del estado de Missouri, Kansas City, y la evolución y gestión de uno de sus principales monumentos, la Catedral católica de la Inmaculada Concepción, constituyen los objetivos de nuestra investigación. Esta catedral es uno de los edificios históricos más antiguos y emblemáticos, aunque el catolicismo no es la religión mayoritaria en la urbe. Es más, se podría calificar como una religión minoritaria en el estado. Debido a esta particularidad hemos introducido de manera transversal dos tipos de análisis. Por un lado, aspectos ligados al estudio de la diversidad religiosa, con la finalidad de presentar el escenario plural en el que se inserta este monumento, que comparte espacio con más de dos mil edificaciones religiosas pertenecientes a diferentes confesiones. Por otro, breves referencias al panorama religioso español, con el objetivo de establecer comparaciones que nos ayuden a comprender mejor la singularidad del caso americano que centra nuestro estudio.

El contenido del artículo se estructura en seis apartados. El primero incluye la introducción y el segundo aborda las cuestiones de metodología y fuentes. Un tercer apartado nos aproxima al ámbito religioso estadounidense y español. El cuarto epígrafe pone el acento en la realidad religiosa particular de Kansas City. En el quinto haremos un recorrido por la historia de la catedral católica prestando atención a las intervenciones arquitectónicas y decorativas sufridas en las diferentes etapas, principalmente a la última reforma que tuvo lugar en 2003.

1 Este artículo se integra en el plan de investigación actualmente en curso, correspondiente al proyecto: PID2019-110231GB-I00. «Estudio diagnóstico comparado entre la conservación del patrimonio artístico religioso y sus modelos de gestión en las islas de Mallorca y Menorca». Programa Estatal de Generación de Conocimiento y Fortalecimiento Científico y Tecnológico del sistema de I+D+I. Ministerio de Ciencia Innovación y Universidades. 
El sexto se dedica al análisis del modelo de gestión. El trabajo se completa con las conclusiones.

\section{METODOLOGÍA Y FUENTES}

La metodología seguida para alcanzar los objetivos propuestos es básicamente cualitativa. La consulta y análisis de fuentes bibliográficas y documentales son la base para el estudio del tema religioso en Estados Unidos y España, y más concretamente de Kansas City, como medio para contextualizar su monumento religioso más importante. La investigación empírica propiamente dicha se ha fundamentado en la interrelación de tres tipos de fuentes.

En primer lugar, la información estadística generada por diferentes organismos ha sido fundamental para conocer el peso de las diferentes religiones en Kansas City. En este sentido, se distinguen dos tipos de fuentes. Unas sobre religiones y número de fieles por confesión, incluso con datos territoralizados: PolicyMap (Joint Center for Housing Studies de Harvard University), American Values Atlas (un proyecto de Public Religion Research Institute) y Association of Religion Data Archives. Y, por otro lado, The Pluralism Project (Harvard University), que aporta información detallada de los equipamientos religiosos por confesión en el mapa de la ciudad. En segundo lugar, el Archivo Diocesano de la Diócesis de Kansas City-St. Joseph no solo nos ha proporcionado los informes de las sucesivas reformas de la Catedral de la Inmaculada Concepción, sino también una selección de fotografías que ilustran la evolución sufrida por el edificio.

El análisis documental se ha completado con una tarea fundamental para el desarrollo de este trabajo, como han sido las entrevistas semiestructuradas a representantes eclesiásticos y gestores culturales, entre las cuáles destacamos las realizadas al párroco de la Catedral de la Inmaculada, al obispo de la Diócesis, al director del Museo Nelson-Atkins, al director de la Oficina de los Archivos Diocesanos y a la responsable de la oficina de Información Turística del Power and Light District. Estos nos han presentado, desde diferentes puntos de vista, la realidad cultual y patrimonial que vive la institución en la actualidad.

El trabajo de campo estuvo centrado en las visitas a la catedral y a las principales iglesias y templos de las confesiones con más peso en la ciudad. De este modo hemos tenido oportunidad de conocer los bienes materiales e inmateriales que atesoran estos lugares y de experimentar su funcionamiento, participando en los programas religiosos y culturales que ofrecen al visitante como parte de su proyecto espiritual y de difusión del patrimonio. ${ }^{2}$

2 Estas visitas se han materializado en el marco de una estancia de investigación realizada en University of Missouri-Kansas City (UMKC) durante el año 2019. 


\section{CAMBIOS EN EL CONTEXTO RELIGIOSO GLOBAL}

\subsection{El escenario estadounidense}

En Estados Unidos no hay religión oficial, ni confesionalismo, ni Iglesia de Estado $\mathrm{y}$, pese a estas circunstancias, los estadounidenses son más religiosos que los ciudadanos de otros países con economías de desarrollo similar. Sus tendencias presentan elementos diferenciadores, toda vez que su realidad está en constante cambio. ${ }^{3}$ Tradicionalmente el conjunto de la nación ha presentado una gran diversidad religiosa favorecida por la Constitución (Primera Enmienda de 1791), que defiende el libre ejercicio de la religión (SÁNCHEZ-BAYón, CAMPOS y FUENTE, 2017: 635). ${ }^{4}$ En la actualidad, esta diversidad ha alcanzado los porcentajes más elevados hasta la fecha. Las sucesivas olas de inmigración vividas durante el siglo xx, y que se han acentuado a partir de 1965 a raíz de la nueva legislación en este campo, han convertido al país en un microcosmos del mundo y en un crisol de civilizaciones y religiones. ${ }^{5}$ Los nuevos pobladores han traído consigo sus tradiciones religiosas que se han unido a las cristianas como parte de una identidad que les mantiene unidos con sus lugares de origen.

Tres obras clave de distintos momentos nos permiten profundizar en la realidad religiosa estadounidense. La primera es el libro del sociólogo Will Herberg (1960), Protestant, Catholic, Jew, cuyo título hace referencia a las religiones predominantes a mediados del siglo $x x .{ }^{6} \mathrm{Su}$ autor articuló un nuevo status quo para Estados Unidos, argumentando que en este momento fue un país de tres religiones en donde se esperaba que el recién llegado cambiase muchas cosas a medida que se fuese integrando como estadounidense (nacionalidad, idioma, cultura...), pero no su religión. ${ }^{7}$ Una década después de la publicación de esta obra se aprobó la Ley de Inmigración de 1965, que propició una nueva fase de inmigración y provocó que la etnia y la religión estadounidenses fueran más texturizadas y complejas de lo que Herberg había imaginado, con el crecimiento sustancial de las comunidades musulmana, budista, hindú y sij.

Una segunda obra que nos puede ayudar a entender el escenario religioso americano es el libro del profesor de la Universidad de Harvard Samuel P. Huntington (2004) titulado Who Are We: The Challenges to America's National Identity. A lo largo de sus páginas, el autor hace una reflexión sobre la cuestión identitaria y religiosa, defendiendo que la configuración nacional fue el resultado

3 Disponible en https:/ / www.pewforum.org/2008/06/01/u-s-religious-landscape-survey-religiousbeliefs-and-practices, fecha de última consulta: 24-09-2020.

4 En este escenario, la Iglesia cristiana ha sido la dominante, destacando en número los católicos.

5 A principios de siglo la inmigración fue principalmente europea y de otros lugares de América. En los últimos años el porcentaje de inmigrantes que más ha crecido es el de asiáticos y del Pacífico.

6 Esta obra se ha convertido en un clásico para la interpretación de América en la década de 1950. La articulación de Herberg del «crisol triple» y del papel de la religión a la hora de conformar una identidad estadounidense proporciona un punto de partida para la discusión sobre una América religiosa más compleja en la década de 1990. Disponible en http://pluralism.org/document/protestantcatholic-jew-will-herberg-1959, fecha de última consulta: 27-09-2020.

7 Disponible en http://pluralism.org/encounter/historical-perspectives/a-three-religion-country, fecha de última consulta: 27-09-2020. 
de la cultura WASP, acrónimo de white anglo-saxon protestant. Para Huntington, esta es la cultura dominante que se superpone a otras minoritarias como puede ser la católica latina (SÁNCHEZ-BAYón, CAMPOS y FuENTE, 2017: 635).

La tercera obra a tener en cuenta es un volumen que recoge participaciones de varios autores de diversos ámbitos, publicado recientemente bajo el título $A$ Nation of Religions: The Politics of Pluralism in Multireligious America. El objetivo de su editor, Stephen Prothero (2006), se basó en intentar esclarecer los complejos desafíos planteados por la nueva situación religiosa en donde ya no se puede hablar como, en los otros casos, de religiones predominantes, sino de multiplicidad religiosa. El libro, que aglutina doce ensayos sobre las principales religiones, ofrece a sus autores la posibilidad de explicar cómo la diversidad religiosa está transformando la vida pública y privada de muchos estadounidenses. ${ }^{8}$ En el conjunto de la obra se refleja como la mayoría cristiana fue dando paso a la llegada de judíos, musulmanes, budistas, hindúes y sikhs, entre otros grupos. Un proceso singular y de cariz positivo que, no obstante, conllevó ciertas fricciones cuando «los valores estadounidenses de la Ilustración y la religión judeocristiana chocaron contra los valores del islam, el budismo y el sikkhismo» (PROTHERO, 2006: 7). La investigadora francesa Sylvie Grenet (2007) ha publicado una reseña bibliográfica en donde analiza el interés de los artículos que componen esta obra, concluyendo que «el principal activo del libro de Prothero es mostrar cómo la sociedad estadounidense está transformando la diversidad religiosa de las comunidades migratorias $\mathrm{y}$, al mismo tiempo, cambiando lentamente los valores y creencias estadounidenses» (GRENET, 2007: 3).

Las tres obras radiografían la situación religiosa estadounidense en diferentes momentos del siglo xx que, según avanzan los años, se vuelve cada vez más compleja. En este contexto entendemos que el reto está en crear una sociedad verdaderamente pluralista que involucre la diversidad religiosa en un proyecto común, en donde personas de diferentes credos y culturas convivan en armonía. La misión es, sin duda, difícil por los problemas asociados a la inmigración y al racismo que, en ocasiones, provocan una respuesta de exclusión, si bien es cierto que este país es más tolerante que otros y cuenta con una mayor experiencia y tradición en la gestión de cuestiones de este calibre. El ideal está en alcanzar un pluralismo en donde las religiones, con todas sus diferencias y particularidades, se integren en el puzzle religioso-cultural de los Estados Unidos. Un propósito ya soñado en la década de 1960 por el líder de los derechos civiles de Estados Unidos, Martin Luther King.

\subsection{El escenario español}

Como contrapunto al panorama estadounidense, en España nos encontramos

\footnotetext{
8 Las primeras tres partes de la obra están dedicadas a examinar desde un punto de vista histórico y antropológico las religiones musulmana, budista, hindú y sij; la cuarta sección se ocupa de las respuestas legales dadas por el sistema judicial estadounidense a varios temas religiosos; $y$, en la quinta, se exponen las conclusiones.
} 
con una situación más uniforme, de claro predominio católico. No obstante, la reciente llegada de inmigrantes ha abierto las puertas a la entrada de nuevas religiones con lo que esto implica de implantación de nuevos ritos y construcción de edificios para el culto. La mayoría católica y la no religiosa conviven con un número cada vez mayor de minorías religiosas que no han dejado de crecer en los últimos quince años y que marcan el rumbo hacia un nuevo futuro. Estos procesos se hacen especialmente visibles en ciudades como Madrid, Barcelona, Palma, Málaga, Tarragona, Castellón, Murcia o Santa Cruz de Tenerife (PiQueras, 2011: 208). ${ }^{9}$ En general en las grandes ciudades y en todo el eje mediterráneo, la inmigración tiene una doble procedencia: del Norte y Sur global. La primera compuesta por inmigrantes mayoritariamente del centro y norte de Europa, atraídos por el ocio y el clima. Y la segunda de tipo laboral, formada por latinoamericanos y africanos principalmente (DOMÍNGUEZ et al., 2011; DOMínGUEZ et al., 2008).

Los cambios derivados de la inmigración afectan también a la esfera religiosa. En España, la situación histórica en materia de religión y la evolución hacia la contemporaneidad ha sido abordada por diferentes autores. Una referencia clave es la obra colectiva titulada La historia religiosa de la España contemporánea: Balance y perspectivas (2017), en donde han participado especialistas de diversos ámbitos coordinados por Feliciano Montero, Julio de la Cueva y Joseba Louzao. ${ }^{10}$ Los capítulos que la componen abordan variados temas, entre los que se encuentran los principales conflictos religiosos que tuvieron lugar desde el siglo XIX, el papel desempeñado por el clero y los laicos, y los nuevos enfoques de la religión en la actualidad, toda vez que también se presta atención a la historiografía de carácter regional, nacional e incluso internacional. En esta obra se incluye también un trabajo redactado por Francisco Díez de Velasco, que constituye una de las más recientes aportaciones al tema de las minorías religiosas, hasta el momento poco investigado en España. ${ }^{11}$ En el marco de las minorías, el estudio del islam español es el que ha recibido una mayor atención «marcando el 11M un punto de inflexión propio a añadir al 11S en el interés general por el asunto» (DíEZ, 2017: 306). ${ }^{12}$ Las otras dos que suscitan interés, y con las que el Estado ha firmado acuerdos de

9 Véase el cuadro realizado por Juan Piqueras que recoge los datos de los «migrantes del sol» correspondientes a ciudadanos del norte de Europa residentes en España en 2010 (PIQUERAS, 2011: 204). Esta información se refiere a las provincias españolas que, según datos del INE, registran más de 5.000 extranjeros.

10 Los responsables de la edición de la obra dirigen también un proyecto de investigación sobre religión del Plan estatal titulado «¿Hacia una superación del conflicto catolicismo-laicismo? España 1960 1975» (HAR2014-55393-C2-1-P), financiado por la Agencia Estatal de Investigación del Ministerio de Economía y Competitividad.

11 Este trabajo se inserta en el contexto de los proyectos de investigación «La Historia de las Religiones y el Estudio de las Religiones en España antes del Concilio Vaticano II» del Plan Nacional de I+D+I, Ministerio de Ciencia e Innovación (HAR2011-25292) (2012-2015), y «Bases teóricas y metodológicas para el estudio de la diversidad religiosa y las minorías religiosas en España» (HAR2016-75173-P) del Ministerio de Economía y Competitividad de España (2017-2020).

12 Otros autores que han tratado temas relacionados con el islam han sido Álvarez (2005); LACOMBA (2001); López García (2002); López ReQuena (2015); López Rodríguez (1976); Losada (2003); Mijares y Ramírez (2008); Moreras (2008); Rosón y Tarrés (2013); SAlguero (2014); TARrés y JimÉnez (2012) y VALENCIA (2003), entre otros. 
cooperación por la importancia que han adquirido en los últimos tiempos, son la judía y la de los cristianos evangélicos. Por su parte, el budismo y la ortodoxia cristiana son confesiones que comienzan a tener una presencia significativa, dado el peso del fenómeno migratorio especialmente rumano. También en alza, pero con menor incidencia, estarían los testigos de Jehová y los sijs (Díez, 2017: 308). En definitiva, la tendencia es al aumento del número de minorías religiosas que comparten su espacio con las mayorías católica y no religiosa, un rasgo que se percibe en prácticamente todas las comunidades autónomas.

\section{LA SINGULARIDAD DE KANSAS CITY COMO CRISOL RELIGIOSO}

Kansas City refleja la realidad religiosa que afecta a todo Estados Unidos. Esta ciudad que tiene una población de 476.974 habitantes es la más importante del área metropolitana (2,1 millones de habitantes) y la más poblada del estado de Missouri. ${ }^{13}$ En conjunto, se caracteriza por su perfil multicultural y multirreligioso representado por la presencia de templos y centros budistas, cristianos, judíos, mormones, taoístas, hindúes, jainistas y zoroastrianos, así como centros bahá'ís, humanistas y paganos, de tradiciones nativas, centros islámicos y masajid, y sikh gurdwaras.

En 2015 el Public Religion Research Institute, puso en marcha un proyecto que tuvo por objetivo conocer cuáles eran las religiones más practicadas en el área urbana de Kansas City. ${ }^{14}$ Los datos resultantes se representan en la Tabla 1: $:^{15}$

TABLA 1

Composición religiosa de adultos en Kansas City

\begin{tabular}{|l|c|l|c|}
\hline Cristianos & $76 \%$ & No Cristianos & $4 \%$ \\
\hline Evangélicos protestantes & $31 \%$ & Testigos de Jehová & $1 \%$ \\
\hline Protestantes principales & $24 \%$ & Judíos & $<1 \%$ \\
\hline Protestantes negros históricos & $2 \%$ & Musulmanes & $1 \%$ \\
\hline Católicos blancos & $10 \%$ & Budistas & $1 \%$ \\
\hline Católicos hispanos & $7 \%$ & Hindús & $<1 \%$ \\
\hline Otros católicos & $1 \%$ & Otras religiones del mundo & $<1 \%$ \\
\hline Mormones & $1 \%$ & Otra fe & $2 \%$ \\
\hline Cristianos ortodoxos & $<1 \%$ & No afiliados (no religiosos) & $20 \%$ \\
\hline
\end{tabular}

Fuente: www.pewforum.org/religious-landscape-study/state/Kansas.

13 La fuente utilizada para obtener este dato ha sido el United States Census Bureau.

14 Disponible en https://www.flatlandkc.org/newsletter/major-religions-kansas-city/, fecha de última consulta: 03-11-2020.

15 American Values Atlas (AVA 2018) y https://www.pewforum.org/religious-landscape-study/state/Kansas, fecha de última consulta: 13-11-2020. 
El funcionamiento de la ciudad no se puede entender sin prestar atención a este escenario, debido a que la religión es una poderosa fuerza en la vida privada y pública y condiciona el desarrollo de la urbe. Las filiaciones religiosas son fundamentales para comprender los puntos de vista sociales y políticos básicos, toda vez que la arquitectura condiciona la imagen estética de los barrios. Por un lado, observamos como el incremento mayor en los últimos años se ha dado entre las filas de los protestantes sin denominación, que son en gran parte evangélicos y ofrecen una religión más personal y unos servicios de culto que tienen lugar en edificios poco uniformes que no dejan de multiplicarse. ${ }^{16}$ Por otro, la Iglesia Católica Romana es la que ha experimentado las mayores pérdidas a pesar de contar con una amplia tradición desde 1821, cuando los primeros fieles llegaron a Kansas City. Los católicos son poseedores de los edificios religiosos más antiguos de la ciudad entre los que se encuentra la Catedral de la Inmaculada Concepción, que también es sede de la diócesis. ${ }^{17}$ En este contexto, en donde los evangélicos aumentan y los católicos disminuyen, los musulmanes rivalizan con los mormones y judíos por tener las familias más grandes, si bien el porcentaje de afiliados a estas religiones no es muy elevado. Por último, también es apreciable una tendencia ascendente hacia la secularización sobre todo entre la población joven que, por regla general, es menos religiosa que sus mayores.

Una consecuencia de esta diversidad es que no solo existen edificios para el culto y los servicios religiosos sino también una enorme infraestructura compuesta por más de veinte organizaciones dedicadas a dialogar y mejorar el entendimiento interreligioso y a tender nuevos puentes que fomenten contactos muchas veces sin precedentes. ${ }^{18}$ Entre las organizaciones y asociaciones congregacionales presentes en la ciudad destaca el Consejo Interreligioso Metropolitano del Gran Kansas City (GKCIC). ${ }^{19}$

\subsection{Las huellas de la religión en la arquitectura religiosa metropolitana}

Desde principios del siglo xIx la llegada continua de inmigrantes a Kansas City ha contribuido a la diversidad religiosa que se ha materializado en la existencia de iglesias y templos muy diferentes como contenedores de múltiples credos. Este proceso se acentuó a partir la Segunda Guerra Mundial cuando arribaron nuevas comunidades. Algunas dieron sus primeros pasos ocupando el espacio de iglesias más antiguas ya establecidas con las que, en ocasiones, compartieron

16 Los grupos predominantes de iglesias protestantes son la Iglesia Metodista Unida, la Iglesia Luterana Evangélica, la Iglesia Presbiteriana, la Iglesia Episcopal, la Iglesia Unida de Cristo, la Iglesia Cristiana (Discípulos de Cristo) y las Iglesias Bautistas. Disponible en https://www.pewforum.org, fecha de última consulta: 14-11-2020.

17 En la actualidad los católicos de la diócesis alcanzan la cifra de 143.351. Estos son atendidos en 84 parroquias y 16 misiones.

18 En Kansas City (MO) se formó un grupo de trabajo de varias religiones para medir las experiencias de discriminación a raíz de los eventos del 11 de septiembre de 2001. El grupo de trabajo fue presidido por el reverendo Vern Barnet, fundador del Consejo Interreligioso de Kansas City. Disponible en https:/ / es.qwerty.wiki/wiki/Vern_Barnet, fecha de última consulta: 17-11-2020.

19 Disponible en https:/ / www.kcinterfaith.org, fecha de última consulta: 17-11-2020. 
instalaciones, de las que, poco a poco, se irán desvinculando.

Por lo general, se observa cómo en la construcción de los inmuebles se han priorizado criterios de funcionalidad sobre parámetros estéticos y de creación artística y, además, salvo excepciones, también se encuentran bastante desprovistos de decoración. ${ }^{20}$ En algunos, no obstante, reconocemos valores simbólicos, históricos o histórico-artísticos, como en el caso de la primera sinagoga judía, de la catedral católica o del Templo de la Independencia, sede internacional de la Comunidad de Cristo. ${ }^{21}$ La primera sinagoga, la Congregación Keneseth Israel, fue establecida en 1878 por inmigrantes rusos y polacos, y su edificio figura en el Registro Nacional de Lugares Históricos. ${ }^{22}$ Por su parte, el Templo de la Independencia de la Comunidad de Cristo, levantado en 1994, se alza como una de las obras contemporáneas más destacadas de toda la urbe (Fig. 1).
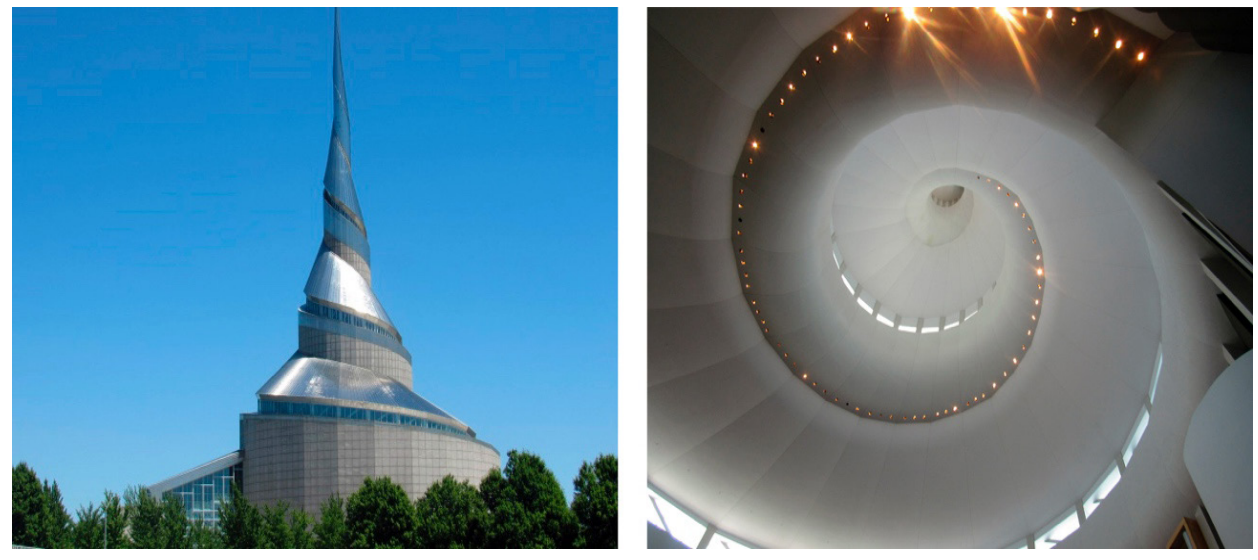

Figura 1. Templo de la Independencia de la Comunidad de Cristo. Vista del exterior (izqda.) y detalle del interior de la cúpula (dcha.), 2019. Fotografías de autores.

El edificio del Templo de la Independencia llama la atención por la estética de su arquitectura firmada por el arquitecto japonés Gyo Obata, quien apostó por un diseño contemporáneo con una estructura que evoca la forma de una concha de nautilo en espiral cubierta por una placa de acero y que es visible desde diferentes puntos de la ciudad. ${ }^{23}$

20 Los bienes muebles de carácter religioso y los objetos litúrgicos o decorativos que pueden tener algún valor artístico, por lo general, se han desplazado al ámbito de los museos.

21 El primer Templo Budista y la Asociación de la India se fundaron en 1965 y al final de esta década también se construyó el primer Sikh gurdwara. En 1991 el Templo Hindú y el Centro Cultural de Kansas City fueron inaugurados en un suburbio al oeste de la ciudad. En 2010 se realizó la ceremonia de la primera piedra y la dedicación eclesiástica del terreno sobre el cual se construiría el primer templo mormón.

22 Esta sinagoga se fusionó con la Congregación Beth Shalom a principios del siglo xx.

23 Disponible en https://www.azahner.com/works/independence-temple, fecha de la última con- 


\section{LA CATEDRAL DE LA INMACULADA CONCEPCIÓN (KANSAS CITY)}

\subsection{Antecedentes}

La historia de la Catedral de Kansas City se remonta al año 1833, cuando un misionero francés, el padre Benedict Roux, llegó a la ciudad con instrucciones de formar una parroquia permanente. Esta habría de dar servicio a los primeros católicos que se aventuraron a venir por el río Missouri y, al mismo tiempo, servir de ayuda en la tarea de evangelizar a las tribus nativas. Para cumplir con este cometido, el padre Roux compró un solar de cuarenta acres de tierra por los que pagó seis dólares (COLEMAN, 2014: 18). ${ }^{24}$ En 1835 la comunidad católica, por iniciativa de la orden jesuita, construyó en él una iglesia de madera, una rectoría y un pequeño cementerio. Esta parroquia constituyó la congregación de adoración más antigua de la ciudad.

Más tarde un pionero irlandés, el padre Bernard Donnelly’s, decidió levantar en sus cercanías una iglesia permanente de ladrillo dedicada a la Inmaculada Concepción. El edificio se comenzó a construir en 1856 y en él trabajaron durante un año alrededor de trescientos obreros irlandeses que, además, establecieron una fábrica de ladrillos en la zona. (BRANDT, Doering y BEEMONT, 1992: 33). ${ }^{25}$ La planta, de estructura rectangular, acogía cinco grandes ventanas en las paredes de los lados más largos, enlazadas entre sí por arcos apuntados imitando al gótico. La fachada, poco ornamentada, estaba precedida de una escalinata que conectaba con la puerta principal, a su vez cobijada por una arcada de influencia también gótica. En el frente izquierdo, una enorme pilastra actuaba como campanario (BRANDT, DOERING y BEEMONT, 1992: 34).

La iglesia se terminó en 1857 y este mismo año se estableció una primera diócesis en la ciudad de San Joseph. En 1880, debido al aumento de la población en el área, se constituyó una segunda en Kansas City (KelLy, 2003: 30). La iniciativa partió del obispo John Joseph Hogan. Por entonces, entre ambas diócesis, había alrededor de treinta mil católicos.

\subsection{La fundación de la Catedral}

En 1882 el prelado John Joseph Hogan escogió la iglesia de la Inmaculada Concepción para convertirla en la Catedral de Kansas City y él mismo fue quién colocó la piedra angular. Por tal circunstancia y para atender a las nuevas necesidades de la institución, la fábrica antigua fue ampliada hasta convertirse en el monumento más alto de la urbe y su torre, cubierta con una cúpula de cobre, fue visitada por un gran número de personas para disfrutar de las vistas. ${ }^{26}$ La iglesia

sulta: 02-12-2020.

24 El solar estaba muy cerca del lugar que hoy ocupa la actual Catedral.

25 Estos mismos obreros también se ocuparon de pavimentar con ladrillo las calles de los alrededores. Desde entonces, el ladrillo se utilizó como principal material constructivo en los edificios históricos de la ciudad.

26 Un año después, en 1883, la nueva iglesia estaba ya en servicio. 
fue planificada para acoger en su interior a mil doscientas personas y las obras contaron con un presupuesto de ciento veinticinco mil dólares. Esta actuación coincide con la importancia adquirida en este momento por el Movimiento Litúrgico que potencia una renovación en aras de una mayor participación en el rito de la misa, hasta ahora prácticamente inexistente, dado que los fieles se ocupaban en otros ejercicios de piedad individual. ${ }^{27} \mathrm{Su}$ pujanza derivó en una gran cantidad de publicaciones sobre las nuevas aplicaciones arquitectónicas que hacen referencia a la renovación del espacio sacro (Delgado, 1999). Además, la nueva tendencia renovadora recibió el apoyo del papa Pío x, promotor de la aprobación de tres decretos (años 1903, 1905 y 1910) que abogan por incrementar la participación de los fieles. Según Tiziano Ghirelli, la reforma litúrgica supuso que desde entonces «al sacramento no se asiste, se participa», con lo cual se aumenta mucho el grado de implicación de los asistentes a las misas (GHIRELLI, 2012: 99).

El arquitecto encargado del diseño de la nueva catedral fue T.R. Tinsley, que optó por el estilo neoclásico en un espacio interior de tres naves dividido por columnas corintias que descansaban sobre grandes arcos (BRANDT, DOERING y BEEMONT, 1992: 37). La decoración estuvo a cargo del artista Dante Cosentino. Las vidrieras fueron realizadas con posterioridad, concretamente en 1912, por especialistas ingleses y alemanes que ejecutaron este proyecto en colaboración con artistas locales. ${ }^{28}$ Las escenas de la vida de Cristo y otros temas bíblicos inundaron sus múltiples cristales que, no obstante, filtraban una luz tenue a causa de haber sido oscurecidos con una técnica de lavado en frío (Fig. 2). La idea era proporcionar una sensación de recogimiento al interior del templo, de acuerdo con la teología predominante de la época (Teología de la Encarnación) en sintonía con lo establecido con anterioridad al Concilio Vaticano II. Algunas de las dieciséis vidrieras iniciales todavía permanecen en sus lugares de origen (sacristía del oeste y torre campanario), mientras que otras se movieron durante las reformas operadas en 1930, 1955, 1972 y 2003 (ColemaM, 2014: 18).

27 A esta corriente y, más concretamente, al tema de los espacios sagrados cristianos desde el punto de vista de la reforma litúrgica del Concilio Vaticano II dedica su tesis doctoral el obispo italiano Tiziano Ghirelli, uno de los mayores especialistas en el estudio de estas cuestiones. Sus investigaciones han sido recogidas en la obra Ierotopi Cristiani alla luce de la reforma liturgica del Concilio Vaticano II. Le chiese secondo el magistero (2012), Librería Editrice Vaticana, Città del Vaticano.

28 La compañía Kansas City Stained Glass Company fue la encargada de la realización de los vitrales. 


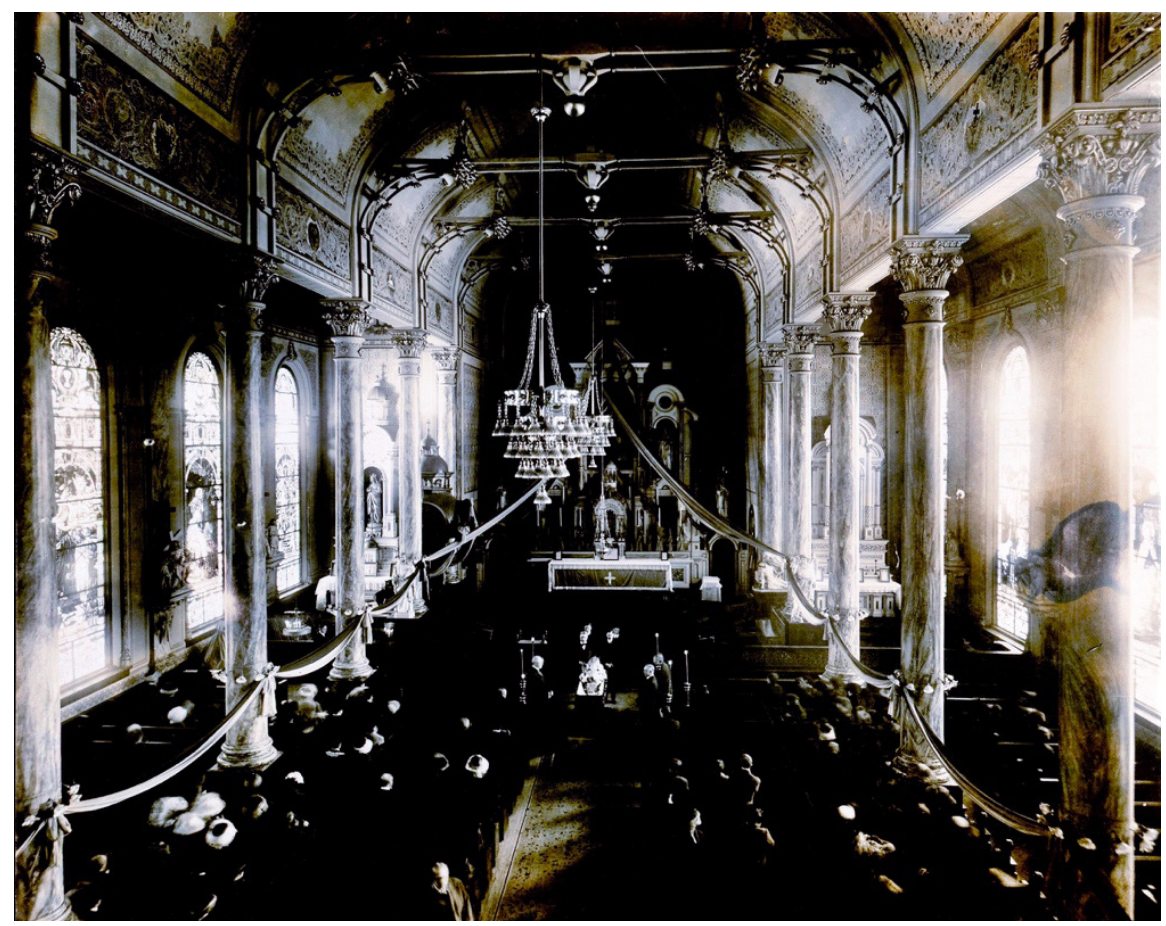

Figura 2. Catedral de la Inmaculada Concepción durante el funeral del obispo John Joseph Hogan (febrero de 1913). Fotografía cortesía de los Archivos Diocesanos de la Diócesis de Kansas City-St. Joseph.

El edificio catedralicio de este momento fue muy apreciado entre sus contemporáneos tanto por su valor histórico-artístico como porque albergaba una serie de piezas simbólicas que lo conectaban con los inicios del catolicismo en la ciudad: una pintura al óleo de Sant Dennis de París, la llave de la antigua iglesia construida por iniciativa del padre Donnelly, y la primera campana de la ciudad..$^{29}$ Durante esta etapa la Catedral constituyó un edificio significativo en el entorno urbano (Fig. 3).

29 La pintura de Sant Dennis permanece colgada en la Cancillería Católica de Kansas City, mientras que la llave y la campana se encuentran custodiadas en el convento de Santa Teresa. 


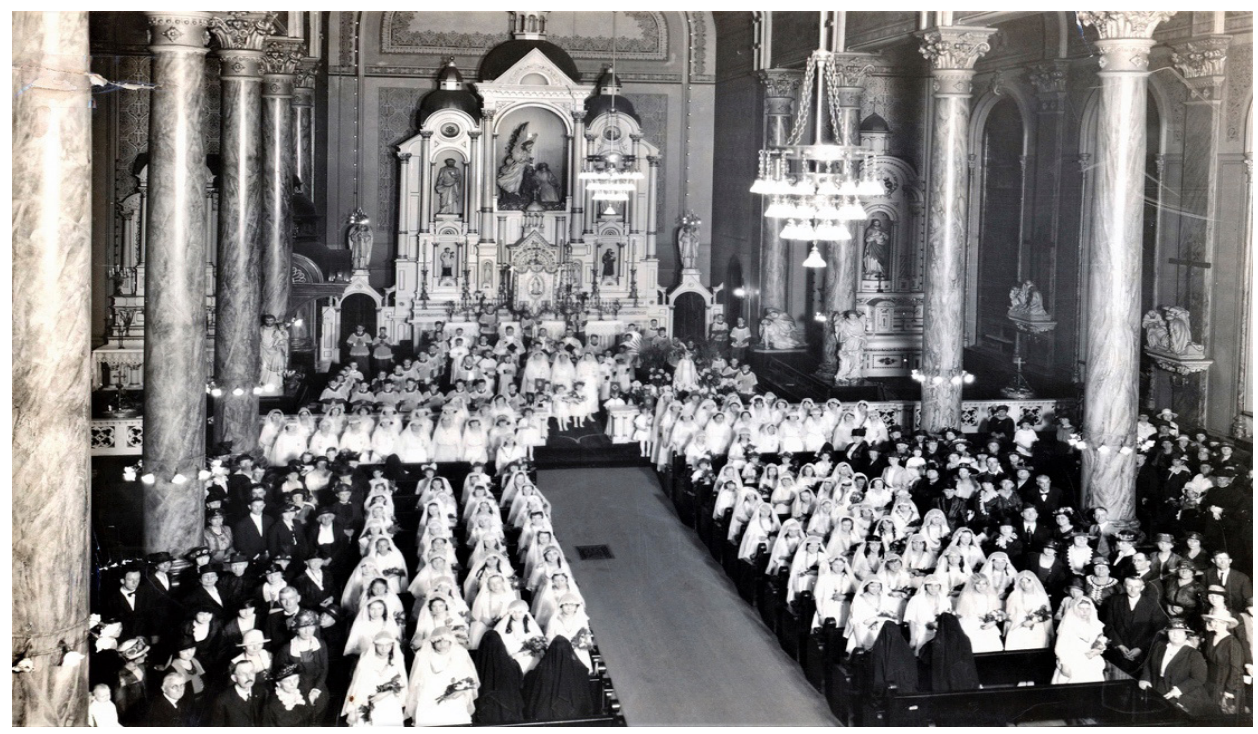

Figura 3. Interior de la Catedral de Kansas City (1930). Fotografía cortesía de los Archivos Diocesanos de la Diócesis de Kansas City-St. Joseph.

\subsection{Las renovaciones de 1955 y 1972}

La falta de mantenimiento de la fábrica catedralicia durante el segundo cuarto del siglo xx acabó provocando un deterioro que condujo a su renovación en 1955 (Fig. 4). Las reformas fueron impulsadas por la celebración del jubileo de la diócesis y tuvieron un coste de trescientos cincuenta mil dólares.
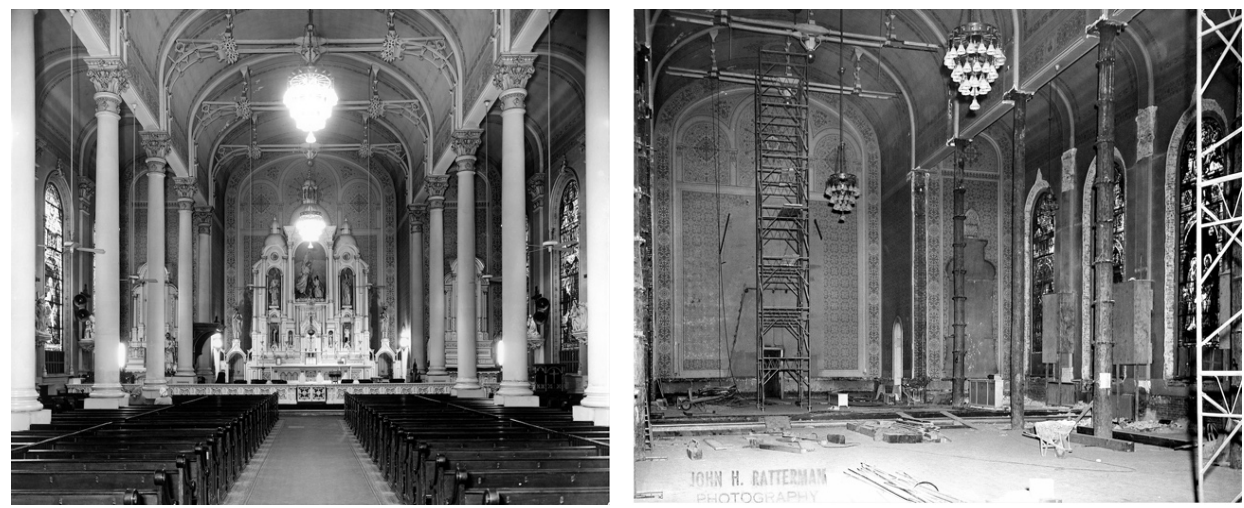

Figura 4. Interior de la Catedral antes de la reforma (izqda.) y en el momento de la renovación de 1955 (dcha.). Fotografías cortesía de los Archivos Diocesanos de la Diócesis de Kansas City-St. Joseph. 
Una vez comenzadas las obras en el inmueble, el papa Pío xII promovió la fusión de la parte occidental de la diócesis de San Joseph con la parte norte de la de Kansas City, circunstancia que derivó en la creación en 1956 de la actual de Kansas City-St. Joseph. Desde entonces, la nueva diócesis cuenta con dos catedrales: la Catedral de la Inmaculada Concepción de Kansas City y la Concatedral de Sant Joseph. A mediados del siglo xx ambas instituciones, en coordinación con las noventa y ocho parroquias existentes en el área, dieron cobertura religiosa a una población de ciento treinta y tres mil católicos (KelLy, 2003: 90). En esta misma época los papas, Pío XII y Pablo vi continuaron dando su apoyo e impulsando las reformas promovidas por el Movimiento Litúrgico, que encarnaban criterios de modernidad (Delgado, 1999). En este sentido, un cambio trascendental fue el reconocimiento por parte de Pablo VI de la libertad del artista. Para este papa, la Iglesia era un espacio para la libertad de expresión, aunque siempre manifestando respeto al edificio y a los ritos sagrados (GHIRELLI, 2012). ${ }^{30}$

La reforma que sufrió la Catedral en 1955 fue de gran consideración y estuvo abanderada por el artista californiano Charlton Fortune, encargado de llevar a término diferentes actuaciones marcadas por los preceptos del nuevo movimiento litúrgico, cuya seña de identidad fue la simplificación del interior del edificio (BRENNAN y RAMSEY, 1995). Entre las intervenciones llevadas a cabo destacan la elevación del suelo, que se cubrió con placas de mármol negro y gris, el reemplazo de las columnas y capiteles de madera por vigas de acero, y el diseño de un mosaico de mármol de gran tamaño que fue colocado detrás del altar, donde se representó la figura de María compuesta por tres mil piezas de diferentes colores. Otra actuación trascendente fue la construcción de una capilla dedicada a Pío $\mathrm{X}$ en la cabecera del templo, al sur de la nave principal, que funcionará como extensión del cuerpo de la catedral aumentando considerablemente su capacidad. La edificación de esta capilla obligó a derribar la antigua casa rectoral (Fig. 5).

30 Tras la celebración del Concilio Vaticano II se recomienda instituir academias de arte sacro para la formación de los artistas, cuyas obras deberán contribuir a la formación religiosa de los fieles. Por lo que se refiere a la iconografía y objetos de devoción se establece que deben de conducir al fiel hacia el corazón de la liturgia, pero nunca distraerlo de ella. Para profundizar en estas cuestiones véase la obra de Tiziano Ghirelli (2012). 

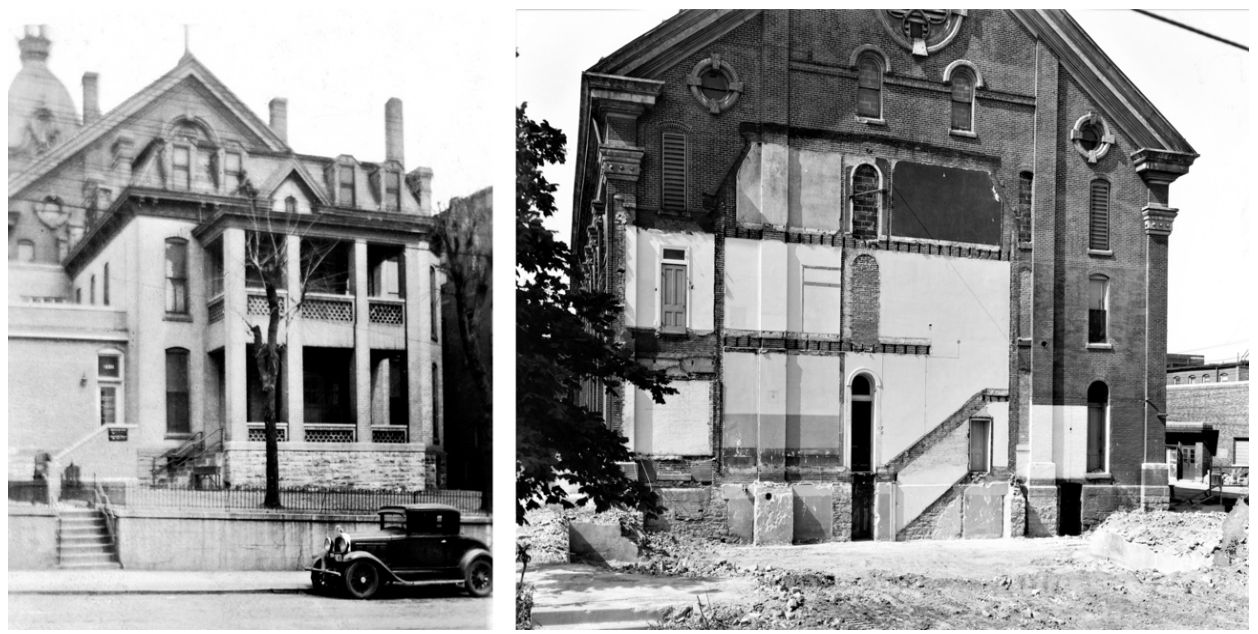

Figura 5. Casa rectoral de la Catedral de la Inmaculada Concepción antes (izqda.) y después de su destrucción. 1930 / 1955 (dcha.). Fotografía cortesía de los Archivos Diocesanos de la Diócesis de Kansas City-St. Joseph

En 1960, se prestó atención al aspecto externo de la catedral, procediendo a recubrir la cruz y la cúpula con láminas de pan de oro (COLEMAM, 2014: 16). Años después, en 1972, Fortune propiciará una segunda fase de reformas que fueron ejecutadas bajo una orientación minimalista y simplificadora, en sintonía con las propuestas de reforma litúrgica del Concilio Vaticano II. Estas se centraron en la recolocación del altar, el tabernáculo y la cátedra del obispo, que fueron trasladados al centro del santuario.

\subsection{La última reforma de 2003}

A principios del siglo xxI se llevaron a cabo las últimas obras de acondicionamiento de la catedral que culminaron en 2003 bajo el mandato del obispo Raymond J. Boland. Estas fueron muy costosas (ocho millones y medio de dólares), no solo por la gran cantidad de trabajadores profesionales implicados sino también por la riqueza y procedencia de los materiales utilizados, algunos traídos de diferentes partes del mundo (Italia, España, China...). Esta fue la última intervención de envergadura efectuada en la catedral, cuya principal seña de identidad fue la subordinación a la reforma litúrgica y, de hecho, se justifica básicamente en el seguimiento de criterios teológico-litúrgicos unido a un intento por mejorar la funcionalidad del edificio. Las actuaciones llevadas a cabo reflejan el cambio teológico del Concilio Vaticano II, cuyas directivas prácticas en relación a la construcción de iglesias fueron recogidas en la Instrucción Inter Oecumenici, dictada el 26 de septiembre de 1964 que, a su vez, dará lugar a la publicación de 
una gran variedad de documentos por parte de las Comisiones Episcopales de los distintos países, muchos de los cuales recogen propuestas que tienen como punto en común la búsqueda del sentido funcional del espacio litúrgico (GHIRELLI, 2012). ${ }^{31}$

El arquitecto encargado de las obras del interior fue Michael Shaughnessy, August Huber el contratista general y Butch Schasteen el supervisor del proyecto de renovación (COLEMAM, 2014: 21). Los trabajos exteriores fueron dirigidos por Berger Devine Yaeger quién, sin abandonar el diseño neoclásico, devolvió al edificio el brillo de tiempos pasados al promover el dorado de la cúpula, a la vez que desarrolló un plan de mantenimiento centrado en la conservación del ladrillo, la piedra y el hierro ornamental. Por su parte, Carol Frenning, profesora de Arte y de Historia de la Arquitectura de la University of St. Thomas de St. Paul de Minnesota, fue seleccionada como consultora artística y ambiental en todo el proceso de restauración y conservación, ocupada en orientar a los directores del proyecto en la tarea de captar el espíritu del lugar. Asimismo, la firma artesana Fratelli Ruffatti (Padua-Italia) acometió los trabajos de renovación del órgano y la empresa de Michael Pilla (Wisconsin) gestionó la restauración de las vidrieras históricas. El objetivo de todo este equipo de expertos fue unir la belleza de la arquitectura a la liturgia de la Iglesia sin romper con el pasado ni con el carácter del templo, pero abriendo camino hacia el futuro y adecuándolo a una liturgia más funcional y próxima a los fieles. El espacio interior, antes mucho más austero y oscuro, se abrió a la luz y al empleo de nuevos materiales como una celebración de la salvación.

Entre las primeras actuaciones llevadas a cabo se constata la colocación de una fuente bautismal con agua que fluye y cae sobre una gran concha, tras la cual se encuentra una vidriera en donde se representa el tema del Bautismo de Cristo en el río Jordán. A esta le seguirán otras disposiciones: la colocación en la nave de grandes columnas coronadas con capiteles dorados que soportaban arcos clásicos; la limpieza y restauración de los vitrales compuestos por diferentes escenas de la vida de Cristo; el diseño de un gran rosetón con símbolos de María extraídos del Apocalipsis que representan en abstracto la idea de la inmaculada concepción de María; la colocación de un nuevo altar, un ambón y una cátedra para el obispo; la renovación del techo que se pinta en color azul profundo; la restauración y recolocación del órgano; la reforma del pavimento; y la construcción de un nuevo tabernáculo y capilla de reserva a la derecha del altar. En paralelo a estos cambios, se reforzó el eje que discurre desde la entrada a la parte trasera de la iglesia, haciendo converger el centro del nuevo rosetón y el del altar. Todos los elementos se colocaron de acuerdo a esta línea de visión y a sus perpendiculares, trabajando las formas desde el centro hacia la parte externa.

31 Esta Primera Instrucción General, de 26 de septiembre de 1964, fue publicada por la Sagrada Congregación de Ritos y el Consilium. Con posterioridad, la Comisión Litúrgica de la Conferencia Episcopal alemana emite en 1988 el documento titulado «Líneas guía para la construcción y adecuación de edificios litúrgicos», al igual que el episcopado irlandés que también publica en esta etapa dos documentos con nuevas normas en este sentido. Lo mismo hacen las Conferencias Episcopales de Italia, Inglaterra, Estados Unidos o Canadá. Para consultar toda esta documentación véase GHIRELLI, 2012: 179-254. 


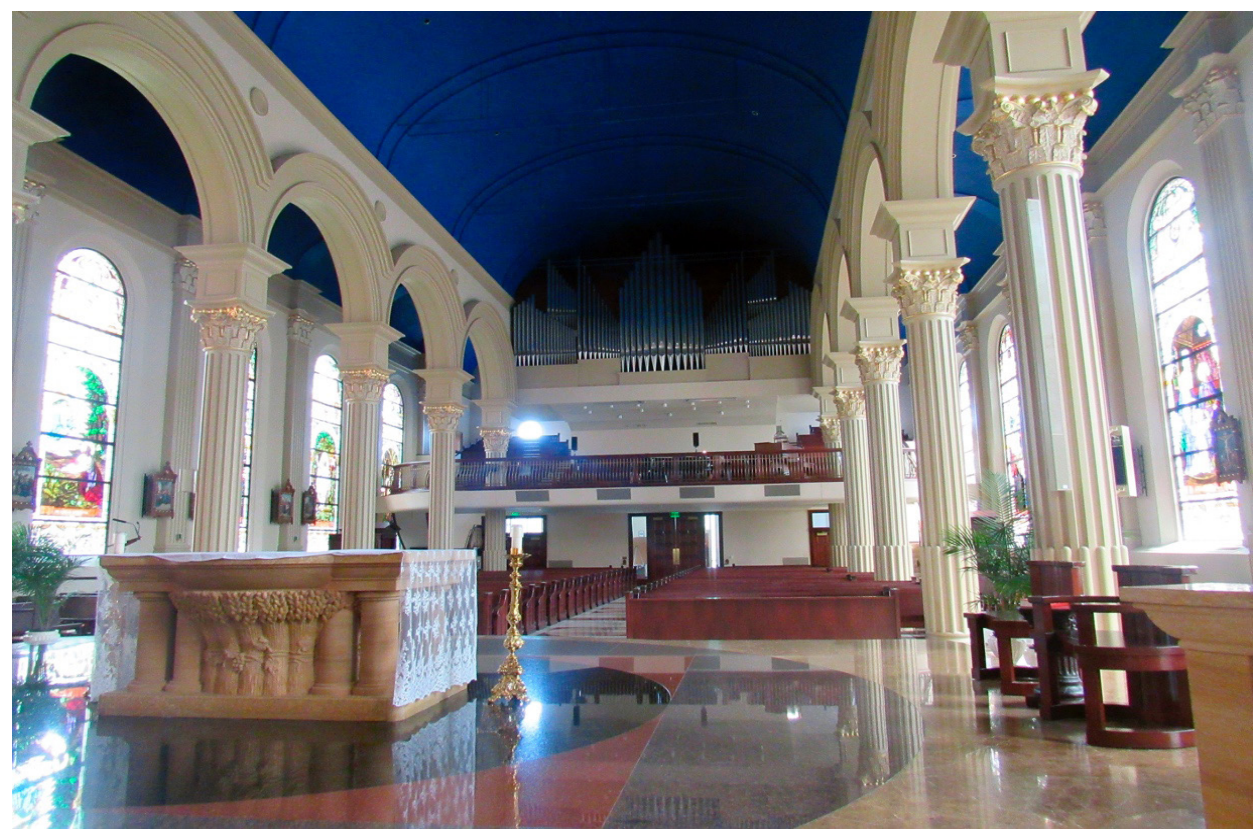

Figura 6. Vista del interior de la Catedral de Kansas City (2019). Fotografía de los autores.

El espacio de la nave resultó de gran amplitud y fue cubierto con una bóveda de cañón enlucida con pintura azul y estrellas en un intento de representar la bóveda celeste acorde a la visión del Apocalipsis (Fig. 6). En ella se colocaron luces empotradas para dar sensación de espacio vacío solo ocupado por la presencia de Dios, idea también reforzada por la secuencia continuada de vitrales en donde se representan escenas del Antiguo y Nuevo Testamento como parte de la estructura litúrgica del edificio. ${ }^{32}$ Las vidrieras y el nuevo rosetón que dominaba la pared sur iluminaron el espacio interior, proporcionando un $80 \%$ más de luz natural. Paralelamente, las oscuras y viejas ventanas que había en el exterior se reemplazaron por vidrios de seguridad transparentes. Al simbolismo de la luz se unió el de las formas cuadrangulares y circulares que invaden el pavimento marmóreo y dinamizan el interior dirigiéndonos hacia el altar a través del pasillo procesional. Los cuadrados representan la tierra, finita y limitada, mientras que los círculos simbolizan el cielo, el infinito. Caminando desde la puerta de entrada por el espacio de adoración se simboliza el encuentro de la tierra y el cielo. Por último, también se aumentó el protagonismo del coro al ser sustituido por otro nuevo, dispuesto a un nivel más bajo con la intención de aproximarlo a la congregación

32Al exterior estos vitrales aparecen separados por pilastras de ladrillo. El rítmico movimiento creado entre ambos elementos constituye una reminiscencia de la primera iglesia de ladrillo de 1857. 
siguiendo las indicaciones del Vaticano II y sus textos posteriores de aplicación. ${ }^{33}$

En el espacio ocupado por las naves laterales fueron dispuestas dos capillas enfrentadas. Una presidida por una escultura de María como Madre del Universo esculpida en cristal, que representa a una mujer madura multirracial envuelta en una mandorla de rayos gloriosos. La otra, decorada con la escena del Milagro de la Multiplicación de los Panes y los Peces, acoge al tabernáculo con el Sagrado Sacramento, cuyo pedestal está tallado con relieves alusivos a la vid y el trigo, que simbolizan la Eucaristía. La capilla de Pío x fue también intervenida al ser decorada con un viacrucis y amueblada con sillas móviles que combinaban con el acabado de los bancos delanteros.

\section{EL MODELO DE GESTIÓN DE LA CATEDRAL DE LA INMACULADA CONCEPCIÓN}

El modelo de gestión de la Catedral de la Inmaculada Concepción de Kansas City es un instrumento de suma importancia dada su repercusión en el día a día de la institución. En líneas generales, llama la atención el hecho de que apenas tiene en cuenta el desarrollo de la función cultural, a pesar de que este edificio es uno de los más antiguos y con mayor valor histórico-artístico y además está localizado en el barrio más céntrico de la ciudad, el Power and Light District. Mientras esta función es altamente significativa en otras catedrales americanas (Catedral de San Fernando en Texas, Catedral de San Patricio en New York, Catedral de San Luis en New Orleans, Catedral del Santo Nombre en Chicago, Catedral de la Santa Cruz en Boston...), en la mayor parte de las europeas, y en prácticamente todas las españolas, en donde se combina un alto capital cultural con una flexibilidad litúrgica; la de Kansas City, prioriza las tareas sociales/asistenciales, litúrgicas y administrativas, derivadas de su papel como sede de la diócesis. Una y otras responden a dos modelos totalmente diferentes que, en gran medida, derivan del perfil de las ciudades en donde se localizan estos monumentos y de su grado de turistización.

Los servicios de culto y de asistencia a los necesitados marcan la hoja de ruta de la Catedral de la Inmaculada, observándose un desequilibrio entre la programación de las actividades cultuales y las culturales. El programa cultural es muy reducido, quedando prácticamente limitado a la realización de unas jornadas musicales orientadas a los fieles. Las actividades sociales y litúrgicas tienen una importancia muy superior $y$, en consecuencia, requieren una mayor inversión económica y condicionan el modelo de gestión implementado por la institución (Tabla 2). En este sentido los gestores de la institución habrían de tener en cuenta que un incremento de la actividad cultural pudiera servir también como medio de sostén de la propia catedral y de sus actividades asistenciales.

33 Véase, Constitución Sacrosanctum Concilium sobre la Sagrada Liturgia, del Concilio Vaticano II, disponible en: http://www.vatican.va/archive/hist_councils/ii_vatican_council/documents/vat-ii_ const_19631204_sacrosanctum-concilium_sp.html, fecha de la última consulta: 12-04-2021; y Concilio Vaticano II. Constituciones. Decretos. Declaraciones. Documentos pontificios complementarios (1965), BAC, Madrid. 
TABLA 2

Características del modelo de gestión de la Catedral de Kansas City

\begin{tabular}{|c|c|}
\hline Actividades de culto & $\begin{array}{l}\text { Las actividades de culto ordinario se centran en la } \\
\text { celebración litúrgica. La catedral oficia una misa diaria } \\
\text { en la capilla de Pío x y dos durante el fin de semana en } \\
\text { el altar que preside la nave central. Los actos litúrgicos se } \\
\text { multiplican y solemnizan cuando se conmemora alguna } \\
\text { festividad extraordinaria. }\end{array}$ \\
\hline Actividades asistenciales y sociales & $\begin{array}{l}\text { Desde hace unos años está en marcha un programa, } \\
\text { Morning glory ministries, dirigido a personas sin hogar que } \\
\text { ofrece un servicio de comidas (comida caliente o lunch para } \\
\text { llevar) a un máximo de ciento cincuenta personas durante } \\
\text { seis días a la semana. De manera complementaria a este } \\
\text { programa se han implementado otros servicios regulares } \\
\text { de asistencia a la población necesitada del barrio: provisión } \\
\text { de ropa limpia y calzado, servicio de ducha e higiene } \\
\text { personal, provisión de productos básicos alimenticios y de } \\
\text { bonos de transporte, ayuda en cuestiones burocráticas y } \\
\text { traslados de enfermos al hospital. }\end{array}$ \\
\hline Actividades culturales & $\begin{array}{l}\text { El programa cultural anual se limita a la organización } \\
\text { de actividades musicales que, no obstante, se orienta } \\
\text { básicamente a los fieles. }\end{array}$ \\
\hline $\begin{array}{l}\text { Inversión/adquisición de obras } \\
\text { artísticas }\end{array}$ & $\begin{array}{l}\text { La inversión en obras de arte mueble es muy escasa. Desde } \\
\text { el momento de la última renovación (2003), la catedral } \\
\text { no ha adquirido obras artísticas y solo ha invertido en } \\
\text { la compra de objetos litúrgicos que se han considerado } \\
\text { necesarios. Tradicionalmente el medio más habitual para } \\
\text { la adquisición de piezas artísticas y para la financiación de } \\
\text { las reformas han sido las donaciones de afiliados. }\end{array}$ \\
\hline Número de visitantes/turistas & $\begin{array}{l}\text { La catedral recibe pocos visitantes no afiliados y mucho } \\
\text { menos visitantes de otros estados. Por esta razón solo } \\
\text { está abierta en horario de culto. No obstante, si algún } \\
\text { grupo muestra interés por visitarla, los administradores } \\
\text { facilitan el contacto de una persona que se encarga de } \\
\text { mostrarla al público interesado. Los visitantes también } \\
\text { pueden descargar a través de internet una pequeña guía } \\
\text { con información histórico-artística del edificio y realizar la } \\
\text { visita por su cuenta. }\end{array}$ \\
\hline Museo & $\begin{array}{l}\text { La catedral no tiene museo propio, ni siquiera un lugar } \\
\text { para custodiar el tesoro. Los ornamentos litúrgicos se } \\
\text { guardan en la sacristía y los pocos objetos de arte mueble } \\
\text { que pueden tener valor material y que son propiedad de } \\
\text { esta institución se encuentran expuestos en una vitrina en } \\
\text { el Centro Católico de Kansas City. }\end{array}$ \\
\hline $\begin{array}{l}\text { Personal encargado de los servicios } \\
\text { culturales y sociales }\end{array}$ & $\begin{array}{l}\text { En la catedral no existe la figura de gestor cultural y } \\
\text { cualquier actividad de este tipo es gestionada por el } \\
\text { personal administrativo de la institución. Los servicios } \\
\text { sociales/asistenciales están dirigidos por personal } \\
\text { especializado contratado que es apoyado por voluntarios. }\end{array}$ \\
\hline
\end{tabular}




\begin{tabular}{|l|l|}
\hline $\begin{array}{l}\text { Valoración de los servicios cultuales } \\
\text { y culturales por los fieles y los } \\
\text { ciudadanos }\end{array}$ & $\begin{array}{l}\text { Los servicios de culto son altamente apreciados por los } \\
\text { fieles de esta parroquia. No obstante, desde un punto } \\
\text { de vista cultural la catedral no es muy valorada ni por } \\
\text { los ciudadanos ni por los practicantes católicos, que la } \\
\text { consideran un mero contenedor de la función religiosa. } \\
\text { Estos últimos reconocen que tiene un valor estético, pero } \\
\text { no lo perciben como un canal que les aproxime al hecho } \\
\text { religioso, como sí sucede con la música. Este es uno de } \\
\text { los motivos por los que la institución no invierte en la } \\
\text { adquisición de obras artísticas, ni organiza visitas de } \\
\text { manera regular, ni tiene un museo propio. }\end{array}$ \\
\hline
\end{tabular}

Fuente: Elaboración propia.

La escasa importancia concedida a la función cultural no significa que no exista una gran preocupación por el mantenimiento del edificio, cuya preservación y conservación han constituido una prioridad a lo largo de toda su historia. Las obras realizadas, al igual que la mayor parte de las actividades emprendidas por la catedral, han sido financiadas en un elevado porcentaje por las donaciones de los afiliados católicos.

\section{CONCLUSIONES}

El estudio del comportamiento religioso en Estados Unidos y España nos remite a dos escenarios tradicionalmente muy distintos pero cuyas diferencias se han atenuado durante la última década. Esto se debe al aporte religioso derivado de la llegada de inmigrantes extranjeros que nos sitúa en un contexto global más diverso, en donde se percibe un crecimiento de las minorías religiosas. En Kansas City, no solo existe un número mayor de religiones, sino que, además, el patrimonio religioso recibe un tratamiento diferente. En el caso de la Iglesia católica nos encontramos con una menor inversión en obras artísticas, no tanto en lo referente al continente (inmuebles) sino sobre todo al contenido (bienes muebles). Este aspecto nos lleva a considerar que, por un lado, el patrimonio tiene un papel más secundario como medio de expresión de la devoción y, por otro, que en el interior de las iglesias la obra de arte se lee en clave litúrgica o devocional pero no en clave cultural. Por lo tanto, a pesar de la existencia de hábitos cultuales similares entre la Catedral de Kansas City y resto de catedrales católicas americanas y/o europeas, hay una gran divergencia entre las prácticas culturales. En la de Kansas, el culto y la labor social constituyen los elementos prioritarios que marcan la hoja de ruta de la gestión, mientras que en España la tendencia se dirige a la consecución de un equilibrio entre el uso cultual y cultural de estos monumentos.

Los canales por los que actualmente se accede a las obras de arte y a la oferta cultural religiosa determinan también el contraste entre ambos territorios. En España, el medio más usual para la adquisición de nuevas piezas es la compra por parte de la Iglesia, mientras que, en nuestro estudio de caso norteamericano, 
Kansas City, los donativos de los fieles constituyen la vía más frecuente para ello. Lo mismo sucede con el escenario en donde tiene lugar la exposición y aprecio de los bienes patrimoniales. En las ciudades españolas una gran parte del patrimonio religioso (bienes muebles e inmuebles) se aprecia in situ, en el lugar para el que fueron creados y, de hecho, se podría incluso entender que una catedral constituye un museo en sí mismo. ${ }^{34}$ Por el contrario, los habitantes de Kansas City aprecian la catedral en su papel de contenedor de servicios religiosos, pero no le otorgan un valor artístico, que sí conceden a las catedrales españolas. Esto es debido a que, en España, estos monumentos tienen una mayor riqueza que les viene dada tanto por la superposición de diferentes estilos artísticos que han dejado su huella en los edificios, como por el brillo que les confiere la pátina del tiempo, elemento que, por razones obvias de su juventud como país, los americanos todavía no poseen. Partiendo de estas premisas, es comprensible que los ciudadanos de Kansas City, tal y como nos han confirmado representantes eclesiásticos de las diócesis y gestores patrimoniales de la ciudad, conozcan mejor las catedrales europeas y españolas que la suya propia, a la que únicamente otorgan un valor cultual derivado de su papel evangelizador y apostólico.

En Kansas City, las piezas de arte religioso con mayor valor artístico se exhiben en los museos. No obstante, la mayoría son de origen externo y no se difunden como arte religioso sino como piezas de colecciones vinculadas a diferentes etapas y estilos artísticos. En este sentido, uno de los principales centros expositivos de la urbe, el Museo Nelson Atkins, considerado entre los más importantes de Estados Unidos, cuenta con un fondo de arte religioso de elevada categoría artística que incluye destacadas obras, muchas de ellas atribuidas a reputados maestros europeos.

Otro elemento a considerar son las intervenciones que la Catedral de la Inmaculada Concepción de Kansas City ha sufrido a lo largo de sus diferentes etapas, de acuerdo a las necesidades de la institución como sede de la diócesis y a las impuestas por la liturgia. Estas no han tenido repercusión en el modelo de gestión, en contraste con lo ocurrido en otras catedrales americanas y europeas en donde han contribuido a reforzar la función cultural, tratando de adaptarse a las nuevas exigencias contemporáneas y a las derivadas de sus contextos específicos. Así, catedrales de urbes españolas como Palma, Santiago de Compostela, León, Vitoria o Sevilla han optado por implementar planes de gestión que, priorizando el culto y la liturgia, tienen en cuenta el aumento experimentado por el turismo cultural para, de este modo, poder establecer un equilibrio entre las funciones cultuales y culturales. Este modelo reporta beneficios económicos que se traducen en un aporte de fondos para el mantenimiento de los propios monumentos en un país que, a diferencia de Estados Unidos, no cuenta con una cultura de mecenazgo.

El momento actual es clave para repensar el modelo de gestión implementado teniendo en cuenta la calidad del patrimonio y la incidencia del turismo. En Kansas

\footnotetext{
34 No obstante, y a pesar de esta apreciación tampoco se deben obviar circunstancias como la invasión napoleónica, el fenómeno desamortizador o la secularización, que tuvieron como como consecuencia que una gran cantidad de obras de tema religioso ubicadas originalmente en los templos fueran también a parar a los museos.
} 
City, las autoridades católicas y la administración pública han de considerar si quieren que la catedral se oriente también a un nuevo uso cultural y, en tal caso, tratar de incluirla dentro de las políticas de difusión del patrimonio urbano. La riqueza de su arquitectura facilita su inclusión, pero siendo conscientes de los impactos que puede provocar su localización en un área rehabilitada en pleno corazón de la ciudad y próxima al principal centro de convenciones. La catedral es uno de los edificios más emblemáticos del Power and Light District, el barrio de la ciudad más afectado por los procesos de recentralización y gentrificación (GONZÁLEZ-PÉREZ, 2021).

\section{REFERENCIAS}

Álvarez De MirAndA, B. (2005): «La religiosidad de los inmigrantes musulmanes: marroquíes en Madrid, turcos en Berlín y bengalíes en Londres», Panorama Social, 2: 129-143.

ANDRADE CAMPO, G.E. (2002): «Las nuevas tendencias religiosas a partir de la globalización», Revista de Ciencias Sociales, 8 (1): 62-74.

Brandt Marra, D.; Doering, C.M.; Beemont, B.R. (1992): This far by faith: A popular history of the catholic people of west and northwest Missouri, Wlasworth Publishing Company, Marceline.

BRENNAN, R.E.; RAMSEY, D. (1995): The religious art of E. Charlton Fortune: a chapter in the early history of the American liturgian revival, Archives of Modern Christian Art, College of Notre Dame, Belmont.

Carroll Spalding, C. (1858): Annals of the city of Kansas: embracing full details of the trade and commerce of the great western plains, together with statistics of the agricultural, mineral and commercial resources of the country west, south, and south-west, embracing western Missouri, Kansas, the Indian country, and New Mexico, Van Horn \& Abeel's printing house, Kansas City.

Colemam, M. (2014): Further by faith. Celebrating the art and architecture of the Diocese of Kansas City-St. Joseph, Diocese of Kansas City-St. Joseph, Kansas City.

Delgado Orusco, E. (1999): Arquitectura Sacra Española 1939-1975: De la Posguerra al Posconcilio, Departamento de Composición Arquitectónica, Escuela Técnica Superior de Arquitectura de Madrid, Tesis Doctoral, Universidad Politécnica de Madrid, Madrid.

Díez de Velasco, F. (2017): «Las minorías religiosas en España: un campo de investigación emergente», en F. MonTERo, J. DE LA Cueva y J. LouZAo (eds.), La historia religiosa de la España contemporánea: balance y perspectivas, Servicio de publicaciones de la Universidad de Alcalá, Alcalá de Henares: 299-316.

Domínguez Mujica, J.; González Pérez, J.M.; Parreño Castellano, J.M. (2011): «Tourism and Human Mobility in Spanish Archipiélagos», Annals of Tourism Research, 38 (2): 586-606. DOI: 10.1016/j.annals.2010.11.016.

Domínguez Mujica, J.; García Coll, A.; González Pérez, J.M.; SÁnchez Aguilera, D. (2008): «La population étrangère en Espagne: vuelques éléments d'une 
géographie changeante Sud-Ouest Européen», Revue Géographique des Pyrénées et du Sud-Ouest, 26: 71-88.

GHIReLli, T. (2012): Ierotopi Cristiani alla luce de la reforma liturgica del Concilio Vaticano II. Le chiese secondo el magistero, Librería Editrice Vaticana, Città del Vaticano.

GonZÁLez-PÉrez J.M. (2021): «Racial/Ethnic Segregation and Urban Inequality in Kansas City, Missouri: A Divided City», City \& Community. DOI:10.1177/1535684121990799.

Grenet, S. (2007): «Review of Prothero, Stephen, ed., A Nation of Religions: The Politics of Pluralism in Multireligious America», H-Nationalism, H-Net Reviews.

Herberg, W. (1960): Protestant-Catholic-Jew. An Essay in American Religious Sociology, Anchor Books, New York.

Huntington, S. P. (2004): Who Are We: The Challenges to America's National Identity, Simon \& Schuster, New York.

Kelly, K.A. (2003): History of the Diocese of Kansas City-Sant Joseph, Éditions du Signe, Strasbourg.

LaComba VÁzQuez, J. (2001): El islam inmigrado. Transformaciones y adaptaciones de las prácticas culturales y religiosas, Ministerio de Educación, Cultura y Deporte, Madrid.

LÓPez GARCíA, B. (2002): «El islam y la integración de la inmigración social», Cuadernos de Trabajo Social, 15: 129-143.

López Requena, F. (2015): Los mormones en España La Iglesia de Jesucristo de los Santos de los Últimos Días: Implantación, desarrollo en España y estudio comparativo con otros países europeos, Create Space Independent Publishing Platform, New York.

López Rodríguez, M. (1976): La España protestante. Crónica de una minoría marginada, Sedmay, Madrid.

LOSADA, T. (2003): «El islam en España pertenencias y dinámicas comunitarias. Del islam en Cataluña al islam de Cataluña», en M.A. Roque i Alonso, El islam plural, Icaria, Barcelona: 353-360.

Mijares Molina, L.; Ramírez Fernández, A. (2008): «La islamización de la inmigración: algunas hipótesis acerca del caso español», Quaderns de la Mediterrània, 9: 389-392.

Montero, F.; De la Cueva, J.; Louzao, J. (eds.) (2017): La historia religiosa de la España contemporánea: balance y perspectivas. Universidad de Alcalá, Servicio de Publicaciones, Alcalá de Henares.

Moreras, J. (2008): Musulmans a Catalunya. Radiografia d'un islam implantat, Institut Europeu de la Mediterrània, Barcelona.

Piqueras Haba, J. (2011): «El mundo en movimiento, migración internacional y globalización», Cuadernos de Geografía, 90: 187-210.

Prothero, S. (ed.) (2006): A Nation of Religions: The Politics of Pluralism in Multireligious America, Chapel Hill, University of North Carolina Press.

ROSÓN, J.; TARRÉS, S. (2013): «Inmigración, integración y comunidades musulmanas», en O. Orozco y G. Alonso (eds.), El Islam y los musulmanes 
hoy. Dimensión internacional y relaciones con España, Escuela Diplomática/Casa Árabe, Madrid: 249-263.

Salguero Montaño, O. (2014): Espacio público y privado en el contexto del pluralismo religioso: minorías religiosas en Granada y su área metropolitana, (Tesis doctoral), Universidad de Granada, Granada. http://hdl.handle.net/10481/31206m [Consulta: 10-08-2020].

Sánchez-Bayón, A.; Campos García de Quevedo, G.; Fuente Lafuente, C. (2017): «Historia cultural estadounidense desde el factor religioso: fallos de americaness y sus velos», Cauriensia: revista anual de Ciencias Eclesiásticas, 12: 627-659. DOI: 10.17398/1886-4945.12.627.

TArrés Chamorro, S.; Jiménez de Madariaga, C. (2012): «El pluralismo religioso en Andalucía», en C. Jiménez de Madariaga y J. Hurtado Sánchez (coords), Andalucía. Identidades culturales y dinámicas sociales, Aconcagua, Sevilla: 261286.

VAlENCIA RodRíGueZ, R. (2004): «Comunidades musulmanas en Andalucía: el Islam de la inmigración», en A. TORRES y R. VelAsco (coords), El Magreb hoy: estudios sobre historia, sociedad y cultura, Alfar, Sevilla: 97-126.

Woods, M. (2010): Cultivating Soil and Soul: Twentieth-Century Catholic Agrarians Embrace the Liturgical Movement, Pueblo Books, Liturgical Press, Collegeville. 


\title{
La imagen del Japón imperial a través de la prensa canaria: los inicios de la segunda guerra sino-japonesa
}

\author{
The Image of Imperial Japan in the Canarian Press: \\ The Beginning of the Second Sino-Japanese War
}

\author{
Ismael Rodríguez Marrero \\ Universidad de Las Palmas de Gran Canaria \\ https:// orcid.org/0000-0002-0517-817X \\ ismael.rodriguezmarrero@ulpgc.es
}

Recibido: 07/09/2020; Revisado: 12/01/2021; Aceptado: 11/03/2021

\begin{abstract}
Resumen
El estallido de la segunda guerra sino-japonesa supuso, junto con la Guerra Civil española, uno de los eventos bélicos preliminares de la Segunda Guerra Mundial. A raíz de ello, tanto España como Japón fueron generando una filia con respecto a Alemania e Italia y también una intensificación de las relaciones hispano-japonesas. Unas relaciones que proyectaron, entre otros elementos, un acercamiento propagandístico del que la prensa canaria no era ajena. Mediante el análisis de las principales cabeceras de Gran Canaria desde julio de 1937 hasta finales de 1938, este trabajo pretende ahondar en la conformación de la imagen del Japón imperial, así como la información de guerra proporcionada durante este conflicto.
\end{abstract}

Palabras clave: Propaganda, Japón, prensa canaria, relaciones hispano-japonesas, segunda guerra sino-japonesa.

\begin{abstract}
The outbreak of the Second Sino-Japanese War was, along with the Spanish Civil War, one of the preliminary military episodes of the Second World War. This led to both Spain and Japan cultivating a relationship with Germany and Italy, as well as an intensification of Spanish-Japanese relations. Amongst other elements, these relations began to display a propagandistic inflection which did not escape the attention of the Canarian press. By analysing the main headlines in Gran Canaria from July 1937 to the end of 1938, this work delves into the construction of Imperial Japan's image, as much as coverage of conflict during the course of the war.
\end{abstract}

Key words: Propaganda, Japan, Canarian Press, Spanish-Japanese Relations, Second Sino-Japanese War. 


\section{INTRODUCCIÓN ${ }^{1}$}

A diferencia de otros periodos históricos, la historia contemporánea se caracteriza, entre otros elementos, por el auge exponencial de fuentes susceptibles de ser compiladas y analizadas por los historiadores. Entre ellas se sitúa la prensa que, a pesar de que su origen se remonta a tiempos más pretéritos del que nos concierne en este trabajo, se erige con especial importancia a la hora de profundizar en aspectos como la opinión pública o en las diversas narrativas políticoideológicas con un afán proselitista, es decir, las intenciones propagandísticas. En efecto, el uso de la prensa como fuente histórica se ha venido dando desde el siglo XIX con una incipiente teorización sobre su uso a inicios del siglo XX después de la Primera Guerra Mundial. Mediante ella, podemos profundizar en la información u opinión pública de la época, así como también realizar un relato histórico sobre las ideologías o las mentalidades y su evolución tal como apunta Jean-Michel Desvors (1999: 69). Una afirmación que cobra sentido si se observa este tipo de fuente como un testigo directo que plasmaba, desde sus diversos prismas, los acontecimientos y procesos que se sucedían. A su vez, la prensa puede contemplarse como una ventana directa hacia el pasado dado que nos muestra a qué tipo de información estaban expuestas las masas del periodo que se quiera abordar. En este sentido y en lo concerniente a la tarea de investigación, la propia labor de la Historia o el Periodismo convergen en diversos puntos como la búsqueda de una veracidad factual respaldada por la aplicación de técnicas rigurosas y con la contrastación de múltiples fuentes.

La utilización de la fuente periodística por parte de los historiadores no difiere mucho de la actitud crítica y las técnicas de investigación aplicadas también al resto de fuentes. Así, la prensa es susceptible de someterse a las diversas técnicas cualitativas y cuantitativas cuya importancia es tal que, como remarca Julio ARÓstegui (2001: 406), «por sí misma constituye, incluso, un campo de estudio historiográfico preciso -historia de la prensa o del periodismo». Una historia que se diferencia, aunque se interrelaciona con ella, de la historia de la propaganda que posee un propio "corpus científico» bien delimitado a la vez que tiene un carácter específico. La propaganda como tal puede definirse como un proceso comunicativo que se subdivide en dos: la información y la persuasión. Este último se erige como objetivo primordial tanto en cuanto se intenta influenciar en la recepción de la información dada. Del mismo modo, el cariz poliédrico de la propaganda, en el que se incluyen los múltiples medios en los que esta se materializa, hace que imbuya diversos procesos de comunicación social. Por tanto, la propaganda es indisoluble del Estado emanando de esta simbiosis con la propaganda estatal o inherente también a la guerra dando lugar a la propaganda de guerra. Así, Alejandro Pizarroso (1999: 145-147) aduce que:

Si la propaganda es un fenómeno comunicativo polimórfico que impregna o al menos puede impregnar prácticamente todos los procesos de comunicación social,

1 Este trabajo ha sido posible gracias a la ayuda a la formación del personal investigador para la realización de tesis doctorales de la ACIISI y el Fondo Social Europeo. 
la Historia de la propaganda no sería otra cosa que la Historia de la Comunicación social ateniendo, eso sí, con particular interés al aspecto persuasivo.

Ciertamente, el elemento persuasivo como característica esencial se muestra con más obviedad en el campo de la propaganda de guerra. Y es que esta no se configura como un medio de entre tantos dirigido al exterior, sino que tiene una especial incidencia en la propia población civil y militar partícipes del conflicto. Ello se demuestra con la preeminencia del rol propagandístico de la Guerra Civil española que se solapa con la segunda guerra sino-japonesa y que, grosso modo, convergen en el desarrollo de ciertas narrativas ideológicas justificadoras de las acciones bélicas. Durante el comienzo de estos conflictos, Canarias, y más concretamente la provincia de Las Palmas que es el lugar que nos atañe, quedaba bajo el dominio del bando sublevado y no tardó en ser testigo de la gestación propagandística característica de los planteamientos franquistas en ámbitos como la imagen favorable del que fue el nuevo Estado en el ámbito internacional. Similitud que comparte con la captación de información externa, en este caso sobre la segunda guerra sino-japonesa, para plasmarla según unos designios ideológicos pautados. Todo ello enmarcado en la intensificación de contactos, sobre todo diplomáticos, entre el imperio del sol naciente y España a partir de 1937. En este sentido, el objetivo primordial de este trabajo es analizar la imagen del Japón imperialista de finales de la década de los treinta, concretamente durante los comienzos de la segunda guerra sino-japonesa (1937-1945), a través de la prensa canaria de la época, cuyos ejemplares comprenden desde julio de1 1937 hasta finales de 1938, desde este enfoque propagandístico-informativo.

\section{METODOLOGÍA Y ESTADO DE LA CUESTIÓN}

Este trabajo tiene como fuentes primarias la compilación y análisis de varios números de la cabecera Falange complementado con ejemplares de Acción y Amanecer: diario de la revolución nacional-sindicalista, desde julio de 1937 hasta diciembre de 1938, recogidos en el archivo digital Jable. ${ }^{2}$ El diario Falange nace de la ambición del Movimiento en «re-españolizar» Canarias el 7 de diciembre de 1936 tras el fallido intento de crear otro diario de corte fascista, Arriba. Por su parte, el diario Acción emergió el 17 de abril de 1935 siendo la voz en la prensa del partido católico Acción Popular. De igual forma, el diario Amanecer tuvo sus inicios en agosto de 1937 y se erigió como portavoz de las consigas de Falange en Tenerife. Su especialidad radicó en la prensa de guerra y en febrero de 1939 se disolvió para dar paso, junto al diario La Prensa, a El Día. Estos fueron los principales exponentes conservadores durante la Guerra Civil dado que las antiguas cabeceras conservadoras, La Provincia, Diario Las Palmas y Hoy fueron censuradas. La idoneidad, por tanto, de estas fuentes radica no solo en la imagen propagandística que pueden ofrecer, sino también en la información de guerra

2 Acceso en línea mediante el siguiente enlace: https://jable.ulpgc.es/ [Ejemplares última vez consultados en diciembre de 2020]. 
que en ellas quedó constatada. Por ende, siguiendo la consideración que pone de manifiesto Pizarroso Quintero (1999: 159) acerca de los diversos elementos que se deben estudiar dentro de la investigación histórica de la propaganda, este trabajo se centrará en el análisis del contenido de los mensajes en su deriva más propagandística, así como la contrastación de los elementos informativos que recogían la evolución de los comienzos de la agresión japonesa a China en 1937. Concretamente el marco cronológico que se atañe es entre julio de 1937 y finales de 1938 como se ha mencionado, siendo esta etapa uno de los momentos de mayor acercamiento entre Japón y España a la vez también del periodo de mayor expansión japonesa en China.

La teorización de la prensa y propaganda en perspectiva histórica, así como la utilización de esta como fuente para la investigación histórica ha sido estudiada por diversos autores como Aróstegui (2001), Dolores (1996), Hernández (2017) y Desvois (1999). Concretamente, la propaganda e información inserta en conflictos bélicos ha sido abordada por PIZARROso (1990; 1999; 2005) y PINEDA (2004) que trazan de manera somera el uso de la prensa como un medio para fines bélicos en los conflictos de la primera mitad del siglo xx. En el caso de España, la conexión entre el aparato propagandístico y de prensa queda bien retratado con los estudios de Sevillano (1998; 1999), Giménez (2015), Pulpillo (2014) o González (2012). Por su parte, uno de los autores que más ha trabajado el ámbito de las relaciones hispano-japonesas, así como la propaganda bélica que se intercambiaba entre estos dos países, es Florentino RodAo García (1993; 1995; 2004; 2013) que se complementa con las investigaciones de Moya (2019a; 2019b) o con las de CENTENO (2019; 2020) siendo este último el que ofrece un análisis de la industria fílmica japonesa durante el periodo de la guerra. Por su parte, PIKE (2008) o HotTA (2007; 2015) ahondan en un marco más general donde se desarrollaron las guerras en España y China mediante el estudio de los contactos internacionales de España con los países del Eje como es el caso de PIKE, o en el detenimiento en los elementos más ideológicos que subyacen a la pura praxis militarista japonesa como pone de relieve HoTTA.

\section{PRENSA Y PROPAGANDA DURANTE LOS INICIOS DEL ESTADO FRANQUISTA}

El estallido de la Guerra Civil española (1936-1939) propició diversos cambios en la futura conformación de la estructura estatal del país ibérico. Así, el primero de ellos en el bando sublevado se manifiesta en el surgimiento de una primigenia organización gubernativa que fue acuñada por Serrano Suñer como «Estado campamental» tras su llegada a Salamanca en febrero de 1937 (citado en PRESTON, 1994: 321-322). Una situación que cambió con la promulgación del Decreto de Unificación en abril de 1937, la reformulación del primer gobierno franquista en Burgos a principios de 1938 y la Ley de Prensa de abril de ese mismo año. Con estos pasos, se hizo evidente la aglutinación de la amalgama de fuerzas sociales que nutrían el joven Estado rebelde (falangistas, monárquicos alfonsinos, carlistas 
y tradicionalistas católicos) y que tuvo su proyección en el campo de la prensa y la propaganda (PIZARROso, 2005: 7).

Concretamente, las ideas que emanaban del preámbulo de la Ley de Prensa de 1938 dejaron claros sus designios ideológicos desde un primer momento. Es por ello por lo que los males del país se resarcirían con «devolver a España su rango de Nación unida, grande y libre, de los daños que una libertad entendida al estilo democrático había ocasionado» (BoE, Ley de Prensa de 22 de abril de 1938, preámbulo: 6938). En efecto, fueron las ideas de un nacionalismo de cariz tradicional junto con una clara posición antiliberal, antimarxista y antidemocrática las que vertebraron los discursos y narrativas en los diversos editoriales de prensa. Del mismo modo, y coincidiendo con la fascistización de los primeros años del Estado franquista de la mano de Falange, las pretensiones de crear una cultura totalitaria a través de la prensa se plasmaron también en esta nueva ley. Así, «siendo la Prensa órgano decisivo en la formación de la cultura popular y, sobre todo, en la creación de la conciencia colectiva, no podía admitirse que el periodismo continuara viviendo al margen del Estado» (BOE, Ley de Prensa de 22 de abril de 1938, preámbulo: 6938). Este proceso obtuvo su inspiración en el modelo propagandístico fascista italiano o de la Alemania nazi. Sin embargo, Francisco Sevillano Calero (1998: 89-90) pone de manifiesto el debate existente entre historiadores sobre la cuestión de la cultura o ideología propia del régimen. Mientras unos abogan por una incapacidad y desidia de los estados fascistas para generar una cultura propia, lo cierto es que las nuevas investigaciones evidencian que los diferentes regímenes se afanaban por la implementación de una auténtica cultura totalitaria en la sociedad en aras de la «nacionalización de las masas».

En el caso de las autoridades franquistas, estas destacaron por su voluntad de conformar una cultura oficial que diseminara la «recatolización» y «respañolización» asentadas en un marco teórico contrarrevolucionario. Esta discrepancia no parece ser marginal ya que son varios los autores que difieren en la carencia o multiplicidad de elementos ideológicos de los grupos franquistas y una difusa unión al respecto (GIMÉnEZ, 2015: 14). En este sentido, uno de los grupos con una innegable elaboración cultural e ideológica clara para su proyección a las masas se observa en Falange tal y como aducen Salvador GiNER y Eduardo SeVIlla (1975: 95). Sin embargo, las intenciones no siempre coinciden con la materialización de los hechos. Y es que la voluntad de Falange de crear de forma autónoma una movilización cultural de corte totalitario se vio truncada por dos factores: la férrea oposición de los actores conservadores y católicos que, a pesar de tener Falange una preeminencia en los resortes e instituciones propagandísticos, lograron difundir en la sociedad unos valores tradicionales de cariz religioso. El segundo factor viene dado por una desmovilización de la población, a causa de la posterior derrota de la guerra y la represión, caracterizada por la resignación y la pasividad con una fuerte influencia de los elementos socializadores de la Iglesia.

Asimismo, la violencia fue un elemento distintivo durante este proceso. Una violencia que también tuvo un rol protagónico en el auge de los movimientos fascistas europeos donde esta, más que ser un medio entre otros para alcanzar la conquista del poder político, se erigió como la impronta identitaria por 
antonomasia de tales ideologías (GentiLe, 2004: 21). Por su parte, la filiación militarista en la organización del aparato de prensa y propaganda franquista se dejó sentir cuando el 14 de enero de 1937 se creó la Delegación del Estado para la Prensa y Propaganda auspiciada por la Secretaría General del Estado con el general Millán Astray como delegado, que ejerció un dominio cuartelero de la organización. Junto a él, el comandante Arias Paz y el comandante Moreno Torres fueron designados también para este puesto tiempo después, aunque finalmente fue Serrano Suñer quien pasó a tomar posesión de este cargo en 1938 así como de la dirección de la Delegación de Prensa y Propaganda de FET y de las JONS (Pizarroso, 2005: 8). Ciertamente, una de las premisas inherentes de la Delegación era la de organizar los servicios informativos, así como sus contenidos con un cariz unificador para luchar contra la propaganda republicana y mostrar una legítima imagen del Estado franquista al exterior. Para ello, la centralización de todos los servicios bajo la nueva organización orquestada por Serrano Suñer se manifestaba como inexorable. La coordinación, el control de los canales informativos y la censura fueron las herramientas aplicadas para la búsqueda de una coherencia y supeditación para con las administraciones y organizaciones regionales o locales de prensa. La nueva organización del aparato propagandístico se caracterizaba por la notoria fuerza que iba cobrando Falange en él. (Pulpillo, 2014: 120-121). El escritor Dionisio Ridruejo fue uno de los principales artífices de esta nueva empresa. Stanley PAYNE (1984: 185) habla de su figura señalando que:

Se dedicó a montar un aparato de propaganda «totalitario» y los elementos más revolucionarios de la Falange ejerciendo casi un control absoluto sobre la información. El joven Dionisio fue calificado de «Goebbels español», comparación a todas luces excesiva, basada únicamente en la escasa estatura física de ambos. Ridruejo era el mejor orador del Partido después de José Antonio, y se esforzó en mantener el «estilo poético» del jefe desaparecido.

Del mismo modo, los mecanismos de violencia se palparon en este ámbito ya desde el decreto del 13 de septiembre de 1936 que permitió la incautación sumaria de los periódicos de izquierda, sobre todo por parte de Falange, y la aplicación de una censura militar. Algunos de los primeros rotativos notorios incautados fueron Arriba España de Pamplona, el periódico nacionalista vasco La Voz de Navarra o la creación del diario gran canario Falange, que es uno de los que nos compete en este trabajo, a causa del cierre forzoso del Diario de Las Palmas. En ellos destacaban «una abigarrada selección de simbología imperial» con un diseño de «extrema religiosidad» $\mathrm{y}$ «su lenguaje simbólico, cortado, imperial y poético, aspiraba a ser la norma literaria del falangismo» (GonZÁlez, 2012: 21). Pero estas no fueron las únicas características intrínsecas de la nueva prensa franquista. A la sazón de los afanes propagandísticos para crear una «cultura de guerra» ligada a una nueva "cultura política», los medios impresos quedarían impregnados de un discurso nacional-patriótico que pivotaba sobre tres elementos que se palpan en los discursos y mensajes empleados: la representación maniquea del enemigo republicano con categorizaciones ligadas al sesgo franquista, «rojos, anti-España, traidores extranjeros, marxistas y masones», la evocación de la figura carismática 
del Caudillo garante del Nuevo Orden y enarbolada con elementos y rituales religiosos, «Alzamiento Nacional o Cruzada», y la colectivización de la memoria mediante el culto a los caídos en la guerra (SEviLLANo, 2014: 235).

La consideración de estos factores no es baladí dado que la propaganda en los medios de comunicación era utilizada por el nuevo Estado como un arma de guerra más. Con ello, «para que los hombres sean capaces de afrontar el horror de la guerra debemos manipular sus emociones, sus sentimientos. Y eso es precisamente la propaganda» como recalca PizArroso (2005: 2). En este sentido, la propaganda de guerra estaría íntimamente ligada al concepto de la guerra psicológica, entendida esta como un tipo concreto de "propaganda orientado hacia el rival». Por ello, la propaganda de guerra se enmarcaría en un fenómeno comunicativo-persuasivo más amplio dirigido tanto al exterior como al interior. Del mismo modo, la piedra angular que vertebra y motiva al aparato propagandístico es el mantenimiento del poder. En efecto, el claro control estatal de los medios de comunicación con afán propagandístico evidencia este rasgo que se ve materializado en la desinformación, el falseamiento o la simple negligencia a la hora de transmitir un determinado mensaje (PINEDA, 2004: 822).

Por su parte, si la organización y los supuestos teóricos del aparato propagandístico franquista estaban bien definidos, no puede decirse lo mismo de su alcance y repercusión social. En este punto entraría en escena uno de los aspectos fundamentales que remarcaba Pizarroso (1999: 159) a la hora de investigar el fenómeno propagandístico en perspectiva histórica: su repercusión y calado en la opinión pública. Una problemática que se agudiza con el alejamiento del periodo histórico que se quiera abordar y se hace casi inevitable «basarnos en conjeturas». Por lo que, de nuevo a la luz de las propias palabras de Pizarroso (1999: 171), «es muy difícil, por no decir imposible en la mayoría de los casos, medir los efectos reales de la propaganda en cada momento histórico» sumado a que la opinión pública «se hace un concepto mucho más difuso, de imposible cuantificación». Esta tesitura se adhiere a la desconfianza existente hacia los medios informativos oficiales franquistas y el acudimiento a los medios de comunicación clandestinos por notorios grupos de la sociedad. Tanto el acceso como sus efectos fueron de carácter reducido, dándose una gran disparidad de los mensajes propagandísticos a raíz del sector poblacional que los recibía, su predisposición y «su propia experiencia cotidiana». Todo ello auspiciado bajo una capacidad informativa atrasada y una mala estructura, especialmente en la prensa (Sevillano, 1998: 166). El ámbito regional no distaba mucho de esta panorámica general. Así, por ejemplo, la población canaria para la década de los treinta y los cuarenta estaba más centrada en su propia supervivencia, dada la nefasta coyuntura económica que estaba experimentando, que en prestar atención a los avatares externos. Incluso, tal indiferencia se aumentaba cuando la prensa empezaba a virar hacia una alineación con el Eje a medida que se desarrollaba la Segunda Guerra Mundial. De la misma forma, la entrada clandestina de prensa ilegal se dejó notar en el archipiélago a la que se añadían las publicaciones antifranquistas de españoles exiliados, entre los que se encontraban autores isleños (DíAz, 2004: 1048-1049). 
Por su parte, el analfabetismo y las bajas tiradas jugaron un rol preeminente en lo concerniente al estudio de la opinión pública y la recepción propagandística. En lo referido a las tiradas, estas no estuvieron bajo un control oficial hasta la creación en 1964 de la Oficina de Justificación de la Difusión (OJD). Anterior a ella, el control y contabilización de las tiradas estaban bajo la actuación de cada empresa periodística que ofrecía datos difusos, mayormente con el número de tiradas incrementadas, motivado por el miedo de perjudicar su papel en el mercado publicitario y dar una cuestionable imagen hacia el lector (SEVILLANO, 1998: 183184). No obstante, la fiabilidad de las fuentes de la época que se encargaban de recopilar los datos relacionados con la opinión pública tiene que ser considerada. En efecto, la creación del Servicio Español de Auscultación de la Opinión Pública, integrada en la Delegación Nacional de Prensa, se encargó de realizar encuestas acordes a la concepción totalitaria de la información. La precisión de la información recabada adolecía de una respuesta que venía condicionada por el compromiso de algunas preguntas, su complejidad, un desconocimiento del tema por parte de los encuestados o la falta de preparación de las propias encuestas. Ello no disminuye el valor de este tipo de fuentes en su calidad de aproximación a una realidad que, claramente, debe ser contrastada (PIZARroso, 1990: 232-233).

Sin embargo, ciertos temas de la propaganda del nuevo Estado franquista habían tenido una aceptable proliferación y acogida. Es el caso de la narrativa que enarbolaba la figura carismática de Franco como garante y precursor del orden y la paz con unos claros valores del régimen, así como el trato y la inserción en la cotidianeidad de la población de asuntos de política exterior y relaciones diplomáticas entre España y diversos países (SEVILLANo, 1999: 158). Por ende, y como aduce Pablo Hernández (2017: 470), todos estos factores impulsan a los investigadores a tratar a la prensa como fuente para identificar y separar la información de la opinión para, a la sazón de estos, analizar el producto periodístico en sí como elemento propio de su contexto. En efecto, la aparición de nuevos medios de comunicación, entre los que se encuentra la prensa, propicia inexorablemente la adherencia, e incluso el desplazamiento tal como apunta Dolores SÁINZ (1996: 139), de las clásicas fuentes de información.

\section{PROPAGANDA Y RELACIONES HISPANO-JAPONESAS}

Mucho antes del estallido de la Guerra Civil española (1936-1939) o de la segunda guerra sino-japonesa (1937-1945), las relaciones e imágenes mutuas que se percibían desde ambos países ya se habían dejado notar. Fue el caso del resultado de la guerra ruso-japonesa (1904-1905) que tuvo repercusiones sobre el semblante nipón que se proyectó hacia España. En efecto, la inesperada y sorprendente victoria japonesa fue percibida desde una perspectiva política favorable dado que España en esos momentos se encasillaba como una potencia marginal dentro del orden internacional. Concretamente, la rápida modernización que experimentó el país del Sol Naciente, especialmente en el ámbito militar, obnubiló a militares y figuras españolas tal como es el caso de Luis Carrero Blanco o Ramón Serrano 
Suñer (RoDAO, 2004: 28). Cabe detenerse en la anecdótica admiración que sentía Millán Astray hacia la ideología adoctrinadora japonesa sobre el código de valores militares que se desarrolló desde finales del siglo XIX y principios del XX. La filia a este código de valores, el Bushidō, alcanzó tal importancia que el propio Millán Astray se inspiró en él para los valores militares que debía seguir la Legión. ${ }^{3}$ El escritor falangista Ernesto Giménez Caballero, uno de los desatacados colaboradores del aparato de prensa y propaganda franquista, recordaba como el fundador de la Legión le espetaba «Mientras no tengas ánimo de samurái, no me sirves» (GIMÉNEZ, 1979: 359).

El desencadenamiento del Incidente de Manchuria en 1931 provocó una tensión en las relaciones hispano-japonesas. La diplomacia de la España republicana se caracterizó durante estos acontecimientos por mostrar una actitud sancionadora en lo relativo a las acciones niponas. Este sentimiento se plasmó, del mismo modo, en la prensa española de la época que recogió una contraposición de opiniones acerca de los movimientos japoneses en China. Este evento, así como la imagen japonesa, quedó en un relativo olvido hasta que se produjo el ataque nipón sobre Shanghái en 1932 y el asesinato del primer ministro Inukai Tsuyosi el mismo año. Estos nuevos sucesos belicistas proyectaron una imagen negativa de Japón en el marco internacional de cariz autoritario y militarista que se agudizó con el abandono de la Sociedad de Naciones por parte del país asiático en 1933. No obstante, los lazos diplomáticos hispano-japoneses se siguieron manteniendo bajo cierta normalidad. En lo referido a imagen propagandística proyectada por los diarios españoles de estos años, ejemplos como el $A B C$ o la revista Blanco y Negro recogieron las acciones japonesas en Manchuria bajo una retórica de complacencia y admiración mientras que remarcaban una clara culpabilidad a China. En este sentido, la imagen forjada en los medios más conservadores años antes de la sublevación se conformaría como el sustrato del imaginario franquista que continuará con la misma línea en el alineamiento ideológico y propagandístico con respecto a Japón (Moya, 2019a: 122-123).

Consecuentemente, desde la década de los 30 del sigloxxlas relaciones hispanojaponesas se caracterizaban por una cierta fragilidad y cuyas orientaciones iban cambiando según los sucesos externos, especialmente con los conflictos bélicos. La España republicana no cortó abruptamente los contactos con Japón al iniciarse el conflicto civil, pero fue solo cuestión de tiempo que estos se vieran encorsetados hasta su finalización con el reconocimiento oficial del Gobierno japonés al Estado de Franco a finales de 1937. Así, por ejemplo, el lingüista José Luis Álvarez Taladriz, encargado de negocios en Tokio por el Gobierno republicano, nunca

3 A finales del siglo xIx, en medio de la vertiginosa modernización que experimentó Japón, comenzó la gestación teórica de la que fue una de las piedras angulares ideológicas dentro del militarismo japonés: el Bushidō (el camino del guerrero). Los valores que emanan de este código fueron discutidos y argumentados por diversos autores a la sazón de la evocación de una imagen mitificada y romántica de la antigua clase samurái. La obra por antonomasia en la que cristaliza esta ideología fue Bushidō. The Soul of Japan escrita por Inazō Nitobe y publicada en 1900. En esta monografía se destaca la proyección de los valores militares hacia el conjunto de la población japonesa. Para una mayor profundización en la construcción del Bushidō y su fuerte unión con el militarismo japonés ver BENESCH (2014); BOLITHO (1984); LÓPEZ-VERA (2016). 
llegó a ocupar su cargo dado el acoso que recibió por parte de agentes franquistas junto a la indiferencia de la policía japonesa a la hora de respaldar su legalidad (MOYA, 2019b: 157).

La intensificación de contactos entre Japón y España a partir de 1937 se vio imbuida por la proliferación de una imagen japonesa idealizada tal y como apunta Florentino RoDAO (1998: 436) que se resume en las siguientes características: la admiración por el progreso, especialmente militar, de Japón como se mencionó anteriormente, la comparación del país del Sol Naciente como una nación diferente y civilizada con respecto a sus vecinos asiáticos a los que se atribuía un semblante de «barbarie» e inferioridad, la similitud de guerras anticomunistas que se solaparon al mismo tiempo en los extremos del continente euroasiático y la inexistencia en España del miedo al «Peligro Amarillo». No obstante, estos contactos nunca se vieron materializados en una ayuda militar tangible de Japón a España como sí había ocurrido con Alemania o Italia durante la Guerra Civil. Estos se centraron más en el mantenimiento de unos lazos diplomáticos, la creación de una imagen propagandística favorable o la utilización de agentes para fines diplomáticos o de mediación en el marco de la guerra. Desde 1937 hasta la finalización de la Segunda Guerra Mundial, las relaciones hispano-japonesas se encauzaron por un valle de altibajos donde las acciones de cada país marcaron los enfriamientos o acercamientos a la sazón de la coyuntura internacional. El estallido de las guerras en España y en China propició, como se ha mencionado, uno de los acercamientos más notorios que cobró su máxima expresión en la firma del Pacto Antikomintern por parte de España en abril de 1939. El estallido del conflicto mundial unos meses después de la firma española de este pacto supuso, además de insuflar bríos renovados en las relaciones hispano-japonesas, un replanteamiento estratégico por parte de los firmantes anticomunistas dado que viraron su enemistad contra Moscú hacia los imperios europeos francés y británico cuya influencia colonial arribaba hasta los territorios asiáticos (RODAO, 2013: 1691).

Uno de los puntos de inflexión en las relaciones hispano-japonesas radicaba en la retórica de la ambición expansionista de ambos países. En efecto, la defensa de la creación de un Nuevo Orden en el marco internacional era un aspecto compartido por las naciones integrantes o con filiación hacia el Eje. Sin embargo, las discrepancias salieron a la luz a la hora de interpretar el imaginario de este Nuevo Orden. Las aspiraciones de Franco por conseguir una mayor preeminencia en el marco internacional bajo la sombra del expansionismo militar norteafricano, la idea de un imperio hispano o el «iberismo» quedaron retratadas en la prensa de la época (GARCía, 2018: 4).

Por su parte, el expansionismo japonés asentó su concepción en la confluencia de diversos elementos que convergieron en la denominada ideología «panasianista». Lejos de conformarse como un sustrato ideológico monolítico e inmutable, lo cierto es que el panasianismo se originó, junto a sus homólogos ideológicos del paneslavismo o panislamismo de finales del siglo XIX, bajo el halo de los derechos civiles del liberalismo internacionalista. Dada las múltiples transformaciones que sufrió, sería equívoco entender el panasianismo en categorizaciones simples. Para 
Eri HоттA (2007: 2) uno de los puntos vertebradores de la lógica panasianista fue la paradójica concepción de este como un «nacionalismo transnacional» que englobaba a todas las sociedades asiáticas dentro de un grupo homogéneo. Este imaginario ideológico evidenció tintes militaristas desde el incidente de Manchuria y la creación del Estado del Manchukuo como la primera nación emergida del panasianismo. A partir de entonces, una de las premisas que cobró más fuerza fue la de la liberación de las sociedades asiáticas del yugo imperialista occidental. Evidentemente, esta liberación tuvo como artífice principal al país nipón que se situó a la cabeza de la denominada «Esfera de Coprosperidad de la Gran Asia Oriental», término usado por vez primera por el ministro de Asuntos Exteriores, Matsuoka Yosuke, en agosto de 1940 (SATŌ, 1994: 6).

Esta nueva proyección no estaba exenta de un discurso racista que bebía de autores de corte supremacista como el filósofo Tanabe Hajime (1885-1962), ${ }^{4}$ de la Escuela de Kioto, que abogaba por una supremacía racial japonesa. Ya en 1932, el Estado de Manchukuo pivotaba sobre la denominada «armonía de las cinco razas» (gozoku kyōwa) en el que se agrupaban chinos, manchúes, mongoles, coreanos y japoneses, siendo estos últimos los que tuvieron que liderar el «Nuevo Orden de Asia Oriental» propagando la civilización y valores japoneses al continente (HоттA, 2007: 110). Precisamente, fue este rasgo racial un elemento preeminente en el desarrollo de la Guerra del Pacífico (1941-1945) que quedó retratado en la propaganda de guerra estadounidense y japonesa en aras de representar al enemigo como un ser infrahumano y legitimar así las acciones bélicas (DOWER, 1986: 73). Esta situación condicionó, entre otros factores, la alianza entre España y Japón que Florentino RODAO (2013: 1708) calificaba: «con expectativas brillantes, pero también con unas contradicciones importantes que socavaban el futuro a más largo plazo».

Por otra parte, y en lo concerniente a la materialización de estos lazos por las vías más diplomáticas o de espionaje, en septiembre de 1939 se instaló una red de espionaje en la embajada española en Londres financiada por Alemania y controlada en parte por el embajador japonés en Madrid, Suma Yakichiro. El objetivo primordial de esta red, llamada Tō (traducido literalmente como «puerta» o también «este» como punto cardinal), era conocer los movimientos de los convoyes marítimos aliados. Este espionaje cobró una nueva dimensión cuando Japón atacó Pearl Harbor en diciembre de 1941 dado que España se erigió como uno de los mejores candidatos para jugar el rol de mediador en las relaciones entre japoneses y estadounidenses. Con el abandono de la representación diplomática japonesa en Washington, España recibió 500.000 dólares para el mantenimiento y extensión de las operaciones Tō en el país norteamericano (PIKE, 2008: 71).

Los intereses japoneses en América venían marcados no solo por las misiones de espionaje, sino también por la gran cantidad de colonias niponas que estaban establecidas por el continente, especialmente en Perú, Brasil o Estados

4 Tanabe Hajime fue integrante, junto con Nishida Kitarō y Nishitani Keiji, de la Escuela de Kioto. Influenciado por el idealismo alemán al igual que el resto de los filósofos de esta escuela, Tanabe reflejó sus ideas supremacistas en su obra La lógica de la especie como dialéctica que bebe del sistema dialéctico hegeliano. Para profundizar ver Dilworth y TAIRA (1969). 
Unidos. Fue en la nación angloamericana donde España desempeñó un papel más notorio. La inclinación por el país ibérico para esta tarea vino condicionada por dos factores: una mejor capacidad técnica que se traducía en una amplia red diplomática y la alineación política marcada por la imagen propagandística de una amistad anticomunista. Fue esta última característica la más destacable por la cual giraban las relaciones hispano-japonesas y que se nutrían de las victorias que iba cosechando el Eje en los inicios de la guerra. Sin embargo, esta dinámica fue cambiando a medida que los Aliados comenzaron a contrarrestar el expansionismo nipón a partir de 1942 con la batalla de Midway como punto de inflexión. El cambio de tornas en lo militar tuvo sus repercusiones claras en las relaciones diplomáticas y en la imagen propagandística. Otros de los factores que agudizaron el declive de las relaciones fue la política de no agresión por parte del Gobierno de Tokio a la URSS cuando ya Alemania había comenzado a avanzar contra esta en julio de 1941. Incluso ante los ojos de los grupos fascistas más projaponeses esto resultó verdaderamente sorprendente a la vez que decepcionante.

A todo ello se le sumó el viraje español de la no beligerancia hacia nuevamente la neutralidad que fue pilotado bajo el nombramiento de Francisco Gómez-Jordana Sousa como nuevo ministro de Asuntos Exteriores en agosto de 1942. La prioridad por la neutralidad fue en detrimento de la actitud de acercamiento a Japón manifestado en la etapa de Serrano Suñer. Con ello, la actividad intermediadora en EE. UU se vio comprometida doblemente: por una parte, el Gobierno nipón se quejaba cada vez más de las ineficaces labores de supervisión y recopilación de información sobre las colonias niponas recluidas en los Centros de Realojamiento de Guerra y, por otra parte, el Gobierno español protestó ante el embajador Suma por el tratamiento de la colonia hispana en Filipinas. Por tanto, no es de extrañar que, dadas las condiciones, las relaciones hispano-japonesas fueran entrando en debacle. En este sentido, y a la sazón de que la guerra se decantaba hacia el bando aliado, cabe destacar el oportunismo del gobierno de Franco en aprovechar cualquier coyuntura para su supervivencia, máxime ello supusiera cortar los lazos de ayuda humanitaria que desempeñaban los diplomáticos y agentes españoles motivado, en parte, por la mala imagen propagandística que se difundía en la nación angloamericana (RoDAO, 1995: 187-188).

No obstante, durante y después de la Guerra Civil, la filiación que se tenía con Japón se veía multiplicada cuando se producían acercamientos con Italia y Alemania. Así, la prensa de 1940 cobra un evidente cariz beligerante dentro del marco de la no beligerancia española. La germanofilia y la mayor afluencia de noticias provenientes de agencias extranjeras del Eje se produjeron con la entrada de Italia en la guerra. Las agencias DNB y Transocean por parte de Alemania y la Stefani por parte de Italia eran las principales suministradoras de información en estos países. De hecho, los únicos corresponsables de prensa que poseía el Estado franquista para 1939 se hallaban en Roma y Berlín constatándose así la precariedad de medios de los que disponía el aparato de prensa y propaganda (GARCíA, 2018: 13). El Gabinete Diplomático de la Junta de Defensa Nacional, transformado en el Ministerio de Asuntos Exteriores en 1938, fue, desde el primer momento, el principal artífice en regular las oficinas de prensa franquistas en el exterior y en 
buscar apoyos ideológicos bajo las directrices de Franco (Moreno, 2008: 51).

Por su parte, los agregados de prensa en el extranjero informaban a la Sección de Prensa Extranjera del Ministerio de Exteriores sobre las dinámicas de prensa en el país que se situaban mediante recortes de prensa con especial mención a aquella información de cariz político y que aludiera a España. Del mismo modo, estos debían de tratar de influir en la prensa del país en el que se encontraran mediante la ayuda del Negociado de Agencias. En lo referido a los corresponsales extranjeros que llegaban a España, era la sección de Corresponsales, una de las secciones que conformaba la Delegación Nacional de Prensa de la Vicesecretaría de Educación Popular, la que se encargaba de controlar y documentar a los agregados de prensa extranjeros. Para el caso de Japón, las noticias provenientes de este país venían de la mano de la Agencia Dōmei con Kojima Ryoichi como director de esta y agregado en España (Moreno, 2008: 204).

Sin embargo, la prensa no fue el único medio al servicio de la guerra por el que fluía la propaganda totalitaria. La radio cobró un desarrollo e importancia sin precedentes en España, tal y como aduce Pizarroso (2005: 1), durante la Guerra Civil a pesar de estar por detrás de sus homólogos europeos. En efecto, la ventaja e innovación que suponía el hecho de que los mensajes se retransmitieran instantáneamente a los diversos frentes de batalla fue un aspecto crucial. Esta cualidad fue aprovechada por el bando sublevado para sus fines propagandísticos a la hora de retransmitir el seguimiento de la guerra tanto al interior como al exterior. Así, la radio jugó un rol protagónico en los inicios del levantamiento militar que fue retrasmitido por Radio Las Palmas, Radio Club Tenerife, Radio Tetuán o Radio Ceuta a las que se sumarían otras radios regionales del país a medida que avanzaba la contienda (PiZARroso, 2005: 10).

Pero, si hubo un medio prolífico y notorio a la hora de transmitir información este fue el cine. La captación y representación de la realidad mediante imágenes con una fuerte carga simbólica fue uno de los elementos esenciales en este potente medio de comunicación. Para la década de los treinta del siglo xx el noticiario documental se erigió como formato preferido en la producción cinematográfica dedicada al ámbito de la guerra. Precisamente, fue en el país nipón donde la elaboración de estos noticiarios cobró una importancia elevada y fueron confeccionados por los principales periódicos nacionales como Asahi Sekai Nyusu (Noticias del Mundo Asahi), Daimai Tōnichi Nyusu (Mainichi Osaka-Tokyo Noticias Diarias), Yomiuri Nyusu (Noticias Yomiuri) o la propia Agencia Dōmei que lanzó su noticiario Dōmei Nyusu (Noticias Dōmei) en 1936. ${ }^{5}$ Sea como fuere, tanto en los medios de comunicación escritos, radiofónicos y cinematográficos las narrativas propagandísticas quedarían supeditadas al desarrollo de la guerra y a la política exterior española con respecto a Japón que, como se mencionó anteriormente, dieron un giro irreversible a partir de 1942. Así, en palabras de Florentino RoDAO (2013: 6849):

Este segundo periodo de Jordana, en definitiva, ofrece el ejemplo más claro de

5 Para una mayor profundización en el desarrollo de la industria fílmica japonesa, especialmente de los noticiarios de guerra, y su llegada y cambio en el ámbito español ver CENTENO MARTín (2020). 
dualidad en la relación entre ambos países, porque frente a esa imagen amistosa ante el exterior, cada uno estaba dispuesto a traicionar al otro, si así convenía a sus intereses. La relación era esencialmente inestable porque comenzaba a considerarse que el otro no sólo era inútil para la consecución de sus objetivos, sino que incluso los obstaculizaba.

\section{LOS INICIOS DE LA SEGUNDA GUERRA SINO-JAPONESA A TRAVÉS DE LA PRENSA CANARIA: HERMANDAD ANTICOMUNISTA E INFORMACIÓN DE GUERRA}

En este apartado conviene exponer, previa y someramente, el desarrollo general de la segunda guerra sino-japonesa para tener un marco de referencia a la hora de profundizar en las siguientes cuestiones. Este conflicto puede dividirse en dos claros periodos. El primero de ellos, que es el que atañe a este trabajo, coincide con el momento de mayor expansión japonesa en China. Dio comienzo con el incidente del puente de Marco Polo en julio de 1937 y prosiguió hasta finales de 1938 cuando las conquistas niponas se estabilizaron. ${ }^{6}$ Respecto al segundo, este quedó inserto entre 1939 hasta 1945, cuando las fuerzas imperiales quedaron inmersas en un proceso de estancamiento marcado por avances y retrocesos constantes. Además de las principales ciudades y puertos de la costa oriental china, las conexiones ferroviarias de Tianjin-Pukou y Pekín-Wuhan eran también otros objetivos militares importantes. Durante la segunda mitad de 1937 fueron varios los enclaves y puntos que cayeron en manos japonesas como Shanghái, Nankín, la conexión Tianjin-Pukou, la provincia de Chahar, Shanxi y la zona baja de la región del Yangtzé. Con estas conquistas los japoneses albergaron la esperanza de realizar una campaña corta y, con ello, hacer claudicar a Chiang Kaishek lo antes posible. Lo cierto es que la realidad se truncó contra las expectativas de los mandatarios nipones y pronto se encontraron en la tesitura de hacer frente a vastas extensiones territoriales en el interior de China donde las tácticas de flanqueo y cercamiento resultaron inadecuadas para combatir a las tropas del Kuomintang. Pero si los japoneses se habían quedado sin ideas para forzar la rendición china, el Generalísimo tampoco sabía o era incapaz de idear nuevas formas para repeler la invasión. Sin embargo, con la toma de Wuhan y Cantón por parte de las fuerzas imperiales en la segunda mitad de 1938, y estableciendo con ello el límite de la expansión nipona, el repliegue chino hacia la provincia de Sichuan y el restablecimiento de la capital en Chongqing trajo consigo un nuevo replanteamiento estratégico para enfrentar a los invasores (DREA; VAN DE VEN, 2011: 30-35).

En efecto, la nueva fase del estancamiento japonés en lo referido a sus conquistas estuvo marcado por el acoso guerrillero de las tropas chinas en vez

6 Para la historiografía japonesa existe un debate en torno al concepto de la «Guerra del Pacífico» dado que este resalta el punto de partida del conflicto en Asia con el ataque japonés a Pearl Harbor en 1941, solapándose de este modo con la Segunda Guerra Mundial. El reconocimiento claro de la guerra en este escenario para los autores nipones comenzó con el incidente del puente de Marco Polo e, incluso, algunos sostienen que con la ocupación de Manchuria seis años antes. Véase HоттA (2007). 
de una confrontación directa. Este hostigamiento fue combatido por una nueva estrategia antiguerrillera promovida por el que fue el nuevo comandante del Ejército Expedicionario al norte de China en 1941, el general Okamura Yasuji. Con él se llevó a cabo la denominada política de «Los tres todos» que consistía en «matarlos a todos, quemarlo todo y saquearlo todo», o, en otras palabras, una política de contrainsurgencia basada en el terror. La inserción de Estados Unidos en el conflicto tras el ataque de Pearl Harbor en diciembre de 1941 condicionó las acciones japonesas en el teatro chino. Así, los preparativos nipones para la captura de Chongqing en septiembre de 1942 tuvieron que ser pospuestos ante el desembarco norteamericano en Guadalcanal. Del mismo modo, desde los inicios de la campaña en China los japoneses adolecían de serios problemas en torno a los recursos logísticos, de abastecimiento y un agotamiento extendido de las tropas. Algunos territorios fueron perdidos como el norte de Birmania, pero en general las fuerzas imperiales seguían manteniendo su presencia en los territorios donde se habían expandido inicialmente. En este sentido, la última gran ofensiva en China se llevó a cabo en abril de 1944 bajo la operación Ichigō que consistió en la destrucción de las bases aéreas estadounidense en China. Finalmente, el desalojo de los japoneses no llegaría hasta su definitiva derrota en agosto de 1945 (Drea; VAn De Ven, 2011: 39-45).

Retornando al ámbito de los medios de comunicación escritos, al igual que el resto de los periódicos regionales, la prensa canaria se inspiró en la proyección doctrinal editorial del que fue el verdadero vertebrador periodístico del Movimiento: el diario Arriba, siendo este el periódico español con mayor filiación hacia el Eje y, por ende, más pro-japonés (Sevillano, 1998: 179). Con ello, una de las más claras características de la prensa canaria a la hora de referenciar al país del Sol Naciente era su alineación propagandística. La gran admiración hacia la nación japonesa radicaba en los rasgos de su auge militar moderno, así como de su afán anticomunista:

El Japón comprendió lo que tenía que hacer. Empezó su Era nueva señalada por una transformación a lo occidental, y sabiendo que para ser respetados es preciso ser fuertes, se dedicaron, sobre todo, a aumentar el poder militar del país (...) Tenía muy cerca el ejemplo de China (...) Japón no quiso correr la misma suerte. Sus estudiantes frecuentaron las universidades europeas, sus técnicos conocieron nuestros secretos, y aquel pueblo unido y vibrante de patriotismo ideal, se convirtió en una gran potencia. Asombró al mundo en la guerra chinojaponesa, venció al Oso ruso en el Puerto Arthur y le hizo firmar una paz ventajosa (...) Seamos fuertes y empleemos, como Japón, la fuerza al servicio del bien. ${ }^{7}$

La mayoría de las imágenes favorables que se ofrece por parte de Japón en su vertiente más propagandística se producen a finales de 1937 coincidiendo con varios sucesos como la rápida expansión japonesa hacia el sur de China o el reconocimiento oficial de España por parte del país nipón. Precisamente, fue este reconocimiento uno de los eventos más destacados y adornados de una

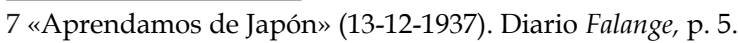


brillante estrategia en el ámbito internacional en la prensa canaria. En efecto, el reconocimiento oficial tenía como consigna retórica «la lucha a fondo, con calidades de operación quirúrgica, para extirpar al comunismo». ${ }^{8}$ Dado que «en Asia como en España se vive la hora de la verdad $»^{9}$ parecía inexorable que de las similitudes de guerras en ambos continentes se forjara una especie de hermandad anticomunista que cristalizó en «la cadena que los pueblos forman alrededor del mundo para salvarlo de la caída en el caos soviético». ${ }^{10}$ A este gran afán anticomunista se le suma «el más formidable triunfo de nuestra diplomacia» ${ }^{11}$ que consigue, además de sus victorias en ámbito militar, «Una victoria en lo internacional». ${ }^{12}$

Esta brillantez en las labores de la política exterior se reflejaba también en los anteriores reconocimientos por parte de otras naciones: «también Polonia y Yugoeslavia se disponen a mantener relaciones con la España Nacional» o «el gobierno húngaro considera a la España Nacional como la verdadera España». ${ }^{13}$ La enfatización de estas promulgaciones venía siguiendo la estela de la adhesión italiana al Pacto Antikomintern en noviembre de 1937. De este pacto se resaltaba que «no va contra ninguna potencia, sino que asume un sentido de defensa cultural». ${ }^{14}$ Los detalles del acuerdo se reducen a su razón de ser en la lucha contra el comunismo siendo más abundantes los elogios de Von Ribbentrop, el conde Ciano o el embajador Hotta sobre el pacto. Por su parte, la posible adhesión española al acuerdo se dejó entrever por la prensa aduciendo que «la España nacionalista y el Manchukuo firmarán su adhesión al Pacto Antikomintern el día veinticinco del actual mes de noviembre». ${ }^{15}$ Una información que el diario Falange recogió de los periódicos japoneses «Hasani Shimbun» (refiriéndose al diario Asahi Shimbun) y el «Nichinichi Shimbun» (correctamente el Tōkyō Nichi Nichi Shinbun) a través de la agencia Dōmei, creada justo en 1936 a la sazón de las intenciones gubernamentales centralizadoras de la información. Es común observar en la prensa insular diversos errores de traducción, sobre todo en las noticias internacionales que aludían a Japón o a China. El Tōkyō Nichi Nichi Shinbun era el diario más afín a las acciones del Eje.

Por su parte, la prensa japonesa recogió los acontecimientos de la Guerra Civil española con cierta negligencia en lo concerniente a la veracidad de la información $\mathrm{y}$, a menudo, a través de noticias de otros periódicos, especialmente de origen norteamericano. Ello provocó que en diversos diarios nipones se mostraran contradicciones e, incluso, una visión crítica respecto a la figura de Franco. En España, fue Sakai Yoneo uno de los principales corresponsales del periódico Asahi Shimbun el que recogió las principales noticias del país ibérico

8 «La cadena de los pueblos» (06-12-1937). Diario Falange, p.1.

9 Íd.

10 Íbid.

11 «Japón y la España Nacional» (22-11-1937). Diario Falange, p. 1.

12 Íd.

13 «España en el concierto de las Naciones» (20-11-1937). Diario Falange, p.1.

14 «El pacto germano-nipón contra el comunismo quedó ayer firmado por Italia» (07-11-1937). Diario Falange, p.1.

15 «España en el concierto de las Naciones» (20-11-1937). Diario Falange, p.1. 
(RoDAO, 1993: 139).

Sin embargo, lo que la prensa canaria no plasmó sobre estas victorias diplomáticas son las dificultades que encontró el Gobierno de Franco a la hora de ser reconocido por Japón. En efecto, el acercamiento oficial por parte de ambas naciones no estuvo exento de enfriamientos y enfrentamientos internos. Así, uno de los factores favorables para el reconocimiento de la España nacional fue la figura de Konoe Fumimaro, a mediados de 1937 primer ministro, que era más proclive al reconocimiento franquista junto con el apoyo de la facción del Ejército que tenía peso en el Gobierno nipón. En España, el reconocimiento por parte de Japón era visto con esperanzas de que le siguieran otras naciones como así se evidenció con orgullo en la prensa: «Ayer, reconocimiento por el Japón. Hoy, reconocimiento por el Manchukuo de nuestro Gobierno Nacional. Mañana, Holanda, que se apresta al reconocimiento», ${ }^{16}$ acompañada la noticia principalmente por felicitaciones y halagos sobre figuras como el ministro Hirota, el agregado de Negocios de la Legación española en Tokio Francisco José del Castillo o el propio Franco y el reconocimiento de la mediación italiana. A su vez, esta información se vería concatenada en los siguientes días con otras también en lo referente a las relaciones internacionales, como es el caso de la prohibición de la entrada en Japón de españoles con pasaporte republicano con el usual lenguaje propagandístico: «Mientras la España nacional se abre paso ante las demás naciones, se cierran las puertas a los rojos (...) los pasaportes visados por las autoridades rojas serán considerados nulos y los que los lleven no podrán pisar territorio japonés». ${ }^{17}$

Pero, fue del Castillo el que tuvo que mediar en las negociaciones para el reconocimiento de la España del Caudillo en solitario. Un reconocimiento que conoció detractores en el Gobierno japonés con figuras como el ministro de Asuntos Exteriores Hirota Kōki o los condes de Matsudaira y de Makino, ambos integrantes del Consejo Imperial. A mediados de septiembre de1937las intenciones del Castillo sufrieron una decepción dada la negativa inicial de Alemania e Italia para mediar entre la Legación española y el Gaimushō (Ministerio de Asuntos Exteriores). Una negación que estuvo inserta en un marco internacional delicado para Japón puesto que la guerra en China había ocasionado ciertos incidentes con el Gobierno británico, concretamente sobre el ametrallamiento del embajador británico en China por parte de la aviación japonesa que quedó saldado con una indemnización. Ello quedó retratado en la prensa: «Inglaterra acepta las excusas del Japón, quedando así zanjado el grave incidente». ${ }^{18}$ En la noticia se recoge también la intención japonesa respecto a los bombardeos que se sucedieron sobre Nankín en septiembre aduciendo que «Los japoneses no atacan a la población civil, ni se propone perjudicar los derechos de los súbditos a las terceras potencias», ${ }^{19}$ algo que no llegó a cumplirse.

Para finales de octubre, esta dinámica internacional pareció cambiar, así como

16 «Una victoria internacional por día» (02-12-1937). Diario Falange, p.1.

17 «A las tres de la tarde de ayer los japoneses entraron en Nankín» (11-12-1937). Diario Falange, p. 8. 18 «Inglaterra acepta las excusas del Japón» (23-09-1937). Diario Falange, p. 4.

19 Íd. 
los acontecimientos en China, a favor del reconocimiento franquista. Uno de los factores que propulsó este viraje fue la adhesión italiana al Pacto Antikomintern. Por su parte, Japón puso como condición que España reconociera al mismo tiempo al Estado del Manchukuo en aras de que otras naciones siguieran su ejemplo. Del mismo modo, la culminación de estos acercamientos iniciales se produjo con la integración española en el Pacto Antikomintern que en un primer momento el gobierno de Franco quería hacer secreta (RoDAO, 1993: 171-176). Quizá por ello no se ha encontrado constatación del reconocimiento del Manchukuo o de la unión al pacto por parte de España en la prensa canaria.

Unas semanas antes del conflicto en China, las pretensiones japonesas por construir un Nuevo Orden en Asia, con claros tintes panasianistas anteriormente retratadas, quedaron plasmadas en la prensa con el titular «Oriente exige su personalidad». ${ }^{20}$ En efecto, «El ministro-presidente japones Hiranuana [correctamente Hiranuma] ha exhortado al pueblo chino a liberarse de los influjos de las potencias occidentales disponiéndose a construir un nuevo orden en Asia Oriental de acuerdo con el Japón y el Manchukuo»». ${ }^{21}$ Asimismo, otro ejemplar recoge la reunión de organizaciones de juventudes asiáticas provenientes de la India, Siam, el Manchukuo, el norte de China y Mongolia para la adherencia del partido Antikomintern, aunque no se especifica el lugar y más detalles de los participantes o sus organizaciones. A su vez, esta noticia es seguida por otra que sostiene que «el Gobierno japonés no tolerará la intervención de extranjeros». ${ }^{22} \mathrm{Es}$ en este tipo de información donde la contradicción ideológica entre el Gobierno franquista y el japonés se pasa por alto no solo por la imagen estereotipada favorable sobre Japón, sino también por la propia dinámica interna de España donde las preocupaciones estaban más centradas en ganar la guerra que en tomarse la expansión colonial como una prioridad.

El estallido de la segunda guerra sino-japonesa fue recogido por la prensa insular bajo una retórica de tensiones diplomáticas en la que subyace como principal provocador el Gobierno chino. Por el contrario, «Las intenciones del Japón son las de actitud conciliadora, estando dispuesto a entablar negociaciones a base de la retirada de tropas». ${ }^{23}$ Del mismo modo, el incidente del puente de Marco Polo del 7 de julio de 1937, como evento iniciador del enfrentamiento, está ausente en las noticias internacionales de la prensa. La única mención que se tiene de este suceso se recoge en el diario Amanecer en noviembre de 1938 y se plasma bajo una clara retorica propagandística donde la culpabilidad del conflicto reside en China que, tras haberse dejado embaucar e influenciar por las acciones comunistas y judías, había forzado a Japón a entrar en la senda belicista. ${ }^{24}$ Los siguientes días al incidente, y a raíz de los enfrentamientos continuos, la actitud agresora japonesa, pero siempre justificada, se hizo más evidente: «El Japón y el

20 «Oriente exige su personalidad»(03-06-1937). Diario Falange, p.6.

21 Íd.

22 «Japón no tolera intervenciones en el conflicto chino-nipón» (04-11-1937). Diario Falange, p. 4.

23 «El grave conflicto chino-japonés sigue pendiente de solución» (22-07-1937). Diario Acción, p. 8.

24 «Orígenes de la guerra chino-japonesa. Intrigas del judaísmo y del bolchevismo contra el Japón» (23-11-1938). Diario Amanecer, p. 2. 
Mandshukuo [Manchukuo] marcharán unidos contra el comunismo en el deseo de hacer un lejano Oriente lleno de grandeza». ${ }^{25}$ Shanghái fue el primer punto estratégico en el expansionismo nipón. La fuerza naval japonesa en el delta del río Huangpu de esta ciudad estaba formada por la $3^{\text {a }}$ flota compuesta de la décima y undécima divisiones de barcos de combate, de los cuales la mayoría eran cañoneros fluviales seguidos por destructores, corbetas y cruceros protegidos, y reforzada con tres portaviones (LAI, 2017: 21). De la misma noticia se recoge que esta guarnición fue reforzada con «dos destructores». ${ }^{26}$ Con ello, «ante las constantes provocaciones de China, el Japón sigue teniendo fondeados barcos en las aguas de Shanghai». ${ }^{27}$

Una de las maniobras más ambiciosas a mediados de agosto por parte de Chiang Kai-shek era la de asestar un golpe sorpresa sobre la flota japonesa anclada en el puerto del citado río, con las miras fijadas en el crucero protegido japonés Izumo como objetivo principal. Ello no queda evidenciado en la prensa a pesar de las fatídicas consecuencias que tuvo debido a fallos por parte de la aviación china que bombardeó lugares concurridos de la ciudad como el camino de Nankín, el hotel Cathay o la Avenida Eduardo VII (MitTER, 2013: 112). Por otra parte, durante los combates de Shanghái para mediados de octubre se recogió la cifra de combatientes chinos «de un millón de soldados instruidos militarmente (...) En caso de ser necesaria una movilización en Kwangsi podrían reclutarse otros tres millones de hombres». ${ }^{28}$ Una cifra exagerada dado que para principios de noviembre el total de movilizados era de un máximo de medio millón de soldados de los que derivaron 187.000 bajas entre muertos y heridos (MitTeR, 2013: 121). De igual forma, el avance japonés se plasmó de una forma confiada y sobrada de fuerza tanto en el frente del norte de China como en Shanghái:

En el Norte las tropas japonesas después de una lenta y sabia preparación caen como torrentes sobre la región al Oeste de la antigua capital, encontrando tan sólo la resistencia de tropas mal pertrechadas y mal entrenadas para resistir al armamento modernísimo que los japoneses tienen en gran cantidad. No nos extrañaría que después de consolidadas las regiones ocupadas en el Norte por los japoneses, se parase [pasase] a la acción de las tropas desembarcadas cerca de Shanghai. ${ }^{29}$

En efecto, el posterior ataque anfibio del $10^{\circ}$ Ejército japonés en la bahía de Hangzhou el 5 de noviembre al sur de Shanghái contribuyó de manera decisiva a la inminente caída de la ciudad. Sin embargo, y a pesar del impecable y arrollador avance nipón expuesto en la prensa, para finales de octubre las bajas japonesas ascendieron a un total de 42.202 entre heridos y muertos (MITTER, 2013: 146). Para finales de noviembre y principios de diciembre la caída de Shanghái fue definitiva y, con ello, la acelerada llegada y conquista de Nankín en las dos primeras semanas de este último mismo mes. Durante este lapso el Grupo de

25 «El Japón no cede un paso» (10-07-1937). Diario Falange, p.8.

26 Íd.

27 «Los incidentes entre China y Japón» (15-07-1937). Diario Acción, p.1.

28 «Los japoneses concentran sus tropas para atacar Shanghái» Diario Falange, p.4.

29 «El plan japonés prevé la desintegración de China por el Norte» (02-10-1937). Diario Acción, p.4. 
Voluntarios Soviéticos, compuesto por pilotos de los cazas Polikarpov I-16, fue enviado en ayuda a China como consecuencia del pacto de no agresión firmado entre la URSS y el Gobierno republicano chino (LAI, 2017: 43). No hay constancias de la aparición de esta fuerza en la prensa canaria salvo su breve referencia en el diario Amanecer en la segunda quincena de diciembre que fue cuando los pilotos soviéticos intensificaron su presencia en las cercanías de Nankín al interceptar a la aviación nipona: «Pilotos yanquis y rusos al servicio de los chinos (...) cincuenta aparatos soviéticos con tripulaciones moscovitas han llegado a china tomando parte activa en los combates aéreos en la zona de guerra». ${ }^{30} \mathrm{La}$ única información acerca de los combates aéreos que se ofrece por parte de Falange, principal difusor de la propaganda franquista en Gran Canaria, para este periodo es muy vaga donde apunta que entre las zonas de Shanghái y Nankín se produjo «una gran actividad y los aviones japoneses volaron repetidas veces sobre el frente de combate». ${ }^{31}$

Lo que sí se recogió fue el acercamiento del ejército japonés a Nankín. Así, en los días anteriores a la capitulación definitiva de la capital china Japón mostró una imagen conciliadora con esperanzas de arribar a un cese del conflicto siempre que «el gobierno chino se decida a abandonar su actitud antijaponesa colaborando abierta y lealmente con Japón». ${ }^{32}$ Una actitud contraria a las ya definidas maniobras de las tropas imperiales que trazaron un plan de ataque simultaneo por varios puntos entre los que se encontraban el ataque naval por el río Yangtzé: «En el Yangtse han logrado los barcos de guerra romper la barrera del río avanzando hacia Nankin»». ${ }^{33}$ A los dos días siguientes ya la prensa proclamaba la ocupación efectiva, a pesar de que esta se produjo el 13 del mismo mes, bajo el titular «Japón ha plantado sus banderas en Nankin». ${ }^{34}$ Aunque no se expone el grado de avance dentro de la ciudad, sí se detalla el avance del desarrollo de las maniobras en el Yangtzé. Del mismo modo, en el ejemplar de Acción de ese mismo día se ensalza las acciones de la «gloriosa Marina japonesa ${ }^{35}$ en la captura de un barco chino o en la entrada de la ciudad con una información más matizada que la noticia de Falange: «continúa el brillante avance japonés, cuyas tropas se encuentran, no en el interior de Nankin como se ha querido decir, pero sí en los suburbios». ${ }^{36}$

Ciertamente, y en la línea de la inminente victoria, el día 10 se plasmaba en la prensa la simultaneidad del flanqueo de las maniobras militares, así como la euforia en Japón: «Las calles de Tokio están hirviendo de júbilo». ${ }^{37}$ En este caso, $\mathrm{y}$ al igual que las ausencias anteriormente aludidas de ciertos eventos, no se

\footnotetext{
30 «El gobierno de los Estados Unidos envió una nueva nota de protesta al Japón» (19-12-1937). Diario Amanecer, p.1.

31 «En Extremo Oriente hubo ayer gran actividad de la aviación japonesa» (24-11-1937). Diario Falange, p. 4.

32 «Los japoneses, a la vista de Nankin» (06-12-1937). Diario Falange, p. 5.

33 Íd.

34 «Japón ha plantado sus banderas en Nankin» (08-12-1937). Diario Falange, p5.

35 «Los japoneses han entrado en los suburdios [suburbios] de Nankin» (08-12-1937). Diario Acción, p.8.

36 Íd.

37 «Tokio, jubiloso, está esperando la caída de Nankín» (10-12-1937). Diario Acción, pp.1 y 5.
} 
encuentran ejemplares que ratifiquen la entrada definitiva de las tropas japonesas en la capital china. Por su parte, uno de los supuestos que se tenía casi por seguro por parte de los mandatarios nipones era que la campaña en China iba a ser breve, más aún con la posesión de los territorios más ricos y estratégicos del país para finales de 1937. Ello quedó también expuesto, bajo el confiado titular de «Toca a su fin el conflicto chino-japonés», cuando «las aseveraciones de los peritos militares ingleses y norteamericanos se ha comprobado que son falsas, puesto que el conflicto que se ha iniciado hace pocos meses ya toca a su fin». ${ }^{38}$ Como consecuencia de la batalla, se dieron a conocer las cifras de muertos y heridos de «ochocientos»y «cuatro mil» respectivamente por parte del bando japonés mientras que los chinos acumularon un total de «ochenta y cuatro mil muertos». ${ }^{39}$ Unas cifras poco exactas dado que los informes nipones tendían a disminuir e inflar los números en cuanto a bajas propias y enemigas respectivamente. Una cantidad aproximada más acertada sería la de 1.953 muertos y 4.994 heridos japoneses y entre 10.000 y 20.000 muertos chinos, aunque estas cifras son siempre objeto de debate entre autores al igual que la ocasionada en la «Masacre de Nankín» la cual está igualmente ausente en la prensa (YАмАмОто, 2000: 87-88).

En efecto, la única descripción de violencia reflejada en este medio de comunicación se hace en lo concerniente al combate militar de Nankín sin demasiados detalles: «la batalla trabada en las calles de la ex-capital china, era de gran intensidad (...) La toma de Nankín ha sido furiosa y violenta y particularmente intensa la actuación de la artillería y de la aviación». ${ }^{40}$ Incluso, días después de la toma de la capital china, se recoge una noticia favorable a la actuación japonesa en el conflicto. Al igual que ocurre con diversos ejemplares, las consignas propagandísticas se imponen a la realidad sobre la que se asientan y es que, ante la fatídica situación de China en alusión a la fractura interna entre nacionalistas y comunistas, se enfatiza que «El agregado militar japonés en esta capital [Peiping según se resalta en la información previa] ha declarado ante los representantes de la prensa extranjera, que el Japón, de acuerdo con su espíritu tradicionalmente caballeroso no intentará aprovecharse de la mala situación en China. El Japón espera - dijo el agregado militar - que China pueda sacudirse del grave peligro que le amenaza por parte del comunismo». ${ }^{41}$ Finalizado el primer año de campaña, a principios de enero de 1938 las dinámicas propagandísticas prosiguieron con su habitual dinámica en el seguimiento de los eventos de la toma de Nankín:

La maravillosa máquina de guerra, que es el ejército nipón está asombrando al mundo con la serie de victorias fulminantes, que han de culminar con la conquista y sujeción de ese gigante debilitado que es China (...) La «democracia», del mundo occidental emplea un truco ya gastado, para desacreditar al Imperio del Sol naciente. El Japón, dicen, es una nación imperialista, que para satisfacer desmesurados apetitos de grandeza ha declarado la guerra a China, desmembrada y pacífica (...)

38 «Toca a su fin el conflicto chino-japonés» (16-12-1937). Diario Acción, p.1.

39 «La guerra chino-japonesa» (30-12-1937). Diario Falange, p.5.

40 «A las tres de la tarde de ayer los japoneses entraron en Nankín» (11-12-1937). Diario Falange, p. 8. 41 «La revolución comunista en el noroeste de China» (17-12-1937). Diario Falange, p. 3. 
Nosotros comprendemos bien los afanes del pueblo nipón, sobrio y disciplinado, y entre la maraña de extraños nombres que nos llegan de la lejanía, vemos cómo va perfilándose nítidamente su triunfo, con la iniciación de una era de influencia japonesa en China; influencia pacificadora y benéfica, no amenazada por el fantasma soviético, definitivamente alejado y sin fuerza. Una obra magnífica que el mundo no comprende. Afortunadamente el Japón es un pueblo vigilante y consciente de su misión. Por eso acaba de conquistar Nankin. ${ }^{42}$

De la misma forma, a finales de este mismo mes se recogieron, favorablemente, las intenciones de los mandatarios nipones sobre el conflicto que conectan con la imagen expuesta por parte de la prensa isleña unas semanas antes. Así, «Hirota subrayó igualmente que Japón no tiene ambiciones territoriales en China y que tampoco anhela separar el Norte de China del resto de la nación, Luego ha expresado que todo lo que desea Japón es la unión chino-japonesa a fin de posibilitar mediante la colaboración chino-japonesa el bienestar y progreso de ambos pueblos». ${ }^{43}$ Igualmente, en la misma noticia se mostraron los futuros planes nipones en China dado que «las fuerzas japonesas, después de la ocupación de la región sur del río Yangtsé preparan otras acciones militares», ${ }^{44}$ aunque no se concreta cuáles. Habría que esperar a un ejemplar días después para conocer que estas acciones consistirían en la toma de la conexión ferroviaria Tianjin-Pukou, así como el aumento de efectivos para lo que parecía ser una prolongación de los enfrentamientos. Además, se resaltaba el inicio de las prácticas guerrilleras chinas. ${ }^{45}$ Ciertamente, desde el Cuartel General Imperial japonés, establecido en noviembre de 1937, se consideraba que el incremento de soldados, que a finales de 1937 sumaban un total de 600.000, era una necesidad imperiosa. Pero a este capital humano se le sumó también la necesidad de supeditar todos los sectores productivos de la economía nacional a los objetivos militares, algo que se expuso igualmente en la prensa. ${ }^{46}$

Paralelamente a la campaña contra el Kuomintang, los eventos relacionados con los choques fronterizos entre Japón y la Unión Soviética fueron el segundo fenómeno bélico más remarcable de 1938, conocido este como el incidente de Changkufeng. Antes de que estallara la principal batalla a la sazón de esta dinámica entre el 29 de julio y el 11 de agosto, esto es la batalla del lago Jasan, ya la prensa en mayo remarcaba la preeminencia de estas dos potencias en torno a la región de Manchuria. Concretamente, el ejemplar mostraba una narrativa propagandística que hundía su discurso en la confrontación fronteriza de estos dos países en perspectiva histórica, especialmente a partir de finales del siglo XIX. Una vez más, la admiración por Japón, justificando sus acciones militares entre sutilezas retóricas y evidentes declaraciones, se erigía como la consigna principal del relato donde el país nipón era el único «baluarte anticomunista en Oriente»

42 «Para la comprensión del conflicto chino-japonés» (14-01-1938). Diario Falange, p. 3.

43 «Ante la Cámara japonesa los gobernantes de Tokio dan cuenta al país que todo su interés está concentrado en salvaguardar la futura paz de Extremo Oriente» (22-01-1938). Diario Falange, p. 8. 44 Íd.

45 «La guerra chino-japonesa» (28-01-1938). Diario Falange, p. 5.

46 Íd. 
con la misión casi determinista de detener «la sovietización de China». ${ }^{47}$ En efecto, la razón de ser de las injerencias rusas en las fronteras chinas quedan supeditadas a sus consignas ideológicas remarcando una complacencia, por tanto, en la loable expansión japonesa en esta región que, entre tantos logros, consiguió «la independencia de Manchuria, que tomó el nombre de Manchu-kuo»». ${ }^{48}$

En lo concerniente a la cobertura informativa de este incidente, habría que esperar hasta el 2 de agosto cuando el diario Acción publicó un número donde puso de relieve las perspectivas soviéticas y japonesas sobre el inicio del choque. A saber, desde las fuentes japonesas se manifestó que la ocupación de la zona se debió por una invasión previa de las tropas rusas, mientras que desde Moscú se desmintió tal información arguyendo que habían sido los contingentes nipones los que habían violado la frontera al ocupar Changkufeng. ${ }^{49}$ Dos días más tarde, y con los combates en auge, el mismo diario plasmó la intención de Japón por resolver el conflicto vía diplomática junto con las protestas del Gobierno japonés a Moscú. Asimismo, los únicos datos de la pugna que se ofrecen se relaciona con una ofensiva soviética del día anterior en el que «atacaron cuatro batallones de infantería soviética, protegidos por 30 tanques, 25 cañones y otro material a las posiciones japonesas de Chaotsopri que se encuentra al norte de ChangkuFeng». ${ }^{50}$ Ciertamente, fue en este incidente cuando el Ejército Rojo probaría por vez primera, junto con el escenario de la Guerra Civil española, un uso intensivo de tanques y aviones de combate. Esta intensificación se recoge también un ejemplar de Amanecer, aunque, al igual que su homologo periodístico, no se ofrecen muchos detalles de las maniobras militares. ${ }^{51}$

Sin embargo, lo que no se recogió en la prensa es que tanto la actuación de la aviación como de las divisiones de tanques dejaron mucho que desear principalmente por una falta de preparación y descoordinación además de las dificultades que presentaba el terreno para el despliegue y acción de los tanques. De hecho, la ofensiva rusa del 2 de agosto careció de un total apoyo aéreo (HiLl, 2017: 87-88). Así pues, y encarando la recta final del conflicto, la prensa ponía de manifiesto la intencionalidad japonesa centrada en cesar los combates fronterizos además de continuar con la inexactitud de los datos de combate: «Japón no está dispuesto a mantener con los Soviets conversaciones de carácter discontinuo (...) con la misión de solventar las cuestiones territoriales de la frontera del Mandchukuo [Manchukuo]. La Agencia Domei dice que detrás del frente ruso se ha concentrado numerosos tanques. La línea fronteriza continúa amenazada por la aviación soviética». ${ }^{52}$ Aunque el fin de las hostilidades entre Japón y Rusia finalizaron con un Alto el fuego el 11 de agosto, las tensiones y escaramuzas se siguieron manteniendo, un aspecto que se refleja en los diarios gran canarios, ${ }^{53}$

47 «El conflicto chino-japonés. Rusia y Japón ante China» (12-05-1938). Diario Acción, p. 3 48 Íd.

49 «La pregunta inquietante: ¿Habrá guerra ruso-japonesa?» (02-08-1938). Diario Acción, p. 8.

50 «El pacifismo de Japón y la persistencia de los conflictos ruso-manchukuos» (04-08-1938). Diario Acción, p. 8.

51 «La situación del conflicto nipón-soviético» (10-08-1938). Diario Amanecer, p. 1.

52 «Stalin no se fía ni del mariscal Voroschiloff» (10-08-1938). Diario Falange, p. 5

53 «Rusia viola el convenio de suspensión de hostilidades con Japón» (17-08-1938). Diario Acción, p. 8. 
hasta que estas culminaron de nuevo con el incidente de Nomonhan al año siguiente.

Volviendo de nuevo al desarrollo de la campaña en China, en la cobertura periodística de las maniobras niponas hacia el centro y sur del continente destacaron las capturas de Hankou, Cantón o Wuhan, puntos que previamente habían sido bombardeados. La ciudad de Wuhan, conectada con las ciudades de Hankou y Wuchang, fue uno de los puntos más importantes en la recta final de las conquistas japonesas donde se apostaron un millón de soldados chinos. No obstante, nada se mencionó sobre su captura o sobre los combates entre las fuerzas imperiales y los defensores liderados por Chiang Kai-shek. La única información de relevancia al respecto viene dada por los bombardeos que la aviación japonesa realizó en dichas ciudades. ${ }^{54}$ Asimismo, tampoco se aluden muchos detalles del ataque anfibio japonés en la captura de Cantón más allá de que el desembarco no encontró una gran resistencia..$^{55}$ Otras informaciones que se plasmaron en este escenario fueron los esfuerzos japoneses por «limpiar las regiones ocupadas de los restos de las tropas chinas y de los guerrilleros chinos», ${ }^{56}$ o lo que es lo mismo la aplicación de la política de contrainsurgencia ideada por Okamura, la retirada de las tropas chinas de Wuhan o la certeza casi completa, y con unas claras consignas propagandísticas, de que con la caída de estas últimas ciudades Japón cruzaría definitivamente el umbral de la victoria acompañada de la finalización del conflicto. ${ }^{57}$

Las noticias relevantes que se expusieron a finales de 1938 estuvieron marcadas por una clara narrativa propagandística en torno a eventos de política exterior. En efecto, los aniversarios del Pacto Antikomintern o del reconocimiento oficial de la España franquista por parte de Japón fueron los sucesos más reseñados. Continuando con la lógica de alineamiento ideológico, lo cierto es que la tónica de estos artículos no difirió en exceso con respecto a los que se mostraron primeramente en este apartado en torno a los eventos diplomáticos. En este sentido, el único valor que reside en la información dada viene por la consigna complaciente que se dejó entrever con respecto a Japón. Una vez más el sentimiento anticomunista se erigió como eje vertebrador de los discursos planteados: «Combatiendo el peligro comunista Japón ha dado el primer paso para realizar su gran ideal que consiste en crear en Extremo Oriente un orden nuevo». ${ }^{58}$ Por su parte, los elogios del reconocimiento a la España de Franco estuvieron imbuidos casi por una mística espiritual, donde Japón y España, contra todo pronóstico, estaban destinados al entendimiento gracias a su hermandad

\footnotetext{
54 «100 aviones japoneses bombardearon ayer trece posiciones chinas de la provincia de Wuhan, sobre las que arrojaron más de dos mil bombas» (12-08-1938). Diario Falange, p. 2. Como se mencionó anteriormente, la prensa solía cometer errores de transcripción de nombres además de ofrecer una información inexacta de los datos que en ella se recogían. En este caso, el error viene dado por calificar a Wuhan como provincia cuando esta era una de las ciudades principales de la provincia de Hubei.

55 «Japón opera a fondo en el sur de China» (13-10-1938). Diario Falange, p. 5.

56 «Rasgos de la próxima campaña japonesa en China» (28-10-1938). Diario Falange, p. 5.

57 «Rusia morirá por asfixia, cerrada por Oriente y Occidente» (26-10-1938). Diario Acción, p. 1. 58 «Hoy, segundo aniversario del pacto anti-Komintern» (25-11-1938). Diario Falange, p. 1.
} 
anticomunista. ${ }^{59}$

Finalmente, el año se cerraría con las intenciones por parte del país nipón de establecer una paz en China. Unas intenciones que se dejaron sentir en la prensa y que fueron adornadas por la loable predisposición japonesa en proponer a China unas condiciones justas. Ciertamente eran justas, a la par que beneficiosas, para el propio Japón, dado que estas consistieron en «el reconocimiento del Manchukuo, la adhesión al Pacto Antikomintern y la libertad de residencia y comercio para los japoneses». ${ }^{60}$ En el ejemplar del día siguiente se resaltó el rechazo del Gobierno chino para negociar una paz enfatizando su predisposición de dejarse embaucar por las presiones soviéticas. ${ }^{61}$ Lo cierto es que la guerra en China estaba convirtiéndose en una auténtica sangría para Japón en muchos aspectos. El volcamiento de todos los recursos del país a la campaña o la militarización de la vida de la sociedad nipona, con un exponencial aumento del reclutamiento o los paupérrimos productos alimenticios que los civiles optaban por medio del racionamiento, son un claro ejemplo de la fatiga que suponía alargar la guerra. La figura del primer ministro japonés, Konoe Fumimaro, fue esencial para el deterioro de esta situación. Siguiendo las premisas de HоттA (2015: 66-67), la política exterior ejercida por Konoe se caracterizó por ser ambigua para con sus intenciones. El primer ministro reconoció el compromiso que suponía mantener una prolongada campaña militar, pero sus acciones derivaron en apoyar más a la facción dura de los militares japoneses, de entre los cuales se encontraban miembros del fallido golpe de estado de 1936, a la par que mantenía una imagen propagandística favorable y exitosa sobre las acciones militares hacia la población japonesa. En su figura política, tal y como sostiene Hotta, se conjugaron el autoengaño y la ineptitud ocasionando así un agravamiento irreparable del conflicto con China.

\section{CONCLUSIONES}

Los enfrentamientos bélicos de las primeras décadas del siglo xx supusieron, entre otros elementos, un uso intensivo de los medios de comunicación por parte de los beligerantes cuyo principal objetivo reside en su carácter más propagandístico. En este sentido, es este carácter propagandístico el que se impone en numerosas ocasiones a la veracidad factual cuyo elemento más informativo se plasma según el prisma pertinente. En este caso, tal como se ha retratado, las relaciones hispanojaponesas de la década de los treinta y los cuarenta estuvieron auspiciadas más por el halo propagandístico y simbólico que por la concreción de una colaboración más tangible salvo en su aspecto más diplomático.

La simultaneidad de guerras en China y en España constituye uno de los momentos álgidos en la idealización de la imagen japonesa a la sazón de sus

59 «I aniversario del reconocimiento del Gobierno de España por el Japón» (01-12-1938). Diario Falange, p. 8

60 «Japón ofrece a China unas condiciones dignas de paz» (23-12-1938). Diario Falange, p. 2

61 «China, al repudiar las generosas proposiciones japonesas deja entrever sus concomitancias con la Rusia soviética» (24-12-1938). Diario Falange, p. 1. 
atributos anticomunistas y nación moderna susceptible de ser imitada. Todo ello quedó bien recogido en la prensa canaria durante los primeros meses de la agresión japonesa a China en 1937 cuando el seguimiento de los eventos bélicos entró en simbiosis con la forja de esta imagen. No obstante, la cobertura de los sucesos del conflicto se caracterizó por ser irregular, explicada en parte por las limitaciones propias de las agencias de prensa españolas que se servían de informaciones dadas por terceros. Una irregularidad palpable no solo en la concreción y matización de la información dada, sino también en la falta de un seguimiento diario o en la ausencia de eventos trascendentes de la segunda guerra sino-japonesa como el incidente del puente de Marco Polo, en este caso tratado muy superficialmente, el fallido ataque chino al crucero Izumo o la masacre indiscriminada que se sucedió en Nankín durante las primeras semanas de su ocupación por parte del Ejército imperial. Esta dinámica no era exclusiva para con las noticias provenientes de Asia, sino que se extendió también al resto de informaciones que se ofrecían como las concernientes a la Segunda Guerra Mundial. Más que informar, la prensa se erigió para proyectar una serie de consignas y generar así una opinión pública favorable respecto al régimen de Franco. En suma, con este trabajo hemos querido poner de relieve la faceta propagandística e informativa de la prensa canaria acerca de la actuación bélica japonesa en los inicios de su agresión a China, así como su uso como mediador favorable en las relaciones hispano-japonesas. Esta última característica puede ser contrastada también con los estudios que se han venido dando desde un ámbito más estatal e inserto en las relaciones más puramente diplomáticas. Por ende, este estudio nos permite ratificar la continuación de un acercamiento ideológico y de política exterior del gobierno franquista con respecto a Japón en los primeros momentos del conflicto en Asia.

\section{HEMEROGRAFÍA}

Diario Acción (de julio de 1937 a octubre de 1938).

Diario Amanecer (de diciembre de 1937 a agosto de 1938).

Diario Falange (de julio de 1937 a diciembre de 1938).

\section{REFERENCIAS}

Aróstegui Sánchez, J. (2001): La investigación histórica: teoría y método, Editorial Crítica, Barcelona.

BENESCH, O. (2014): Inventing the Way of the Samurai. Nationalism, Internationalism, and Bushidō in Modern Japan, Oxford University Press, New York.

Bolitho, H. (1984): «The Myth of the Samurai», en A. Rix y R. Mouer (eds.) Japan's Impact on the World, , Japanese Studies Association of Australia, Nathan: 2-8.

Centeno Martín, M.P. (2019): «Comunicación visual de conflictos: imágenes de la Masacre de Nankín», en A.I. Arévalo Salinas, G. Vilar Sastre, T. Al NajJar TrujILlo (eds.), Comunicación, paz y conflictos, Dykinson, Madrid: 103-113. 
Centeno Martín, M.P. (2020): «Reeditando la guerra en Asia. Noticiarios japoneses en España (1931-1945)», L'Atlante Revista de estudios cinematográficos 1: 101119.

Desvois, J.-M. (1999): «Manuel Tuñón de Lara y la historia de la prensa», en J.L. DE La Granja, A. Reig Tapia y R. Miralles (eds.), Tuñón de Lara y la historiografía española, Siglo xxI, Madrid: 69-76.

Díaz Benítez, J.J. (2004): «La Segunda Guerra Mundial a través de la prensa canaria», XV Coloquio de Historia Canario-Americana, Casa de Colón, Las Palmas de Gran Canaria: 1047-1061.

Dilworth, D. y TAIRA, S. (trad.) (1969): «The Logic of the Species as Dialectics», Monumenta Nipponica, 24: 273-88.

Dolores SÁINZ, María (1996): «Nuevas fuentes historiográficas», Historia y comunicación social 1: 131-143.

Dower, John W. (1986): War without mercy: race and power in the pacific war, Pantheon Books, New York.

DreA, E.J. y VAN DE VeN, H. (2011): «An Overview of Major Military Campaigns during the Sino-Japanese War, 1937-1945», en M. Peattie, E. Drea y H. VAN DE VEN (eds.) The Battle for China. Essays on the Military History of the Sino-Japanese War of 1937-1945, Stanford University Press, Stanford: 27-48.

GARCÍA CABrera, M. (2018): «De la neutralidad a la no beligerancia española en la II Guerra Mundial: análisis a través de la prensa canaria», Anuario de Estudios Atlánticos 64: 1-18.

GeNTILE, E. (2004): Il fascismo in tre capitoli, Editori Laterza, Bari.

Giménez Caballero, E. (1979): Memorias de un dictador, Editorial Planeta, Barcelona.

GimÉnEZ MARTínez, M.A. (2015): «El corpus ideológico del franquismo: principios originarios y elementos de renovación», Estudios Internacionales 180: 11-45.

Giner, S. y Sevilla Guzmán, E. (1975): «Absolutismo despótico y dominación de clase. El caso de España», Cuadernos de Ruedo ibérico 43-45: 83-104.

GonzÁlez Calleja, E. (2012): «La prensa carlista y falangista durante la Segunda República y la Guerra Civil (1931-1937)», El argonauta español 9: 1-44.

Hernández Ramos, P. (2017): «Consideración teórica sobre la prensa como fuente historiográfica», Historia y comunicación social 22: 465-477.

Hill, A. (2017): The Red Army and the Second World War, Reino Unido, Cambridge University Press, New York.

HotтA, E. (2007): Pan-Asianism and Japan's War 1931-1945, Palgrave Macmillan, Nueva York.

HotтA, E. (2015): Japón 1941. El camino a la infamia: Pearl Harbor, Galaxia Gutenberg, Barcelona.

LAI, B. (2017): Shanghai and Nanjing 1937: Massacre on the Yangtze, Osprey Publishing, London.

López-VERA, J. (2016): Historia de los Samuráis, Satori Ediciones, Gijón.

MitTER, R. (2013): Forgotten Ally: China's World War II, 1937-1945, Houghton Mifflin Harcourt, Boston.

Moya Martínez, M.(2019a): La imagen de Japón en España. Prensa, propaganda y cultura (1890-1945), Tesis doctoral, Universidad de Córdoba, UCOPress, 
Córdoba.

Moya Martínez, M. (2019b): «La invasión japonesa de Manchuria vista por la prensa española (1931-1934)», Mirai. Estudios Japoneses 3: 111-125.

Moreno CANTANO, A.C. (2008): Los servicios de prensa extranjera en el primer franquismo (1936-1945), Tesis doctoral, Universidad de Alcalá, Alcalá de Henares.

PAYNe, S.G. (1984): Falange. Historia del fascismo español, SARPE, Madrid.

PIKE, D.W. (2008): Franco and the Axis Stigma, Palgrave Macmillan, New York.

Pineda Cachero, A. (2004): «Más allá de la historia: aproximación a los elementos teóricos de la propaganda de guerra», en A. PENA (ed.), Comunicación y guerra en la historia, Tórculo, Santiago de Compostela: 807-823.

Pizarroso Quintero, A. (1990): Historia de la propaganda. Notas para un estudio de la propaganda política y de guerra, Editorial Eudema, Madrid.

Pizarroso Quintero, A. (1999): «La historia de la propaganda: una aproximación metodológica», Historia y comunicación social 4: 145-171.

Pizarroso Quintero, A. (2005): «La Guerra Civil española, un hito en la historia de la propaganda», El argonauta español 2: 1-18.

Preston, P. (1994): Franco, "Caudillo de España», Grijalbo, Barcelona.

Pulpillo Leiva, C. (2014): «La configuración de la propaganda en la España nacional (1936-1941)», La Albolafia: Revista de Humanidades y Cultura 1: 115136.

Rodao García, F. (1993): Relaciones Hispano-japonesas, 1937-1945, Tesis doctoral, Universidad Complutense de Madrid, Madrid.

Rodao García, F. (1995): «Difícil y sin apoyos políticos. La Representación por España de los intereses japoneses durante la Guerra del Pacífico», Espacio, Tiempo y Forma, Serie V, $H^{\mathrm{a}}$ Contemporánea 8: 179-194.

RoDAO GARCíA, F.(1998): «Japón y la propaganda totalitaria en España, 1937-1945», Revista española del Pacífico 8: 435-454.

Rodao García, F. (2004): La imagen de España en Japón, Real Instituto Elcano, Madrid.

Rodao García, F. (2013): Franco y el imperio japonés. Imágenes y propaganda en tiempos de guerra, Plaza \& Janes, Barcelona.

SATŌ, S. (1994): War, Nationalism and Peasants. Java under the Japanese occupation 1942-1945, Sharpe, Nueva York.

Sevillano Calero, F. (1998): Propaganda y medios de comunicación en el franquismo, Universidad de Alicante, Alicante.

Sevillano Calero, F. (1999): «Cultura, propaganda y opinión en el primer franquismo», Ayer 1: 147-166.

Sevillano Calero, F. (2000): «Notas para el estudio de la opinión en España durante el franquismo», REIS: Revista Española de Investigaciones Sociológicas 90: 229-244.

Sevillano Calero, F. (2014): «La propaganda y la construcción de la cultura de guerra en España durante la Guerra civil», Studia Historica. $H^{a}$ contemporánea 32: 225-237.

Yамамото, M. (2000): Nanking: Anatomy of an Atrocity, Westport, Connecticut, Praeger. 
Reseñas / Reviews 

Vegueta. Anuario de la Facultad de Geografía e Historia

21 (2), 2021, 191-221

eISSN: 2341-1112

https://doi.org/10.51349/veg.2021.2.08

\section{RESEÑAS}

Óscar Recio Morales, Alejandro O'Reilly, inspector general. Poder militar, familia y territorio en el reinado de Carlos III, Sílex Ediciones, Colección Sílex Universidad, Madrid, 2020, 516 págs., ISBN: 978-84-7737-837-2.

Alejandro O’Reilly, inspector general es un libro que tiene como valor fundamental mantener la continuidad de una serie de estudios históricos sobre personalidades relevantes del siglo XVIII español que seguían sin contar con una biografía, cuando ya la tienen importantes ministros de los Borbones como Carvajal, Grimaldi, Wall o Gálvez. El libro es una completa biografía personal del irlandés Alejandro O'Reilly, aunque en algunos momentos también se atisban elementos propios de una biografía familiar, al acercarnos por momentos a las redes familiares, sociales o político administrativas a través de las cuales pretendía dar continuidad a su linaje.

El profesor Óscar Recio, titular de Historia Moderna de la Universidad Complutense de Madrid, se adentra por esos derroteros, abundando en el interés que sigue teniendo la biografía histórica como género historiográfico y nos ofrece un intenso estudio sobre la figura de O'Reilly, un militar y político no tan destacado como los citados. Sin embargo, él nos presenta la persona de O'Reilly revestida de un merecido interés, no sólo por tratarse de un militar y político controvertido, sino también y, en primer lugar, porque se trata de un irlandés de nacimiento, cuya trayectoria personal y profesional aporta nueva información sobre el papel de un importante grupo de extranjeros, particularmente de esa nacionalidad, en torno a la Corona española. Precisamente una de las líneas en las que viene trabajando desde hace años el profesor Óscar Recio que cuenta ya con un importante conjunto de publicaciones en ese sentido.

El libro describe detalladamente cómo las estrategias de O'Reilly parten de la dinámica propia de los extranjeros llegados a España que acaban siendo premiados por su fidelidad al monarca y su eficiencia en el manejo de su cargo y en la gestión de los distintos cometidos que se le encomendaban. Óscar Recio es consciente de que se ha indagado sobradamente acerca de la alta administración española en España y en sus territorios ultramarinos, y también en distintos aspectos de la biografía de O'Reilly. Un hecho que le ha permitido documentar gran parte de su ascenso y trayectoria profesional, como fiel sujeto de origen irlandés y servidor de la corona y el estado. Pero quiere ir más allá, para profundizar en todo el proceso de formación y consolidación, también en las crisis y fracasos, 
como miembro destacado de la elite de poder de la que formaba parte destacada. Tal es el propósito de este nuevo libro del profesor Óscar Recio, que nos permite contemplar, por primera vez en su conjunto, la vida O'Reilly, desde su origen hasta su muerte, pasando por su ascenso a importantes puestos en el aparato del estado borbónico y sus intervenciones en distintos territorios.

Esta biografía de O'Reilly nos sitúa ante uno de esos personajes construido a partir de la evolución desde la simple biografía descriptiva del devenir humano hasta objetivos más amplios de carácter militar, administrativo, político, social o económico, algo que contribuye a personalizar la historia. Entre las premisas de las que se parte destacan el entronque entre el devenir del individuo y la colectividad, los aspectos psicológicos del personaje y la incidencia de los aspectos familiares o de comportamiento y convicción. Ciertamente, a través de su persona, conocemos más del funcionamiento de la administración o de los mecanismos de ascenso del ejército español en la segunda mitad del siglo XVIII; de los intentos por implantar las reformas militares promovidas por Carlos III; de las estrategias de defensa del imperio colonial; y, en general, de las tensiones partidistas, con graves situaciones internas, -como el «motín de Esquilache» de 1766, que forzaron la huida del rey de la Corte de Madrid-, un conjunto de enfrentamiento políticos y maniobras cortesanas durante el reinado de Carlos III, también presentes en distintos apartados del libro. No en vano estamos ante un hombre que fue durante décadas ese «inspector general» que le da título. Un libro de más de quinientas páginas en el que Óscar Recio reflexiona no sólo sobre el personaje, aportando una visión de conjunto de la figura de O'Reilly, sino también sobre lo que ha dicho de él la historiografía, ya que el libro se ha elaborado a partir de las fuentes y de la bibliografía anterior (pp. 479-483) y posterior a 1900 (pp. 483-508), aunque en ocasiones se echa en falta algún título señero, o aportaciones recientes, también biográficas, a importantes coetáneos, como en el caso de José de Gálvez y su «círculo» de poder. Es este sentido, la obra tiene también un subtítulo, «poder militar, familia y territorio en el reinado de Carlos III»; porque el título alude a lo que significó el hecho de estar al frente de la Inspección General de Infantería de España y de América; mientras que el subtítulo nos sitúa ante la territorialidad del alcance de sus actuaciones, entre Madrid, La Habana, Puerto Rico, Luisiana y Cádiz, si bien es aquí donde se puede apreciar que son los espacios socioeconómicos los menos transitados por su autor, sin duda porque el mayor peso del libro quizá incide en la historia político-militar, familiar y personal.

No vamos a pormenorizar en el largo recorrido biográfico del personaje, reconstruido minuciosamente por el profesor Óscar Recio a partir de una abundante documentación y bibliografía, y con todo lujo de detalles. Pero si queremos destacar que es un libro denso, que no defrauda al lector. Un libro que se divide en seis partes, cada una de ellas subdividida es cinco apartados y la última en cuatro, buscando un equilibrio entre ellas, cuyo desarrollo, en casi una treintena de apartados, permite a su autor desentrañar prácticamente la totalidad de las circunstancias vitales y profesionales de O'Reilly. Va precedido de un acertado prólogo en el que el propio autor nos presenta su propuesta biográfica para la persona de O'Reilly, como él mismo señala, más personal, porque si bien la 
historiografía ya se ha ocupado de las distintas etapas y aspectos de su trayectoria militar y administrativa, él nos aporta una visión más global. Desde su origen y formación, pasando por sus actuaciones en los territorios americanos (Cuba, Puerto Rico, Luisiana); de sus fracasos junto a otros significados militares de la época como en Argel; de su actuación como gobernador en Cádiz; y de su final.

El primer capítulo comienza por sus años de formación (1723-1763), claves en una persona que iba a encargar de la administración e inspección de una parte del enorme aparato militar y burocrático del estado, una cuestión que implicaba poder. Sus orígenes y familia, la llegada a España, su experiencia europea, la sintonía con la necesidad de reformas y su papel en la «guerra fantástica» contra los portugueses.

Un segundo capítulo, señalado como América (1763-1769), marca el recorrido por las reformas en Cuba (pp. 105-125), cuando la isla se convertirá en una pieza clave para el futuro de su familia. Su intervención en Puerto Rico; también en la Luisiana, cuya sociedad merecería un análisis con mayor profundidad. Y lo que el autor define como «la conexión vasca», marcada por los lazos familiares, económicos y sociales con su cuñado Luis de las Casas, quien se convertirá en Capitán general y gobernador de Cuba, figura clave en la fortuna de la familia. O'Reilly, se convierte así en una de las personas a favor de la alternativa de emplear esclavos en Cuba, haciendo exaltación de la esclavitud y defensa de la trata libre en su obra «Descripción de la Isla de Cuba» (1764), conservada en la Real Biblioteca de Palacio de Madrid y citada en el libro (pp. 121-122). De hecho, el comercio habanero y la explotación azucarera, en manos de la «sacarocracia» de la que formaba parte la familia O'Reilly a través de sus alianzas matrimoniales con la familia Las Casas y Calvo de la Puerta, cada vez fue dependiendo menos de los puertos peninsulares, como Cádiz, y más de los contactos con su poderoso vecino, los Estados Unidos. Una relación que estuvo siempre supeditada al éxito de la producción azucarera y, en general, al sistema de plantaciones en el que la implicación de la familia O'Reilly-Las Casas-Calvo fue absoluta. De ahí su postura proesclavista, cuando su llegada se incrementó de modo muy considerable sobre todo por la liberalización del tráfico respaldada por la Real Cédula de 28 de febrero de 1789, decretando la libre introducción de esclavos africanos. Pedro Pablo O'Reilly, hijo de Alejandro y sobrino de Luis de las Casas, funda su propio ingenio, «La Alejandría», en honor a su padre, con 120 esclavos, convirtiéndose en un gran hacendado azucarero. La larga coyuntura bélica en que se verá sumida España a partir de 1793, que ya no conocerá su padre, fallecido en 1794, supondrá grandes cambios para Cuba y para los intereses de su familia, con los Estados Unidos como principal cliente para la producción de azúcar cubano. Una situación que cambiará tras la abolición de la «trata» por Inglaterra y la posibilidad de inspeccionar los barcos para liberar esclavos, lo que conlleva la ruina de las grandes haciendas azucareras. A partir de entonces, el alto precio de los esclavos y la obtención de azúcar de la remolacha pondría fin al predominio de esa «sacarocracia» cubana, y con él, a la gran fuente de la fortuna y poder de los O'Reilly.

Por tanto, algunas de las actuaciones de O'Reilly en los distintos territorios 
americanos, pero sobre todo en Cuba, desde esa perspectiva social y económica, resultaron trascendentales para el futuro de su familia, y matizarían ese «todo lo debo al rey, 1770-1774», de la tercera parte del libro, más allá de su ideario militar o su proyecto personal de la Academia Militar de Ávila, donde coincidió con Bernardo de Gálvez y se fraguó su círculo de relaciones. Y será en Argel, tema de la cuarta parte del libro, donde en 1775 , O'Reilly cosechará uno de sus más estrepitosos fracasos, coincidiendo con Bernardo de Gálvez, con Francisco de Miranda y todos los grandes militares de la época. De su paso por Cádiz se ocupa la quinta parte del libro. En esa etapa 1775-1786 el profesor Óscar Recio se centra en su actuación como gobernador, destacando su intervención en materia de obras públicas y su intento de Escuela Militar en El Puerto. Precisamente, a su posición privilegiada en Cádiz se refiere el diplomático francés Jean François Bourgoing cuando, en su Tableau de l'Espagne Moderne (París, 1797), reconoce que O'Reilly «gobernaba, o mejor dicho reinaba» en la ciudad en el momento de su llegada en 1785. Primer secretario en la embajada francesa en Madrid desde 1777, Bourgoing, con información de primera mano y gracias a su gran capacidad de análisis y de observación, llegó a ser un verdadero experto en la política española y un buen conocedor de sus artífices, no sólo de O'Reilly, sino también de ministros como el poderoso José de Gálvez, cuando dice de él que «no cabe negarle cierto talento para la administración, no obstante, un talento al que sumaba la actitud petulante y las pretensiones de un visir». En definitiva, altos funcionarios transidos de reyes o visires, como O’Reilly y Gálvez.

Finalmente, O'Reilly regresa a la Corte desde su dorado retiro en Cádiz, para culminar la última etapa de su vida, a la que está dedicada el sexto y último capítulo del libro, con el título de «tres condes hay en Madrid, 1786-1794». Con el que se cierra esta completa biografía, la primera, ya que hasta este momento sólo se había biografiado parcialmente su presencia en determinados territorios o hechos políticos y militares concretos. Páginas finales muy interesantes, porque en ellas se refieren sus esfuerzos para perpetuar su apellido irlandés y su legado, algo que pasaba por el regreso de los O'Reilly a Cuba, donde la familia tenía importantes intereses económicos. Ese «monstruo de fortuna» como lo define Óscar Recio, se acercaba al final de sus días, ya que, tras aceptar un último nombramiento para ponerse al frente de la defensa de la ciudad francesa de Tolón con su importante puerto en el Mediterráneo, determinado por la intervención de España en la Guerra de la Convención, la muerte le sorprendió camino a su nuevo destino militar, el 23 de marzo de 1794. O'Reilly vivió una época de fuertes contrastes, marcada por el despotismo ilustrado de Carlos III y el posterior ocaso del antiguo régimen, pero también por la revolución norteamericana de 1776 y la revolución francesa de 1789. Quizá por ello el libro incluye una amplia cronología (pp. 469-473) con los principales acontecimientos de su vida, desde su nacimiento el 24 de octubre de 1723.

Abreviaturas, ilustraciones, cuadros y un índice onomástico completan el libro. Junto a un breve apunte biográfico (pp. 28-35) de los principales personajes de que aparecen citados, más de ochenta; una docena de apellido O'Reilly, también otros varios de apellido Las Casas o Calvo de la Puerta, o con la conjunción de dos 
o tres de ellos, por lo ya señalado de sus fuertes intereses hacendísticos azucareros y esclavistas en la isla de Cuba.

Con este libro del profesor Óscar Recio continúa completándose la nómina de personajes históricos destacados del siglo XVIII español que han merecido el esmero de los historiadores en las últimas décadas, cuando hasta hace relativamente poco tiempo todavía resultaba bastante sencillo encontrar grandes protagonistas abandonados por la historiografía y sin un estudio biográfico profundo. Pero su autor nos habla de esa España y sus territorios americanos a partir de una enorme riqueza de información, plagada de detalles, a partir de la trayectoria vital de O'Reilly, de su hijo Pedro Pablo, y algunos parientes y allegados, personas con poderosos intereses de prestigio social y enriquecimiento económico, que no repararon en medios para conseguir perpetuar su linaje. Con este fin, son varios los elementos que el autor toma en consideración, desde la estrategia familiar y matrimonial fraguada por Alejandro O’Reilly al frente del linaje, su recorrido militar, administrativo, institucional, político y de gobierno, y las redes de poder tejidas en la isla de Cuba en torno a fuertes intereses económicos. Del arraigo en las instituciones derivó precisamente su ascenso militar, político, social y económico, contemplándose en el libro cuestiones tan diversas como la vida familiar y las estrategias matrimoniales; la proyección pública y dentro de la propia administración del estado; y el nivel de vida alcanzado por el militar, funcionario y gobernador, y, en su conjunto, por la familia O'Reilly-Las Casas, a todas luces vinculado a sus intereses en las plantaciones azucareras en la isla de Cuba, marcados por sus posturas a favor de la esclavitud y la trata.

Libros como el que nos presenta Óscar Recio siguen mostrando el camino que deben y pueden seguir las investigaciones históricas en torno al siglo XVIII, aunque en cierta medida se vean opacados los temas sociales y económicos en favor de la apuesta por la historia político-militar. El libro contiene una profunda revisión sobre lo que hasta el momento se ha escrito sobre $\mathrm{O}^{\prime}$ Reilly y nos proporciona los recursos metodológicos y documentales necesarios para emprender ese tránsito hacia una mejor comprensión de nuestro siglo XVIII. En ese sentido se convierte en una buena guía histórica que permite comprender el papel de tantos y tantos los personajes que, con independencia de su origen y condición, ilustran y llenan de vida y color, cada época y cada sociedad. Personajes que progresivamente van marcando las pautas que enriquecen el género biográfico, al que no escapan personajes quizá menores, pero cuyo microcosmos también proporciona una visión de conjunto, una síntesis, del personaje y la época, sin huir de lo concreto y sin caer en abstracciones de dudosa validez.

Un libro como este siempre llega en el momento apropiado, porque la biografía como género, cada vez está más en boga, y especialmente la de los personajes históricos, algunos de ellos convertidos en auténticos éxitos comerciales por el número de ejemplares vendidos y por el impacto mediático. Biografías redactadas por escritores de buena pluma y conocimiento de los hechos históricos, como no podía ser menos, pero también por historiadores profesionales y a la vez reconocidos investigadores, como es el caso de Óscar Recio. El libro se suma así a ese amplio abanico de ilustres biografiados que, más allá del propio personaje, nos 
presenta un ser humano, el irlandés O'Reilly, extranjero en España y en América, con sus rasgos más personales y distintivos. La historia de vida de alguien sin el renombre de otros altos funcionarios de la época, pero que consiguió perpetuar su legado y su apellido extranjero, lo que nos permite abundar en el conocimiento de los mecanismos de permeabilidad social que utilizaban extranjeros y nobles de servicio en la España del siglo XVIII.

El libro va más allá de la mera biografía, para ser también una contundente plasmación de la realidad de la época, vislumbrada por tantos coetáneos, laicos o eclesiásticos, a propósito de la concentración de poder político, social y económico reforzada de forma sistemática por las alianzas matrimoniales a la hora de desempeñar cargos en España, América o en otros territorios. Apoyado en una ingente labor de investigación y relectura de todo lo escrito hasta el momento, traza la trayectoria vital de O’ Reilly, desentrañando su ascenso social y enriquecimiento, sus claroscuros, sus éxitos y fracasos.

Un relato pormenorizado de las estrategias de hombres que, como O'Reilly, formaban parte de un selecto grupo de funcionarios de gobierno, procedentes de capas intermedias de la sociedad, extranjeros o no, hábiles, preparados y aunque no siempre eficaces, fueron premiados por su fidelidad al monarca, por el manejo del cargo o la gestión de los recursos del estado, al tiempo que se convertían en los artífices de las reformas borbónicas. Eso sí, siempre atrapados por su condición y convicciones en la complejidad de la España del siglo XVIII. Su lectura es rápida y amena, sencilla, pero a la vez rigurosa y de buena redacción, que va dando cumplido repaso a las aportaciones bibliográficas aparecidas, a los avatares historiográficos y a numerosas fuentes. En definitiva, un libro muy recomendable y accesible a toda suerte de lectores y no sólo a especialistas en la historia de la época moderna.

Manuel Casado Arboniés

Universidad de Alcalá

https:// orcid.org/0000-0002-0011-8362

manuel.casado@uah.es

Manuel-Reyes García Hurtado (ed.), Las innovaciones de la Armada en la España del siglo de Jorge Juan, Biblioteca de Historia CSIC, Madrid, 2020, 618 págs., ISBN: 978-84-00-10646-1.

A pesar de la enorme vinculación de España con el mar y de la aparición en los últimos años de interesantes aportaciones en ámbitos como las estrategias defensivas (destacando el dossier publicado por la revista Vegueta en 2016 y coordinado por Sergio Solbes Ferri y Luis Fé Cantó), la logística (donde sobresale el dossier de la Revista Universitaria de Historia Militar «La logística anfibia: el poder naval del Imperio español en el Mediterráneo durante el siglo XVIII», coordinado 
también en 2016 por Manuel Díaz-Ordóñez, uno de los autores del volumen que nos ocupa), la construcción naval, las expediciones científicas y el papel de las armadas en el contractor state y el fiscal-military state, la historia naval española no ha compartido la relevancia reciente de la historia militar, especialmente en lo que respecta a análisis sociales, arquitectónicos, institucionales o económicos. Por ejemplo, como señala Manuel-Reyes García Hurtado, queda por realizar un estudio social de la marina española del XVIII parangonable al que llevó a cabo F. Andújar Castillo para el ejército (pp. 18-19). Las innovaciones de la Armada en la España del siglo de Jorge Juan viene a llenar parte de este nicho al incluir textos de algunos de los mejores especialistas españoles en historia naval. Este libro colectivo tiene por principal objetivo renovar el panorama historiográfico sobre la Armada del XVIII ampliando el foco a ámbitos menos trabajados hasta ahora (como la formación de la oficialidad, las infraestructuras portuarias, la tecnología o las condiciones de vida y servicio de la marinería) y tomando en consideración «la distancia entre lo pretendido y lo que fue posible» (p. 14): cómo lo planificado en las ordenanzas no siempre se plasmó en la realidad, lo que explica la debacle en el xIX a pesar del éxito parcial en la protección del imperio español y sus rutas de comunicación logrado en el XVIII.

El libro reúne catorce contribuciones estructuradas en tres grandes apartados: «Puertos y ciudades», «Naves y marinos» y «Arsenales». Cabe plantearse si esta división no resulta algo arbitraria o accesoria, habida cuenta de que los arsenales están presentes en casi todos los capítulos en mayor o menor medida, pero al menos facilita la lectura y la consulta. El encargado de editar y coordinar el libro ha sido Manuel-Reyes García Hurtado (Universidade da Coruña). A lo largo de más de tres décadas de carrera académica y sobre todo desde la lectura en el año 2000 de su tesis doctoral El ejército y la literatura histórica española en el siglo XVIII (1700-1808), García Hurtado ha desarrollado una ingente labor no solamente como autor en aspectos como la cultura escrita en los militares del XVIII, la historia marítima y portuaria (destacando sus trabajos sobre el arsenal de Ferrol) o la relación de las mujeres con el ejército, sino también como coordinador de proyectos e iniciativas internacionales plasmadas en congresos o publicaciones colectivas tan influyentes como Soldados de la Ilustración: el ejército español en el siglo XVIII (2012) o El siglo XVIII en femenino. Las mujeres en el Siglo de las Luces (2016). En el volumen que es reseñado en estas líneas, García Hurtado se ocupa de un clarificador prólogo que va más allá de una mera introducción para hacer las veces de estado de la cuestión general sobre los estudios actuales en torno a la Armada española del xVIII, al tiempo que hilvana las diferentes contribuciones dando consistencia a la propuesta del conjunto de la obra, así como de un extenso capítulo sobre la importación de bibliografía para la Armada desde el norte de Europa. Este apartado sirve de muestra para profundizar en una de las grandes cuestiones de la marina española del xVIII y del libro: el dilema entre la importación de profesionales cualificados extranjeros o bien de tratados y metodologías de formación para instruir a los técnicos en España. Dilema para el que, al menos en el caso del ejército, la corona se decantó en la primera mitad de la centuria por la atracción de militares de origen foráneo, los cuales coparon 
numerosas plazas en la oficialidad, particularmente en armas como el Cuerpo de Ingenieros. Solo en la segunda mitad del siglo, gracias a la labor de personajes destacados como Alejandro O’Reilly, la disyuntiva basculó más decididamente hacia la preponderancia de la importación de libros. García Hurtado analiza las misiones en el norte de Europa de Jorge Juan y Santacilia, Antonio de Ulloa y de la Torre-Giralt o José de Mendoza y Ríos, detallando los libros que elegían destinar a España y su uso previsto, el papel de la Inquisición como censora y emisora de licencias para que los títulos pudieran usarse en las academias y las tensiones con los militares derivadas de sus inspecciones. La misión de Mendoza en París (y también en Inglaterra y los Países Bajos) ocupa gran parte del texto: el oficial estuvo encargado de conseguir libros para la biblioteca general del proyectado Museo de Marina que debía construirse en la Nueva Población de San Carlos. Mendoza concibió el proyecto de reunir en Cádiz centros que trabajaran todas las ciencias relacionadas con la Armada, pero ni su idea ni el museo acabaron viendo nunca la luz. Los 2905 volúmenes que envió a España vivieron un periplo caótico tras llegar a Cádiz, fragmentándose como colección. Se perdieron ejemplares por robo o dejadez y junto a otros libros de las bibliotecas de la Armada sufrieron condiciones de conservación lamentables durante décadas, en ocasiones sin salir de las cajas en las que fueron enviados. García Hurtado desgrana la composición de la colección adquirida, en la que predominan las obras recientes de autores del XVIII en francés (aunque en muchos casos se trataba de traducciones de otras lenguas) sobre ciencia, viajes, historia y geografía. Es difícil resistirse a pensar que el autor elaboró este extenso capítulo teniendo en mente la metáfora de la Armada del XVIII que suponía el caso de Mendoza: una misión ilustrada, ambiciosa y bien dotada que finalmente queda en agua de borrajas coincidiendo con el cambio de centuria, con el propio protagonista expulsado de la Armada en 1800 (p. 361), con un gran aporte de origen foráneo incomprendido y desaprovechado y con las obras importadas, sin lectores, acumulando humedad y polilla, como ocurrió con el propio Tratado de navegación de Mendoza (1787), prestigioso entre los científicos europeos del momento pero ignorado en España (p. 358). No podemos dejar de destacar en el texto de García Hurtado el completísimo apartado gráfico, con ilustraciones seleccionadas de láminas de las obras importadas.

Ricardo Franch Benavent (Universitat de València) inicia la sección sobre puertos y ciudades con un capítulo introductorio sobre la evolución de las dársenas mediterráneas en el XVIII, desde Málaga a Barcelona, Palma, Valencia, Alicante y Cartagena. Franch Benavent afirma que la presencia en Málaga y Barcelona (ciudades que experimentaron problemas similares de colmatación de fondos por acumulación de sedimentos) del ingeniero general, Jorge Próspero de Verboom, para planificar e iniciar la reforma de sus puertos evidencia la importancia que se le daba a esos proyectos (pp. 29-31). La realidad es que en esos primeros años tras la Guerra de Sucesión, el Real Cuerpo de Ingenieros se encontraba tan falto de efectivos con la suficiente experiencia y formación específica que era el propio Verboom el que se veía en la tesitura de tener que afrontar personalmente casi todas las iniciativas de importancia, como de hecho se concluye más adelante en el libro (p. 190). El capítulo muestra cómo la 
reforma de los puertos no obedeció únicamente a causas militares sino también y principalmente al aumento del tráfico comercial y del porte de los navíos, por lo que la historia de la transformación de los puertos mediterráneos españoles en el XVIII es una historia de colaboración público-privada entre las autoridades reales y los poderes mercantiles. La proliferación de consulados y juntas de comercio aumentó la capacidad de presión sobre las instituciones del Estado para mejorar, ampliar y limpiar permanentemente unas dársenas cada vez más insuficientes para las nuevas oportunidades generadas por el comercio con América, aunque la invasión napoleónica detendría el proceso durante décadas.

Juan José Iglesias Rodríguez (Universidad de Sevilla) glosa la estrecha relación de Cádiz con Jorge Juan, alumno y después director de su Escuela de Guardias Marinas, y los principales hitos del desarrollo demográfico y económico de la ciudad y las poblaciones de su bahía como El Puerto de Santa María o Puerto Real a lo largo del XVIII gracias a la expansión mercantil y a la política naval de los Borbones, que tras la creación de los departamentos marítimos en 1726 estimuló la industria de construcción de buques de guerra así como una industria auxiliar para abastecer a los mismos. En este capítulo se pone de manifiesto una vez más la conexión entre presencia de extranjeros y progreso técnico y económico.

Alfredo Vigo Trasancos (Universidade de Santiago de Compostela) analiza la relación de Jorge Juan con las obras en la villa y el arsenal de Ferrol entre 1751 y 1765. Las tensiones entre ingenieros navales y del ejército ejemplificadas en la difícil relación entre Julián Sánchez Bort y Francisco Llobet prefiguraban la cercana creación del Cuerpo de Ingenieros de la Armada en 1770. A través del ministro Ensenada, la corona fomentó con entusiasmo la construcción del nuevo arsenal, en una muestra de proyecto con evidente iniciativa real a diferencia de los puertos del sur y este de España en los que los intereses privados también jugaban un importante papel. Su caída supuso la ralentización de las obras y la reducción del recinto portuario (p. 106).

El capítulo de Alfredo Martín García (Universidad de León) es seguramente uno de los que tiene una personalidad más diferenciada al examinar la plaza de Ferrol desde un punto de vista social, exponiendo cómo el crecimiento de población paralelo a la construcción del arsenal llevó aparejadas pobreza, marginalidad y tensiones sociales que las autoridades no siempre pudieron solventar con intervenciones públicas por falta de recursos, en un contexto en el que gran parte de los ferrolanos dependían económicamente del Estado, cuya capacidad de pago estaba sujeta al secular problema de los atrasos. Se dio una compleja relación bipolar entre civiles y militares, que se necesitaban mutuamente pero a la vez desconfiaban unos de otros (pp. 148-149).

Desde el ámbito de la historia del arte, Juan Miguel Muñoz Corbalán (Universitat de Barcelona) ha sido en los últimos treinta años uno de los mayores investigadores españoles en historia de los ingenieros militares del XVIII y sus proyectos y construcciones y sin duda el mayor experto en la figura de Jorge Próspero de Verboom y los demás ingenieros de origen extranjero venidos durante la Guerra de Sucesión. En su participación en esta obra, Muñoz Corbalán vuelve sobre un tema habitual en su prolífica producción académica: 
la arquitectura hidráulica y la introducción en España de técnicas y métodos de trabajo en entornos acuáticos. Gran parte de los trabajos realizados por Verboom y sus subordinados en sus viajes por la costa mediterránea y hasta Cádiz a partir de 1721, especialmente las reformas de los puertos de Barcelona y Málaga, tuvieron que ver con el agua y no siempre por motivos defensivos, sino también con un espíritu de promoción económica del territorio coherente con la letra de la Ordenanza de Ingenieros de 1718. Para este tipo de proyectos, el ingeniero de origen flamenco se vio en la necesidad de recurrir a otros técnicos foráneos ante la escasez de profesionales españoles, habiéndose formado muchos de ellos en el mismo contexto geográfico del norte de Francia y los Países Bajos españoles donde las canalizaciones tienen un papel tan predominante. Pese a la lentitud en los avances provocada por la escasez de recursos humanos y materiales, Verboom fomentó el empleo de un método racional para el análisis y la resolución de problemas de ingeniería que procuraría implantar en las academias que se irían creando en España, empezando por la de Barcelona en 1720, y que consolidarían las nuevas ideas venidas de fuera no solo con la importación de profesionales sino también con la de tratados para las bibliotecas del Cuerpo de Ingenieros (pp. 188189), conformando una contribución a la modernización de la Monarquía que iba más allá de lo meramente material.

El apartado «Naves y marinos» comienza con la aportación de María Baudot Monroy (UNED), una de las mayores expertas en la proyección de la Armada del xVIII en el Mediterráneo, América y Filipinas, que estudia el proyecto de rearme naval de Jorge Juan en 1766 que pretendía acelerar la recuperación de la marina española tras el desastre de 1762 frente a los británicos. Para ello, Baudot Monroy sigue el ambivalente intercambio epistolar entre Jorge Juan y el secretario de Marina Julián de Arriaga. Encontramos aquí un proceso lleno de obstáculos por los recelos respecto a los distintos astilleros (Jorge Juan desconfiaba de La Habana, mientras que Arriaga lo favorecía) y la falta de confianza con los asentistas, lo que en última instancia llevó al fracaso la intención de Jorge Juan de construir seis navíos en Cádiz y dos en Génova que se habrían unido a los doce encargados en Cuba.

Marta García Garralón (Universidad de Exeter/UNED) trata en su texto las reales escuelas de náutica de Cádiz, Cartagena y Ferrol y cómo la labor deinspección de las mismas por parte de Francisco Javier Winthuysen y Pineda fue fundamental para renovar su organización y sus métodos de enseñanza. Garralón se adentra en el XIX hasta la fecha de su cierre en 1846, ampliando el marco cronológico en comparación con otros capítulos para ofrecer avances de investigación sobre el desolador panorama posterior a la Guerra de la Independencia (pp. 236-237). La autora detalla la extracción social de los pilotos en formación, el modelo de docencia y la composición de las bibliotecas y archivos. El capítulo resulta una interesante aportación sobre un tema poco investigado, realizada con uso intensivo de fuentes primarias del Archivo General de Simancas y el Archivo General de Marina. Garralón reivindica el papel de los pilotos en los éxitos de la Armada del xVIII gracias a su larga experiencia en la mar y a las enseñanzas recibidas. 
La contribución de José Manuel Vázquez Lijó (Universidade da Coruña) busca mostrar el punto de vista de la marinería a través de la correspondencia de los pontevedreses a bordo del navío San Agustín, parte de los pescadores obligados a inscribirse en las listas de la matrícula de mar para dotar los buques reales. En 1777, en el marco de la expedición al Río de la Plata, el barco fue capturado por los portugueses y su tripulación hecha prisionera. Sus cartas hablan de lo sucedido hasta entonces en el combate y en Brasil, de las penalidades del cautiverio, de sus condiciones de vida y servicio y de sus emociones respecto a los que quedaron en casa. La paz al año siguiente permitió su liberación y repatriación y que su correspondencia llegara a sus familiares. Es de agradecer que Vázquez Lijó haya añadido un apéndice con la transcripción de algunas de las misivas y una solicitud de los familiares de los marineros para su liberación.

Agustín Guimerá Ravina (Instituto de Historia, CSIC) ha sido uno de los máximos exponentes españoles en historia naval del xVIII y de época napoleónica en las últimas décadas. Colabora en la obra con el que es probablemente el texto más netamente militar y técnico, analizando el navío de línea del xVIII como máquina de guerra. Guimerá usa como hilos conductores el tratado V de las ordenanzas navales de 1793, sobre el plan de combate, y la Instrucción militar para el navio Conquistador, redactada por Cosme Damián Churruca en 1799. Sin dejar de ser un capítulo de sumo interés y muy didáctico gracias a sus ilustraciones y tablas, la contribución de Guimerá adolece de algo que el propio autor señala en el epílogo como objetivo para futuras investigaciones: ejemplos prácticos en campaña que muestren el grado de aplicación de los textos teóricos expuestos.

El libro concluye con la sección «Arsenales», empezando por el capítulo de Juan Torrejón Chaves (Universidad de Cádiz) sobre Jorge Juan y la introducción de la máquina de vapor en los arsenales en el siglo xVIII. El texto narra cómo, por iniciativa de Jorge Juan y en colaboración con el incansable ingeniero naval Julián Sánchez Bort, el problema del vaciado de agua en los diques de carenar en seco del arsenal de Cartagena fue resuelto con la instalación de máquinas de vapor a partir de 1773. Torrejón Chaves demuestra cómo la ingeniería española del XVIII era capaz de inspirarse en ideas venidas de fuera para lograr innovaciones pioneras en Europa.

El capítulo de Juan Antonio Rodríguez-Villasante Prieto (ICOMOS) plantea los adelantos en organización, logística, ingeniería o arquitectura que se fueron introduciendo en el proyecto de construcción del arsenal de Ferrol con el concurso de especialistas como el mencionado Sánchez Bort, entre otros.

Manuel Díaz-Ordóñez (Universidad de Sevilla) estudia en su texto la relación entre Jorge Juan y el arsenal de Cartagena, prestando especial atención a la fabricación de jarcia para la Armada. Díaz-Ordoñez presenta los antecedentes históricos del uso militar del puerto de Cartagena y a continuación detalla los sucesivos proyectos que plantearon los ingenieros militares del XVIII, como los de Alejandro de Rez, Sebastián Feringán y Antonio de Montaigú en 1728 y 1731, el de Esteban Panón en 1739, el de Feringán y Ulloa en 1749 y por último el de Feringán y Jorge Juan en 1751 . Después, el capítulo analiza las iniciativas de Jorge Juan respecto a la fabricación de jarcia en Cartagena y la homologación de su 
producción en los tres arsenales.

Concluye el libro el capítulo de José Quintero González (IES La Bahía, San Fernando) dedicado al arsenal de La Carraca. El mismo comienza diciendo que la paz de Utrecht desposeyó a la Monarquía hispana de toda presencia en Europa (p. 599). Si se refiere a fuera de la península ibérica, no es del todo cierto, ya que Felipe V conservó Porto Longone en la isla de Elba. Quintero González pondera el protagonismo de Patiño, Jorge Juan y los ingenieros Ignacio Sala y José Barnola en la puesta en marcha del proyecto y cómo los cambios en la construcción naval influyeron en la erección de los diques secos a lo largo del siglo.

En síntesis, podemos decir que las contribuciones del libro muestran cómo el pensamiento científico o ilustrado iba avanzando a pesar de las dificultades y permitía desbloquear avances técnicos y plantear mejores formas de gestión y resolución de problemas, en un proceso paralelo al que ingeniería y arquitectura militar experimentaban en tierra y en el que no cabe minusvalorar la influencia de la tratadística y los profesionales de origen foráneo. La presencia extranjera, si bien no explica por sí sola la implantación de todas las innovaciones, fue un catalizador que aceleró los progresos en áreas tan diversas como el comercio, la construcción naval o la ingeniería. Como en el ejército, queda patente que el desempeño de la Armada en el XVIII dependió en gran medida de la actividad constante de algunos oficiales dotados de una rigurosa ética de trabajo además de inteligencia, como es el caso de Jorge Juan, que a fuerza de perseverar consiguieron que los navíos de los Borbones españoles siguieran disputando la hegemonía en el Mediterráneo y el Atlántico a pesar de los escasos recursos económicos, las tensiones entre grupos sociales, facciones y personajes poderosos y los problemas seculares nunca solventados del todo.

Como elemento mejorable, cabe mencionar que los contenidos del libro a veces son reiterativos, un peligro que se corre habitualmente en las obras colectivas y que la coordinación difícilmente puede subsanar, y que la cantidad de aportes novedosos de las contribuciones es desigual, aunque todas sirven para compilar y actualizar los conocimientos en torno a los temas que tratan, establecimiento un punto de partida óptimo para ulteriores investigaciones. La extensión de los capítulos difiere grandemente, con unos que prácticamente son tesis doctorales a pequeña escala y otros más cercanos a una revisión temática limitada. Aunque la presentación deja claro que las guerras del siglo y los marineros en tanto militares no son el principal objeto de atención de la obra, se echan de menos aportaciones que hubieran tratado lo bélico desde una perspectiva más actual y cercana a la historia social de la guerra o que utilizaran fuentes primarias inéditas o poco trabajadas, pues siguen quedando huecos historiográficos en torno a la guerra naval en el XVIII pendientes de rellenar.

A modo de conclusión, es posible afirmar que Las innovaciones de la Armada en la España del siglo de Jorge Juan tiene los mimbres necesarios para convertirse en un referente para el estudio de la Armada española del siglo XVIII, capaz no solamente de mostrar los últimos resultados de investigación sino también de inspirar nuevas líneas de trabajo para otros historiadores navales en el futuro, y que colabora en la construcción de una historia de la Armada científica, diversa y 
consistentemente levantada sobre los sólidos cimientos de las fuentes primarias de archivo.

\author{
Víctor García González \\ Universidad de Málaga \\ Departamento de Historia Moderna y Contemporánea \\ https:/ / orcid.org/0000-0002-1062-8059 \\ victorgg@uma.es
}

\begin{abstract}
Valeria Aguiar Bobet, El orientalismo a la vuelta de la esquina. Crónicas y relatos sobre Marruecos en la prensa tinerfeña entre los siglos XIX y XX, Ediciones Idea, Santa Cruz de Tenerife, 2020, 247 págs. (Cuadernos del Magreb, 14), ISBN: 978-84-18138-47-8.
\end{abstract}

El recurso de la información obtenida a través de la prensa histórica ha sido una herramienta primordial para todo estudioso que se adentra en el margen cronológico comprendido entre la aparición de los primeros diarios impresos y la actualidad. Ese acercamiento suponía, de manera intrínseca, el afrontamiento de dos obstáculos al menos hasta hace una década: la producción asincrónica de periódicos (bien sea en el ámbito nacional, en las capitales o en las diferentes localidades de nuestra geografía), que obligaba a desviar el ámbito de estudio o investigación hacia zonas «cubiertas» por ese recurso de la prensa; y la obligatoria dosis de paciencia y método a la hora de consultar las decenas o centenares de cajas de periódicos que entraban en el marco cronológico ansiado.

Afortunadamente, este segundo hándicap se ha ido venciendo con la implementación y sucesivos avances de la digitalización de las colecciones hemerográficas, que han permitido dar un imponderable salto de calidad y de eficiencia/eficacia a la hora de acometer esta labor de documentación. Atrás queda esa consulta ejemplar por ejemplar, a la busca y captura de referencias de interés para el investigador, una labor que podríamos tildar, desde nuestra perspectiva actual, como de auténtica «artesanía del estudio» tan solo por el caudal de tiempo invertido en esa criba (en ocasiones, por motivos de premura lógica de plazos y tiempo disponible, dividida en tramos o catas).

No obstante, la solución de este último obstáculo ha traído aparejada una nueva tesitura, en la que el exceso de información y referencias que nos brinda la prensa histórica, que pone a nuestra disposición todo tipo de buscadores y metabuscadores para el afinamiento de ese proceso de búsqueda del investigador hacia un tema concreto, obliga al estudioso a hacer gala de sus conocimientos y de una adecuada metodología de análisis. Podríamos decir que justo ese es el momento en que se distingue al verdadero historiador quien, con su discernimiento para ir clasificando, ordenando y seleccionando todo el material que se ajusta a su perfil de búsqueda, en una tarea también paciente y esmerada, acaba por obtener, como 
en todo proceso de decantación, el resultado buscado. Este es el ejemplo de la obra que nos ocupa, en la que la autora, la doctora Valeria Aguiar Bobet, nos brinda un material de primera mano obtenido tras un inteligente y acertado análisis del fondo hemerográfico disponible para el tramo temporal seleccionado (finales del Ochocientos y primeras décadas del siglo $\mathrm{xx}$ ) en un acercamiento renovador de la visión que existe desde las Islas sobre Marruecos, y viceversa.

El contexto general de los textos seleccionados, centrados en torno al orientalismo o africanismo, lleva impregnada la «moda» que afectó a todos los escenarios y ámbitos del día a día de entonces (decoración, comidas, literatura, política, ropajes...), una situación multivalente que nos conduce a tener conocimiento directo de ese rasgo de la otredad del isleño frente al cercano continente, en ese proceso interminable de búsqueda de las causas que nos expliquen satisfactoriamente las diferencias en los testimonios de los distintos viajeros y eruditos que pisaron Marruecos en los albores del siglo xx. Como bien nos apunta la autora, esta selección de textos «nos ayudará a interpretar la invención de una tradición histórico-cultural», unida a la representación insular del vecino continente, que se ha mantenido anclada en el subconsciente de las Islas hasta nuestros días.

El total de textos capturados de ese caótico «mar» que puede representar la prensa digitalizada, y que van a ejercer el papel de valedores de ese acercamiento en esta obra, asciende a casi el medio centenar, cantidad que puede subdividirse en tres grandes apartados: las crónicas periodísticas (19 en total), con registros versados en su mayor parte en la información y/o la opinión expresada por el corresponsal o enviados especiales; los relatos de viaje (hasta un número de 18), que nos ofrecen un caudal enriquecedor de imágenes, sesgos e impresiones de primera mano por todo ese conjunto de visitantes del cercano continente; $y$, por último, los textos exclusivamente literarios (5 en esta ocasión), que asimismo enfatizan los valores ensalzados anteriormente sobre pasión por el orientalismo y el exotismo inherente a su cultura. En este punto debe recalcarse la relevancia de este tipo de trabajos que cumplen, por un lado, con la necesaria labor (en ocasiones, ingrata por el coste temporal añadido) de recopilación de materiales «perdidos» en un contexto infinitamente mayor -en este caso, la prensa-, pero sin descuidar, por otro, esa labor de clasificación, de estudio pormenorizado y de afirmación de las claves esenciales para su mejor entendimiento.

Autores como Enrique Segovia Rocaberti, Eduardo Dolkowsky, Antonio María Manrique, Luis Morote, Maximiliano Hardisson Espou, Martínez Yagües o Adolfo Febles Mora, entre otros, brindan el material ansiado para el análisis de las circunstancias y objetivos marcados en este estudio, y permiten a la autora ir introduciendo en el discurso histórico las diferentes tendencias, sesgos políticos y focos de atención que han ido conformando la peculiar y sugerente otredad del isleño respecto al vecino continente.

La doctora Aguiar Bobet sigue un meticuloso proceso de análisis con todos y cada uno de los textos, iniciado siempre con las pertinentes referencias al contexto biográfico y personal del autor de los mismos. De todos estos personajes, cuyo nexo de unión es su interés por el orientalismo, la autora diferencia a los simples 
reporteros, colaboradores o aquellos cuyos textos aparecen firmados con perfiles anónimos y tras enigmáticas iniciales, frente a los escritores más reconocidos en la época, tal es el caso de Eduardo Dolkowsky, cuyo testimonio de absoluta empatía con el territorio y cultura de Marruecos descuella de forma singular. Nos atreveríamos a afirmar que ya de por sí la recopilación de los textos salidos de la pluma de este escritor, deslavazados hasta hoy en día en los distintos ejemplares de la prensa, supone un motivo de felicitación hacia la autora.

A lo largo de los textos seleccionados podemos distinguir un gran abanico de temáticas, con focos que van desde los asuntos económicos (productos, precios, perspectivas de comercio...) o temas políticos o sencillamente de matiz colonial, hasta visiones de enorme trascendencia sobre aspectos tan de actualidad como la emigración, la multiculturalidad o el exotismo. El conjunto exhibe asimismo descripciones y noticias de prensa a modo de quejas, avisos o recomendaciones al lector de entonces, ofreciendo siempre un fiel reflejo de la visión del orientalismo donde tampoco faltan las llamadas a la tolerancia, la fraternidad y la disminución de las diferencias.

Los títulos de la prensa histórica presentes en este estudio se encuentran accesibles a través del inestimable fondo de prensa histórica que la Biblioteca de la Universidad de La Laguna pone a disposición de la comunidad investigadora a través de su servicio de digitalización en el Fondo de Canarias. A través de esa aplicación Valeria Aguiar Bobet pudo consultar con todas las facilidades posibles los ejemplares de los rotativos El Amigo del País (1866), La Opinión (1885-1911), Diario de Tenerife (1887-1917), Liberal de Tenerife (1893-1894), El Progreso (19071918), La Prensa (1911-1914) y Gaceta de Tenerife (1928).

Daniel García Pulido

Universidad de La Laguna

Biblioteca

https://orcid.org/0000-0001-9415-3945

dgarciap@ull.edu.es

Yolanda Aixelá-Cabré (ed.), «Local versions and the global impacts of EuroAfrican memories: A revision through Spanish colonial imprints", Culture and History Digital Journal, 9 (2), December 2020, https://doi.org/10.3989/chdj.2020. v9.i2.

Este dosier, editado por Yolanda Aixelà-Cabré, que es también la investigadora principal del proyecto ${ }^{1}$ en el cual se enmarcan las investigaciones que conforman seis artículos, constituye una notable contribución a la historia

1 El proyecto es African Memories: Reconstructing Spanish Colonial Practices and their Imprint in Morocco and Equatorial Guinea. Towards a Hispano-African Cultural Heritage, 2016-2018 (HAR2015-63626-P, MINECO/FEDER, UE). 
y la memoria colonial hispano-africana. El dosier se ocupa de las huellas de las identidades y las memorias euro-africanas, es decir, de las narrativas individuales y colectivas que versan sobre las relaciones entre poblaciones europeas y africanas durante el colonialismo. El análisis se centra en dos de los territorios africanos que estuvieron bajo control colonial español: el Protectorado español de Marruecos (1912-56), por un lado, y los Territorios españoles del Golfo de Guinea (1777/81968), por otro lado. En estos dos territorios la población civil local y española compartieron espacio y se produjeron relaciones -de mayor o menor calado, y a menudo marcadas por una fuerte jerarquía- que no se dio en el caso de Sidi Ifni o el Sahara Occidental, los otros dos territorios africanos colonizados por España, en los que predominó la ocupación y la presencia militar.

Tal y como detalla Aixelà-Cabré en la introducción, el dosier se propone ir en contra de la inercia de supeditar el caso del colonialismo español al de los demás países europeos en África, en especial el británico, el francés y el portugués. Esto es importante por varias razones. En primer lugar, para contrarrestar la amnesia colonial que reina en España, en especial en lo que a los territorios africanos se refiere. Cabe resaltar que, si bien es un campo en el que queda mucho por hacer, la introducción ofrece una panorámica de lo que se hecho hasta ahora y los trabajos que rompieron el hielo en este ámbito. En segundo lugar, el dosier propone indagar en las especificidades sociales, étnicas, religiosas y lingüísticas de las «localidades» africanas colonizadas para poder entender de manera más compleja las huellas afro-españolas y los legados imperiales. Entre los legados está la construcción moderna de la(s) alteridad(es) en España, que Juan Manuel Santana desarrolla en relación al interesante caso de las Islas Canarias, así como «los espejismos» coloniales que rigen la gestión de la diversidad religiosa, étnica y cultural de las potencias de Europa occidental (AIXELÀ-CABRÉ, 2018: 60), pero también la transformación en las prácticas matrimoniales bubi que estudia Nuria Fernández Moreno, la vuelta a la circulación del conocimiento colonial en torno a las demarcaciones socio-lingüísticas del norte de Marruecos que pone de manifiesto Araceli González Vázquez, o la contribución imperial a la constitución del Hajj en el fenómeno que es hoy en día, tal y como se desprende de la contribución de Jordi Moreras. En tercer lugar, entender las especificidades de los discursos históricos coloniales en su contexto permite analizar las narrativas euroafricanas de una manera más compleja, en su heterogeneidad, y problematizando los sesgos coloniales que les subyacen. Catalina Iliescu-Georghiu destaca el peso que los patrones de poder que influyeron en la (re)construcción postcolonial de la identidad nacional y étnica en Guinea Ecuatorial tienen en la mirada refractada de los «emixiliados» en España. Aixelà-Cabré, por su parte, rescata las silenciadas memorias que hablan de la explotación laboral que sufrían las y los ex-colonizados, y de la (de)segregación familiar que la economía colonial y otros factores sociogeográficos y políticos produjeron.

Sin lugar a dudas, entre las contribuciones del dosier destaca lo metodológico. Los artículos adoptan una mirada postcolonial que arroja luz sobre los procesos de hibridación, la heterogeneidad de las huellas coloniales y la influencia de los legados coloniales en la construcción de las identidades y los estados postcoloniales. Es esta una contribución más anodina y necesaria de lo que cabría esperar, ya que el análisis del colonialismo español en África desde una perspectiva postcolonial ha sido muy escaso (Fernández Parrilla, 2018). La reseñable contribución metodológica del dosier también la constituye 
la perspectiva comparativa diacrónica y sincrónica de los procesos de los que hablan esas memorias, a nivel local (colonial y post-colonial) y global (imperial y post-, o neo-imperial). Otro gran mérito del dosier es su pluridisciplinariedad: las contribuciones se sitúan en los campos de la antropología, la historia y la lingüística, y exploran la interrelación de las memorias -orales y escritas- que se pueden rescatar haciendo uso de herramientas teóricas y metodológicas variadas que ofrecen puntos de vista diversos, plurales.

En "The Formation of North African Otherness in the Canary Islands from the 16th to 18th Centuries", Juan Manuel Santana se centra en la población morisca canaria que, a diferencia de la peninsular, no fue obligada a abandonar la Corona española a principios del siglo XVII. Y es que, en el momento del Real Decreto de 1609 de expulsión de los moriscos de la Península, la mayoría de los cristianos viejos del archipiélago canario declararon que los moriscos de allí eran buenos cristianos y vasallos leales. Aún así, el rechazo a la población morisca seguía existiendo y se constituía, de acuerdo con Santana, en torno a tres ejes principales: el de la sangre, el de la religión y el político; que además intersectaban, con lo cual se conjugaba la estigmatización basada en conceptos de la (im)pureza de sangre con las de los linajes religiosos (p. 5). El panorama que se desprende del artículo de Santana, por tanto, es el de que en las Islas Canarias existía una permisividad social y una laxitud jurídica mayor que en la península, si bien es palpable una hostilidad entre las comunidades de cristianos viejos y moriscos que repercutía de manera negativa, tanto en lo social como en lo ecónomico, a los moriscos: de ahí la persistencia de la «otredad» que da título a este artículo. Santana también apunta a la confluencia existente en la legislación que prohibía la tenencia de armas a la población morisca, negra e indígena. Considero que este es un hilo del que sería muy interesante seguir tirando; porque, tal y como ha destacado Elsa Dorlin, «la historia de los dispositivos de desarme» ilustra la construcción de los grupos sociales a los que se niega la capacidad de defenderse (2019: 55). La posición subalterna que estos sectores sociales ocupaban en las Canarias del siglo XVI es visible en la emisión de la prohibición de tenencia de armas de la población indígena guanche (en 1514) y de moriscos y negros (en 1549) (pp. 6-7).

Doy un salto desde las Islas Canarias hasta la Isla de Bioko, en la actual Guinea Ecuatorial, y paso a comentar los dos artículos que se centran en esta excolonia española (que tan poco se conoce) y sus diásporas. Cambio, por tanto, el orden que sigue el dosier, y aúno tras estos dos los artículos que versan sobre el Protectorado en el norte de Marruecos antes de cerrar con el artículo que compara ambos territorios.

"Between Tradition and Evangelisation: Marriage Ritualisation on Colonial and Contemporary Bioko Island", de Nuria Fernández Moreno, se centra en las transformaciones que han sufrido diferentes prácticas matrimoniales de la población bubi a lo largo de la historia. Lo hace basándose en documentación etnográfica y de archivo que presenta haciendo uso de unas ilustraciones de lo más didácticas. Las prácticas matrimoniales constituyen una parte importante de la organización social bubi y, como tales, han jugado y siguen jugando un papel primordial en la construcción de la identidad de este grupo, arguye la autora. El artículo se centra en los matrimonios denominados «de país» y «mododo» que compara con los rituales matrimoniales históricos llamados «rivala re rijole» y «rivala re eoto». A través de esta comparación, Fernández Moreno muestra que la transformación de estas prácticas es el resultado de la colonización, pero también 
de factores históricos socio-políticos y culturales locales y regionales. Por un lado, las misiones coloniales evangelizadoras aplicaron incentivos y penalizaciones con el objetivo de establecer el matrimonio cristiano monógamo y acabar con las prácticas locales; pero, por otro lado, los cambios también han sido motivados por conflictos internos en el seno de la Isla de Bioko, que son a su vez el resultado de diferentes olas migratorias procedentes del continente, y que han reforzado la construcción de la identidad bubi en oposición, o al menos distinción, de las prácticas y la población fang. Fernández Moreno arroja luz, por tanto, sobre diferentes factores que han marcado la historia y las prácticas matrimoniales guineoecuatorianas, que están marcadas por la colonialidad española pero también van más allá de la misma. Esto es importante, como apunta la autora, basándose en el trabajo de GLEDHILL (2000: 113), porque atribuir todo cambio en la sociedad local a la dominación colonial sería, de alguna manera, negar el papel que la población nativa jugó en la historia colonial (p. 2).

En "Power through Language, the Language of Power: Equatoguinean Emixiles Facing Lingua Franca" Catalina Iliescu-Gheorghiu se centra en el papel que la lengua castellana ha jugado en la definición de la identidad de seis ecuatoguineanos que define, tomando prestado el concepto de Michael Ugarte (2010: 2), como «emixiliados», es decir, una combinación de «exiliados» y «emigrantes», cuya diferenciación se difumina en el actual mundo globalizado. El artículo revela que los informantes (que pertenecen a diferentes etnias, lugares de origen, edad, posición social y narrativas ontológicas) se reconocen como españoles, no en cuanto a nacionalidad, sino por lengua (p. 5). Iliescu-Gheorghiu sitúa dicha adscripción en el contexto de la paradoja que representa el castellano en tanto en cuanto, por un lado, constituye la lengua en la que se articula la resistencia y las «respuestas» de quienes fueron colonizados y colonizadas (el 'writing back' de Ashcroft, Griffiths y Tiffin 1989) y, por otro lado, es la lengua de cohesión nacional o lingua franca utilizada por las diferentes comunidades lingüísticas guineoecuatoriales. No cabe duda de que el hecho de que el español funcione como lingua franca se debe a la marginalización que sufrieron las lenguas locales durante la colonización (como bien apunta la primera parte del artículo). El español, además, goza de un prestigio que se deriva del colonialismo pero también de la globalización actual, en la que las oportunidades laborales y de acceso a una parte importante del mundo, según la autora, están avocando a las lenguas ecuatoguineanas vernáculas a la desaparición (p. 7).

En "The Way to Mecca. Spanish State Sponsorship of Muslim Pilgrimage (1925-1972)", Jordi Moreras muestra el papel que jugó el patrocinio español del peregrinaje a La Meca a la hora de reforzar el discurso colonial de la «hermandad» hispano-marroquí en el Protectorado español de Marruecos, por un lado, y la «hermandad» hispano-árabe en el ámbito árabe en el que la propaganda franquista se centró mayormente a partir de los años 40, a raíz del aislamiento internacional que sufrió el régimen, por otro. Moreras enmarca la iniciativa en lo que Luc Chantre (2018) ha calificado de "políticas del peregrinaje a La Meca» a cargo de potencias coloniales como Francia, Gran Bretaña e Italia. El artículo desvela que los esfuerzos del militar e ideólogo africanista Tomás García Figueras para que España patrocinara la peregrinación se retrotraen hasta 1925, aunque la falta de interés por la misma por parte del gobierno de la República hizo que la puesta en marcha no se produjera hasta 1937, cuando pasó a estar bajo la dirección del Alto Comisario Juan Beigdeber. Además, Moreras revela (aunque, desgraciadamente, 
no desarrolla) que el patrocinio de la peregrinación siguió hasta 1972, ya que tras la independencia de Marruecos España siguió promocionando el Hajj de destacadas figuras de Ifni y el Sáhara. Esta es una importante contribución que nos anima a seguir indagando en la política colonial de la instrumentalización del Islam por parte de las instituciones franquistas, que es un campo en el que falta trabajo por hacer, aunque recientemente se han publicado trabajos con los que Moreras dialoga. El hecho de que la peregrinación a La Meca, como la conocemos actualmente, sea, al menos en parte, un legado del imperialismo moderno es una de esas aparentes paradojas (que se vuelven tales cuando leemos la historia desde los presupuestos actuales) en las que necesitamos ahondar; porque, como dice Lynn HunT (2018: 1) hoy en día hay una obsesión con la historia, pero al mismo tiempo existe una "profunda ansiedad con respecto a la verdad histórica».

Creo recomendable leer el artículo de Moreras junto con el de Aixelà-Cabré (sobre el que ofreceré más detalles más adelante), por cuanto esta última se centra en la ciudad de Al-Hoceima, en el Rif marroquí, una «periferia» desde la que el Protectorado se ve de manera diferente al mayormente estudiado caso de la capital arabófona Tetuán y al discurso de la «hermandad hispano-marroquí» (MATEO DiEsTe, 2003), que no apareció en Al-Hoceima hasta después de la independencia (Aixelà-Cabré, 2019), y en el seno del cual se sitúa el patrocinio del Hajj. La capital del Rif contaba con una abrumadora población española (que en 1933 representaba un $91 \%$ versus el $4,6 \%$ de la totalidad del Protectorado) que en su mayoría estableció vínculos de servitud con la población local, de quien conocía bien poco. El desconocimiento y la falta del estudio de la población rifeña por parte de las autoridades coloniales, de hecho, también se desprende del artículo de Araceli González Vázquez que paso a comentar.

En "Detribalizando los archivos (post)-coloniales españoles: registros materiales, construcción de fronteras y diversidad lingüística entre los berberófonos del norte de Marruecos", Araceli González Vázquez realiza una notable aportación en lo que a la reproducción del conocimiento colonial en la actualidad se refiere. La autora se centra en particular en los procesos de creación y fijación de las identidades socio-lingüísticas de poblaciones hablantes del bereber (el amazigh rifeño o tarifiyt) del norte de Marruecos. González Vázquez recupera los neologismos que para el caso sudafricano han empleado Carole Hamilton and Nessa Liebhammer (2016) para ver hasta qué punto el material colonial producido en los siglos XIX y Xx «tribaliza» ("tribe" en el original inglés, empleado como verbo), es decir, construye o produce categorías fijas que impiden ver las formas de identificación alternativas de dichas «tribus» en diferentes momentos históricos. Las autoridades coloniales del Protectorado español no fomentaron un estudio socio-lingüístico sistematizado del bereber, pero ello no impidió que se generara un conocimiento sobre las demarcaciones lingüísticas y las fronteras socio-políticas que la autora repasa en el artículo. Algunas de estas, tal y como apunta González Vázquez, se están recuperando y volviendo a poner en circulación (en general, de manera acrítica) a través de los actuales proyectos de digitalización. Además, lo más problemático de la reproducción actual del conocimiento colonial es que deja de lado los resultados de los estudios más recientes, realizados por investigadores locales como Mena B. LAFKIOUI (2007), cuyos análisis contradicen las demarcaciones «tribales» coloniales españolas. Este es, sin duda, un fenómeno que debería alentarnos a utilizar los recursos (tanto los materiales digitalizados como las referencias bibliográficas) que empleamos 
en nuestras investigaciones de manera crítica y escrupulosa; para decolonizar, o caminar hacia la decolonización, del conocimiento que este artículo y el dosier en su conjunto proponen.

El artículo que cierra el dosier lo escribe la editora, Yolanda Aixelà-Cabré, y lleva como título "Colonial Spain in Africa: Building a Shared History from Memories of the Spanish Protectorate and Spanish Guinea". El objetivo que persigue es escribir una «historia social compartida» (p. 2) de la época colonial, basándose en memorias y experiencias personales de españoles, y sobre todo de marroquíes y guineoecuatorianos. Aixelà-Cabré sitúa su trabajo en el seno de las perspectivas post- y decoloniales, y aspira a construir una memoria «más consensuada» (p. 2) que incorpore las silenciadas experiencias africanas al trabajo de recuperación de la memoria colonial en el que tanto queda por hacer en España. Especialmente interesante es el objeto de análisis, que se centra en el día a día y las experiencias de la "gente común» (en palabras de Lee [2005]), y que Aixelà-Cabré extrae tanto de las entrevistas que ha realizado a un gran número de guineanos, marroquíes y españoles, como de la documentación de archivo, publicaciones de boletines, prensa y también privada; de éstas se desprenden también una gran cantidad de datos sociológicos incluidos en el artículo en forma de tablas. El artículo pone de manifiesto la enorme influencia que la población civil española ejerció en el ámbito social, político y lingüístico guineoecuatoriano, donde los españoles constituyeron una minoría poderosa, y en el Rif, donde eran mayoría también numérica. Pese a las diferencias demográficas, en ambos casos la población española carecía de voluntad de mezclarse con la población local, lo cual dio lugar a dinámicas distanciadas y fuertemente jerarquizadas (p. 5). Esta diferenciación y la desigualdad (y en muchos casos, la explotación) es visible en las memorias africanas y los silencios postcoloniales que este artículo, y el dosier en general, visibiliza y problematiza con acierto.

\section{Referencias}

AixelÀ-CABré, Y. (2018): La gestión de la diversidad religiosa, étnica y cultural en Europa en el siglo XXI: La variedad de las visiones nacionales, Edicions Bellaterra, Barcelona.

AixelÀ-CABrÉ, Y. (2019): Ciudades, glocalización y patrimonio contestado. Una historia de Bata y de Al-Hoceima, 1900-2019 (Guinea Ecuatorial y Marruecos), Edicions Bellaterra, Barcelona.

Ashcroft, B.; Griffiths, G.; Griffiths, G.; Ashcroft, F.M.; Tiffin, H. (1989): The Empire Writes Back: Theory and Practice in Post-Colonial Literatures, Routledge, London-New York.

Chantre, L. (2018): Pèlerinages d'empire. Une histoire européenne du pèlerinage à La Mecque, Éditions de la Sorbonne, Paris.

Dorlin, E. (2019): Autodefensa: una filosofía de la violencia, traducción del francés de Margarita Martínez, Txalaparta, Tafalla (Nafarroa).

GLEDHILL, J. (2000): El poder y sus disfraces, Bellaterra, Barcelona.

Fernández PARriLla, G. (2018): «Disoriented Postcolonialities: With Edward Said in (the Labyrinth of) Al-Andalus», Interventions, 20 (2): 229-242.

Hamilton, C.; Liebhammer, N., eds. (2016): Tribing and untribing the Archive, 
University of Kwazulu-Natal Press, Pietermaritzburg. Hunt, L. (2018): Why History Matters, Polity Press, Cambridge. LAFKIOUI, M. (2007): Atlas linguistique des variétés berbères du Rif, Köppe, Köln.

LeE, C.J. (2005): «Subaltern Studies and African Studies», History Compass, 3: 1-13. Mateo Dieste, J.L. (2003): La hermandad hispano-marroquí. Política y religión bajo el Protectorado español en Marruecos (1912-1956), Bellaterra, Barcelona.

Ugarte, M. (2010): Africans in Europe. The Culture of Exile and Emigration from Equatorial Guinea to Spain, University of Illinois Press, Urbana and Chicago.

Itzea Goikolea-Amiano

SOAS-University of London https://orcid.org/0000-0002-3629-8705

Itzea.goikolea@gmail.com

Jennifer Guerra Hernández, Canarias ante la guerra de Marruecos (1909-1927). Miradas desde el Atlántico, Las Palmas de Gran Canaria, Cabildo de Gran Canaria, 2019, 307 págs., ISBN: 978-84-8103-928-3.

En febrero de 2018 la historiadora grancanaria Jennifer Guerra Hernández recibió el Premio de Investigación Viera y Clavijo de Humanidades, otorgado por el Cabildo de Gran Canaria por esta obra, una parte de su tesis doctoral, en la que aborda el impacto que tuvo en la sociedad canaria la participación de España en las sucesivas campañas militares libradas en Marruecos entre 1909 y 1927. Una investigación impecable, bien redactada y que queda sólidamente asentada en el dominio y conocimiento de una amplia panoplia de fuentes, algunas procedentes de un exhaustivo manejo de indagaciones oralistas, además acompañadas de la utilización de fuentes archivistas y hemerográficas, inéditas en parte, impresas e iconográficas. Son destacables asimismo una metodología pegada a la documentación y un trabajo, en suma, oportuno en su concepción y magnífico en su ejecución, por cuanto su autora ha logrado combinar las exigencias científicas propias de un estudio académico con un discurso narrativo y reflexivo accesible al lector medio, en el que por otro lado quedan adecuadamente engarzados el uso de las fuentes históricas y el conocimiento previo de las líneas historiográficas española y marroquí.

Es de reseñar la forma en que han quedado articulados los tres niveles de investigación contemplados en el trabajo, a saber la evolución interior de Marruecos a partir de 1900, la política practicada por los gabinetes restauracionistas españoles en el noroeste de África y el campo de las relaciones internacionales, aspectos tratados en el capítulo primero del libro «El Protectorado español en el norte de Marruecos: regeneración y nuevo proyecto colonial (1860-1923)» (pp. 17-87). En lo tocante al primero de los planos citados, se esboza con detalle el convulso panorama protagonizado, de una parte, por la movilización democrática 
de ciertas élites intelectuales marroquíes que apoyaron la candidatura al trono del Sultanato del príncipe Mawlay Hafid (Allendesalazar, 1990: 174-175) y, de otra, por la constante competición pública de algunas fuerzas dirigentes, grandes caídes o pretendientes al trono -desde el Rogui Bou Hamra hasta el Raisuli- en torno a la posición clave simbólica del verdadero portavoz popular del pueblo marroquí, sucediendo que en cada ocasión conseguía el poder el grupo o el líder que con mayor eficacia desenmascaraba a sus oponentes como «traidores del pueblo» y «vendidos a los extranjeros» y se presentaba a sí mismo, del modo más convincente, como agente fiduciario del «pueblo» (pp. 23-24 y 30-31).

En el segundo nivel de investigación, la autora ahonda en la explicación de cómo el carácter ambicioso de la política restauracionista con el vecino del sur tenía una explicación, en gran medida utópica. Para un determinado sector de los militares españoles y para ciertos gobiernos del turno, la intervención colonial en Marruecos solucionaría los problemas internacionales de España y parte de los nacionales. El Imperio magrebí podía ser una nueva esperanza, en el post-98, para recuperar los sueños de grandeza destrozados en Ultramar, un tónico para resucitar la imagen de la España imperial y participar en la configuración de los dominios coloniales al lado de las grandes potencias. Una solución al aislamiento internacional de España, una vez rotos los tenues hilos que la ligaban a la Triple Alianza austro-germano-italiana y un paso positivo hacia el aperturismo; asimismo, una garantía de seguridad para los territorios insulares y peninsulares (pp. 91-94). La intervención en Marruecos debía ser un antídoto contra el pesimismo nacional y un generador de patriotismo contra los movimientos revolucionarios antimonárquicos.

En lo tocante al tercer plano de análisis, la autora ahonda en cómo el período comprendido entre finales del siglo XIX y principios del XX supuso un lapso temporal en el que se agudizó la dialéctica surgida entre la problemática interna que representaba la vulnerabilidad (económica, política y militar) de las islas Canarias y la exterior, relacionada con las tensiones del sistema capitalista, en el marco de un encrespamiento de los choques entre las potencias imperialistas. De hecho, en el plano internacional, el Estado español intentó establecer un hinterland atlántico y africano que al tiempo que garantizaba su seguridad y el mantenimiento de su statu quo, sirviese como vía de expansión colonial (pp. 9293). Así, políticos como Silvela, Romanones o, sobre todo Maura hicieron suya la tesis de la seguridad nacional hispana, obsesionados por la noción de la «frontera estratégica»; en virtud de ella, España debía estar presente en el norte de África porque era importante para los Estados tener una frontera estratégica natural como garantía de su independencia, y el estrecho de Gibraltar no constituía esa frontera estratégica (MADARIAGA, 2005: 26-27). Al no existir esa frontera, había que reemplazarla con la penetración colonial en una doble dirección: a) en el litoral mediterráneo del Sultanato marroquí y b) en la costa atlántica del vasto sur del Imperio jerifiano, y en particular en el litoral sahariano, para garantizar la seguridad y el papel geoestratégico de Canarias en el marco de la defensa nacional.

Con todo, las ensoñaciones utópicas de una exitosa (y pacífica) expansión 
colonial en el noroeste africano devinieron en 1909 y, sobre todo en 1921, en una serie de situaciones novedosas, no esperadas por el gobierno español. Con ellas, la utopía, golpeada por la realidad de la feroz resistencia marroquí a la penetración extranjera en el Sultanato, perdió sentido. Parafraseando a Lur Sotuela, la idea imaginativa, subjetiva, fantasiosa, la sensación de ensueño colonial moviéndose sobre el lienzo cinético de la época de los imperialismos como la representación de un esperanzador anhelo triunfalista arrollador, el mito de que a España le bastaría con unas breves campañas bélicas para ocupar posiciones en las costas anheladas del Imperio jerifiano e irradiar desde allí su acción hacia el interior en una penetración gradual y pacífica, limitando las operaciones militares a las estrictamente necesarias, fueron abordados por la crudeza de una escalada de encarnizados enfrentamientos, culminados en julio-agosto de 1921 en Annual y Monte Arruit (pág. 178 y siguientes). Fue, sin rodeos, de sopetón la irrupción de sensaciones de pavor, terror y tragedia que acabarían rodeando el proceso colonial español en Marruecos y que provocaron, como resalta Guerra, una profunda metamorfosis en las emociones populares (pp. 271-272). Recalca la autora cómo a partir de entonces, el archipiélago canario fue cada vez más consciente de la proximidad y del peligro inminente que suponían los conflictos en Marruecos. De hecho, la reacción en Canarias ante la guerra de Marruecos -estudiada en el capítulo segundo de la obra- fue bastante heterogénea, igual que en el resto del Estado, según el grupo social que se analice. Por ejemplo entre las clases populares, de escasos medios económicos, el número de jóvenes que eludían la prestación del servicio militar obligatorio y se convertían en «prófugos» empezó a crecer, aunque este fenómeno, ligado a la emigración a Centro y Sur América desde las islas, como recalca la autora, no se puede atribuir exclusivamente a una respuesta escapista al conflicto bélico.

Como es obvio, Jennifer Guerra descarta acertadamente una aproximación monocausal a este fenómeno histórico, a partir de un único factor explicativo, lo cual a todas luces sería excesivamente simplista. Guerra entiende, por el contrario, que la explicación histórica se caracteriza no sólo por la multifactorialidad, sino por la articulación en forma dialéctica, jerarquizada de los distintos factores en un discurso plausible que los integre. Y así entiende que la relevancia de los prófugos y de su emigración americana está íntimamente ligada a la coyuntura económica canaria del período histórico analizado y a otros factores como el aislamiento canario, el atraso secular de las islas, la persistencia y la naturaleza misma del fenómeno del caciquismo (pp. 15 y 112-131). En definitiva, la cuestión de Marruecos le permite a la autora interpretar las alteraciones que sufrió el régimen restauracionista en Canarias en un análisis original y novedoso; así se evidencia cómo la percepción de la crisis colonial fue captada a través de la prensa de las islas, cuyo análisis permite encontrar sugerente información y nuevos puntos de vista sobre el conflicto, como los de varios periodistas canarios de la prensa republicana y socialista que fueron sometidos a censura, a la retirada de sus ediciones e incluso tuvieron problemas con la justicia, derivados de su opinión contraria a la guerra. Por ello, además de constituirse el libro como una interesante aportación a la historia de la cuestión marroquí, nos enfrentamos con 
él a un solvente y documentado trabajo sobre la prensa como medio fundamental para conocer las motivaciones y actitudes políticas de los diferentes sectores sociales ante aquella guerra, sin obviar los problemas que plantea al historiador el empleo de fuentes periodísticas.

Jennifer Guerra analiza exhaustivamente, en este sentido, las posiciones a favor y en contra de la ocupación militar del Rif en la prensa canaria (pp. 133148) a lo largo de un capítulo completo del libro, el tercero, constituyéndose este bloque como un estudio pormenorizado y serio, donde se deja poco espacio a las opiniones no contrastadas y donde el prurito de exactitud casi raya con el formalismo y la asepsia. Guerra confirma así el carácter sumamente heterogéneo del pensamiento político español en aquel contexto histórico y resalta cómo la euforia patriótica seguía muy viva en el imaginario colectivo: la mayoría de los medios de comunicación escritos sirvieron, en este sentido, de altavoz de quienes apoyaban la guerra y pretendían influenciar la opinión de sus lectores inculcando su visión del conflicto y de la sociedad.

Además, una parte sustancial del estudio (pp. 46-87) viene dedicada a la campaña de 1921. Tal como recalca la autora, Annual vino a ratificar las críticas vertidas en 1898 hacia el sistema político restauracionista, precisamente cuando las fuerzas conservadoras hicieron del Ejército la columna vertebral del orden político y social de España. La aniquilación del ejército de Silvestre y el desplome militar de la Comandancia General de Melilla, fue, por ende, una abrumadora sorpresa para el régimen de la Restauración y una angustiosa realidad para el país. El primero perdía su prestigio; el segundo perdía no ya a ocho mil de sus hijos, sino su plena confianza en la Monarquía y en la esperanza propia de no conocer más tragedias familiares por Marruecos. Nunca, hasta entonces, había perdido la España contemporánea un ejército al completo. En bloque y de la forma espantosa -asesinado, en su mayoría, luego de capitular en sus posiciones- en que lo fueron los hombres de Silvestre. Desvela Guerra cómo la derrota de Annual acentuó la sensibilidad de los gobiernos restauracionistas, pero en contrapartida, los ciudadanos canarios respondieron, como en el resto del país, de forma visceral, con la masiva inscripción de voluntarios para marchar sobre Marruecos. No obstante, durante la dictadura de Primo de Rivera hubo que reavivar de nuevo la llama patriótica en el contexto de las operaciones de reorganización de las posiciones defensivas en el protectorado marroquí y en concreto, en el repliegue de 1924, para lo que se tuvo que contar con la propaganda informativa de las acciones llevadas a cabo en Marruecos, creando héroes y censurando los reveses, algo que se consiguió con la complicidad de buena parte de la prensa provincial canaria, en la que destacó la campaña de ánimos y ayudas para los soldados.

El extenso capítulo cuarto del libro, «Los isleños participan en el conflicto (1921-1927)» (pp. 177-233) viene a refrendar, en gran medida, la tesis de que en la investigación histórica, la práctica ha venido a demostrar que la búsqueda del rigor científico con el recurso exclusivo a documentación de hemerotecas y archivos conduce, en muchas ocasiones, hacia una Historia sin humanidad. Es por ello por lo que la subjetividad de la encuesta oral, del testimonio individual o del recurso literario no debería acobardarnos, sino que, al contrario, deberíamos 
emplearla para complementar al frío dato histórico. En este sentido, las campañas militares en el norte del Sultanato a partir de 1921 suponen un magnífico reto para aquellas profesionales que como Jennifer Guerra en este estudio o también María Gajate Bajo en sus diversas investigaciones se han mostrado interesadas en conocer las incontables experiencias personales vividas al hilo del conflicto marroquí.

En este sentido, Guerra ha rescatado en este libro no sólo los testimonios de militares profesionales sino también las crónicas de jóvenes soldados canarios (y a la vez periodistas) como José Batllori Lorenzo o Vejota que ejercían la doble función de combatientes y de corresponsales de guerra; a través del análisis de estos textos, la autora puntualiza sobre cómo los jóvenes canarios que se incorporaban a filas para luchar contra los resistentes marroquíes pertenecían por lo general a las clases obrera y campesina y contaban con escasa formación académica. Queda así esbozada a lo largo del capítulo quinto, "Muestras de apoyo de las islas a sus combatientes» (pp. 235-270) la problemática dialéctica que se establecía en el archipiélago canario entre los grupos socialmente dominantes y dominados, una recreación de las tensiones que expresaban una estructura social, no entendida por Guerra de una manera mecánica, sino a través de los efectos objetivos y subjetivos producidos por tal estructura, a su vez resultado de profundas transformaciones acontecidas en el siglo XIX español. La autora resalta como, tanto la burguesía comercial como la oligarquía terrateniente de las islas, incentivaron activamente actos de colaboración con los soldados enviados al frente y se encargaron de publicitarlos a través de los principales medios de comunicación.

En resumen, nos encontramos ante una obra cuyo principal mérito es seguramente su planteamiento integral, la pretensión de abordar la historia del impacto producido por las campañas de Marruecos sobre Canarias y la opinión pública canaria como un todo, desde los puntos de vista espacial, temporal, social, moral, ético y económico, en contraposición a la relevancia que ha ido adquiriendo en nuestro tiempo el análisis de hechos o situaciones históricos, la mayor parte de las veces meramente coyunturales, tendencia que, sin duda, dificulta adquirir la imprescindible visión de conjunto para poder comprender y valorar la posible relevancia o trascendencia de un determinado proceso histórico. Jennifer Guerra nos entrega como en un caleidoscopio una sucesión de hechos históricos que van recomponiéndonos el proceso colonizador hispano en el noroeste africano a lo largo de los primeros treinta años del siglo xx y a la vez nos recrean el cuadro de toda una época; la autora se mueve con un gran dominio del tema y se advierte inmediatamente que su investigación ha sido exhaustiva, tan extraordinariamente exhaustiva que, al llegar a la última página del libro, el lector lamentará no disponer de otros estudios similares para otros territorios españoles. 


\section{Referencias}

Allendesalazar, J.M. (1990): La diplomacia española y Marruecos, 1907-1909, Ministerio de Asuntos Exteriores, Madrid.

Madariaga, M.R. DE (2005): En el barranco del Lobo. Las guerras de Marruecos, Alianza Editorial, Madrid.

Francisco Manuel Pastor Garrigues IES Sanchis Guarner de Silla (Valencia) http://orcid.org/0000-0002-6359-2256 franciscomanuelpastor@yahoo.es

\section{Ángel Dámaso Luis León, El Rey de la Octava Isla. Canarias ante Chávez y la Revolución Bolivariana, Ediciones Idea, Santa Cruz de Tenerife, 2020, 226 págs., ISBN: 978-84-18138-66-9.}

La realidad canaria, actual y pretérita, no pueden entenderse sin asomarse al balcón de lo que ocurre en Venezuela. Quizás lo mismo suceda al contrario, pero en menor medida. Varios siglos de trasvases poblacionales y culturales refuerzan una vinculación histórica que trasciende lo meramente circunstancial y que convierte a los dos territorios en dos áreas profundamente unidas. De ese vínculo y esa necesidad de estudiarlo en sus múltiples vertientes, surgen algunas publicaciones interesantes como es el caso de la que aquí se aborda, la cual busca analizar los vínculos existentes entre Hugo Chávez, quizás uno de los líderes políticos latinoamericanos más importantes de lo que llevamos de siglo XXI y las islas Canarias, un territorio profundamente ligado al país donde Chávez nació, vivió y gobernó.

La obra tiene un objetivo principal que es analizar todo lo relacionado con la relación de Chávez con Canarias y viceversa, ampliando esa visión a todo lo que tenga que ver con lo que podría denominarse como «la Venezuela de Chávez», aquella donde se convierte en un actor principal. Dentro de esa ambiciosa tarea, que podría pecar, aunque no lo hace, de exceso de desconexión entre las partes, de puzle en definitiva, es esencial la esquematización de la obra, que es la que debe conectar las diferentes situaciones que se abordan.

El primer capítulo del libro, más allá de la necesaria, aclaratoria y pertinente introducción, se centra en la imagen que Chávez tiene del archipiélago en su conjunto. Aparte del anecdotario, que en esta sección aparece en relación con diversas cuestiones vinculadas con el personaje y con Canarias, este capítulo sirve para constatar una realidad que, aparentemente, podría resultar evidente, pero que no tiene por qué serlo, y es la relación intelectual y, si se quiere, mental con Canarias. En esta parte se observa y constata cómo Hugo Chávez, ya desde su juventud, tiene constancia de la existencia de Canarias, y cómo experimenta 
en primera persona las múltiples extensiones de la realidad canario-venezolana. Además de ello, este capítulo sirve también, aunque ello se va desgajando por toda la obra, para introducir al lector en la dinámica general y contextual de Venezuela y de Chávez, un discurso que le permite al autor dirigir su obra no solo a la academia, sino también ampliar el rango de lectores potenciales u objetivos. Todo ello, y he aquí lo más complicado, sin perder un ápice de rigurosidad en la metodología histórica.

La segunda parte aborda la cuestión de las estancias de Chávez en Canarias. Las dos estancias de Chávez en las Islas. Aunque la segunda de las visitas, la que realiza ya como presidente de la República, es la que produce una mayor cantidad de información, cuantitativamente hablando, es la primera de ellas, la que se produce a mediados de la década de los noventa, la que aporta un mayor valor añadido investigador a la obra. La utilización de fuentes de diversa naturaleza en un segmento de la historia no del todo conocido, es el que permite establecer un relato nítido sobre la personalidad del Chávez aún no presidente, y de las motivaciones de su corta estancia. La segunda de las visitas a Canarias, la presidencial, lo que permite es relacionar la parte con el todo o, mejor dicho, con todos. Es decir, relacionar la visita a Canarias con la dinámica históricorelacional de autoridades venezolanas con el Archipiélago; vincular la visita con el pensamiento y la ubicación ideológica del primer Hugo Chávez; y, en fin, analizar la visita con la singular relación que siempre han tenido Chávez y el chavismo con la prensa y los medios de comunicación. Se trata, en resumen, de poner una pieza más en el amplio rompecabezas que es la definición política del chavismo y su relación con diferentes actores internacionales, en este caso, las autoridades canarias.

Aparte de lo señalado, la revisión de la política no solamente se centra en el plano institucional, sino que profundiza en otro tipo de cuestiones de diferente calado, las cuales se abordan en el tercer capítulo. El papel político y decididamente militante del Consulado General de la República Bolivariana en Canarias, con sede en Santa Cruz, y su análisis, permiten acceder a conocer otro entresijo más de la captación del estado propiciada por el chavismo durante estos años. Pero en este capítulo también se habla de las organizaciones políticas canarias que han apoyado al chavismo, tanto las que lo hicieron desde su origen, como las que han sido asociadas por el discurso mediático al mismo, caso de Podemos y su versión en Canarias. El epígrafe llamado «Una especie de adenda «necesaria»: el chavismo y la problemática de Podemos en Canarias», aborda, con una precisión quirúrgica y toda la rigurosidad posible, una problemática compleja y difícil pero que como bien dice su título, resulta a todas luces, necesaria.

El cuarto y último capítulo estudia la cuestión humana del vínculo. A pesar de las limitaciones sociológicas y de fuentes reconocidas por el propio autor en la obra, el capítulo describe una radiografía más o menos fiable de la relación de los canarios y los canario-venezolanos con el chavismo. Analiza el rechazo mayoritario, pero también los tímidos apoyos que recibe y, sobre todo, estudia tanto el plano individual-electoral, como el de las colectividades surgidas en el Archipiélago, con un chavismo que modifica sustantivamente las condiciones 
políticas y de vida de estas comunidades en su país de origen. Todo ello desarrollado en un contexto de buena interrelación con el saber previo presentado en forma de bibliografía intensa.

Finalmente, el trabajo concluye con un capítulo dedicado a recapitular unas líneas generales y maestras que ya se dejan entrever en toda la obra, pero que son refrendadas en una acertada síntesis. Le sigue, además, un amplio anexo documental, en el que destacan las alocuciones de Hugo Chávez en las que hace referencia directa a Canarias, y que sirven además para analizar las fuentes utilizadas en la obra, las cuales destacan por su heterogeneidad. La combinación de fuentes orales, junto a la prensa escrita, documentos institucionales, etc. se relaciona con datos estadísticos de diversa índole, construyendo un relato riguroso. La metodología y las fuentes empleadas son adecuadas, por lo que la obra se convierte en un texto perfectamente encajado en lo que se puede denominar Historia Actual o Historia del Tiempo Presente.

En definitiva, es ese trabajo intenso y complejo (más que complicado) con las heterogéneas fuentes que el autor utiliza, lo que convierte a la obra en un ensayo importante para el estudio de las relaciones canario-venezolanas en su última etapa. Para poder afirmar esto no es necesario solo un buen trabajo de fuentes, sino también una investigación rigurosa y una cuidada lectura de una bibliografía tan amplia como necesaria, así como la utilización del método crítico y del rigor inmanente a nuestra disciplina histórica. En resumidas cuentas, la obra consigue en mi opinión sus objetivos, que no son otros que ampliar el conocimiento de las relaciones canario-venezolanas y convertirse en un referente imprescindible de la época objeto de estudio.

Manuel De Paz Sánchez

Universidad de La Laguna Departamento de Geografía e Historia http://orcid.org/0000-0002-9556-9157 mdepaz@ull.edu.es

Juan Manuel Matés-Barco and Leonardo Caruana de las Cagigas (eds.), Entrepreneurship in Spain: A History, Routledge, 52 Vanderbilt Avenue, New York, NY 10017 and 2 Park Square, Milton Park, Abingdon, Oxon, OX14 4RN, 2021, 200 pages, ISBN: 978-0-367-64922-7 (hbk), ISBN: 978-1-003-12697- (ebk).

Estamos ante una obra colectiva, dirigida por Juan Manuel Matés Barco y Leonardo Caruana de las Cagigas, profesores de Historia e Instituciones Económicas de la Universidad de Jaén y de Teoría e Historia Económica de la Universidad de Granada, respectivamente. Publicado en la prestigiosa editorial Routledge de Taylor \& Francis Group, el volumen, titulado «Entrepreneurship 
in Spain: A History», o «Emprendimiento en España: una historia» proporciona una mirada al pasado, de lo que podemos aprender para construir el presente y el futuro.

Este libro ha sido editado en 2021 en medio de la crisis económica desatada por la pandemia de la Covid-19. Las políticas económicas que se van a aplicar para paliar las consecuencias de la crisis necesitan la respuesta consensuada de los organismos públicos -la Administración, y las instituciones empresariales privadas-.

La obra contribuye a la historia empresarial y la historia económica española (Sudríá y Fernández Pérez, 2010), enriquece el conocimiento de las tres cuestiones generales, planteadas por VALDALISO (2006: 235-286): la oferta de empresarios y su papel en el crecimiento y el atraso económico del país, la competitividad internacional de la empresa española y las relaciones entre los empresarios y el poder político. La historia económica española intenta formular respuestas a las causas de atraso relativo en el desarrollo económico, articulado en la brecha de los términos del PIB/cápita en comparación con los de los países de Europa Central y Occidental.

El trabajo colectivo, constituido por 12 capítulos y la introducción, escrita por Juan Manuel Matés, abarca el marco cronológico desde el s. XVI hasta el inicio del S. XXI, siendo el núcleo de los capítulos correspondientes a los SS. XIX-XX, período histórico conveniente a la tardía Revolución Industrial en España.

La aportación de Mariano Castro Valdivia, que abre la edición, trata de responder las preguntas sobre la importancia de la figura del empresario, relación entre los estudios de caso y el espíritu empresarial, etc. Haciendo un recorrido por las teorías de la historia económica y profundizando sobre los estudios de caso, el autor concluye que es de gran utilidad acudir a estos estudios, comprender los éxitos y fracasos empresariales, de los libros en forma teórica y posteriormente en forma práctica. Cabe añadir que el espíritu emprendedor es clave en los momentos de las crisis económicas, donde la realidad que estamos atravesando no es una exclusión.

El segundo capítulo, desarrollado por David Carvajal, se centra en el estudio de las empresas comerciales y financieras de Castilla del siglo XVI, correspondiente a la expansión y crecimiento europeo y el resplandor de los Imperios Ibéricos (Yun-Casalilla, 2019). Apoyándose en las fuentes documentales del Archivo Municipal de Valladolid, Archivo de la Real Chancillería de Valladolid y del Archivo General de Simancas, el autor indica que el éxito del modelo empresarial se basa en la capacidad de desarrollar diferentes estrategias de especialización y diversificación, creación de las redes mercantiles, mejora en la gestión de riesgo, controlándolo a través del apoyo entre los comerciantes o la suscripción de contratos de seguros.

Rafael Barquín presta atención al «perfecto imperfecto» mercado de trigo en la zona del Norte de Castilla, en las condiciones de la prohibición de las importaciones entre 1820-1880, siendo Santander el puerto de exportaciones. Utilizando los datos estadísticos del Boletín de Comercio de Santander, y aplicando métodos cuantitativos, el autor subraya que el panorama del trigo español no se diferenciaba del mercado de trigo en Francia, Italia o Gran Bretaña. La España del siglo XIX gozaba del régimen capitalista liberal, el más exitoso de aquel entonces, que permitió la construcción de las fábricas de harina en toda la ruta de Reinosa y aseguró la prosperidad del puerto marítimo de Santander. Las fluctuaciones de 
los ingresos por las exportaciones de trigo estaban relacionadas con la coyuntura mundial del grano.

María Vázquez Fariñas esclarece las figuras de los empresarios gaditanos Lacave y Echecopar, involucrados en los negocios de vino. Con el respaldo de las fuentes primarias del Archivo Histórico Provincial de Cádiz y otros documentos primarios, fue construida la historia del exitoso negocio familiar. La autora subraya que los socios adoptaron una estrategia de diversificación de la actividad empresarial, integraron el negocio de vino, controlando la extracción, producción, transporte y distribución del mercado con otros negocios importantes de la región.

El quinto capítulo de Mercedes Fernández Paradas y José Francisco García Ariza, se dedica a la Sociedad Azucarera Antequera, que funcionaba en Málaga a finales del s. XIX. Apoyándose en las fuentes primarias del Archivo Histórico Municipal de Antequera y archivo de la compañía, los autores indican que uno de los éxitos de la compañía fue la adopción de la tecnología francesa, instalación de las máquinas de vapor, el desarrollo del ferrocarril en la región, relaciones familiares entre los socios e involucración de algunos en la política.

Juan Manuel Matés-Barco examina el papel de las compañías privadas -pequeñas, medianas y grandes empresas-, implicadas en el servicio público del abastecimiento de agua en las ciudades españolas en una larga perspectiva histórica, 1840-1940. El autor, utilizando las publicaciones estadísticas de los organismos oficiales, argumenta que predominaban las grandes empresas; además, el tamaño de las empresas, el carácter del capital, incluido la inversión extranjera, dependía de la distribución geográfica de las compañías y el nivel de industrialización regional. El negocio del abastecimiento de agua - estaba sujeto a las regulaciones y el establecimiento de tarifas.

María José Vargas Machuca estudia el sector financiero de Andalucía en el período comprendido entre 1800-1936. La investigación, basada en las fuentes primarias del Anuario-Almanaque del comercio, de la industria, de la magistratura y de la administración, revela dos tipos de entidades financieras en Andalucía: la banca constituida de forma individual o en forma de sociedades colectivas. Si el Decreto Echegaray de 1874 llevó a la desaparición de las entidades bancarias autóctonas, posteriormente el nicho fue ocupado por grandes bancos nacionales, cuyo proceso de consolidación siguió en el primer tercio del s. xx.

Miguel Muñoz Rubio y Pedro Pablo Ortúñez Goicolea prestan atención al desarrollo del ferrocarril en España, haciendo el recorrido histórico desde 1848 hasta 1941. La Ley de Ferrocarriles, aprobada el 3 de junio de 1855, dio impulso al avance de la red ferrovial, lo que conllevó a la modernización de la economía nacional y al incremento del porcentaje del sector secundario hasta el $30 \%$ en el PIB del estado en 1941. Los autores subrayan que inicialmente fue la iniciativa y el capital privado, involucrado en la construcción del ferrocarril durante la época liberal del s. XIX, habiendo un cambiado en el paradigma por la mayor intervención pública después de la i Guerra Mundial.

El noveno capítulo de Carlos Larrinaga ofrece el análisis de los antecedentes de la industria turística de España durante el Primer Franquismo. Comenzada la regulación del sector turístico y agencias por el BOE de 1942, habría que esperar la salida del aislamiento político de los 1950 y la liberación económica después del Plan de Estabilización de 1959, para conseguir el resplandecimiento del sector terciario, coincidiendo, además, con los años «industriosos» de la economía española. 
El fruto de la investigación de Leonardo Caruana esclarece la internacionalización de la marca española: la compañía aseguradora Mapfre. La liberalización política, traída por la Transición, y la consecuente económica -la adhesión de España en el mercado europeo- crearon un marco institucional favorable para la expansión al exterior. Manejando los informes anuales de la compañía como fuentes primarias, el autor revela los claves de éxito internacional: aplicación de know-how en los determinados segmentos de mercado y lazos culturales como en el caso de Latinoamérica.

El undécimo capítulo, redactado por Jorge Lafuente del Cano, esclarece el papel de los empresarios y de la Confederación Española de Organizaciones Empresariales (CEOE), fundada en 1977, en el diálogo económico, político y social durante la Transición. Con el soporte documental del Archivo de Leopoldo Calvo-Sotelo en las relaciones con la CEOE, el autor esclarece la posición favorable de los empresarios respecto a la entrada en la OTAN, rechazo de las políticas keynesianas, y ciertos recelos respecto a la entrada de España al Mercado Común.

La edición la finaliza la aportación de Pablo Alonso Villa y Pedro Pablo Ortúñez Goicolea, dedicada al estudio de Lingotes Especiales, un grupo industrial de Valladolid, especializado en diseño y producción de las piezas para el sector automovilístico. Teniendo sus raíces en la Sociedad Española del Carburador en 1922, fortalecido por la política industrial de los Planes del Desarrollo y sobreviviendo a las políticas de desindustrialización del final del s. Xx, la empresa representa un potente clúster nacional de la producción para los automóviles.

Felicitamos a los directores y a los autores-contribuyentes de este libro por este magnífico trabajo, que brinda la oportunidad del estudio de emprendimiento español a través de los casos presentados.

\section{Referencias}

Sudría, C. and Fernández Pérez, P. (2010): «Introduction: the evolution of business history as an academic field in Spain», Business History, 52 (3): 359-370.

VALDALISO, J. (2006): «El factor empresarial y el desarrollo económico de España en los siglos XIX y xx: algunas reflexiones derivadas de la producción historiográfica en los últimos veinte años», en C. BARCIELA, G. CHASTAGNARET y A. Escudero (eds.), La historia económica en España y Francia (siglos XIX y XX), Casa de Velázquez, Universidad de Alicante: 235-287.

Yun-CASAliLla, B. (2019): Iberian World Empires and the Globalization of Europe 14151668, Palgrave Macmillan.

Irina Yányshev Nésterova

Universidad de las Palmas de Gran Canaria https:// orcid.org/0000-0003-3592-5022 irina.yanyshev@ulpgc.es 




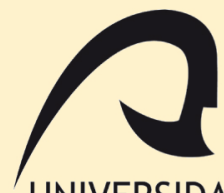

UNIVERSIDAD DE LAS PALMAS DE GRAN CANARIA Facultad de Geografía e Historia 